\title{
Fundamentos para la cualificación del talento humano:
}

Primera infancia y conflicto en Colombia

Rita Flórez Romero

Rosa Julia Guzmán Rodríguez

Jaime Alberto Castro Martínez
Ingrid Carolina Anzelín Zuluaga

Diana Paola Gómez Muñoz

Nicolás Arias Velandia 



\section{Fundamentos para la cualificación del talento humano:}

Primera infancia y conflicto en Colombia 


\section{(POLI \\ POLITECNICO \\ onancolomaiamo}

๑ Institución Universitaria Politécnico Grancolombiano

Fundamentos para la cualificación del talento humano: primera infancia y conflicto en Colombia

ISBN: 978-958-5142-05-3

E-ISBN: 978-958-5142-07-7

Digital ISBN: 978-958-5142-06-0

Editorial Politécnico Grancolombiano

Calle 61 No. 7 - 69

Tel: 7455555, Ext. 1516

Bogotá, Colombia

\section{Autores:}

Grupo de Investigación Cognición y Lenguaje

en la Infancia

Rita Flórez Romero

Diana Paola Gómez Muñoz

Nicolás Castillo Triana

Paula Katerine Contreras Ruiz

Andrés Henao Flórez

Diana Milena Ramírez Toro

Germán Camilo Zárate Pinto

Grupo de Investigación Educación y Educadores

Rosa Julia Guzmán Rodríguez

Ingrid Carolina Anzelín Zuluaga

Leidy Carolina Ruiz Herrera

Johanna Emperatriz III Chocontá Bejarano

Grupo de Investigación Educación, Innovación y Sociedad

Jaime Alberto Castro Martínez

Nicolás Arías-Velandia

Equipo técnico

Roberto Fabio Torres Sandoval

Gloria Elizabeth Bernal de Felipe

Líder de publicaciones:

Eduardo Norman Acevedo

Analista de producción editorial

Carlos Eduardo Daza Orozco

Corrección de estilo:

Hernán Dario Cadena

Diagramación:

Valentina Martinez Muruaga

Impresión:

Xpress Estudio Gráfico y Digital S.A
¿Cómo citar este libro?

Flórez-Romero, R., Guzmán, R., Castro Martínez, J., Anzelin, I., Gómez, D. and Arias-Velandia, N., 2020. Fundamentos para la cualificación del talento humano: primera infancia y conflicto en Colombia. 1st ed. Bogotá: Institución Universitaria Politécnico Grancolombiano.

Creado en Colombia

Todos los derechos reservados

No se permite la reproducción total o parcial de esta obra, ni su incorporación a un sistema informático, ni su tratamiento en cualquier forma o medio existentes o por existir, sin el permiso previo y por escrito de la Editorial de la Institución Universitaria Politécnico Grancolombiano.

Para usos académicos y científicos, la Institución Universitaria Politécnico Grancolombiano accede al licenciamiento Creative Commons del contenido de la obra con: Atribución - No comercial - Sin derivar - Compartir igual.

El contenido de esta publicación se puede citar o reproducir con propósitos académicos siempre y cuando se indique la fuente o procedencia.

Las opiniones expresadas son responsabilidad exclusiva del autor(es) y no constituye una postura institucional al respecto.

Este libro es resultado de un proceso de investigación y ha sido evaluado por pares ciegos cumpliendo con los criterios de selectividad, temporalidad, normalidad y disponibilidad propuestos por Ministerio de Ciencia, Tecnología e Innovación.

Convocatoria 776-2017 conformación de un banco de proyectos elegibles de generación de nuevo conocimiento - 2017

- Grupo de Investigación Cognición y Lenguaje en la Infancia - Universidad Nacional de Colombia

- Grupo de Investigación Educación y Educadores Universidad de la Sabana

- Grupo de Investigación Educación, Innovación y Sociedad - Institución Universitaria Politécnico Grancolombiano

La Editorial del Politécnico Grancolombiano pertenece a la Asociación de Editoriales Universitarias de

Colombia (ASEUC). 


\section{Presentación}

Este libro presenta una propuesta de competencias para el talento humano que trabaja en educación inicial con población afectada por el conflicto colombiano. Lo hace desde una perspectiva sistémica que se preocupa p or la interrelación entre factores individuales, institucionales, interinstitucionales y de gobierno que tienen que ver con la educación para la primera infancia. Por tanto, asume una noción de sistema que define las competencias como un conjunto articulado de conocimientos, prácticas y valores, y propone un marco común de ellas para el talento humano objetivo; para ello toma como antecedentes los estudios CORE (Urban et al., 2011) ${ }^{1}$, CORE-C (Flórez et al., 2013) ${ }^{2}$ y los referentes técnicos para la cualificación del talento humano que trabaja con primera infancia $(\text { MEN, 2014) })^{3}$.

Es, además, resultado de la investigación Las competencias del talento humano que trabaja en la educación inicial con población afectada por el conflicto colombiano, realizada en las localidades de Usme y Ciudad Bolívar en Bogotá, así como en Chía (Cundinamarca), que son, respectivamente, dos de las localidades con mayor índice de población desplazada en la ciudad, y un municipio considerado receptor de población afectada por el conflicto. Sus protagonistas fueron equipos de talento humano con distintos perfiles que trabajan con niños y niñas menores de cinco años y con sus familias en escenarios de educación inicial, una parte de estos niños y niñas, que también dejaron plasmada su voz en una sección específica del libro, y expertos académicos y diseñadores de política pública que hicieron valiosos aportes a los resultados finales de esta investigación.

En concreto, hicieron parte de la investigación 141 miembros de equipos de talento humano entre docentes, auxiliares pedagógicas, psicólogos, trabajadores sociales y coordinadores de los servicios; 163 niños y niñas de escenarios de educación inicial y 31 expertos nacionales sobre los diversos conceptos eje de la investigación que orientaron la propuesta de competencias y que pertenecían a la academia y entidades gubernamentales locales y nacionales sobre primera infancia. De esta manera, por medio de diversos instrumentos de recolección de la voz de todos estos participantes, sobre los que se encontrarán detalles en el libro, y desde una perspectiva de sistema competente en la educación inicial, se conceptualizó y estableció una propuesta de competencias requeridas para responder a las realidades sociales de la primera infancia en el país, específicamente a aquellas relacionadas con el conflicto colombiano y otros tipos de conflictos.

Dichas competencias son las que se presentan en esta obra, junto con algunas recomendaciones para el diseño de políticas de cualificación del talento humano que trabaja con y por la primera infancia.

Rita Flórez Romero

Diana Paola Gómez Muñoz

Nicolás Castillo Triana

Paula Katerine Contreras Ruiz

Andrés Henao Flórez
Diana Milena Ramírez Toro Germán Camilo Zárate Pinto Rosa Julia Guzmán Rodríguez Ingrid Carolina Anzelín Zuluaga Leidy Carolina Ruiz Herrera
Johanna Emperatriz III Chocontá Bejarano Jaime Castro-Martinez Nicolás Arias-Velandia

${ }^{1}$ Urban, M., Vandenbroeck, M., Peeters, J., Van Laere, K. y Lazari, A. (2011). Competence requirements in early childhood education and care. A study for the European Commission Directorate General for Education and Culture (CORE). Londres /Gante: University of East London - Universiteit Ghent.

${ }^{2}$ Flórez-Romero, R., Galvis, D., Gómez-Muñoz, D., Zárate-Pinto, G., Acero, G., Ramírez, P., Castro, J., Tafur, J., y Arias, L. (2013). Estudio de caracterización de los perfiles, las competencias, las necesidades de cualificación y las condiciones sistémicas de apoyo al trabajo del talento humano que se desempeña en las modalidades de educación inicial -institucional y familiar-. Contrato para el desarrollo de actividades de ciencia y tecnología n. ${ }^{\circ} 0766$ celebrado entre Fundación Saldarriaga Concha y la Universidad Nacional de Colombia (Derivado Convenio Asociación 2013-0529 Codificación Interna MEN).

${ }^{3}$ Ministerio de Educación Nacional, (2014b). La cualificación del talento humano que trabaja con primera infancia. Documento No. 19: Referentes técnicos para la cualificación del talento humano que trabaja con primera infancia. Bogotá, Colombia. 


\section{Tabla de contenido}

Capítulo 1. Consideraciones iniciales .................. 8

Capítulo 2. Las identidades profesionales en educación para la primera infancia .............................. 14

2.1. Identidades profesionales de quienes trabajan en educación inicial en Colombia . . . . . . . . . . . . . . . . . . . . . . . . 15

2.2 ¿Qué entendemos por identidades en el trabajo con la primera infancia?: diálogos entre conceptos y evidencias . . . . . . . . . . . . . . . . 19

2.3 Competencias relacionadas con las identidades profesionales en educación para la primera infancia $\ldots \ldots \ldots \ldots \ldots \ldots \ldots \ldots \ldots \ldots \ldots$

2.4. Conclusiones .......................... 40

Capítulo 3. Comprensión y síntesis interpretativa del conflicto colombiano ................................ 46

3.1. Contexto: conflicto en Colombia elementos para su

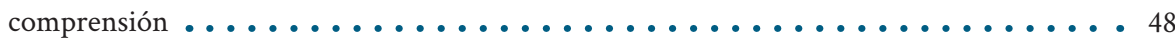

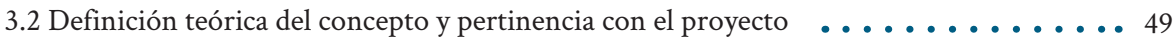

3.3. Impacto del conflicto sobre el talento humano que trabaja con

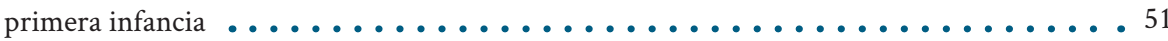

$3.4 \mathrm{El}$ trabajo del talento humano en la disminución de los factores asociados con el establecimiento de dinámicas violentas dentro de las familias y en los contextos escolares, así como en la prevención de la transmisión intergeneracional de dichas dinámicas . . . . . . . . . . . . . . . 56 3.5 Construyendo la línea de tiempo. Diálogo entre el concepto y la evidencia encontrada. Las competencias del talento humano . . . . . . . . . . . 58 3.6. Competencias relacionadas con los orígenes, las múltiples causas y factores de permanencia de los distintos tipos de conflicto a los que están expuestos los niños y sus familias, incluido el conflicto armado . . . . . . . . . . . . . 61

3.7 Competencias relacionadas con los efectos de los distintos tipos de conflicto sobre los niños y sus familias, incluye conflicto armado y otros tipos de conflictos. . . . . . . . . . . . . . . . . . . . . 67

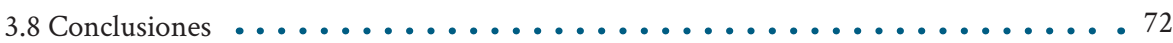

Capítulo 4. Políticas públicas para la atención de la primera infancia afectada por el conflicto colombiano ................. 74

4.1. Sobre el concepto de política pública . . . . . . . . . . . . . . . . . . 75

4.2. Las políticas públicas para primera infancia en Colombia . . . . . . . . . . . 77 4.3. Las políticas públicas para primera infancia y el conflicto colombiano ................................ 79

4.4. Competencias relacionadas con políticas públicas para la primera infancia afectada por el conflicto colombiano: diálogo entre conceptos y evidencias ............................... 79

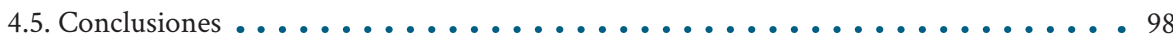


Capítulo 5. El conflicto en Colombia y su impacto en la calidad de vida de la primera infancia: entornos para la promoción del bienestar y el desarrollo infantil ...................... 102

5.1. Sobre el concepto de calidad de vida . . . . . . . . . . . . . . . . . . 103

5.2. Calidad de vida de la primera infancia: elementos nucleares para su

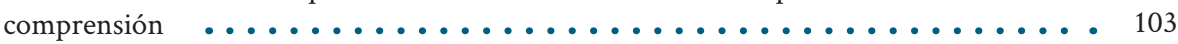

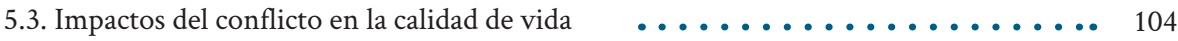

5.4. El trabajo del talento humano para mejorar la calidad de vida de niños y niñas ... . . . . . . . . . . . . . . . . . . . . . 106

5.5. Competencias relacionadas con la calidad de vida desde la primera infancia como condiciones de bienestar y desarrollo en diferentes entornos: diálogos entre conceptos y evidencias . . . . . . . . . . . . . . . . 106

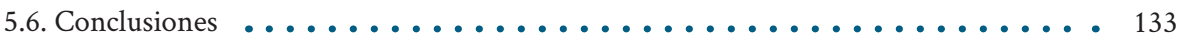

Capítulo 6. Acciones educativas para promover una cultura de

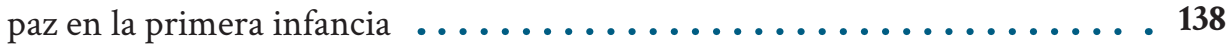

6.1. Naturaleza de las acciones educativas . . . . . . . . . . . . . . . . . 139

6.2. Sentido de la educación en la primera infancia desde una perspecti-

va de construcción de paz . . . . . . . . . . . . . . . . . . . . . . . 145

6.3. Formación de educadores para promover la educación para

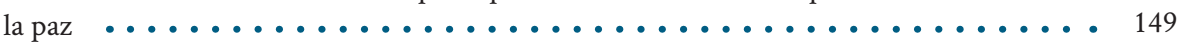

6.4. Condiciones para garantizar el derecho a la educación de calidad . . . . . . . . 166

6.5. Conclusiones . . . . . . . . . . . . . . . . . . . . . . . . . . . 169

Capítulo 7. Participación de los niños en la investigación .......... 174

7.1. Investigación cualitativa con niños . . . . . . . . . . . . . . . . . 175

7.2. Conceptos para indagar las perspectivas de los niños y niñas en

torno al conflicto colombiano ......................... 176

7.3. Proceso de investigación con los niños _ . . . . . . . . . . . . . . . . 180

7.4. Los educadores en relación con los niños y niñas víctimas

del conflicto . . . . . . . . . . . . . . . . . . . . . . . . . . 188

7.5. Propuesta de competencias . . . . . . . . . . . . . . . . . . . . 199

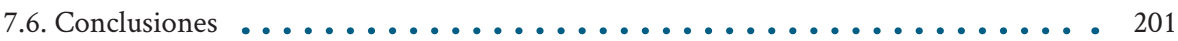

Capítulo 8. Recomendaciones para la política pública de primera infancia desde cada uno de los conceptos establecidos en la investigación 


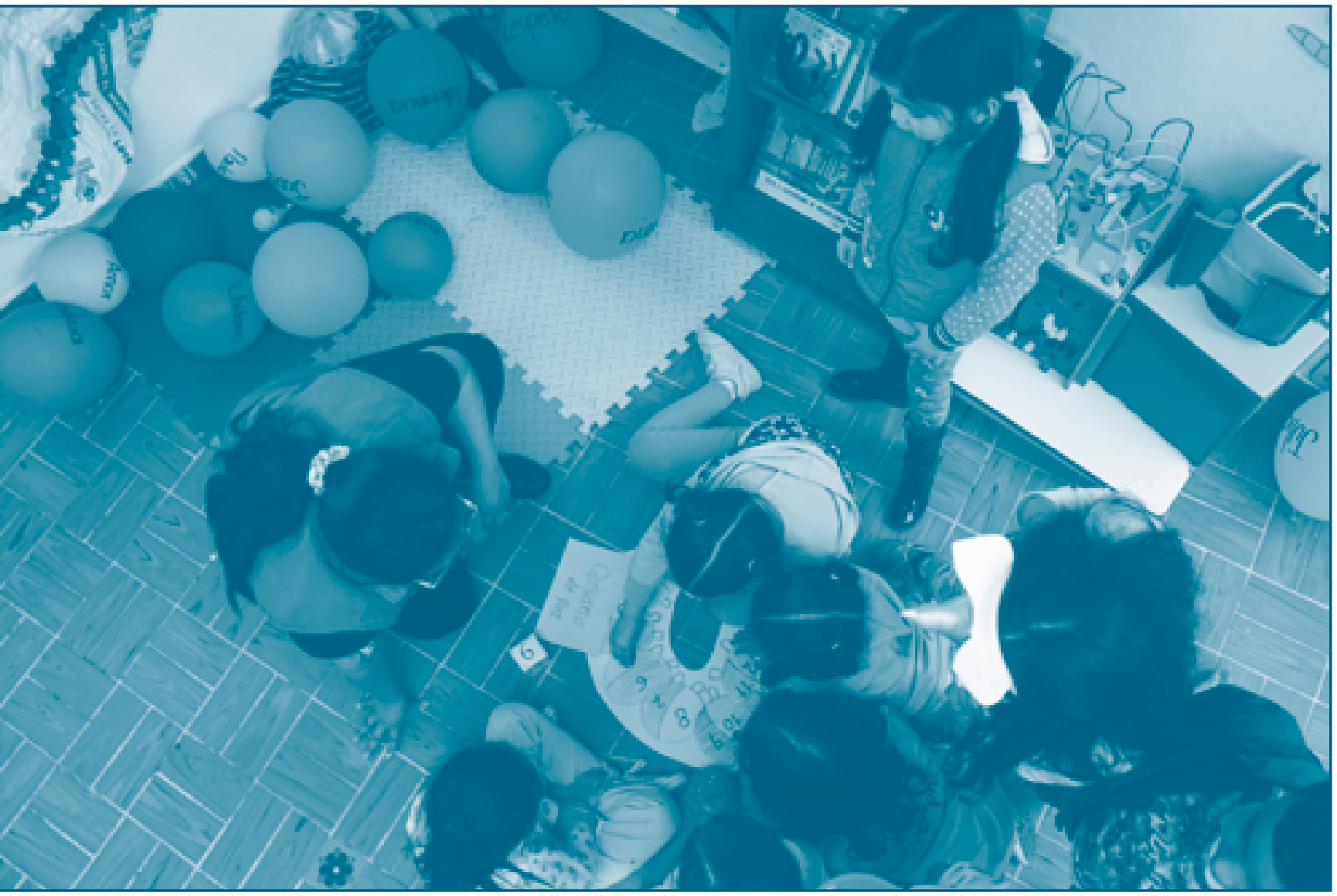

Capítulo 1.

Consideraciones iniciales 
a educación inicial se ha convertido en un tema central para la sociedad y el Estado colombiano; de ahí que exista una amplia formulación de políticas en favor de la infancia, muchas de ellas derivadas de tratados y acuerdos suscritos por los distintos Estados, como aquellos pertenecientes a organizaciones internacionales como UNICEF o UNESCO. En Colombia, con la Ley 1804 de 2016, se establece la política de Estado para el desarrollo integral de la primera infancia, que en su Artículo $5^{\circ}$, "La educación inicial", señala la importancia de la misma como derecho y como proceso educativo y pedagógico intencional, permanente y estructurado, y la obligatoriedad de la prestación, inspección, vigilancia y control de este derecho y proceso (Congreso de la República de Colombia, 2016).

Esta Ley es el resultado de un arduo trabajo del país sobre planes y políticas públicas para el bienestar de la primera infancia, los cuales, a través del tiempo, se han visto representados en los distintos Planes Nacionales de Desarrollo para la Atención a la Primera Infancia. Ejemplo de estos planes es la Política Pública Nacional de Primera Infancia, "Colombia por la Primera Infancia" (Ministerio de Educación Nacional [MEN], 2006), en donde se refuerzan los compromisos adquiridos en la Convención Internacional sobre los Derechos de los Niños y se promueven acciones concretas, como las que aparecen consignadas en el Sistema General de Participaciones para la Primera Infancia (CONPES, 2010), o en el Código de Infancia y Adolescencia (Congreso de la República de Colombia, 2006).

En esta última ley, por ejemplo, en su artículo 29 se mencionan como derechos fundamentales e impostergables: "la atención en salud y nutrición, el esquema completo de vacunación, la protección contra los peligros físicos y la educación inicial” (Congreso de la República de Colombia, 2006, p.5). Estas políticas en el país encontraron sentido en el desarrollo de la estrategia "De Cero a Siempre", creada en el Marco del Plan de Desarrollo "Prosperidad para Todos" 2010-2014, y abanderadas por la Comisión Intersectorial para la Primera Infancia (CIPI).

Hacer realidad los derechos de los niños y las niñas implica reconocer el papel que cumplen las modalidades de educación inicial en el cuidado y educación de los más pequeños, es decir, los derechos de los niños se hacen realidad mediante el trabajo de los equipos de talento humano (Comisión Intersectorial para la Atención Integral de la Primera Infancia, 2013; Urban et al., 2011). Por esta razón, la garantía y la realización de los derechos de los niños y niñas dependen, en cierta medida, de la calidad de la atención que brindan los equipos de talento humano, en otras palabras, la calidad depende de los perfiles y competencias de los equipos de talento humano en relación con los requerimientos para el desarrollo adecuado de los niños (Urban, 2013). Entonces, las competencias de los equipos de talento humano se convierten en una problemática central para la familia, la sociedad y el Estado y, desde luego, para el gobierno nacional, departamental y local; por esto se deben plantear propuestas acerca de la cualificación del talento humano involucrado en la educación inicial, de manera que se aporte a la construcción de las competencias y las ocupaciones de dichos equipos. 
Ahora bien, determinar las competencias implica preguntarse cuál es la manera más adecuada para su construcción. Para ello, en la investigación que hizo posible este libro, se apostó a un enfoque que incluye a todos aquellos que están involucrados en el cuidado y la educación de la primera infancia; dicho enfoque responde a una mirada sistémica de los servicios de la primera infancia, implica la construcción de competencias y demanda la participación y la interrelación de factores individuales, institucionales, interinstitucionales y de gobierno para asumir la atención a la primera infancia como un sistema competente que se desarrolla en las relaciones recíprocas entre los individuos, los equipos, las instituciones y las instituciones públicas (Urban et al., 2011).

La construcción de las competencias de los equipos de talento humano en educación inicial, implica, además, a las problemáticas de cuidado y educación de los niños y niñas menores de cinco años, pues se han revelado ciertas realidades en este campo que están relacionadas con expectativas y necesidades de cualificación específicas (Flórez et al., 2013):

- Los miembros de los equipos de talento humano tienen expectativas frente al fortalecimiento de sus conocimientos, prácticas y valores, pues para ellos estas deben ser más conscientes, estructuradas y menos intuitivas.

- Los equipos requieren una cualificación sobre el desarrollo de los niños, las estrategias de enseñanza, las estrategias de trabajo con familia y comunidad, diversidad, cuidado y protección de niños y niñas afectados por diferentes violencias, entre otras temáticas.

- Los equipos expresan la necesidad de formular planes de cualificación que respondan a las realidades particulares que enfrentan, por lo tanto, implica diseñar dichos planes con los equipos de talento humano, familia y comunidad.

Así mismo, la definición de competencias forma parte de procesos de cualificación del talento humano y esta última se relaciona con la calidad de los servicios diseñados para la primera infancia. Específicamente, el MEN ha establecido dentro de las condiciones de calidad de la educación inicial al talento humano (y su cualificación), como uno de los componentes de calidad para este tipo de educación (MEN, 2014).

Además, en el marco de la Estrategia de Cero a Siempre, se propone la formación y cualificación de agentes educativos responsables de la educación inicial y atención integral de la primera infancia con un enfoque de competencias e inclusión, como una estrategia para dar cumplimiento a los acuerdos fundamentales entre la sociedad civil y el Estado sobre los principios, objetivos, metas y estrategias para la educación y protección integral de las niñas y los niños en la primera infancia (CIPI, 2013, p.83).

En este contexto, las prácticas de gestión y de atención se deben armonizar con los marcos de política y los horizontes de comprensión con los cuales cuenta el país sobre el desarrollo infantil. La cualificación del talento humano se constituye, entonces, en un proceso crucial para asegurar la calidad de la gestión relacionada con la atención integral a las niñas y a los niños en la primera infancia (MEN, 2014a). 
La cualificación se concibe como algo más que capacitaciones puntuales o procesos instruccionales destinados a la difusión de información; el MEN (2014a) la define como un:

Proceso permanente de resignificación y reorientación de las formas de relación con las niñas y los niños, de las comprensiones que poseen los diferentes actores sobre la primera infancia, del desarrollo en este momento del ciclo vital y de las prácticas que realizan cotidianamente para promover el desarrollo humano de las niñas y los niños. (p. 14)

La posibilidad de construir conjuntamente proyectos de cualificación con los equipos de trabajo de las modalidades de educación inicial, es una oportunidad para dinamizar las capacidades reflexivas y críticas del talento humano, familias, comunidad, representantes de los operadores, entidades gubernamentales, entre otros actores, y así garantizar que la gestión administrativa, pedagógica y de operación de las modalidades incida en el desarrollo integral de la primera infancia.

En ese sentido, se reconoce que los procesos de cualificación del talento humano se dirigen a todos aquellos actores que por sus diferentes roles profesionales, sociales e institucionales tienen incidencia en el desarrollo de las niñas y los niños en la primera infancia. El reconocimiento de los saberes, prácticas y desarrollos de las comunidades favorece la consolidación de sistemas competentes y el fortalecimiento territorial para la implementación de la política de educación inicial (CIPI, 2013); por esa razón deben estar involucrados todos los niveles y actores, quienes ejecutan la política en los territorios: equipos técnicos de las instituciones y entidades, equipos de atención directa o que operan los programas y servicios, y equipos de entidades que apoyan la implementación de las políticas de primera infancia (MEN, 2014a).

Adicionalmente, la educación y atención a la primera infancia es una alternativa para ayudar a construir la paz, pues siguiendo a Castañeda (2015):

\footnotetext{
Los niños y niñas de este milenio son la posibilidad para resolver odios fermentados por años de guerras heredadas, que nos han dejado cicatrices profundas de dolor y duelos no resueltos, y garantizar la paz estable, duradera y la no repetición de la oscura historia violenta de nuestro país. (párr.1)
}

Y de nuevo, acá, la definición de competencias y la cualificación son elementos que aseguran que esto pueda llegar a ser posible.

De esta manera, la investigación que se presenta en este libro apuesta por los vínculos que hay entre el cuidado y la educación en la primera infancia y sus aportes a la transformación social hacia la paz y la equidad del país, a través de la generación de condiciones para el desarrollo integral y la calidad de vida de los niños y niñas menores de 5 años y sus familias, por medio de un marco de competencias que intenta dar cuenta de las realidades sociales, políticas y económicas relacionadas con el conflicto armado y otros tipos de conflicto que atraviesan las vidas de los niños y niñas.

En especial, porque la labor de los profesionales que trabajan con la primera infancia dentro de contextos de conflicto puede traer efectos positivos para quienes partici- 
pan de ella, pues estos profesionales tienen la posibilidad de contribuir a la gestión de las necesidades de los niños, niñas y sus familias, y cumplir un rol dentro de sus comunidades para ayudar a construir la paz. En otras palabras, se reconoce que el sector de la primera infancia representa un potencial considerable para contribuir con la construcción de la paz y la reconciliación.

En este libro se desarrollan cinco conceptos con sus categorías y subcategorías, que están en relación con las competencias del talento humano que trabaja en la educación inicial con población afectada por el conflicto armado y otros tipos de conflictos. Estos conceptos se abordarán uno por capítulo y son:

- Identidades profesionales en educación para la primera infancia.

- Comprensión y síntesis interpretativa del conflicto colombiano.

- Políticas públicas para la primera infancia afectada por el conflicto colombiano.

- El conflicto en Colombia y su impacto en la calidad de vida desde la primera infancia como condiciones de bienestar y desarrollo.

- Acciones educativas para promover una cultura de paz en la primera infancia.

A su vez, de acuerdo con la propuesta de Urban et al. (2012), las competencias identificadas por cada concepto se encontrarán configuradas en tres dimensiones: conocimientos, prácticas y valores, que en su interacción "pueden generar diferentes enfoques según los países y los contextos culturales” (Urban et al., 2011, p.516), es decir, que sirven de guía y pueden ser ajustados a las distintas dinámicas locales.

Los conocimientos se conciben como el resultado de la reflexión crítica, la investigación académica y la experiencia práctica en el cuidado y educación de los niños y niñas. Las prácticas, a su vez, se conciben no como habilidades técnicas que se implementan, sino como la capacidad reflexiva y transformadora de las acciones que se llevan a cabo por los equipos de talento humano, en otras palabras, las prácticas pasan por superar la idea de hacer las cosas bien, a pensar si las cosas o acciones llevadas a cabo son las pertinentes y correctas de acuerdo con los contextos sociales y culturales en donde ocurren. Por último, los valores no se entienden como actitudes de los individuos, sino como los objetivos y aspiraciones que se fijan de manera colectiva y negociada (Urban et al., 2012), en otras palabras, corresponden a las metas comunes, los acuerdos generales o los principios de la educación para la primera infancia.

\section{Referencias}

Castañeda, E. (2015). Infancia, un tema clave para el posconflicto. El Tiempo. Recuperado de: https:// www.eltiempo.com/archivo/documento/CMS-16072455

Comisión Intersectorial para la Atención Integral de la Primera Infancia. (2013). Estrategia Integral de Atención a la Primera Infancia. Fundamentos Políticos Técnicos y de Gestión. Bogotá, Colombia. Recuperado de: https://cutt.ly/erqN9yz

Congreso de la República de Colombia. (2006). Ley 1098. Por la cual se expide el código de infancia y adolescencia. Bogotá: Colombia. 
Congreso de la República de Colombia. (2016). Ley 1804 de 2016. Por la cual se establece la política de Estado para el desarrollo integral de la primera infancia de Cero a siempre y se dictan otras disposiciones. Bogotá, Colombia.

CONPES. (2010). Documento Conpes - 162: Sistema General de Participaciones - Recursos para la Atención Integral de la Primera Infancia. Bogotá, Colombia: Departamento Nacional de Planeación.

Flórez-Romero, R., Galvis, D., Gómez-Muñoz, D., Zárate-Pinto, G., Acero, G., Ramírez, P., Castro, J., Tafur, J., y Arias, L. (2013). Estudio de caracterización de los perfiles, las competencias, las necesidades de cualificación y las condiciones sistémicas de apoyo al trabajo del talento humano que se desempeña en las modalidades de educación inicial -institucional y familiar-. Contrato para el desarrollo de actividades de ciencia y tecnología n. ${ }^{\circ} 0766$ celebrado entre Fundación Saldarriaga Concha y la Universidad Nacional de Colombia (Derivado Convenio Asociación 2013-0529 Codificación Interna MEN).

Ministerio de Educación Nacional. (2006). Colombia por la Primera Infancia. Política Pública por los Niños y Niñas, desde la Gestación hasta los 6 Años. Bogotá, Colombia.

Ministerio de Educación Nacional, (2014). Orientaciones para el cumplimiento de las condiciones de calidad en la modalidad institucional de educación inicial. Guía No 51: Serie de orientaciones para favorecer la calidad de la educación inicial en el marco de la atención integral. Bogotá, Colombia.

Ministerio de Educación Nacional. (2014a). La cualificación del talento humano que trabaja con primera infancia. Documento No. 19: Referentes técnicos para la cualificación del talento humano que trabaja con primera infancia. Bogotá, Colombia.

Urban, M., Vandenbroeck, M., Peeters, J., Van Laere, K. y Lazari, A. (2011). Competence requirements in early childhood education and care. A study for the European Commission Directorate General for Education and Culture (CORE). Londres / Gante:University of East London - Universiteit Ghent.

Urban, M. (2012). Researching early childhood policy and practice. A critical ecology. European Journal of Education, 47(4), 494 - 507.

Urban, M. (2013) Sistemas competentes para la educación y cuidado en la primera infancia. In R. Flórez y M. C. Torrado (Eds.). Primera infancia, lenguajes e inclusión social: una mirada desde la investigación. Bogotá, Colombia: Universidad Santo Tomás. 


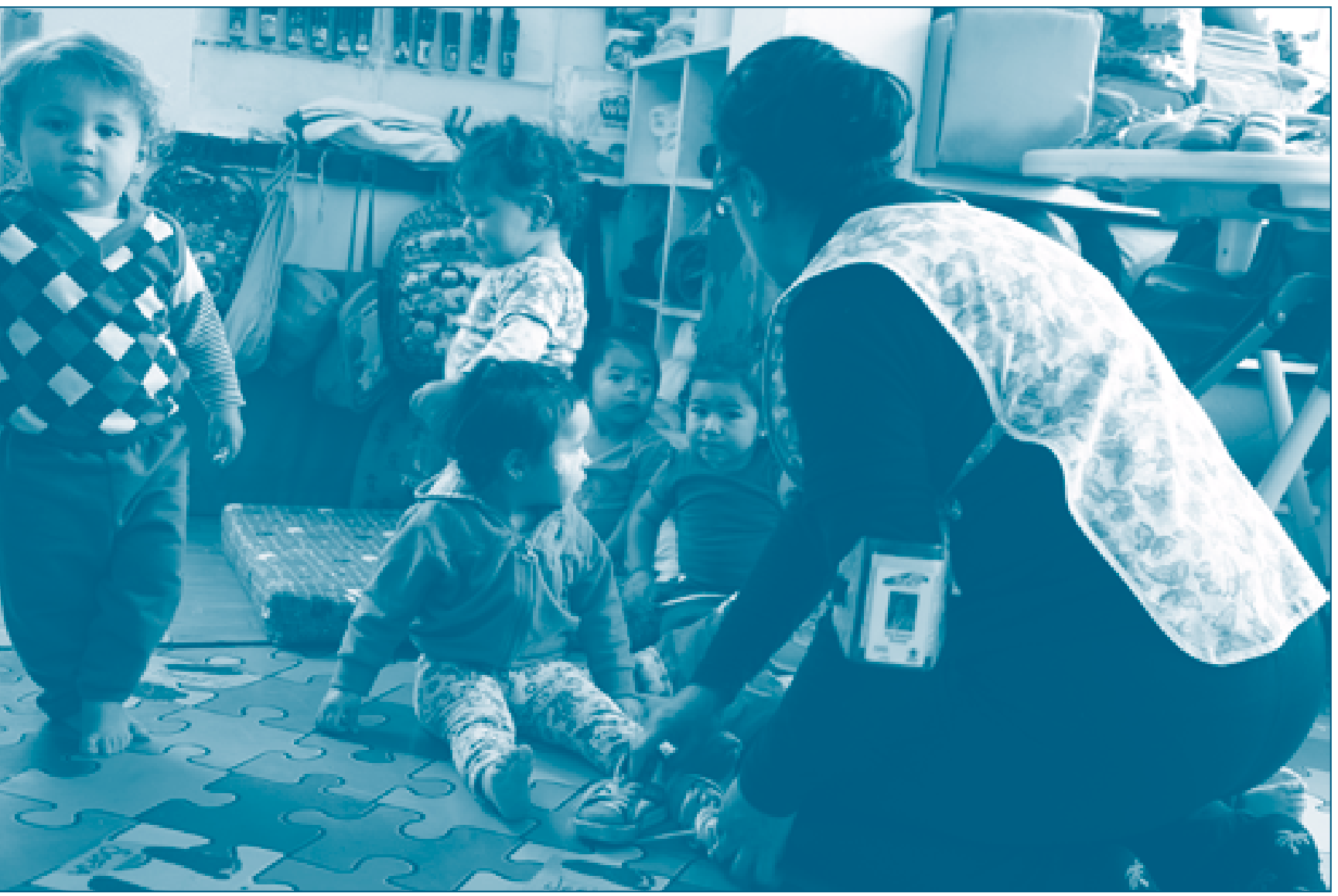

Capítulo 2.

Las identidades profesionales en educación para la primera infancia 
$\mathrm{E}$ $\mathrm{n}$ el marco de la investigación sobre las competencias del talento humano que trabaja en la educación inicial con población afectada por el conflicto colombiano, fue importante indagar acerca del conocimiento histórico sobre el conflicto, no solo como una responsabilidad ciudadana para la construcción de paz, sino, especialmente, para crear una atmósfera de concienciación sobre la historia personal o familiar en el marco de la historia del conflicto en Colombia y sobre las múltiples formas en que dicha historia ha impactado en las relaciones humanas que se construyen diariamente en diferentes escenarios. Este ejercicio permitió que reconociéramos que todos los participantes, en cierta forma, éramos víctimas del conflicto, unos de formas más directas que otros, así como cierta impronta cultural que el conflicto ha dejado en los colombianos; y fue el punto de partida para discutir sobre las competencias (conocimientos, prácticas y valores), que se despliegan en los espacios de trabajo con primera infancia, familias y comunidades.

Esta indagación mostró qué sabía o pensaba el talento humano acerca de conocer la historia del conflicto colombiano. A continuación se presentan algunos de los testimonios de maestras, auxiliares pedagógicos y profesionales psicosociales, en relación con este tema:

\footnotetext{
"Digamos que conocer, digamos todos los hechos sí es importante debido a que también toda la población se sabe que de una u otra forma ha sido tocada por ese mismo conflicto en mayor o en menor medida, puede que unos en mayor medida porque han sido directamente implicados en el mismo, ya que ellos han sido desplazados o han sido que algún familiar haya muerto a raíz de ese hecho de conflicto (...)"

"Normalmente nosotros no conocemos muy bien nuestra historia, pero en la niñez tampoco la presentamos de ninguna manera (...) de pronto algunos que vienen desplazados saben por qué fueron desplazados, pero aun así no saben la historia más a fondo de por qué se presentó ese conflicto (..)"
}

También fue importante indagar sobre las historias y experiencias de los equipos de trabajo que participaron en la investigación, con el propósito de hacer un reconocimiento de sus identidades individuales y colectivas, así como de sus opiniones acerca de la profesionalización y los espacios de trabajo como comunidades de reflexión crítica. Para lograrlo se empleó la metodología biográfica, conocida también como método biográfico, específicamente mediante relatos de vida (Valles, 1999) o relatos autobiográficos (Rodríguez, Gil y García, 1999).

\section{Identidades profesionales de quienes trabajan en educación inicial en Colombia}

Las identidades de quienes están al frente del trabajo con la primera infancia, familias y comunidades han evolucionado (y lo siguen haciendo), en la misma medida en que lo ha hecho la educación, atención y cuidado de la primera infancia en la historia del país y en el contexto global.

Para el caso de Colombia, dicha evolución está en estrecha relación con la diversidad de escenarios creados para la primera infancia desde inicios del siglo XX hasta la 
actualidad, y que han sido ampliamente descritos en documentos de política pública (Comisión Intersectorial para la Atención Integral de la Primera Infancia, 2013; Ministerio de Educación Nacional, 2014; Secretaría Distrital de Integración Social, Universidad Pedagógica Nacional, Secretaría de Educación del Distrito, 2013), en informes de consultoría e investigación (Corpoeducación, 2018; Torrado, Gaitán, Bejarano y Torrado, 2017; Higuita Bedoya, 2016; Castillo-Matamoros, 2016; Flórez et al., 2014; Bernal, 2014; Álvarez, 2012; González y Durán, 2012; Torrado, Gaitán y Bejarano, 2009; Universidad del Valle, Universidad Nacional de Colombia y Universidad Industrial de Santander, 2007), y en sistemas internacionales como el Sistema de Información sobre la Primera Infancia en América Latina (SIPI, 2019), entre otros.

Actualmente, en Colombia, esta diversidad de escenarios la componen las modalidades institucionales, familiares y comunitarias, contratadas por el Instituto Colombiano de Bienestar Familiar en el territorio nacional; jardines infantiles operados por entidades gubernamentales a nivel regional y local (por ejemplo, en las ciudades de Bogotá o Medellín), y la educación preescolar ${ }^{4}$ que se desarrolla en instituciones educativas públicas y privadas -jardines infantiles, escuelas y colegios-. Además, una gran variedad de jardines infantiles de carácter privado, entre los cuales existe también una gran diversidad marcada por factores socioeconómicos. Igualmente, el Ministerio de Educación Nacional (2014a) establece que el 'talento humano' que trabaja por y con la primera infancia está conformado por los siguientes actores: a) planeadores, diseñadores y tomadores de decisión en torno a las políticas públicas para la primera infancia; b) equipos técnicos de las instituciones y entidades; c) equipos de atención directa o que operan los programas y servicios, y d) equipos de entidades que apoyan la implementación de las políticas de primera infancia (p. 13-14).

A lo anterior le es inherente la multiplicidad de perfiles que configuran las identidades de quienes trabajan por y con la primera infancia en el país, en los diferentes niveles del sistema, lo cual constituye un amplio campo de indagación y reflexión que debe profundizarse desde la investigación, la evaluación de la calidad y los sistemas competentes.

En la caracterización sociodemográfica realizada por UNESCO (2016), se confirmó que, en el campo de la educación para la primera infancia en América Latina y el Caribe, prevalece la feminización de la fuerza laboral. En este sentido, un primer aspecto de las identidades es que existe una condición de género que indiscutiblemente incide en las acciones orientadas a la educación y cuidado de la primera infan-

Contempla tres (3) grados: Prejardín, dirigido a niños de tres (3) años de edad; Jardín, dirigido a niños de cuatro (4) años de edad y Transición, dirigido a niños de cinco (5) años de edad, correspondiendo este último al grado obligatorio. (Buitrago, 2015, p.7) 
cia, así como en los imaginarios y el reconocimiento social que se hace de esta labor (Rodríguez, Flórez y Gómez, 2016) ${ }^{5}$.

Otro aspecto relevante que constituye las identidades de quienes trabajan con la primera infancia, dado el devenir histórico de la educación, atención y cuidado de los niños y niñas menores de 6 años en Colombia, es que se han desarrollado estrategias distintas de atención y educación para la primera infancia (CIPI, 2013; SDIS, UPN, SED, 2013; Torrado, Gaitán y Bejarano, 2009) y que, como afirma Corpoeducación (2018):

La educación de los niños y las niñas de la primera infancia ha sido objeto de dos marcos institucionales distintos; por un lado, el Instituto Colombiano de Bienestar Familiar -ICBF- que desde los años 60 ha venido realizando acciones educativas y de protección de la infancia y, por otro lado, el Ministerio de Educación Nacional, que ha orientado la educación preescolar en el país. (p.14)

Las líneas de tiempo de estas dos instituciones son extensas y no es el propósito de este capítulo describirlas en profundidad, sino relacionar los programas que se han implementado con la fuerza de trabajo involucrada en los mismos, entendiendo fuerza de trabajo como los profesionales y trabajadores que hacen parte de los escenarios de educación, atención y cuidado para la primera infancia o, siguiendo la denominación del MEN (2014a), los equipos de atención directa o que operan los programas y servicios. Lo anterior con el propósito de proponer una reflexión sobre la complejidad de los saberes y prácticas que circulan en dichos escenarios y cómo esto influye en la conceptualización de las identidades profesionales y en las acciones orientadas a la profesionalización del trabajo con primera infancia en el país.

En las modalidades y programas del ICBF, que inició su funcionamiento en 1968, trabajan conjuntamente madres comunitarias, maestras/os, profesionales de psicología y trabajo social, técnicos en áreas de servicios generales, administrativas o de alimentos. Una de las estrategias que se implementó para la cualificación de las madres comunitarias fue la creación del programa técnico en atención integral a la primera infancia. Por otra parte, en la denominada educación preescolar, se requiere tener título de licenciado en educación o de normalista superior, lo cual es obligatorio para el servicio educativo estatal (Buitrago, 2015).

\footnotetext{
${ }^{5} \mathrm{El}$ ejemplo más representativo de esto es el de un amplio grupo de mujeres, conocidas como Madres Comunitarias, quienes desde 1987 asumieron el cuidado y la educación de la población infantil en las comunidades más vulnerables en zonas urbanas y rurales del país, en ocasiones también con altos índices de violencia y desplazamiento, y a quienes, solamente desde el 2014, se les empezó a reconocer el pago de un salario mínimo y aún carecen de un vínculo laboral legal claro con la entidad que hace inspección y supervisión de su trabajo (Casas, 2019; Esguerra, 2018; Las Igualadas, 2018; Pinzón, 2015; Buchely Ibarra, 2015; García, 2013; Arteaga, 2004).

${ }^{6} \mathrm{Si}$ bien existen marcos institucionales distintos, tras la puesta en marcha de la Estrategia Nacional de Atención Integral a la Primera Infancia 'De Cero a Siempre' las diversas instituciones del sector público, tanto a nivel nacional como territorial, han propendido por armonizar dichos marcos y se avanza en los esfuerzos por involucrar a las instituciones de carácter privado, pero es claro que queda un largo camino por recorrer.
} 
En síntesis, podemos reafirmar que la diversidad de programas, estrategias y acciones conllevó a una pluralidad de la fuerza de trabajo, lo cual puede verse como una realidad inevitable, dado el trayecto histórico de la educación, atención y cuidado de la primera infancia en Colombia, pero, a la vez, como una oportunidad enriquecedora en un momento histórico del país en el que la construcción conjunta y el reconocimiento del otro es imprescindible para entender las complejas realidades de quienes trabajan con los niños más pequeños, las familias y las comunidades, en distintos escenarios ocupacionales, institucionales, socio-culturales y políticos.

Ahora bien, en Colombia, así como alrededor del mundo, hay un consenso frente al hecho de que la atención integral a primera infancia debe ser una prioridad en las agendas políticas nacionales y, como resultado, ha aumentado el interés por la profesionalización de quienes trabajan con la primera infancia, ligado al argumento de que la calidad de los servicios para la primera infancia y el mejoramiento de las oportunidades para los niños y las familias están asociados con un personal más capacitado (Urban et al., 2019; Urban, Cardini y Flórez, 2018; Vandenbroeck, Urban \& Peeters, 2016; CIPI, 2013; Araujo, López-Boo y Puyana, 2013; Dalli, Miller \& Urban, 2012; OECD, 2012).

Al respecto se viene dando un debate acerca de la naturaleza de las prácticas de educación y cuidado dirigidas a este grupo poblacional, y se han dado pasos importantes para analizar y comprender el estado actual y las realidades de los agentes educativos de la primera infancia en la región latinoamericana y en el país (UNESCO, 2016; Universidad de la Sabana, 2016; Buitrago, 2015; Bernal, 2014; Flórez et al., 2013; Organización Internacional del Trabajo, 2012; Corpoeducación - FES Social, 2012; Centro Internacional de Educación y Desarrollo Humano, 2011, 2009; Instituto para el Desarrollo y la Innovación Educativa, 2008; SENA, 2008). El debate en cuestión ha mostrado un acuerdo importante: reconocer que las prácticas de educación, atención y cuidado dirigidas a la primera infancia, así como aquellas dirigidas a las familias y comunidades, son de naturaleza profesional. Dalli, Miller y Urban (2012) lo plantean de la siguiente forma:

Detrás de la apariencia de actividades triviales y rutinarias, actuar profesionalmente en los diferentes contextos significa reunir múltiples capas de comprensión y pensamiento en la interacción con niños, familias y colegas, en situaciones que a veces son éticamente desafiantes, dentro de un currículum que desde afuera puede parecer fragmentado, pero está intrincadamente conectado. (p.5)

Se reconoce, entonces, que las acciones pedagógicas, las prácticas de cuidado y de atención integral, las acciones educativas y de acompañamiento con las familias, el trabajo en equipo, entre otras, que ocurren en los diversos escenarios expuestos an-

\footnotetext{
${ }^{7}$ Cita original: "behind the appearance of trivial and routine activities, acting professionally in the different contexts means bringing together multiple layers of understanding and thinking in interacting with children, families and colleagues, in situations that are sometimes ethically challenging, within a curriculum that might look outwardly fragmented but is intricately connected." (Dalli, Miller \& Urban, 2012, p.5)
} 
teriormente, no son repetitivas ni replicables en cualquier contexto, requieren de la capacidad de reflexión crítica y de un alto grado de autonomía, parten de un compromiso con la planificación del desarrollo social del país, características que responden a algunos de los requisitos que deben cumplir las ocupaciones para la profesionalización (Sarramona, Noguera y Vera-Vila, 2009; Salazar, 2006; Tenti, 1995).

De igual manera, no se puede perder de vista la importancia de la formación como un proceso de desarrollo personal y profesional, que va más allá de obtener una titulación. La profesionalización de la fuerza de trabajo que hace parte de los diferentes escenarios de educación, atención y cuidado para la primera infancia, deben ser procesos en los que se reflexiona y se reconceptualizan las teorías que sirven de base a su ejercicio, donde se valora y se recupera la experiencia y los saberes construidos en la práctica -lo cual vincula a la familia y las comunidades que rodean los escenarios- que abren espacios para el intercambio de conocimientos y experiencias, y procesos de evaluación y seguimiento que están en sintonía con la naturaleza de lo que sucede en los escenarios, superando la idea de la mera inspección. En consecuencia, es un proceso dinámico y continuo en el que las identidades de los trabajadores y futuros profesionales son elemento central de su formación.

Luego de esta contextualización, a continuación se profundizará en la definición del concepto Identidades profesionales en el trabajo con la primera infancia, y de las categorías que lo configuran.

\section{¿Qué entendemos por identidades en el trabajo con la primera infancia?: diálogos entre conceptos y evidencias}

La identidad se define como un «conjunto de rasgos propios de un individuo o de una colectividad que los caracterizan frente a los demás» (RAE). Partiendo de esta sencilla definición, y considerando que los escenarios para la primera infancia que existen en el país son diversos debido al conjunto de prácticas de educación, atención y cuidado que le han dado materialidad y existencia histórica desde inicios del siglo XX, es importante reconocer las experiencias y saberes particulares que dan forma a las identidades -individuales y colectivas- de las personas que trabajan en los distintos escenarios de atención integral y educación para la primera infancia.

Como se describió anteriormente, el grupo de participantes estuvo conformado por los equipos de trabajo $^{8}$ de modalidades familiares e institucionales de las localidades de Usme y Ciudad Bolívar en Bogotá, y de instituciones educativas del municipio de Chía, departamento de Cundinamarca. Esta variedad de contextos permitió visibilizar las múltiples formas en que se configuran las competencias de las personas y

\footnotetext{
${ }^{8}$ Coordinadoras de las modalidades, profesionales psicosociales, maestras, auxiliares pedagógicos
} 
su relación con los enfoques de las modalidades en las que se desempeñan, así como reconocer las particularidades de las identidades colectivas de estos equipos. Lo anterior también hace posible una aproximación a la complejidad de las identidades de quienes trabajan con la primera infancia, familias y comunidades en el país, teniendo en cuenta que estas, a su vez, están influenciadas por teorías, sistemas y agendas políticas globales (Arndt et al., 2018).

De acuerdo con Arndt et al. (2018), los procesos que constituyen identidades profesionales no solo son diversos, sino que también están estrechamente relacionados con los contextos culturales, históricos y sociales en los que tienen lugar. En este sentido, trabajar con niños pequeños, sus familias y comunidades diversas es una práctica inevitablemente local (p.3). Lo anterior coincide con lo que plantea Urban $(2013,2012,2010,2008)$ y Urban et al. (2012), en relación con la práctica profesional en contextos de educación para la primera infancia, cuando afirma que esta puede definirse desde perspectivas interconectadas como relacional, política e incierta, y que debe articular los entornos, contextos y actores donde transcurre la vida cotidiana de los niños.

Se define como 'relacional', porque se hace y desarrolla con y no para los niños y niñas, familias y comunidades. En este sentido, la práctica relacional significa que los niños y las familias contribuyen a los 'resultados' de la práctica profesional, tanto como los miembros de los equipos de trabajo. El reto implica descubrir la forma de desarrollar, con confianza, identidades profesionales basadas en relaciones de igualdad, respeto y reconocimiento (ídem). Los testimonios de los equipos de trabajo muestran esta concepción relacional de la práctica profesional:

"Nosotros acá pues tenemos actividades en el jardín y lo que hacemos es involucrar mucho al niño y a la familia, sí, que se hagan participes en ello (...)”

Se define como 'política', porque tiene que ver con el cambio y la transformación hacia resultados más equitativos y justos para todos los niños y niñas. Esta perspectiva desafía intereses particulares, por lo cual requiere un compromiso político (micro y macro-político), basado en valores democráticos (Moss y Urban, 2010). Y es incierta porque no hay mapas o rutas establecidas, lo cual requiere nuevos entendimientos sobre lo que significa el 'conocimiento' y la manera como este se produce. En este sentido, se considera que es precisamente en entornos de incertidumbre donde existen múltiples oportunidades de interacción, de diálogo y de encuentros con la diversidad, puesto que la incertidumbre es el terreno propicio para la solución creativa, pertinente y oportuna de los problemas que se vayan generando (Urban et al., 2012; Urban, 2013, 2012, 2010, 2008; Urban y Dalli, 2008).

Considerando las anteriores premisas, la construcción del concepto de identidades profesionales en el trabajo con la primera infancia se hace teniendo en cuenta los contextos políticos, históricos, económicos, sociales y culturales en los que este trabajo tiene lugar en el país; pero también se establece un diálogo con las transformaciones que se requieren para que el reconocimiento de la importancia que tiene 
la atención integral a la primera infancia -con la educación como uno de sus componentes- se materialice en niveles altos de valoración de la formación profesional en el campo, así como una buena remuneración en inversión pública para mejorar la infraestructura y la calidad, y en políticas orientadas a superar la desigualdad e inequidad en la población (Durán, 2017; Rosemberg, 2009; Torrado, 2009; Bennet, 2006, 2003).

Para el análisis y comprensión de las identidades individuales y colectivas de quienes trabajan con primera infancia, familias y comunidades en escenarios de educación inicial, se establecieron cuatro categorías:

- Perfiles y experiencia.

- Profesionalización y cualificación.

- Construcción de comunidades de reflexión crítica y aprendizaje.

- Condiciones de bienestar y satisfacción (condiciones sistémicas de apoyo).

A su vez, el instrumento utilizado para indagar sobre estas categorías se diseñó con el propósito de que la perspectiva sistémica fuera transversal y así propiciar un análisis, desde el punto de vista de las participantes, sobre las competencias de los múltiples actores que trabajan por y con la primera infancia ${ }^{9}$ en los diferentes niveles que plantea la perspectiva del sistema competente (individual, institucional, interinstitucional y gobernanza) (Urban, 2013; Urban et al, 2012, 2011; Flórez et al., 2013).

Las identidades profesionales en educación para la primera infancia

Desde una perspectiva de competencia, se entiende a las identidades profesionales y ocupacionales como una sistémica. Es decir, que las competencias se enmarcan en un sistema conformado por cuatro dimensiones: nivel individual, nivel institucional, nivel interinstitucional y nivel de gobernanza.

A continuación, se presenta el esquema de competencias, resultado de la revisión de la literatura, el diálogo entre dicha revisión y mediante la recolección de información tanto con profesionales como con expertos que trabajan con primera infancia, ubicado en las categorías antes mencionadas: perfiles y experiencia, profesionalización y cualificación, construcción de comunidades de reflexión crítica y aprendizaje y condiciones de bienestar y satisfacción (condiciones sistémicas de apoyo).

\section{Competencias relacionadas con los perfiles y experiencia}

Más allá de describir los niveles de titulación y los años de experiencia que tienen las participantes o de determinar en qué medida se cumplen los perfiles y cargos

'El Ministerio de Educación Nacional (2014a) establece que el 'talento humano' que trabaja por y con la primera infancia está conformado por los siguientes actores: a) planeadores, diseñadores y tomadores de decisión en torno a las políticas públicas para la primera infancia; b) equipos técnicos de las instituciones y entidades; c) equipos de atención directa o que operan los programas y servicios, y d) equipos de entidades que apoyan la implementación de las políticas de primera infancia (p. 13-14). 
para las modalidades de educación inicial y preescolar (MEN, 2014b), la indagación acerca de las historias de vida de las participantes y su experiencia en el trabajo con niños, familias y comunidades se hizo con la intención de destacar las características que componen y dan forma a los perfiles desde un punto de vista colectivo (Oberhuemer, 2012; Flesher- Fominaya, 2010; Dalli et al., 2012).

Considerando el panorama que muestra la variedad de perfiles y experiencias que actualmente constituyen la fuerza de trabajo en escenarios de educación y cuidado para la primera infancia, vale la pena preguntarse ¿cómo imaginamos que será la fuerza de trabajo en 10 años?, ¿qué aspectos de sus competencias, y las de todo el sistema, deben considerarse para que su evolución sea constante?, ¿qué acciones deben desarrollarse para alcanzar ese propósito y contribuir a la consolidación de un movimiento comprometido con la primera infancia y con la construcción de paz en un país como Colombia? Quizás algunas respuestas se encuentren a continuación, relacionadas con las competencias sistémicas para la profesionalización y con la construcción de equipos en los que la prioridad sea la reflexión crítica, el trabajo colaborativo y colectivo, y el aprendizaje continuo de todos los actores que hacen parte del sistema.

\section{Nivel individual}

Los perfiles y experiencias en la atención integral a la primera infancia necesitan de procesos permanentes de interacción para garantizar el desarrollo integral de los niños y las niñas, por lo tanto, los perfiles del talento humano deben estar dirigidos a reconocer las prácticas y políticas de manera inclusiva, equitativa y solidaria, desde una perspectiva intercultural, teniendo en cuenta las condiciones geográficas y socioeconómicas de las diferentes regiones del país, junto con sus necesidades educativas. En este sentido, las competencias se encaminan a satisfacer las necesidades básicas de afecto, cuidado y alimentación, al igual que la participación de la familia y la comunidad que exige la acción articulada de sectores especializados para su atención (MEN, 2014).

A continuación, se presenta el esquema de competencias para la categoría de perfiles y experiencia a nivel individual.

Tabla 2.1 Competencias de la categoría perfiles y experiencia - Nivel individual.

\section{Conocimientos}

- Conocimiento de los elementos conceptuales, políticos y prácticos que orientan los procesos que se desarrollan con las/os niñas/os, familias y comunidades, en los escena-

\section{Prácticas}

- Desarrollar planes y acciones que favorezcan la atención, el cuidado y la enseñanza/aprendizaje de las/os niñas/os en la primera infancia, en los que cada profesional, de acuerdo
Valores

- Reconocer los elementos conceptuales, políticos y prácticos necesarios para el desarrollo de planes y acciones para la atención integral en primera infancia. 


\begin{tabular}{|c|c|c|}
\hline $\begin{array}{l}\text { rios de educación, atención } \\
\text { y cuidado para la primera } \\
\text { infancia. } \\
\text { la conocimiento general de } \\
\text { de la práctica profesional y } \\
\text { ocupacional de los diferentes } \\
\text { miembros del equipo de tra- } \\
\text { bajo de acuerdo con su perfil } \\
\text { y experiencia. } \\
\text { - Conocimiento de los pro- } \\
\text { cesos típicos de desarrollo de } \\
\text { las/os niñas/os en su prime- } \\
\text { ra infancia, así como de las } \\
\text { necesidades a nivel educati- } \\
\text { vo, de atención y de cuidado } \\
\text { que supone cada uno de es- } \\
\text { tos momentos, teniendo en } \\
\text { cuenta, además, el contexto, } \\
\text { la historia de vida y la nece- } \\
\text { sidad de atención diferencial } \\
\text { de cada niña/o de acuerdo } \\
\text { con estos elementos. }\end{array}$ & $\begin{array}{l}\text { con su perfil y experiencia, } \\
\text { aporte elementos conceptua- } \\
\text { les y prácticos para enriquecer } \\
\text { el quehacer profesional y pro- } \\
\text { piciar el desarrollo integral de } \\
\text { las/os niñas/os. } \\
\text { - Realizar prácticas articula- } \\
\text { das con los distintos miem- } \\
\text { bros del equipo de trabajo } \\
\text { que provengan de diferentes } \\
\text { disciplinas para buscar la ade- } \\
\text { cuada atención, cuidado y en- } \\
\text { señanza/aprendizaje de las/os } \\
\text { niñas/os. } \\
\text { - Identificar oportunamente } \\
\text { los procesos y conductas de } \\
\text { las/os niñas/os y ajustar los } \\
\text { planes de atención, enseñanza } \\
\text { y cuidado con los aportes de } \\
\text { las diferentes disciplinas, de } \\
\text { acuerdo con sus necesidades. }\end{array}$ & $\begin{array}{l}\text { - Valorar los saberes cons- } \\
\text { truidos en la experiencia en } \\
\text { pro de enriquecer los sabe- } \\
\text { res y prácticas del equipo de } \\
\text { trabajo, para el beneficio de } \\
\text { la atención integral de las/os } \\
\text { niñas/os. } \\
\text { - Reconocer las necesidades } \\
\text { en los procesos de aprendi- } \\
\text { zaje, atención y cuidado de } \\
\text { las/os niñas/os en las dife- } \\
\text { rentes fases de su proceso de } \\
\text { desarrollo en primera infan- } \\
\text { cia, así como las necesidades } \\
\text { de atención diferencial de } \\
\text { acuerdo con su historia de } \\
\text { vida y el contexto sociocul- } \\
\text { tural de desarrollo. }\end{array}$ \\
\hline
\end{tabular}

\section{Nivel institucional}

Los perfiles y experiencias en las instituciones deben estar dirigidas a orientar la comprensión de los diferentes actores que participan en la atención integral a la primera infancia; además de reconocer a las niñas y los niños como sujetos de derechos, las instituciones deben garantizar su rol como sujetos activos dentro de su propio proceso de desarrollo (MEN, 2014a). También deben fomentar las interacciones entre adultos, niñas y niños para impulsar el desarrollo integral y los derechos de la niñez en la primera infancia.

Las experiencias del talento humano se reconocen desde la diversidad de las niñas, niños, familias y comunidades en los procesos de atención integral, al igual que las dinámicas de las prácticas de gestión y atención. Dentro de estas dinámicas se encuentra la construcción de ambientes seguros que potencien el desarrollo de las niñas y los niños, el conocimiento de las políticas, la articulación intersectorial y la dinamización de escenarios de mutua escucha entre los distintos sectores y actores involucrados.

A continuación, se presenta el esquema de competencias para la categoría de perfiles y experiencia a nivel institucional. 
Tabla 2.2. Competencias de la categoría perfiles y experiencia - Nivel institucional.

\begin{tabular}{|c|c|c|}
\hline Conocimientos & Prácticas & Valores \\
\hline $\begin{array}{l}\text { - Conocimiento de las } \\
\text { acciones pedagógicas, } \\
\text { prácticas de cuidado, } \\
\text { atención integral de } \\
\text { las/os niñas/os y de los } \\
\text { lineamientos para un } \\
\text { adecuado acompaña- } \\
\text { miento a las familias y } \\
\text { las comunidades }\end{array}$ & $\begin{array}{l}\text { - Socializar las com- } \\
\text { petencias y alcance de } \\
\text { la práctica profesional } \\
\text { y ocupacional de las } \\
\text { diferentes disciplinas } \\
\text { de los miembros de } \\
\text { los equipos de traba- } \\
\text { jo de acuerdo con su } \\
\text { perfil y experiencia. } \\
\text { - Construir y dispo- } \\
\text { ner de guías, manua- } \\
\text { les..., de fácil acceso } \\
\text { donde los miembros } \\
\text { del equipo puedan } \\
\text { consultar lineamien- } \\
\text { tos específicos para la } \\
\text { atención de las/os ni- } \\
\text { ñas/os, las familias y } \\
\text { las comunidades. }\end{array}$ & $\begin{array}{l}\text { - Promover la cons- } \\
\text { trucción de identida- } \\
\text { des profesionales ba- } \\
\text { sadas en la igualdad, el } \\
\text { respeto y el reconoci- } \\
\text { miento de la experien- } \\
\text { cia, el saber y la labor } \\
\text { del otro. } \\
\text { - Valorar la importan- } \\
\text { cia de promover el in- } \\
\text { tercambio de saberes y } \\
\text { el trabajo en equipo }\end{array}$ \\
\hline
\end{tabular}

\section{Nivel interinstitucional}

A nivel interinstitucional existe una gama de actores que participan en los procesos de cualificación y en la atención integral, desde una perspectiva de gestión intersectorial que invita a articular los procesos de cualificación desde los sectores, perfiles y experiencias, así como a reconocer la diversidad para favorecer el intercambio de conocimientos, prácticas y valores, buscando la construcción de aprendizajes específicos y las necesidades individuales del talento humano (MEN, 2014a). Por lo tanto, los perfiles y experiencia deben ser lo suficientemente flexibles para favorecer la construcción colectiva de conocimiento a partir de la diversidad de experiencias y de las particularidades de los actores que trabajan en primera infancia.

A continuación, se presenta el esquema de competencias para la categoría de perfiles y experiencia a nivel interinstitucional. 
Tabla 2.3. Competencias de la categoría perfiles y experiencia - Nivel interinstitucional

\begin{tabular}{|l|l|l|}
\hline \multicolumn{2}{|c|}{ Conocimientos } & \multicolumn{1}{c|}{ Prácticas } \\
\hline $\begin{array}{l}\text { Conocimiento de las } \\
\text { necesidades de atención, } \\
\text { cuidado y enseñanza/ } \\
\text { aprendizaje de las/os ni- } \\
\text { ñas/os, familias y comu- } \\
\text { nidades de acuerdo con } \\
\text { sus contextos e historias } \\
\text { de vida. }\end{array}$ & $\begin{array}{l}\text { Acompañar a los equi- } \\
\text { mentación de lineamien- } \\
\text { tos y rutas para asegurar } \\
\text { una adecuada atención a la } \\
\text { primera infancia, familias } \\
\text { y comunidades. }\end{array}$ & $\begin{array}{l}\text { Reconocer la impor- } \\
\text { tancia de la atención di- } \\
\text { ferencial, realizada por } \\
\text { equipos cualificados y } \\
\text { experimentados tenien- } \\
\text { do en cuenta las carac- } \\
\text { terísticas específicas de } \\
\text { determinada población. }\end{array}$ \\
\hline
\end{tabular}

\section{Nivel de gobernanza}

A nivel de gobernanza, es necesario generar e implementar políticas para los perfiles y experiencia desde la construcción de conocimientos y aprendizajes, mediante contenidos trasversales que fomentan las concepciones de las niñas y los niños, el desarrollo integral de la primera infancia, la intersectorialidad, el reconocimiento de la atención a la diversidad y la promoción de alternativas de atención innovadoras en el marco de las políticas públicas con enfoques poblacionales y territoriales (MEN, 2014a).

A continuación, se presenta el esquema de competencias para la categoría de perfiles y experiencia a nivel de gobernanza.

Tabla 2.4. Competencias de la categoría perfiles y experiencia - Nivel de Gobernanza.

\begin{tabular}{|c|c|c|}
\hline Conocimientos & Prácticas & Valores \\
\hline $\begin{array}{l}\text { - Conocimiento de las } \\
\text { necesidades de atención } \\
\text { de las/os niñas/os, fa- } \\
\text { milias y comunidades de } \\
\text { acuerdo con sus contex- } \\
\text { tos e historias de vida. }\end{array}$ & $\begin{array}{l}\text { - Desarrollar políticas } \\
\text { para la adecuada aten- } \\
\text { ción, cuidado y enseñan- } \\
\text { za/aprendizaje de las/os } \\
\text { niñas/os y la atención a } \\
\text { familias y comunidades. }\end{array}$ & $\begin{array}{l}\text { - Reconocer las nece- } \\
\text { sidades específicas de } \\
\text { cada población en rela- } \\
\text { ción con el contexto de } \\
\text { procedencia e historia } \\
\text { de vida. }\end{array}$ \\
\hline
\end{tabular}

\section{La profesionalización y cualificación}

Sin duda, la fuerza de trabajo en primera infancia es esencial para los programas de educación, atención y cuidado existentes, pues es el factor más importante que afecta las experiencias de aprendizaje y desarrollo de los niños, además de representar una gran parte del costo total de los servicios para la primera infancia (Vandenbroeck, Urban y Peeters, 2016); por tanto, de acuerdo con Bernal (2014), "la 
inversión del país en la generación, consolidación y conservación de los maestros es fundamental” (p.15).

En Colombia, el discurso de la 'profesionalización', la 'cualificación' y/o la 'capacitación' (principalmente los dos últimos), en el campo de la educación, atención y cuidado a la primera infancia empezó a circular particularmente en relación con las madres comunitarias - ahora llamadas 'agentes educativas'- y la necesidad de mejorar la calidad de la atención integral de niños y niñas en el país (Arias y Blanco, 2018; Bernal, 2014; Urban, 2010, 2008; Organisation for Economic Co-operation and Development, 2006), y llegó acompañado también como una condición para concederles (a las madres comunitarias) permanencia en los programas (Higuita-Bedoya, 2016). Sin embargo, posteriormente el Ministerio de Educación Nacional planteó que:

La cualificación del talento humano que trabaja por y con la primera infancia tiene como sentido el fortalecimiento y transformación de las prácticas y saberes de los diferentes actores que tienen responsabilidad en la promoción del desarrollo integral de las niñas y los niños en los primeros años de vida. (2014a, p.13)

Justamente es la referencia a los diferentes actores lo que se quiere resaltar en este capítulo, dado que amplía el foco no solo a todos los miembros de los equipos de atención directa (ya no exclusivamente a las madres comunitarias), en los escenarios de educación inicial y preescolar, sino a todos los demás actores que hacen parte del sistema (MEN, 2014a), pues permite abordarlo desde una mirada sistémica. Por otro lado, a pesar de que, en general, en los documentos de política pública del MEN y del ICBF no se hace referencia al concepto de profesionalización, es importante posicionar dicho concepto para que las discusiones y acciones en torno a los retos de la educación, atención y cuidado de la primera infancia en Colombia superen la mirada de las transiciones y la cualificación técnica, y transiten hacia la construcción de una identidad profesional colectiva en el campo de la educación de la primera infancia en el país y hacia la comprensión de qué significa ser profesional en este campo y del propósito de la profesión en la sociedad (Urban, 2010, 2008).

De acuerdo con Urban et al., (2012), el alcance del concepto de profesionalización no se limita a la formación profesional titulada previa a cualquier desempeño profesional, sino a cualquier forma de preparación profesional y de formación continua que tenga por objetivo mejorar la competencia de los profesionales de la educación inicial. Por otro lado, Pirard y Barbier (2012) afirman que la cultura de la profesionalización considera la noción de competencia como un elemento central en los procesos de cualificación y se caracteriza por el trabajo simultáneo de aprendizaje y práctica en los lugares de trabajo, desde lo individual y lo colectivo. Esta perspectiva permite asociar la práctica de la cualificación en términos de competencia y de formación continua de los equipos de talento humano en la educación inicial. Esto significa que las actividades de cualificación apuntan al aprendizaje de nuevas competencias y al fortalecimiento de otras, es decir, a la profesionalización de las prácticas de educación y cuidado de los equipos y de los individuos. 
En relación con esta categoría, se consideraron también aspectos relacionados con la integralidad en las políticas de profesionalización (Durán, 2017), la pertinencia, calidad y sostenibilidad de la oferta de profesionalización, así como las necesidades y expectativas de profesionalización de los equipos de trabajo. En relación con lo anterior, algunos integrantes de los equipos de trabajo opinaron que la oferta de los programas de profesionalización (mencionaron en su mayoría programas con modalidad a distancia), no siempre cumplen con sus expectativas o con las necesidades específicas que ellos tienen y que, al compararla con la oferta de programas técnicos, esta última puede en muchos casos responder de mejor manera a sus necesidades de formación

"Si estamos hablando de la diferencia, para algunas [integrantes de los equipos de trabajo] si es diferente, (...) diría yo aprendí más en el técnico que los dos semestres que estuve [en la universidad]. Allá era solo plataforma y solo lea y haga tareas".

"Digamos en mi caso, una va los sábados con el tutor y el tutor le dice cómo hacer la tarea, pero uno desarrolla la tarea pero no la implementa, entonces como que la tarea se quedó ahí, sí, o digamos una se gradúa y el cartón y ya, en cambio en el técnico [se debe realizar] tarea y una exposición entonces a uno se le queda".

"Y sí es cierto lo que dice la profe yo estuve [en la universidad] (...) y no nada nuevo, sino sobre todo tecnología, que ustedes saben manejar más computador, era lo que nos decían a nosotros, pero en sí un técnico también tiene buenas bases".

"La profe tiene toda la razón, (...) no que solamente plataforma (...), uno va directamente por las materias y las materias que tengan que ver con la pedagogía y hay muchas cosas que no tienen que ver".

“(...): [En que en el técnico] no es solamente sentarse allá, usted tiene que demostrar que lo que está estudiando, lo está colocando en práctica”.

“(...) Porque sí, como dicen uno va a estudiar y todo lo ponen en plataforma y ¿Qué va haciendo uno? Es como persiguiendo unos requisitos para terminar una licenciatura, porque hay muchas materias que no tienen nada que ver con lo que uno está estudiando (...)”

Por otro lado, los equipos de trabajo reconocen la importancia de cualificación específica para trabajar con población afectada por el conflicto, teniendo en cuenta las características y necesidades especiales de esta población.

"En este momento yo pienso que es importante que nos capaciten en todo lo que tiene que ver con el conflicto armado, con los desplazados, con los reinsertados, porque manejar esa población es muy diferente a manejar las poblaciones de los alrededores (...) yo pienso que debe haber una capacitación mucho más profunda para que nosotros sepamos manejar esa población”.

"[Necesitamos] más capacitaciones porque de todos modos, en cuanto a la violencia con las mujeres, uno necesita también como más capacitaciones para poderles dar más fortalecimiento a ellas".

"Yo pensaría que de pronto falta más, más capacitación frente a este tema del conflicto con los psicosociales, digamos que nosotros no hemos tenido casos de violencia, pero yo digo que a los psicosociales les falta mucho, porque digamos que de pronto ellos tratan como muy por encima, pero de pronto les falta también capacitación, claro y para nosotras también, en el momento que tengamos que..., que debamos ayudarlos".

"[Se debe] fortalecer más el conocimiento como cuando llegan personas en desplazamiento, víctimas de conflicto, violación. Porque bueno porque uno acá les abre como una ruta de atención, pero uno no sabe ni como hablarle a esa persona, bueno si digo esto va a estar bien o si 
digo tal cosa no le va a gustar, entonces sí como fortalecernos en esa parte”

"[Necesitamos] pues como una capacitación más profunda en los temas del conflicto, violencia y todas las clases de violencia (...). O las rutas de atención, de atención integral, uno las conoce pero no las conoce bien a profundo".

"Porque no falta la mamá que dice no, yo no quiero que la trabajadora social me oriente, entonces como que le toca a uno orientarlas".

\section{Nivel individual}

A nivel individual los procesos de cualificación deben reconocer las prácticas que constituyen la generación de conocimiento, al igual que la capacidad de reflexión sobre sus acciones cotidianas. La cualificación del talento humano se constituye como un proceso crucial para garantizar la calidad de la gestión; así que se espera que la cualificación del talento humano se articule con las competencias para generar ambientes que propicien un desarrollo infantil óptimo y aseguren en las niñas y los niños el ejercicio de sus derechos (MEN, 2014a).

A continuación, se presenta el esquema de competencias para la categoría de profesionalización y cualificación a nivel individual.

Tabla 2.5. Competencias relacionadas con la profesionalización y cualificación - Nivel individual.

\section{Conocimientos}

- Conocimiento del perfil profesional y ocupacional según la profesión y/o cualificación recibida, que responda a las necesidades de la primera infancia.

- Conocimiento actualizado, en el que se tenga en cuenta los referentes conceptuales y el contexto, para sustentar la atención, el cuidado y la enseñanza/aprendizaje de las/os niñas/os.

\section{Prácticas}

Valores

- Participar en espacios de cualificación conforme a intereses, necesidades y oferta de instituciones de educación formal y no formal que respondan a las necesidades de la primera infancia.

- Evaluar de manera permanente y crítica el trabajo individual y colectivo para verificar que las prácticas estén siendo sustentadas por los saberes y el conocimiento científico adquirido en los procesos de cualificación y profesionalización, y reajustar dichas prácticas de ser necesario.
- Reconocer que el trabajo con primera infancia, familias y comunidades es de carácter profesional.

- Valorar la formación como un proceso de desarrollo personal y profesional. Formación que es construida, además, en la interacción con otros y tiene en cuenta el contexto en el que se desarrollan y se deben aplicar los conocimientos.

- Reconocer la importancia de sustentar la práctica profesional, en saberes y conocimiento científico adquiridos en los procesos de cualificación profesionalización.

- Adoptar una cultura de profesionalización que permita la actualización de manera permanente a lo largo del quehacer profesional. 


\section{Nivel institucional}

A nivel institucional se destaca que los procesos de profesionalización y cualificación deben partir de las necesidades del talento humano, así como de los diferentes actores que desempeñen los procesos de atención integral a la primera infancia, mediante planeadores, diseñadores o tomadores de decisiones articulados con las políticas públicas. Además, los procesos de cualificación deben incluir unos ejes temáticos particulares que fortalecen aspectos específicos de la gestión y la atención integral, como la preservación de condiciones de plena dignidad, el fortalecimiento de los vínculos de las niñas y los niños consigo mismos, con sus familias y con las personas responsables de su cuidado, la promoción de autonomía, autodeterminación, construcción del sentido de identidad personal y colectiva en la diversidad, la creación de ambientes enriquecidos, seguros, protectores, incluyentes, participativos y democráticos (MEN, 2014a).

A continuación, se presenta el esquema de competencias para la categoría de profesionalización y cualificación a nivel institucional.

Tabla 2.6. Competencias relacionadas con la profesionalización y cualificación - Nivel institucional.

\begin{tabular}{|c|c|c|}
\hline Conocimientos & Prácticas & Valores \\
\hline $\begin{array}{l}\text { - Conocimiento de las ex- } \\
\text { pectativas de profesionaliza- } \\
\text { ción de todos los miembros } \\
\text { del equipo de trabajo y las } \\
\text { necesidades en relación con } \\
\text { las características específicas } \\
\text { de la población que atiende } \\
\text { (contexto sociocultural de la } \\
\text { población, víctimas de con- } \\
\text { flicto ...). }\end{array}$ & $\begin{array}{l}\text { - Gestionar los procesos de } \\
\text { profesionalización que res- } \\
\text { pondan a las expectativas y } \\
\text { criterios de los equipos. } \\
\text { - Diseñar estrategias colabo- } \\
\text { rativas para establecer planes } \\
\text { de profesionalización de los } \\
\text { equipos. } \\
\text { - Elaborar planes de cualifica- } \\
\text { ción institucionales que partan } \\
\text { de los intereses y necesidades } \\
\text { de los equipos de trabajo. } \\
\text { - Trabajar articuladamente } \\
\text { con los responsables de la ges- } \\
\text { tión de la política pública de } \\
\text { primera infancia para generar } \\
\text { procesos de integralidad en las } \\
\text { políticas de profesionalización. } \\
\text { - Proporcionar espacios de } \\
\text { cualificación que permitan } \\
\text { fortalecer las prácticas profe- } \\
\text { sionales. } \\
\text { - Estimular el encuentro de } \\
\text { saberes y experiencias en los } \\
\text { procesos de profesionalización } \\
\text { de los equipos. }\end{array}$ & $\begin{array}{l}\text { - Reconocer la importancia } \\
\text { de promover la profesionali- } \\
\text { zación y cualificación perma- } \\
\text { nente del equipo de trabajo, } \\
\text { teniendo en cuenta expectati- } \\
\text { vas personales, profesionales } \\
\text { y las necesidades de atención, } \\
\text { cuidado y enseñanza/apren- } \\
\text { dizaje de acuerdo con las ca- } \\
\text { racterísticas de las/os niñas/ } \\
\text { os, familias y comunidades } \\
\text { (contexto sociocultural, vícti- } \\
\text { mas de conflicto...). }\end{array}$ \\
\hline
\end{tabular}




\section{Nivel interinstitucional}

En la profesionalización y cualificación se identifica la necesidad del trabajo interinstitucional para la atención integral, y se resalta la necesidad de promover y potenciar actores que trabajen con la primera infancia las competencias de cooperatividad y reflexión. Por lo tanto, es necesario un acompañamiento en las prácticas individuales y colectivas, al igual que en la gestión de la política pública, así como la socialización de experiencias y saberes construidos en los diferentes actores e instancias que tienen bajo su responsabilidad garantizar los derechos de las niñas y los niños (MEN, 2014a).

A continuación, se presenta el esquema de competencias para la categoría de profesionalización y cualificación a nivel interinstitucional.

Tabla 2.7. Competencias relacionadas con la profesionalización y cualificación - Nivel interinstitucional.

\begin{tabular}{|c|c|c|}
\hline Conocimientos & Prácticas & Valores \\
\hline $\begin{array}{l}\text { - Conocimiento de las com- } \\
\text { petencias necesarias para } \\
\text { atender primera infancia, } \\
\text { familias y comunidades di- } \\
\text { versas, que provienen de } \\
\text { distintos contextos sociocul- } \\
\text { turales y con historias de vida } \\
\text { particulares, entre ellas vícti- } \\
\text { mas de conflicto, de manera } \\
\text { que los programas de profe- } \\
\text { sionalización y cualificación } \\
\text { respondan a ello. }\end{array}$ & $\begin{array}{l}\text { - Brindar apoyo para fortalecer } \\
\text { el proceso de profesionalización } \\
\text { de los equipos de trabajo. } \\
\text { - Evaluar la pertinencia de la } \\
\text { profesionalización y las necesi- } \\
\text { dades y expectativas de profe- } \\
\text { sionalización de los equipos de } \\
\text { trabajo. }\end{array}$ & $\begin{array}{l}\text { - Reconocer que el trabajo } \\
\text { con primera infancia, familias } \\
\text { y comunidades es de carác- } \\
\text { ter profesional, por lo cual la } \\
\text { oferta de programas debe co- } \\
\text { rresponder a esta concepción. } \\
\text { - Promover programas de } \\
\text { cualificación acordes con los } \\
\text { saberes y competencias nece- } \\
\text { sarias para atender primera } \\
\text { infancia, familias y comuni- } \\
\text { dades diversas, que provienen } \\
\text { de distintos contextos socio- } \\
\text { culturales y con historias de } \\
\text { vida particulares, entre ellas } \\
\text { víctimas de conflicto. } \\
\text { - Reconocer los saberes y ex- } \\
\text { periencias del talento huma- } \\
\text { no en los procesos de profe- } \\
\text { sionalización y cualificación. }\end{array}$ \\
\hline
\end{tabular}

\section{Nivel de gobernanza}

La profesionalización y la cualificación deben realizarse de manera continua; por lo tanto, es un reto para la gobernanza asegurar la permanencia y la articulación entre las prácticas y la construcción de conocimiento, así como los procesos de resignificación de saberes y el aprendizaje constante (MEN, 2014a). Es necesario cualificar al talento humano en la gestión territorial, la calidad de las atenciones, el seguimiento y la evaluación de la política, la movilización social y la generación de conocimiento. 
A continuación, se presenta el esquema de competencias para la categoría de profesionalización y cualificación a nivel de gobernanza.

Tabla 2.8. Competencias relacionadas con la profesionalización y cualificación-

Nivel de gobernanza.

\section{Conocimientos}

\section{Prácticas}

\section{Valores}

- Conocimiento de las expectativas y necesidades de profesionalización de los miembros de los equipos de trabajo, en el que además se articule dicho concomimiento, las necesidades de la población de acuerdo con características específicas (contexto sociocultural, historia de vida...) .
- Asegurar la sostenibilidad de las estrategias de profesionalización y cualificación, como el apoyo a la financiación de estudios de educación superior.

- Asegurar la calidad en el marco del sistema educativo, de los programas de profesionalización para los equipos que trabajan con primera infancia, familias y comunidades.

- Promover proyectos de ley que aseguren la profesionalización y garanticen recursos económicos para el tránsito de agentes educativos que cuentan con la experiencia en el trabajo con primera infancia, familias y/o comunidades.

- Identificar e incluir en las políticas lo que requieren, sienten, piensan y proponen, las/os niñas y niños, las familias y las comunidades para transformar su realidad y conseguir condiciones de vida justa y oportunidades de educación de acuerdo con las expectativas y necesidades de la población.
- Promover que los equipos que trabajan con primera infancia, familias y comunidades, opten por programas de educación superior en cualquiera de sus niveles.

- Reconocer el derecho a la participación de los equipos de trabajo en la construcción de las políticas de profesionalización.

- Concebir que las políticas de profesionalización deben estar basadas en las necesidades de atención de la población.

\section{La construcción de comunidades de reflexión crítica y aprendizaje}

Esta categoría está en estrecha relación con la anterior, ya que es una de las características de la cultura de la profesionalización: el aprendizaje y práctica en los lugares de trabajo desde lo individual y lo colectivo (Pirard y Barbier, 2012). En esta categoría se contempla tanto el nivel individual de la práctica como el trabajo colaborativo y colectivo (comunidades de práctica), las instituciones como comunidades de reflexión crítica (Uban, 2012), y la relación con las familias y comunidades. 
Reflexionar sobre esta categoría requiere del reconocimiento de dos premisas: la primera, que el trabajo con primera infancia es de naturaleza profesional y la segunda, que dicho trabajo requiere de un sistema capaz de alentar y de crear sistemáticamente espacios para el diálogo y para hacer preguntas críticas en cada nivel del sistema, así como para valorar la multitud y la diversidad de respuestas como elemento clave para crear nuevos entendimientos, fomentando la co-construcción de conocimientos y prácticas profesionales (Urban, 2008).

Esta mirada tiene implicaciones y plantea retos en todos los niveles del sistema, ya que la reflexión crítica no es responsabilidad única del profesional como individuo sino que esta se traduce en el diseño e implementación de programas y escenarios de discusión formales y abiertos, por ejemplo encuentros locales, regionales y nacionales donde se expongan y se discutan las temáticas transversales a la atención de la primera infancia, desde los niveles más abstractos como sus principios, fundamentos o enfoques que orientan las prácticas de cuidado y educación, hasta su reflexión al nivel micro de la implementación, por ejemplo, estudios de caso en contextos sociales, económicos y culturales diversos. Lo anterior implica un encuentro de diferentes actores en escenarios donde convergen diferentes disciplinas y prácticas profesionales, actores como los agentes educativos de las instituciones que administran y regulan la educación de la primera infancia, los formadores de profesionales, universidades y centros de investigación, la sociedad civil, organizaciones no gubernamentales, sindicatos y agremiaciones, así como las familias y comunidades que hacen parte vital de los escenarios de educación, atención y cuidado para la primera infancia en el país.

Por lo tanto, la reflexión crítica parte del reconocimiento de la educación de la primera infancia como un campo de discusión y práctica que tiene desarrollos teóricos y políticos, lo que conlleva a una identidad propia que se construye en el reconocimiento social, la reflexión crítica permanente y el aprendizaje.

Las comunidades de reflexión crítica y aprendizaje son además escenarios que pueden ser propicios para que los equipos que trabajan directamente con los niños, niñas y comunidades, puedan participar en la planificación de los temas que tratan en las sesiones de formación y acompañamiento con las familias, teniendo en cuenta que son ellos quienes por tener mayor cercanía conocen mejor las necesidades específicas de las comunidades con quienes trabajan. Uno de los testimonios entregados por una auxiliar pedagógica de un CDI de modalidad familiar, con el que estuvieron de acuerdo sus compañeras, muestra que los equipos de trabajo anhelan tener mayor participación al respecto:

\footnotetext{
"A nosotros nos ponen un cronograma, nosotros tenemos un cronograma y tenemos que trabajar sobre el tema, digamos que esta semana es gastronomía con bienestarina digamos que uno pues ya estudia qué va hacer, pero es a partir de este tema y es eso, es la capacitación con los papás”.
} 


\section{Nivel individual}

Para la categoría de construcción de comunidades de reflexión crítica y aprendizaje a nivel individual, se destaca el reconocimiento de la práctica para los procesos de cualificación, así que se deben generar espacios de socialización, comunicación y reflexión de las experiencias y saberes de los diferentes agentes. Por lo tanto, los procesos de cualificación deben permitir de manera permanente la reflexión, el diálogo entre la teoría y la práctica, bajo la perspectiva que el talento humano debe generar acciones dirigidas a aportar soluciones de acuerdo con su contexto (MEN, 2014a).

A continuación, se presenta el esquema de competencias para la categoría de construcción de comunidades de reflexión crítica y aprendizaje a nivel individual.

Tabla 2.9. Competencias relacionadas con la construcción de comunidades de reflexión crítica y aprendizaje - Nivel individual.

\begin{tabular}{|c|c|c|}
\hline Conocimientos & Prácticas & Valores \\
\hline $\begin{array}{l}\text { - Conocimiento de las di- } \\
\text { ferentes estrategias que se } \\
\text { pueden y deben adoptar para } \\
\text { realizar un intercambio inter- } \\
\text { disciplinar que enriquezca el } \\
\text { quehacer individual y colec- } \\
\text { tivo y se refleje positivamen- } \\
\text { te en la atención, cuidado y } \\
\text { enseñanza/aprendizaje de la } \\
\text { primera infancia. }\end{array}$ & $\begin{array}{l}\text { - Revisar continuamente las } \\
\text { prácticas individuales y co- } \\
\text { lectivas. } \\
\text { - Compartir e intercambiar } \\
\text { experiencias entre colegas du- } \\
\text { rante las reuniones de equipo. } \\
\text { - Participar en las actividades } \\
\text { de discusión y generar apren- } \\
\text { dizajes a partir del desacuerdo } \\
\text { para el fomento del desarrollo } \\
\text { educativo. } \\
\text { - Desarrollar prácticas que } \\
\text { fomenten el trabajo interdis- } \\
\text { ciplinar. } \\
\text { - Co-construir conocimien- } \\
\text { tos pedagógicos. } \\
\text { - Documentar y evaluar las } \\
\text { prácticas pedagógicas a nivel } \\
\text { individual y colectivo. }\end{array}$ & $\begin{array}{l}\text { - Concebir el intercambio } \\
\text { de saberes y la permanen- } \\
\text { te evaluación del quehacer } \\
\text { profesional, como una de } \\
\text { las acciones indispensables } \\
\text { para enriquecer los conoci- } \\
\text { mientos y reajustar la prác- } \\
\text { tica profesional de acuerdo } \\
\text { con las necesidades de las/ } \\
\text { os niñas/os, las familias y las } \\
\text { comunidades. }\end{array}$ \\
\hline
\end{tabular}

\section{Nivel institucional}

A nivel institucional se identifica la importancia de implementar espacios de cualificación abiertos a diferentes métodos, contenidos y estrategias, de modo tal que la cualificación sea pertinente a la amplia gama de actores, saberes, experiencias, contextos y prácticas involucradas (MEN, 2014a). Aunque los procesos de cualificación requieren de diversas metodologías, contenidos y estrategias, también se necesita contextualizar las particularidades de los participantes y sus necesidades de aprendizaje. 
A continuación, se presenta el esquema de competencias para la categoría de construcción de comunidades de reflexión crítica y aprendizaje a nivel institucional.

Tabla 2.10. Competencias relacionadas con la construcción de comunidades de reflexión crítica y aprendizajeNivel Institucional.

\begin{tabular}{|c|c|c|}
\hline Conocimientos & Prácticas & Valores \\
\hline $\begin{array}{l}\text { - Conocimiento sobre las } \\
\text { diferentes estrategias de so- } \\
\text { cialización, intercambio de } \\
\text { conocimiento y reflexión } \\
\text { pedagógica entre los equipos } \\
\text { de trabajo. } \\
\text { - Re-conceptualización de } \\
\text { las teorías que sirven como } \\
\text { base en el trabajo con fami- } \\
\text { lias y comunidades. }\end{array}$ & $\begin{array}{l}\text { - Incentivar la participación } \\
\text { de todo el equipo de trabajo } \\
\text { en el diseño del plan de aten- } \\
\text { ción a las/os niñas/os, fami- } \\
\text { lias y comunidades. } \\
\text { - Promover el aprendizaje } \\
\text { y la reflexión pedagógica de } \\
\text { manera individual y colabo- } \\
\text { rativa. } \\
\text { - Generar el intercambio de } \\
\text { conocimientos y experiencias } \\
\text { entre los miembros del equi- } \\
\text { po de trabajo, incluidos allí } \\
\text { los que se formaron en distin- } \\
\text { tas disciplinas. } \\
\text { - Realizar un seguimiento de } \\
\text { experiencias significativas, } \\
\text { las cuales se profundicen y } \\
\text { sistematicen de manera que } \\
\text { puedan producir teoría peda- } \\
\text { gógica. } \\
\text { - Propiciar intercambio de } \\
\text { conocimientos y experiencias } \\
\text { donde se incluyan familias y } \\
\text { comunidades. Además se pro- } \\
\text { picie el encuentro y se valoren } \\
\text { los saberes encontrados en la } \\
\text { diversidad. }\end{array}$ & $\begin{array}{l}\text { - Valorar la importancia de } \\
\text { promover el intercambio de } \\
\text { saberes, el trabajo en equipo } \\
\text { y la reflexión crítica como } \\
\text { elementos indispensables } \\
\text { para mejorar la práctica pro- } \\
\text { fesional en pro de una aten- } \\
\text { ción más eficiente e integral } \\
\text { a la primera infancia, fami- } \\
\text { lias y comunidades. }\end{array}$ \\
\hline
\end{tabular}

\section{Nivel interinstitucional}

Desde una perspectiva interinstitucional es necesario promover y potenciar en el talento humano que trabaja con la primera infancia, competencias de cooperatividad y de reflexión (MEN, 2014a). Esto requiere un proceso de revisión permanente hacia las prácticas individuales y colectivas que tienen lugar en los diferentes contextos, ya sea a nivel de política pública o en la socialización de prácticas y conocimientos desarrollados por las diferentes instancias que tienen bajo su responsabilidad la garantía de los derechos de las niñas y los niños en la primera infancia.

A continuación, se presenta el esquema de competencias para la categoría de construcción de comunidades de reflexión crítica y aprendizaje a nivel interinstitucional. 
Tabla 2.11. Competencias relacionadas con la construcción de comunidades de reflexión crítica y aprendizaje Nivel interinstitucional.

\begin{tabular}{|c|c|c|}
\hline Conocimientos & Prácticas & Valores \\
\hline $\begin{array}{l}\text { - Conocimientos de la per- } \\
\text { tinencia y el impacto de los } \\
\text { procesos de socialización e in- } \\
\text { tercambio de conocimientos y } \\
\text { reflexión pedagógica entre los } \\
\text { equipos de trabajo }\end{array}$ & $\begin{array}{l}\text { - Apoyar con expertos la } \\
\text { conformación de comuni- } \\
\text { dades de reflexión crítica y } \\
\text { aprendizaje. } \\
\text { - Evaluar el impacto de las } \\
\text { comunidades de reflexión } \\
\text { crítica y aprendizaje en la } \\
\text { atención oportuna e integral } \\
\text { de la primera infancia, fami- } \\
\text { lias y comunidades, así como } \\
\text { en la construcción de nuevo } \\
\text { conocimiento. }\end{array}$ & $\begin{array}{l}\text { - Concebir la importancia de } \\
\text { apoyar y evaluar permanen- } \\
\text { temente el impacto de las co- } \\
\text { munidades de reflexión críti- } \\
\text { ca y aprendizaje, como forma } \\
\text { de retroalimentar la práctica } \\
\text { profesional en pro de una } \\
\text { atención oportuna y eficiente } \\
\text { a las/os niñas/os, familias y } \\
\text { comunidades. }\end{array}$ \\
\hline
\end{tabular}

\section{Nivel de gobernanza}

A nivel de gobernanza se plantea los procesos de cualificación, desde la gestión de la política pública y todos los actores que brindan una atención integral a la primera infancia, en los cuales se invita a reflexionar sobre sus acciones y construirse como sujetos de cambio que permanentemente buscan aprender de sí mismos y de su entorno. También están las diferentes dinámicas de constructividad, referente a la necesidad de comprensión y reconocimiento del talento humano, mediante saberes y experiencias, sobre las cuales se debe iniciar para la gestión de la política pública y la atención integral a las niñas y los niños (MEN, 2014a).

A continuación, se presenta el esquema de competencias para la categoría de construcción de comunidades de reflexión crítica y aprendizaje a nivel gobernanza.

Tabla 2.12. Competencias relacionadas con la construcción de comunidades de reflexión crítica y aprendizajeNivel de gobernanza.

\section{Conocimientos}

\section{Prácticas}

\section{Valores}

- Generar redes de apoyo que contribuyan a las comunidades de reflexión crítica y aprendizaje en la sistematización y socialización del conocimiento generado por medio de ellas.
- Valorar los saberes que se construyen a partir de las experiencias que se exponen en las comunidades de reflexión crítica
- Conocimiento de estrategias adecuadas para la sistematización y socialización del conocimiento generado en las comunidades de reflexión crítica. 


\section{Las condiciones de bienestar y satisfacción (condiciones sistémicas de apoyo)}

Las condiciones de bienestar y satisfacción se entienden como aquellas condiciones materiales y de bienestar en las que los equipos desarrollan sus identidades, lo que se traduce en niveles de calidad deseables para las instituciones de educación, cuidado y atención para la primera infancia. En tal sentido, a nivel individual convergen diferentes aspectos, tales como el apoyo en las actividades de los equipos de trabajo, la participación de la familia, tiempo y espacio para la preparación, reflexión y transformación de las actividades con los niños, familia y comunidad, además de la autonomía en la toma decisiones, recursos, materiales, espacios para el desarrollo de actividades, planes de cualificación y condiciones laborales (Schwartz et al., 2019; Esguerra, 2018; Flórez et al., 2013; OCDE, 2012; Urban et al., 2012, 2011; Salazar, 2006).

Uno de los aspectos en los que el talento humano hizo mayor énfasis, está relacionado con el apoyo que se les brinda a nivel económico para su profesionalización. En su gran mayoría, los equipos de trabajo sienten que no tienen el apoyo que requieren y que sus ingresos económicos no son suficientes para costear por cuenta propia la totalidad del costo de un programa de formación profesional:

\footnotetext{
"[Me gustaría] que no sea tan costosa la licenciatura, así sea las que llevamos años trabajando en esto, que tuvieran algo como para nosotras una oportunidad que no fuera tan costosa”.

"[Nos gustaría] que nos dieran una oportunidad [para estudiar] que no fuera tan costosa, que de alguna manera reconocieran todos esos años de trabajo que realmente nosotras no recibíamos nada y nos lo remuneraran de alguna manera, que así como hubo compañeras que se pudieron adherir a eso que el semestre costaba doscientos mil pesos [e ingresaron las que llevaban] seis meses de ingreso al programa, que se inventaran o crearan algo para las que llevamos años en esto y queremos seguir (...) pero el precio no es accesible, pues porque tenemos otros gastos”.

"Pero no me gusta a veces como la presión que se da acá, como que si usted no estudia no se sabe si va a ser contratada el otro año (...) entonces uno como que no vive tranquilo como por esa parte".
}

Por otro lado, el talento humano reclama mayor apoyo en relación con lo que ellos sienten es una sobrecarga en el diligenciamiento de documentos, que según refieren, les quita tiempo para realizar una planeación de calidad y desempeñar de mejor manera los procesos pedagógicos con las niñas, los niños y la comunidad.

\footnotetext{
"Como tal ICBF coloca muchísimos formatos, muchos, muchos, muchos y pienso yo que de pronto ellos pueden contratar un administrativo para cada CDI que se encargue de hacer esos formatos, porque nosotras estamos es con un fin y es pedagógico, y a veces nos limitamos mucho con lo de los formatos, entonces dejamos de hacer algo lindo para los niños porque es que, aah, toca hacer los formatos, o la compañera está con los formatos (...), entonces pensaría yo que sería bueno que de pronto la asociación contratara un administrativo que se encargue de recopilar todos los formatos y nosotros seamos más la parte pedagógica”.

“El ICBF debería mirar más el trabajo pedagógico y digamos no exigir tanto, tanta documentación, porque eso nos acorta mucho tiempo en otras actividades que nosotras como pedagogas pensamos, para los niños y para las familias"
} 
"Pero igualmente a veces llenamos muchos documentos que son innecesarios, para mí, a veces hay cosas que no son necesarias pero se pide y por eso a veces hay cosas que nos da como un estrés porque nos dicen, bueno, si no llevan esto entonces no hay contratación, o si no cumplimos esto entonces no se contrata, entonces no sé qué, o la asociación se queda sin contrato".

El talento humano pide además mayor acompañamiento de diversas instituciones en las labores que realizan de formación con las niñas, los niños y las familias:

"Fuera bonito que ICBF tuviera convenio con otras instituciones (...), universidades, que ellas puedan venir a aprender y puedan enseñar como tal a las usuarias (...), qué bonito que de pronto una universidad venga y hable de pautas de crianza (...), nosotros venimos y les hablamos acá [a las usuarias], pero muy por encimita, y digo que de pronto sería bueno que muchas instituciones vinieran y trabajaran también con las usuarias".

\section{Nivel individual}

Para la categoría de bienestar y satisfacción se reconoce la complejidad de las prácticas de gestión y de atención integral a la primera infancia, al igual que la diversidad de los agentes educativos que se requieren; entonces, los procesos de cualificación deben dar cuenta de la pluralidad y heterogeneidad de los contextos de atención, con el fin de generar distintos saberes y experiencias que se articulen tanto con los recursos de aprendizaje, como con la construcción de bienestar personal y laboral (MEN, 2014a).

A continuación, se presenta el esquema de competencias para la categoría de condiciones de bienestar y satisfacción a nivel individual.

Tabla 2.13. Competencias relacionadas con las condiciones de bienestar y satisfacción - Nivel individual.

\section{Conocimientos}

Prácticas

\section{Valores}

- Conocimiento de las condiciones que proveen bienestar y satisfacción en el equipo que trabaja con primera infancia, familias y comunidades.
- Generar espacios de discusión donde el equipo que trabaja con primera infancia, familias y comunidades, aporte su experiencia frente a las condiciones de bienestar personal y profesional, así como los elementos que se pueden aportar desde lo individual y lo colectivo para ayudar a que se establezcan dichas condiciones, y los que requieren del apoyo externo al equipo de trabajo.
- Reconocer la importancia de que se establezcan condiciones en el trabajo con niñas/ os, familias y comunidades, para generar bienestar personal y profesional en todos los miembros del equipo de trabajo, de manera que ello impacte positivamente en la atención integral de la primera infancia.

- Valorar la importancia de mantener entre todo el equipo de trabajo interacciones estables, sensibles y estimulantes que se reflejen en la buena interacción que se mantiene con las/os niñas/os, las familias y las comunidades. 


\section{Nivel institucional}

La cualificación desde las condiciones de bienestar requiere del reconocimiento de las particularidades del talento humano, así como los procesos educativos necesarios para asegurar la flexibilidad curricular, y el desarrollo de nuevas experiencias y aprendizajes no previstos inicialmente en el diseño curricular (MEN, 2014a). Lo anterior implica: respuesta a necesidades de cualificación no identificadas inicialmente, generar aprendizajes no previstos e implementar nuevas metodologías según las singularidades de los participantes para garantizar su bienestar personal y laboral.

A continuación, se presenta el esquema de competencias para la categoría de condiciones de bienestar y satisfacción a nivel institucional.

Tabla 2.14. Competencias relacionadas con las condiciones de bienestar y satisfacción - Nivel institucional.

\begin{tabular}{|c|c|c|}
\hline Conocimientos & Prácticas & Valores \\
\hline $\begin{array}{l}\text { - Conocimiento de las con- } \\
\text { diciones que generan bien- } \\
\text { estar y mantienen motivado } \\
\text { al equipo que trabaja con } \\
\text { primera infancia, familias y } \\
\text { comunidad }\end{array}$ & $\begin{array}{l}\text { - Generar espacios de diálogo } \\
\text { donde se escuche y documen- } \\
\text { te lo que expone el equipo } \\
\text { de trabajo en relación con } \\
\text { las condiciones que generan } \\
\text { bienestar personal y laboral } \\
\text { en el trabajo con niñas/os, fa- } \\
\text { milias y comunidad. } \\
\text { - Garantizar condiciones la- } \\
\text { borales al equipo que trabaja } \\
\text { con primera infancia, tenien- } \\
\text { do en cuenta la experiencia y } \\
\text { los procesos de cualificación. } \\
\text { - Realizar procesos de evalua- } \\
\text { ción y seguimiento al equipo } \\
\text { de trabajo, situados en las con- } \\
\text { diciones y recursos disponi- } \\
\text { bles y en las características de } \\
\text { la población que atiende. Pro- } \\
\text { mover un alto grado de auto- } \\
\text { nomía en el equipo de trabajo, } \\
\text { de manera que se incentive la } \\
\text { motivación permanente y la } \\
\text { actitud propositiva. }\end{array}$ & $\begin{array}{l}\text { - Valorar la importancia de } \\
\text { contar con un equipo de tra- } \\
\text { bajo que experimenta bienes- } \\
\text { tar y permanece motivado en } \\
\text { su labor con primera infan- } \\
\text { cia, familias y comunidad. }\end{array}$ \\
\hline
\end{tabular}

\section{Nivel interinstitucional}

Las condiciones de bienestar requieren de un trabajo interinstitucional que garantice la articulación de actores públicos y privados, las dinámicas territoriales y los mecanismos necesarios para garantizar la atención integral a la primera infancia. $\mathrm{Al}$ existir diversidad entre actores, niveles, modalidades, sectores e instituciones se 
requiere de acciones coordinadas que garanticen el bienestar del talento humano, las expectativas de cualificación y la construcción de redes (MEN, 2014a).

A continuación, se presenta el esquema de competencias para la categoría de condiciones de bienestar y satisfacción a nivel interinstitucional

Tabla 2.15. Competencias relacionadas con las condiciones de bienestar y satisfacción - Nivel interinstitucional.

\begin{tabular}{|c|c|c|}
\hline Conocimientos & Prácticas & Valores \\
\hline $\begin{array}{l}\text { - Conocimiento de las condi- } \\
\text { ciones que generan bienestar y } \\
\text { mantienen motivado al equipo } \\
\text { que trabaja con primera infan- } \\
\text { cia, familias y comunidades. }\end{array}$ & $\begin{array}{l}\text { - Evaluar oportuna y perma- } \\
\text { nentemente las condiciones } \\
\text { de bienestar y el cumpli- } \\
\text { miento de las expectativas } \\
\text { profesionales y laborales de } \\
\text { los miembros del equipo que } \\
\text { trabaja con primera infancia, } \\
\text { familias y comunidades. } \\
\text { - Generar redes y rutas de } \\
\text { apoyo para los equipos que } \\
\text { desarrollan acciones con pri- } \\
\text { mera infancia, familias y co- } \\
\text { munidades. }\end{array}$ & $\begin{array}{l}\text { - Promover las condiciones } \\
\text { de bienestar y satisfacción } \\
\text { laboral y profesional de los } \\
\text { equipos de trabajo. }\end{array}$ \\
\hline
\end{tabular}

\section{Nivel de gobernanza}

Para garantizar los procesos de gobernanza y la gestión de la política pública, es necesario implementar recursos pedagógicos para la construcción de ambientes de aprendizaje entre las instituciones públicas, las entidades formadoras, los tutores y los agentes (MEN, 2014a), ya que el aprendizaje es un proceso complejo y permanente, donde la gobernanza debe tener en cuenta los micro contextos, en los cuales intervienen diversos actores y las necesidades individuales; en un contexto macro, se requiere del acompañamiento a las instituciones formadoras, los lineamientos y políticas que garantizan la cualificación desde una perspectiva de bienestar.

A continuación, se presenta el esquema de competencias para la categoría de condiciones de bienestar y satisfacción a nivel gobernanza

Tabla 2.16. Competencias relacionadas con las condiciones de bienestar y satisfacción - Nivel de gobernanza.

Conocimientos

Conocimientos

- Conocimiento de las condiciones que generan bienestar y mantienen motivado al equipo que trabaja con primera infancia, familias y comunidades.

- Conocimiento de los procesos de evaluación y seguimiento

\section{Prácticas}

- Proveer y evaluar el mantenimiento de las condiciones que generan bienestar al equipo que trabaja con primera infancia, familias y comunidades, de manera que se ajusten dichas condiciones, generan-

\section{Valores}

- Considerar a la hora de planificar la evaluación y seguimiento de los equipos de trabajo, las diferencias de los contextos y los desafíos que estos enfrentan en el desarrollo de su labor, con dependencia de las condiciones 
adecuados y realistas en concordancia con las situaciones que enfrentan los equipos de trabajo en la atención de primera infancia, familias y co munidades específicas.

- Conocimiento conceptual de los procesos de cualificación en primera infancia, dentro de los planes de desarrollo social del país. do bienestar colectivo la mayor parte del tiempo.

- Evaluar el trabajo que realizan los equipos de trabajo que atienden primera infancia, familias y comunidades, de forma realista y adecuada a los contextos en que se desempeña cada uno de los equipos. laborales y las características de la población que atienden.

\section{Conclusiones}

- Las identidades profesionales y la cualificación del talento humano necesitan de la intencionalidad de los procesos educativos, dado que son factores de calidad para la atención integral a la primera infancia y la gestión de la política pública.

- Es necesario reconocer los procesos de cualificación desde una perspectiva sistémica, donde se requiere articulación, continuidad y recurrencia de los procesos educativos.

- Los procesos de cualificación y profesionalización requieren de un modelo pedagógico que favorezca la reflexión sobre las prácticas tanto de los participantes como de los saberes y experiencias de los diferentes actores.

- Se requiere de planes de cualificación permanente del talento humano que trabaja en primera infancia en los diferentes niveles territoriales o nacionales.

- Los lineamientos y políticas para las identidades profesionales no pueden construirse desde una mirada externa al territorio, deben estar contextualizadas y basadas en la reflexión de los diferentes actores.

- Los procesos de cualificación requieren de sentido, continuidad y articulación con los diferentes procesos educativos.

\section{Referencias}

Abello, R., y Acosta, A. (2006), Recomendaciones para la Política Pública de Primera Infancia en Materia de Educacion Inicial a Partir del Estudio de Cinco Modalidades de Atención a la Primera Infancia en Bogotá, Colombia. Journal of Education for International Development, 2(3). Recuperado de: https://www.oei.es/historico/inicial/articulos/recomendaciones_politica_inicial_colombia.pdf.

Alarcón-Párraga, C. (2012). Violencia en la comunidad contra niños y niñas en primera infancia. Niños y niñas en primera infancia víctimas del conflicto armado: aproximaciones y acciones. Consulta de Expertos sobre la Prevención y Respuesta a la Violencia contra las Niñas y Niños Pequeños, Lima, 27 - 28 de agosto de 2012.

Álvarez, A. (2012). Los niños de la calle: Bogotá 1900-1950. En Zuluaga, O., et al. (2012). Historia de la educación en Bogotá. Tomo 2. Serie Investigación. Instituto para la Investigación Educativa 
y el Desarrollo Pedagógico, IDEP: Bogotá D.C. Recuperado de: http://biblioteca.clacso.edu.ar/ Colombia/idep/20160105010910/HistoriaEducaB0GTomoll.pdf

Araujo, M., López-Boo, F., y Puyana, J. (2013). Panorama sobre los servicios de desarrollo infantil en América Latina y el Caribe. Banco Interamericano de Desarrollo, División de Protección Social y Salud.

Arndt, S., Urban, M., Murray, C., Smith, K., Swadener, B., \& Ellegaard, T. (2018). Contesting early childhood professional identities: A cross-national discussion. Contemporary Issues in Early Childhood, 19(2), 97-116. doi:10.1177/1463949118768356

Arteaga, L. (2004). Pobreza, Violencia y el Proyecto de Madres Comunitarias en Colombia. Center for International Education. Recuperado de: http://lanic.utexas.edu/project/etext/lilas/ilassa/2004/arteaga.pdf

Bennett, J. (2006) New policy conclusions from starting strong II an update on the OECD early childhood policy reviews. European Early Childhood Education Research Journal, 14(2), 141-156, DOI: $10.1080 / 13502930285209981$

Bennett, J. (2003). Starting Strong: The Persistent Division Between Care and Education. Journal of Early Childhood Research, 1(1), 21 - 48. https://doi.org/10.1177/1476718X030011006

Bernal, R. (2014). Diagnóstico y recomendaciones para la atención de calidad a la primera infancia en Colombia. Cuadernos FEDESARROLLO. Bogotá D.C.: Fedesarrollo

Buchely, L. (2015). El activismo burocrático y la vida mundana del estado. Las madres comunitarias como burócratas callejeras y el programa de cuidado de niños Hogares Comunitarios de Bienestar. Revista Colombiana de Antropología, 51(1), 137-159. https://doi.org/10.22380/2539472X.237

Buitrago, N. (2015). Informe Nacional sobre Docentes para la Educación de la Primera Infancia: COLOMBIA. Proyecto Estrategia Regional Docente OREALC/UNESCO Santiago. Recuperado de: http://www.unesco.org/new/fileadmin/MULTIMEDIA/FIELD/Santiago/pdf/Informe-Colombia-politicas-formacion-carrera-docentes-pr.pdf

Caicedo, S., y Solarte-Pazos, L. (2015). Empoderamiento de mujeres de una ONG colombiana. Un estudio de caso simple. Revista de Administração Pública, 49(6), 1597-1618. https://dx.doi. org/10.1590/0034-7612135980

Campbell-Barr, V. (2018) The silencing of the knowledge-base in early childhood education and care professionalism, International Journal of Early Years Education, 26(1), 75-89, DOI: $10.1080 / 09669760.2017 .1414689$

Casas, P. (2019). De madres comunitarias a maestras: el anhelo de 69.000 mujeres. El Espectador. Recuperado de: https://www.elespectador.com/seguimos-adelante/de-madres-comunitarias-maestras-el-anhelo-de-69000-mujeres

Centro Internacional de Educación y Desarrollo Humano, CINDE - Dirección de Primera Infancia del Ministerio de Educación Nacional. (2011). Documento base para la construcción del lineamiento técnico para la formación del talento humano que trabaja con la primera infancia. Borrador e insumo de discusión para la política de educación inicial en el marco de la atención integral para la primera infancia. Documento inédito. Recuperado de: http://www.colombiaaprende.edu.co/ html/familia/1597/articles-305300_docuformacion.pdf

Centro Internacional de Educación y Desarrollo Humano -CINDE-. (2009). Programas de formación del talento humano en educación inicial: perspectivas para el cambio. Resultados del estudio. Bogotá.

Comisión Intersectorial para la Atención Integral de la Primera Infancia (CIPI). (2013). Estrategia de atención integral a la primera infancia. Fundamentos políticos, técnicos y de gestión. Bogotá D.C.: CIPI.

Corpoeducación-FES Social. (2012). Cartografía social-pedagógica de prácticas y saberes pedagógicos, así como de necesidades formativas de agentes educativos de la primera infancia. Contrato $\mathrm{N}^{\circ}$ 436 DE 2011, Unión temporal alianza por la calidad y la pertinencia. Bogotá.

Corpoeducación. (2018). Una aproximación al desarrollo del talento humano del componente pedagógico de la educación inicial y preescolar: avances, retos y perspectivas. CONVENIO 835, Ministerio de Educación Nacional, Corpoeducación. 
Dalli, C., Miller, L., \& Urban, M. (2012). Early childhood grows up: towards a critical ecology of the profesión. En Dalli, C.; Miller, L.; Urban, M. (Eds.) (2012). Early Childhood Grows Up. Towards a Critical Ecology of the Profession. Serie International Perspectives on Early Childhood Education and Development. London: Springer.

Del Castillo, S. (2009). La génesis del programa de hogares comunitarios del Instituto Colombiano de Bienestar Familiar. [Tesis de doctorado]. Centro de Estudios Avanzados en Niñez y Juventud Universidad de Manizales -CINDE-. Doctorado En Ciencias Sociales, Niñez y Juventud. Recuperado de: https://repository.cinde.org.co/handle/20.500.11907/527

Durán-Strauch, E. (2017). Integralidad y políticas locales de infancia y adolescencia. En Durán-Strauch, E. y Torrado-Pacheco, M. (Eds.) (2017). Políticas de infancia y adolescencia. ¿Camino a la equidad? Colección Centro de Estudios Sociales -CES-, Universidad Nacional de Colombia: Bogotá D.C.

Esguerra, C. (2018). Ni madres ni voluntarias, no hay paz sin cuidado. El Espectador. Recuperado de: https://www.elespectador.com/colombia2020/opinion/ni-madres-ni-voluntarias-no-haypaz-sin-cuidado-columna-859202

Farah, M., y Pérez, E. (2003). Mujeres rurales y nueva ruralidad en Colombia. Cuadernos de Desarrollo Rural, (51). Recuperado de: https://revistas.javeriana.edu.co/index.php/desarrolloRural/article/view/1275

Flesher, C. (2010). Collective Identity in Social Movements: Central Concepts and Debates. Sociology Compass, 4, 393-404. doi:10.1111/j.1751-9020.2010.00287.x

Flórez-Romero, R., Galvis-Vásquez, D., Gómez-Muñoz, D., Zárate-Pinto, G., Acero, G., Ramírez, P., Castro, J., Tafur, J., y Arias, L. (2013). Estudio de caracterización de los perfiles, las competencias, las necesidades de cualificación y las condiciones sistémicas de apoyo al trabajo del talento humano que se desempeña en las modalidades de educación inicial -institucional y familiar-). Contrato para el desarrollo de actividades de ciencia y tecnología n. 0766 celebrado entre Fundación Saldarriaga Concha y la Universidad Nacional de Colombia (Derivado Convenio Asociación 2013-0529 Codificación Interna MEN).

Flórez-Romero, R., Galvis-Vásquez, D., Gómez-Muñoz, D., Castro-Martínez, J., Arias Velandia, N., Acero, G., y Niño, L. (2014). Modalidades de atención, modelos y prácticas para la primera infancia de Bogotá. Una aproximación cualitativa. Instituto para la Investigación Educativa y el Desarrollo Pedagógico, Secretaría de Educación del Distrito: Bogotá D.C. Recuperado de: http://www.idep.edu.co/sites/default/files/libros/Modalidades\%20de\%20atenci\%C3\%B3n\%2C\%20modelos\%20y\%20pr\%C3\%A1 cticas\%20para\%201a\%20primera\%20infencia\%20 de\%20Bogot\%C3\%A1.pdf

Flórez, R., Zárate, G., y Gómez, D. (2017). Avances y retos para el diseño de planes de cualificación para el talento humano de la educación para la primera infancia: un estudio de caso en Bogotá, Colombia (sin publicar).

García, L. (2013). El barrio popular en Bogotá en las voces de sus protagonistas. Madres comunitarias y jardineras: 1980-2011, Usme y Ciudad Bolívar. Folios, (38). https://doi.org/10.17227/01234870. 38 folios 121.140

González, H. (2016). Caracterización del saber pedagógico de los profesores del proyecto académico de investigación y extensión de pedagogía - PAIEP - en la Universidad Distrital Francisco José de Caldas. [Tesis de doctorado]. Centro de Estudios Avanzados en Niñez y Juventud alianza de la Universidad de Manizales y el CINDE. Recuperado de: http://biblioteca.clacso.edu.ar/Colombia/alianza-cinde-umz/20160630111243/HamletSantiagoGonzalez.pdf

González, J., y Durán, I. (2012). Evaluar para mejorar: el caso del programa Hogares Comunitarios de Bienestar del ICBF. Revista Desarrollo y Sociedad, 69, 187-234. https://doi.org/10.13043/ dys.69.6

Guzmán, R., y Ecima, I. (2011). Conocimiento práctico y conocimiento académico en los profesores del nivel inicial (seis preguntas). Folios, (34), 3.13. https://doi.org/10.17227/01234870.34folios3.13

Higuita Bedoya, N. M. (2016). Identidad profesional de las madres comunitarias: entre biografías y 
narrativas: una investigación sobre la profesionalización (Tesis de Maestría). Universidad de Antioquia, Medellín.

Instituto para el Desarrollo y la Innovación Educativa, -IDIE - (2008). Formación de docentes y educadores en educación infantil. Una apuesta clave para el desarrollo integral de la primera infancia. Bogotá D.C., Organización de Estados Iberoamericanos para la Educación, la Ciencia y la Cultura. Recuperado de: https://www.oei.es/historico/noticias/spip.php?article4866

Las Igualadas [@LasIgualadas]. (2018). ¿Conoces la historia de las madres comunitarias? [Archivo de video]. Recuperado de: https://youtu.be/Uno7FchgVjM

McGillivray, G. (2008) Nannies, nursery, nurses and early years professionals: Constructions of professional identity in the early years workforce in England, European Early Childhood Education Research Journal, 16(2), 242-254, DOI: 10.1080/13502930802141659

Ministerio de Educación Nacional. (2014). Sentido de la educación inicial. Bogotá D.C.: MEN. Recuperado de: http://www.deceroasiempre.gov.co/Prensa/CDocumentacionDocs/Documento-N20-sentido-educacion-inicial.pdf

Ministerio de Educación Nacional. (2014a). Cualificación del talento humano que trabaja con primera infancia. Documento No. 19, Referentes técnicos para la cualificación del talento humano que trabaja con primera infancia. Bogotá D.C.

Ministerio de Educación Nacional. (2014b). Modalidades y condiciones de calidad para la educación inicial. Guía No. 50, Serie de orientaciones para favorecer la calidad de la educación inicial en el marco de la atención integral. Autor: Bogotá D.C.

Mitchell, L., Clarkin-Phillips, J., Archard, S., Arndt, S., \& Taylor, M. (2019). What do they do all day? Exploring the complexity of early childhood teachers' work. Early Childhood Folio Online First, 23(1), 1-7. Recuperado de: https://www.nzcer.org.nz/

Moss, P., \& Urban, M. (2010). Democracy and Experimentation: two fundamental values for education. Guetersloh: Bertelsmann Stiftung.

Oberhuemer, P. (2012). Radical Reconstructions? Early Childhood Workforce Profiles in Changing European Early Childhood Education and Care Systems. En Dalli, C.; Miller, L.; Urban, M. (Eds.) (2012). Early Childhood Grows Up. Towards a Critical Ecology of the Profession. Serie International Perspectives on Early Childhood Education and Development. London: Springer

Organisation for Economic Co-operation and Development (OECD). (2001). Starting Strong: early childhood education and care. Paris: OECD.

Organisation for Economic Co-operation and Development (OECD). (2006). Starting Strong II: early childhood education and care. Paris: OECD.

Organisation for Economic Co-operation and Development (OECD). (2012). Starting strong III: A quality toolbox for Early Childhood Education and Care, OECD Publishing. http://dx.doi.org/10.1787/9789264123564-en

Organización Internacional del Trabajo (OIT). (2012). Un buen comienzo: la educación y los educadores de la primera infancia. Informe para el debate en el Foro de diálogo mundial sobre las condiciones del personal de la educación de la primera infancia. Recuperado de: https:// www.ilo.org/wcmsp5/groups/public/@ed_dialogue/@sector/documents/meetingdocument/ wcms_171720.pdf

Ospina, V. (2016). El docente del nivel inicial: retos para la formación profesional y continua. En Revista Educación y Humanismo, 18(30), 107-122. http://dx.doi.org/10.17081/eduhum.18.30.1325

Patiño-Restrepo, J., y Silva-Carreño, G. (2019). Estudios generales: hacia profesionales íntegros y buenos ciudadanos. UN Periódico digital. Recuperado de: http://unperiodico.unal.edu.co/pages/ detail/estudios-generales-hacia-profesionales-integros-y-buenos-ciudadanos/

Peeters, J., Urban, M., \& Vandenbroeck, M. (Eds.) (2016). Pathways to professionalism in early childhood education and care. Abingdon: Routledge.

Peeters, J. (2008). The construction of a new profession: A European perspective on professionalism in in Early Childhood Education and Care. Amsterdam: SWP Publishers.

Pinzón, M. (2015). Madres comunitarias: un caso paradigmático de la forma en que el derecho produce identidades. Revista CS, (15), 111-139. https://doi.org/10.18046/recs.i15.1910 
Pirard, F., \& Barbier, J. (2012). Accompaniment and quality in childcare services: the emergence of a culture of professionalization. Early Years, 32(2), 171-182, DOI: 10.1080/09575146.2011.642852

Rodríguez, G., Gil, J., y García, E. (1999). Metodología de la investigación cualitativa. Ediciones Aljibe: Málaga.

Rodríguez, A., Flórez, R., y Gómez, D. (2016). La formación en ciudadanía en escenarios de educación inicial: una experiencia con madres comunitarias. Panorama, 10(18), 102-119.

Rosemberg, F. (2009). La deuda latinoamericana con respecto a los niños y niñas menores de seis años. En Torrado, M. (Ed.) (2009). Retos para las políticas públicas de primera infancia. Observatorio sobre infancia, Centro de Estudios Sociales - CES, Facultad de Ciencias Humanas, Bogotá D.C.: Universidad Nacional de Colombia.

Salazar, M. (2006). El proceso de profesionalización del trabajo social. En Trabajo Social, (8), 27-36. Facultad de Ciencias Humanas, Universidad Nacional de Colombia

Sarramona, J., Noguera, J., y Vera, J. (2009). ¿Qué es ser profesional docente? Teoría de la Educación. Revista Interuniversitaria, 10. Recuperado de: http://revistas.usal.es/index.php/1130-3743/article/view/2812/2847

Schwartz, K., Cappella, E., Aber, J., Scott, M., Wolf, S., \& Behrman, J. R. (2019). Early Childhood Teachers' Lives in Context: Implications for Professional Development in Under-Resourced Areas. American Journal of Community Psychology. doi:10.1002/ajcp.12325

Secretaría Distrital de Integración Social, Universidad Pedagógica Nacional, Secretaría de Educación Distrital. (2013). Lineamiento pedagógico y curricular para la educación inicial en el Distrito. Bogotá D.C.: SDIS, UPN, SED. [pdf]

Servicio Nacional de Aprendizaje -SENA-. (2008). Caracterización Ocupacional de Atención a la Primera Infancia en Colombia. Bogotá.

Sevilla, M. (2017). Panorama de la educación técnica profesional en América Latina y el Caribe. Serie Políticas Sociales, Comisión Económica para América Latina y el Caribe (CEPAL). Santiago de Chile: CEPAL-UN.

SIPI. (2019). Hogares comunitarios. Sistema de Información sobre la Primera Infancia en América Latina. Recuperado de: www.sipi.siteal.iipe.unesco.org/politicas/1375/hogares-comunitarios

Taggart, G. (2016). Compassionate pedagogy: the ethics of care in early childhood professionalism. European Early Childhood Education Research Journal, 24(2), 173-185, DOI: 10.1080/1350293X.2014.970847

Tenti, E. (1995). Una carrera con obstáculos: la profesionalización docente. Texto de la conferencia magistral pronunciada en el simposio internacional: Formación docente, modernización educativa y globalización. México D.F.

Torrado, M., Gaitán, M., Bejarano, D., y Torrado, M. (2017). La política pública para la primera infancia frente a la desigualdad social en Colombia. En Durán-Strauch, E., y Torrado-Pacheco, M. (Eds.) (2017). Políticas de infancia y adolescencia ¿Camino a la equidad? Bogotá D.C.: Colección Centro de Estudios Sociales -CES-, Universidad Nacional de Colombia..

Torrado, M., Gaitán, M., y Bejarano, D. (2009). La educación inicial en Colombia, ¿tema resuelto?. En Torrado-Pacheco, M. (Ed.) (2009). Retos para las políticas públicas de primera infancia. Observatorio sobre infancia, Centro de Estudios Sociales - CES, Facultad de Ciencias Humanas, Bogotá D.C.: Universidad Nacional de Colombia.

Torrado-Pacheco, M. (Ed.) (2009). Retos para las políticas públicas de primera infancia. Observatorio sobre infancia, Centro de Estudios Sociales - CES, Facultad de Ciencias Humanas, Bogotá D.C.: Universidad Nacional de Colombia.

Universidad del Valle, Universidad Nacional de Colombia, y Universidad Industrial de Santander. (2007). Evaluación nacional de la modalidad de Hogares Comunitarios de Bienestar Familia, Mujer e Infancia HCB-FAMI. Informe de investigación. Bogotá, D.C.: Instituto Colombiano de Bienestar Familiar. Recuperado de: https://www.icbf.gov.co/sites/default/files/evaluacion hcb-fami.pdf

UNESCO. (2016). Estado del arte y criterios orientadores para la elaboración de políticas de formación y desarrollo profesional de docentes de primera infancia en América Latina y el Caribe. Santiago de Chile:Organización de las Naciones Unidas para la Educación, la Ciencia y la Cultura. Re- 
cuperado de:www.redage.org/sites/default/files/adjuntos/estado_del_arte_politicas_for_inicial_en_ infancia_1.pdf

Universidad de la Sabana. (2016). Análisis cualitativo y cuantitativo de la oferta de formación educativa y la demanda laboral para educación inicial en el marco de la atención integral a la primera infancia, existente en las regiones definidas (Producto 2). Convenio de asociación No. 8002006 suscrito entre el Ministerio de Educación Nacional y la Universidad de La Sabana.

Urban, M., Cardini, A., Guevara, J., Okengo, L., \& Flórez, R. (2019). Early childhood development, education and care: The future is what we build today. $2030 \quad$ Agenda for Sustainable Development- T20 Japan 2019. Recuperado de: https://t20japan.org/wp-content/ uploads/2019/03/t20-japan-tf1-3-early-childhood-development-education-and-care.pdf

Urban, M., Cardini, A., \& Flórez, R. (2018). It takes more than a village. Effective early childhood development, education and care services require competent systems. Future of work and education for the digital age - T20 Argentina 2018. Recuperado de: https://t20argentina.org/wp-content/ uploads/2018/07/TF-1-It-takesmore-than-a-village_final_with-template.pdf>

Urban, M. (2013). Sistemas competentes para la educación y cuidado en la primera infancia. En Flórez-Romero, R.. y Torrado, M. (Eds.) Primera infancia, lenguajes e inclusión social: una mirada desde la investigación. Bogotá, Universidad Santo Tomás

Urban, M. (2012). Researching Early Childhood Policy and Practice. A Critical Ecology. European Journal of Education, 47(4), 494 - 507.

Urban, M. (2010). Rethinking Professionalism in Early Childhood: Untested Feasibilities and Critical Ecologies. Contemporary Issues in Early Childhood, 11(1), 1-7. https://doi.org/10.2304/ ciec.2010.11.1.1

Urban, M. (2008) Dealing with Uncertainty: challenges and possibilities for the early childhood profession. European Early Childhood Education Research Journal, 16(2), 135-152. http://dx.doi. org/10.1080/13502930802141584

Urban, M., Vandenbroeck, M., Laere, K., \& Lazzari, A. (2012). Towards Competent Systems in Early Childhood Education and Care. Implications for Policy and Practice. European Journal of Education, 47(4), 508 - 526.

Urban, M., Vandenbroeck, M., Van Laere, K., et al. (2011). Competence requirements in early childhood education and care. Final report. Brussels: European Commission. Directorate General for Education and Culture.

Urban, M., \& Dalli, C. (2008). Editorial. European Early Childhood Education Research Journal, 16(2), 131-133, DOI:10.1080/13502930802141576

Valles, M. (1999). Técnicas de conversación, narración (II): la metodología biográfica. En Valles, M. (1999). Técnicas cualitativas de investigación social. Reflexión metodológica y práctica profesional. Editorial Síntesis: Madrid.

Vandenbroeck, M., Urban, M., \& Peeters, J. (Eds.) (2016). Pathways to professionalism in early childhood education and care. Abingdon: Routledge.

Zapata, B. y Ceballos, L. (2010). Opinión sobre el rol y perfil del educador para la primera infancia. Revista Latinoamericana de Ciencias Sociales, Niñez y Juventud, 8(2), 1069-1082. Recuperado de: http://www.scielo.org.co/scielo.php?script=sci_arttext\&pid=S1692-715X2010000200021\&ln$\mathrm{g}=\mathrm{en} \& \operatorname{lng}=$ 


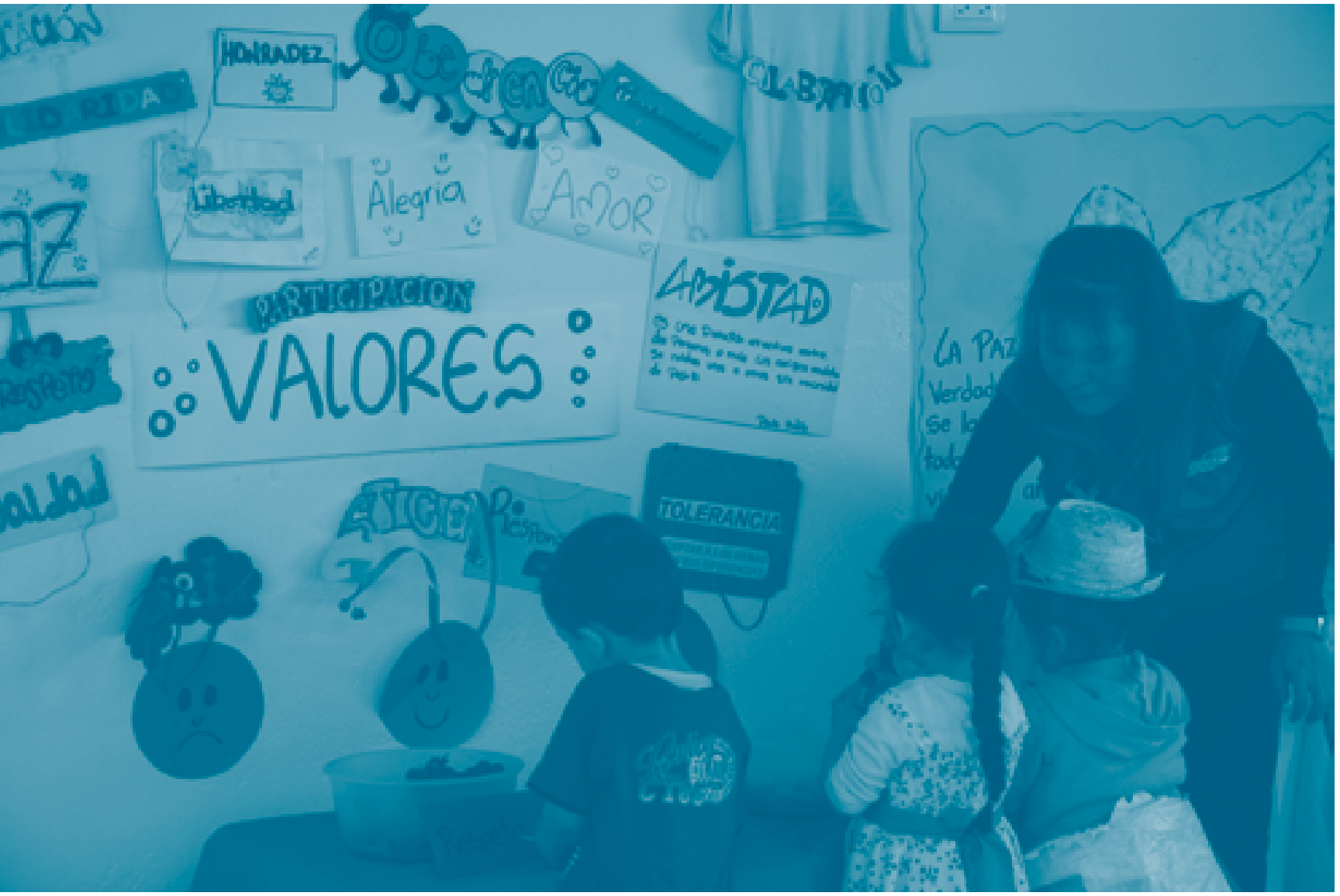

\section{Capítulo 3.}

Comprensión y síntesis interpretativa del conflicto colombiano 
Cada caso es un caso especial, diferente. Pero el conjunto tiene una denominación general: "víctimas de la violencia”. La menor de esas víctimas, Heli Rodríguez, tiene dos años de edad. Apenas si puede decir su nombre. No sabe nada de nada. No tiene la menor idea de en dónde se encuentra. No sabe por qué lo trajeron, ni cómo, ni cuándo. Ignora por completo el paradero de sus padres y no manifiesta emoción alguna cuando se le pregunta si cree que su padre o su madre vendrán a buscarlo. (El drama de 3.000 niños desplazados, Gabriel García Márquez, 1955)

$\mathrm{E}$ 1 objetivo principal de este capítulo es mostrar la pertinencia de los conocimientos, prácticas y valores en torno al conflicto colombiano, incluido el conflicto armado, en el camino de la profesionalización del talento humano que trabaja con primera infancia en Colombia. Para ello debemos partir de una concepción amplia del conflicto, anclada en una teoría del conflicto como aspecto inherente al ser humano que surge de las naturales diferencias o discrepancias en las formas de pensar, sentir o actuar entre las personas (Freund, 2014).

A lo largo del capítulo se concluye que todo abordaje de los conflictos por parte del talento humano que trabaja con la infancia, incluido el conflicto armado y sus víctimas, debe ser precedido por un espíritu comprensivo e interpretativo que va más allá de un enfoque mono-causal o meramente explicativo. Esto guarda una relación profunda con el enfoque de sistema o de sistema competente desarrollado a lo largo del libro, en el que se comprenda el conflicto también con un enfoque sistémico por el cual no es posible explicar un fenómeno si no es precisamente en su relación con el todo.

Una vez delimitado este contexto, se hará una revisión teórica de las miradas más significativas que se han ocupado del conflicto en Colombia y se precisará algunos términos como conflicto armado, conflictividad, violencia, violencia política, etc. Del mismo modo, se hará una revisión histórica del recorrido temporal que han tenido en el marco de la historia colombiana.

Teniendo en cuenta lo antes mencionado, se realizó con el talento humano un taller desarrollado en dos momentos: contextualización temporal del conflicto colombiano y reconocimiento del conflicto en escenarios sociales. En el primero, se indagó sobre qué sabía o reconocía el talento humano que atiende primera infancia afectada por el conflicto, acerca de las causas, los factores de permanencia, y los efectos del conflicto armado colombiano. Para ello se les pidió desarrollar una línea de tiempo en la cual se ubican algunos hitos importantes sucedidos en el transcurso del conflicto. En el segundo, se indagó sobre las causas, factores de permanencia y efectos de otros tipos de conflicto a los que están expuestos los niños y las familias que se atienden dentro de la institución y sobre qué acciones desarrollaban o creían pertinentes desarrollar, tanto para prevenir el surgimiento de causas y factores como para atender los efectos. Se les dio libertad para tener en cuenta conflictos sucedidos dentro de la institución.

Finalmente, recogiendo todo lo anterior se presenta una propuesta de competencias describiendo los conocimientos prácticas y valores del talento humano en relación con el conflicto colombiano, en clave de profesionalización como meta última de este esfuerzo. 


\section{Contexto: conflicto en Colombia; elementos para su comprensión}

Gracias a esta teoría amplia del conflicto, se tiene una perspectiva general en la que se ubica el contexto colombiano, con la aparición del concepto "conflicto armado en Colombia" o "conflicto colombiano". Las tradiciones investigativas consultadas desde distintas disciplinas han coincidido en caracterizar el conflicto en Colombia con el matiz de la multiplicidad (Pizarro, 2015). Esta multiplicidad se refiere a sus causas, factores de permanencia y efectos sobre la población. Conviene detenerse un momento en el concepto de multiplicidad aplicada a la comprensión del conflicto colombiano. Existe un consenso sobre la existencia de una variedad de factores que "en determinadas coyunturas, tanto nacionales como internacionales, y bajo el impulso de antiguos o nuevos actores, provistos de intereses variados y distintas estrategias para acceder al poder, van a generar períodos más o menos prolongados de violencia" (Pizarro, 2015, p.13). Significa que no es posible entender el conflicto en Colombia sin una multiplicidad de miradas y que el propio conflicto en Colombia tiene una configuración múltiple que explica su prolongada duración y sus imbricadas ramificaciones históricas y sociales.

Aún hoy, cuando Colombia ha superado el conflicto con las Farc (tan solo uno de tantos), según Christoph Harnisch, delegado del Comité Internacional de la Cruz Roja, en Colombia se presenta la coexistencia de al menos cinco conflictos no internacionales simultáneos, derivados de otros anteriores, resueltos o no, que alcanzan a cubrir todo el territorio nacional con distinta intensidad y forma, conflictos que se reproducen en otros y que enquistan en el tiempo (Oquendo, 2019). Entendiendo los conflictos no internacionales como enfrentamientos

que se desarrollen en el territorio entre sus fuerzas armadas y fuerzas armadas disidentes o grupos armados organizados que, bajo la dirección de un mando responsable, ejerzan sobre una parte de dicho territorio un control tal que les permita realizar operaciones militares sostenidas y concertadas. (Valcárcel, 2007, p.108)

Es en este marco amplio -internacional del conflicto- en el que se identifica no solo el conflicto colombiano, sino el de diversas sociedades en el mundo contemporáneo. Se inscribe otro concepto clave, el de la singularidad, que lo recubre con particularidades que son únicas, propias y especiales. La cuestión de la singularidad es importante, porque "incorpora una mirada comparada y se interroga por qué Colombia, a diferencia de sus vecinos, se sumió en una guerra de más de cincuenta años" (Wills, 2015, p.3). Es decir, impregna lo que somos como ciudadanos.

Para entender esta singularidad se debe incorporar la dimensión histórica en la que se profundizará más adelante, que permite entender cómo se ha construido nuestro Estado/Nación, pero también cómo cada individuo -desde la propia infancia- se construye como ciudadano dentro de esta singularidad conflictiva, evidenciando no solo las experiencias de vida personales del pasado, sino también las habilidades para sobreponerse a los hechos del mismo en el futuro (Ospina, Alvarado y Fajardo, 2018). De tal forma que entre la Multiplicidad y la singularidad se ubican los 
esfuerzos que se han hecho desde diferentes disciplinas de las ciencias sociales para comprender el conflicto en Colombia, y este marco común de competencias no es ajeno a esta perspectiva.

Siguiendo la descripción de Ítalo Calvino, en las Seis propuestas para el próximo milenio, conferencia que dictó en la Universidad de Harvard, antes de morir, en la que decidió analizar una serie de cualidades que consideraba necesario defender, entre ellas la multiplicidad, o la "red infinita de conexiones entre los hechos" (Calvino, 2012), podemos decir que cada expresión singular del conflicto presente en cada situación que el talento humano en primera infancia encuentra en su labor, está conectada con una infinidad de hechos simultáneos y precedentes, y que debe ser capaz de enlazarlos y comprenderlos en razón de su singularidad (cada niño es único y su historia es única), pero en relación con el contexto vasto y complejo de la conflictividad en Colombia.

Trataremos de ver a lo largo de las páginas siguientes cómo este enfoque se relaciona con los factores que tienen incidencia en la profesionalización del personal que trabaja en los centros de desarrollo infantil, jardines infantiles, etc., y se intenta subrayar su multidimensionalidad y complejidad desde la multidisciplinariedad y la diversidad de enfoques.

Se llama conflicto colombiano al conjunto de hechos violentos sucedidos en el país

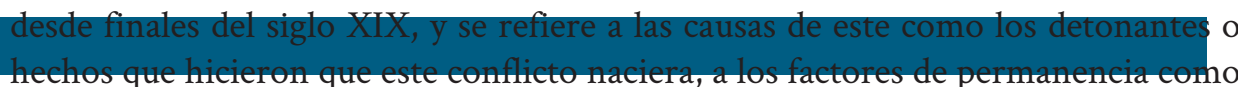

los hechos que han contribuido a que el conflicto se haya mantenido, y a sus efectos como las consecuencias que ha traído para el país.

Sin embargo, no todas las formas de violencia son en sí mismas conflictos, así como desde la teoría amplia del conflicto descrita en la parte inicial, no todos los conflictos derivan en violencia. Es necesario hacer una distinción entre el conflicto armado en el sentido estricto y otras formas de violencia, que van desde tensiones, disturbios y motines; hasta los actos de bandidaje, delincuencia, violencia dentro de las familias, riñas callejeras, violencias sexuales, etc. La situación a la que describe como conflicto armado debe alcanzar el llamado "umbral de enfrentamiento" (Stewart, 2003). Al respecto, Stewart usa dos criterios:

- El nivel de intensidad. El Gobierno tiene que recurrir a la fuerza militar, en lugar de recurrir únicamente a las fuerzas de policía.

- Las partes. Los grupos regulares o irregulares deben ser considerados "partes en el conflicto", en el sentido de que disponen de fuerzas armadas organizadas. Esto significa, por ejemplo, que estas fuerzas tienen que estar sometidas a una cierta estructura de mando y tener la capacidad de mantener operaciones militares.

Sin embargo, y precisamente en virtud de la singular prolongación que ha tenido este conflicto y su normalización en la vida cotidiana, muchas de las manifestacio- 
nes de violencia y agresión cotidianas también se normalizan, se excusan a razón del conflicto armado o el día a día de la guerra e incluso sirven como justificación o coartada para ocultar, o al menos disimular, la sistematicidad de otras violencias contra actores políticos, como cuando los asesinatos de líderes comunitarios se atribuyen a "líos de faldas" (Useche y Gutiérrez, 2017).

Por ello la mirada a estas violencias no es ajena a las preocupaciones de este estudio y, por ejemplo, cuando se trata de las afectaciones del conflicto a la población infantil se tiene en cuenta que estas no son más que trazos dentro de un paisaje general que se ha normalizado, de numerosas violencias en contra de la población infantil, que día a día cobra víctimas y de la que ahora se poseen cifras gracias a la primera Encuesta de Violencia contra Niños, Niñas y Adolescentes (Ortiz, 2018), publicada recientemente por el ICBF. Es evidente que el panorama en donde estas cosas se presentan, se agravan -en esta especie de espiral de violencia, que hace cada vez menos sensible a la población, que ya no reacciona, o pierde capacidad de reacción-, tiene que ver con los profundos quistes del conflicto en la estructura de la sociedad y se buscará entender en perspectiva histórica en las siguientes líneas.

Aunque han sido muchos los hechos de violencia que han sucedido en el marco del conflicto colombiano, existen unos que han sido claves en su desarrollo, puesto que en gran medida han determinado su curso. Pese a que este conjunto de hechos o hitos, llamados así por su trascendencia en el conflicto colombiano, podría diferir según la fuente (Fajardo, 2013), en la indagación de este primer concepto se definieron tres periodos de larga duración, o como los llama Wills, "Los tres nudos de la guerra colombiana”, reconociendo que las fechas exactas siempre son problemáticas, y que los cambios históricos son producto de la convergencia de diversos procesos, fechas no sincrónicas y múltiples dimensiones humanas en juego (Wills, 2015).

- El primer periodo se ubica entre las décadas del treinta y cincuenta del siglo XX (aproximadamente 1929/30 a 1957/58).

Muchos de los rasgos que singularizan la historia colombiana, con relación a la de muchos países muy importantes de América Latina, por medio de la incorporación de la población a los partidos tradicionales, Liberal y Conservador, en donde se da una alta tensión partidista y un contexto de desigualdad en el que se entiende la aparición, por ejemplo, del movimiento gaitanista (Pécaut, 2015).

- El segundo periodo, entre los años sesenta y ochenta del mismo siglo (1958/62 a 1989/91).

Este periodo es llamado de la "Violencia". El modelo político y económico fundado sobre las pasiones partidistas y el mantenimiento de las desigualdades, además de la frustración de un cambio social con el asesinato de Gaitán, introduce una ruptura mayor.

- El tercero, entre la última década del siglo XX y las primeras décadas del XXI (1992 a 2012/14). 
La escalada del conflicto se vuelve cada vez más intensa.

No se entra aquí en detalles, sino a resumir los diferentes periodos. Lo más importante es mostrar las estrategias de sus protagonistas y el rol del Estado y de los actores armados.

Los grupos armados, incluidas las autodefensas, ratifican la opción militar, que se concretiza en una ofensiva de una envergadura impresionante, de la que hacen parte las acciones para reforzar su presencia territorial en el norte del país, el plan de encerramiento de las principales metrópolis, el ataque contra las instalaciones militares o policiales con el empleo de cilindros de gas y todos los daños "colaterales" que de allí resultan.

\section{Impacto del conflicto colombiano en la población: afectación del talento humano, los niños, las niñas y sus familias}

Las narrativas del talento humano, en relación con los conflictos que enfrentan cotidianamente las familias de los niños y niñas con quienes trabajan en los diferentes Centros de Desarrollo Infantil (CDI) y las instituciones educativas, permiten evidenciar que el conflicto colombiano ha tenido un impacto profundo en la manera como la población se aproxima a las situaciones de conflicto, naturalizando en muchas ocasiones la violencia, afectando incluso, y así lo interpreta el talento humano, la manera como los padres educan a sus hijos, implementando pautas de crianza inadecuadas, adoptando el maltrato infantil como natural y necesario para educar a los hijos, manteniendo la inequidad de género y de asignación de roles dentro de la familia. Son este tipo de problemáticas cotidianas que el talento humano atribuye a la violencia que ha sufrido Colombia por décadas. Son estas mismas problemáticas las que ellos han tenido que entrar a intervenir mediante procesos formativos y de acompañamiento a las familias, en pro de garantizar condiciones adecuadas para el desarrollo integral en la primera infancia. Si bien la labor que desempeñan les produce satisfacción al sentir que hacen un aporte importante para cambiar esta realidad, muchas veces se sienten impotentes cuando evalúan las limitaciones que tienen en el ejercicio de su práctica.

\section{Impacto del conflicto sobre el talento humano que trabaja con primera infancia}

Puesto que se reconoce a la familia como el primer entorno de socialización de niños y niñas, el talento humano que trabaja con primera infancia cumple una importante labor acompañando el desarrollo de los niños y las niñas mediante procesos de formación a las familias, no obstante, la relación con ellas es más cercana en los CDI de modalidad familiar, puesto que el talento humano que labora en estos CDI realiza procesos de formación y acompañamiento directo con las familias (Comisión Intersectorial para la Primera Infancia [CIPI], s.f.). 
En el desarrollo de dichos procesos se establecen relaciones cercanas, guiadas por la empatía. Las narrativas del talento humano dan cuenta de que, con el objetivo de brindar herramientas para que se proporcione un entorno adecuado de desarrollo para niños y niñas, se han convertido en mediadores de distintos tipos de conflictos a nivel intrafamiliar: violencia intrafamiliar, embarazo adolescente, relaciones de pareja que no están guiadas por la equidad de género y en las cuales se asigna el rol del cuidado de los hijos casi exclusivamente a las mujeres, pautas de crianza inadecuadas, maltrato infantil, entre otros.

Tal responsabilidad supone un agotamiento emocional, que se expresa en los profesionales con sentimientos de impotencia ante situaciones en las que sienten que no pueden ayudar, todo lo que fuera necesario, para darle solución a una problemática determinada:

\footnotetext{
"Nosotras también tenemos un caso [mujer maltratada por su pareja quien también maltrata a su hijastro, hijo de la mujer], es complicado porque por más de que uno quiera [no puede] ayudar a esa mamá (...) obviamente sí nos da mucho pesar con el niño [hijastro del hombre maltratador], lo que pasa es que nosotras solo podemos entrar a intervenir al beneficiario, a la mamá (...), es complicado (...), pero sí nos da mucha tristeza con el niño (...), es que uno no puede hacer nada".
}

Se considera que tal agotamiento emocional, al que se hace referencia, puede asociarse al concepto de fatiga por compasión, que según Figley (1995), son los comportamientos, las emociones y el estrés que experimentan los profesionales que ayudan, o pretenden ayudar, a personas que han pasado por experiencias traumáticas, no obstante, se está de acuerdo con Campos, Cardona, Bolaños y Cuartero (2015), que en el caso de la mediación familiar puede ser más adecuado hablar de situaciones altamente estresantes y no de experiencias traumáticas. Cabe resaltar que la labor del talento humano, específicamente los que desarrollan su labor en los CDI de modalidad familiar, es la de brindar herramientas para el desarrollo integral de niños y niñas por medio de procesos de formación y acompañamiento. Sin embargo, en dichos procesos, en especial en los de acompañamiento, el talento humano no se puede substraer de cumplir una labor de mediador en los conflictos que enfrentan las familias. Lo anterior, teniendo en cuenta que durante los encuentros con las familias deben abordar temas sensibles, tales como comunicación asertiva, solución de conflictos, relaciones guiadas por la equidad en el establecimiento de roles dentro del hogar, pautas de crianza, corrección con amor y vínculo afectivo, entre otras.

En estos espacios, como ya se anotaba antes, el talento humano establece relaciones de empatía. De acuerdo con Cuartero, Riera y Casado (2016), los profesionales de ayuda, y en especial los trabajadores/as sociales, no podrían tener éxito sin la capacidad para empatizar, concepto que se define como la capacidad de comprender, ser sensibles o experimentar lo que otros piensan o sienten, sin que haya sido expresado de forma explícita (González, 2004); por otro lado, se sabe que la empatía es una capacidad esencial en todos los seres humanos, puesto que permite ponerse en el lugar del otro y poder comprenderle, aunque también conlleva experimentar, hasta cierto punto, el dolor sufrido por otros. Como lo afirman Campos et al. (2015), cuando se 
desarrolla una actitud empática en una relación enmarcada por el conflicto, se experimenta parte del dolor o el sufrimiento que experimentan las partes implicadas.

Por lo anterior, es innegable que el talento humano que atiende niños, niñas y familias que están atravesando por situaciones altamente estresantes, o de intenso dolor y sufrimiento, por estar expuestas a distintos tipos de conflictos, incluido el conflicto armado, pueden experimentar, incluso sin ser conscientes de ello, lo que se denomina fatiga por compasión.

"Mi experiencia allá fue tenaz [auxiliar pedagógica refiriéndose a un centro de acogida para niños abandonados] (...), esa experiencia nunca se me va a olvidar (...), ver niños con discapacidades, niños que dejan las mamás allá, que tienen consumo, que están embarazadas (...), entonces eso a mí me marcó (...), y eso fue una experiencia muy fea, yo no la había vuelto a contar (...), para mí fue muy doloroso, muy doloroso (...), y eso fue hace 17 años que viví eso".

Tomando en cuenta las diversas investigaciones relacionadas con el impacto que tiene en las personas el hecho de estar en permanente contacto con víctimas de la violencia, Agudelo-Vélez (2018) afirma que son más propensas a sufrir de traumas vicarios. El trauma vicario se entiende como la afectación emocional que se desarrolla por estar expuesto de manera indirecta a situaciones traumáticas, no obstante, como ya se mencionó, las problemáticas que atiende el talento humano no son siempre traumáticas, pero sí producen altos niveles de estrés o sufrimiento a las personas implicadas, y por lo tanto es imposible para el talento humano no sufrir de afectación vicaria, puesto que de manera frecuente deben escuchar, apoyar y atender a población víctima de distintos tipos de conflictos.

Es fundamental reconocer el impacto de los conflictos sobre el talento humano, puesto que de esto se desprende la importancia de trabajar con ellos, no solo en la elaboración de sus propias experiencias relacionadas con el conflicto, sino además, en la necesidad de trabajar con ellos acerca del cuidado a sí mismos para la conservación de una buena salud mental, evitando o minimizando el riesgo de experimentar los trastornos asociados a la "fatiga por compasión". La elaboración que el talento humano haga de experiencias traumáticas vividas de manera directa o experimentadas a través de otros, el modo en que re-construya y re-signifique su historia y memoria sobre el conflicto, influenciará el modo en como trabaje con los niños y jóvenes en la construcción de una memoria colectiva del conflicto colombiano, que contribuya -además de sanar las heridas- a la construcción de formas no violentas de dirimir los conflictos.

\section{Impacto del conflicto sobre los niños, las niñas y sus familias}

Los testimonios dados por el talento humano evidencian el impacto del conflicto colombiano sobre las comunidades con quienes trabajan en las diversas instituciones educativas y en los CDI, por ejemplo, niños que recrean situaciones violentas en el salón de clase, como lo muestra el testimonio presentado a continuación, poniendo en evidencia las situaciones altamente estresantes experimentadas por los niños en el marco del conflicto: 
"Te pongo un caso cuando yo era profe [testimonio presentado por una coordinadora de un CDI de modalidad institucional, que antes se desempeñaba en el rol de maestra], yo tenía un niño que se escondía y me decía: me van a disparar, me están disparando, profe agáchese”.

Otro de los impactos comentados por el talento humano es la pobreza causada por la dificultad de las familias desplazadas para encontrar oportunidades económicas en la ciudad, situación que conlleva, además de la pobreza, el desarraigo cultural, entre otras afectaciones.

“porque son personas que no conocen y que llegaron a una ciudad [Bogotá] donde ellos no tienen ninguna clase de redes de apoyo tanto familiares como institucionales, entonces se ven un poco más afectados porque no recibieron ninguna clase de apoyo, definitivamente lo único que recibieron fue la carta de desplazamiento, se les ha complicado un poquito el factor económico, un poquito no, mucho, porque cuando digo contexto cultural es porque ellos trabajaban era la tierra y acá no tenían mucho en qué trabajar".

El anterior testimonio fue dado por una de las profesoras de un CDI de modalidad institucional, y da cuenta del impacto profundo del conflicto en las familias, muchas de ellas campesinas, que fueron desplazadas de sus tierras y tienen que migrar a una ciudad en la que no encuentran oportunidades laborales, por lo que no pueden proporcionar a sus hijos las condiciones necesarias para un adecuado desarrollo.

En relación con el impacto del desplazamiento forzado, Agudelo-Vélez (2018) afirma: "El desplazamiento genera sentimientos de desarraigo, de incertidumbre por el futuro y de pérdida de la identidad cultural, e implica una reacomodación del estilo de vida, lo que tiende a retrasar el ajuste de las personas" (p.4).

En los testimonios antes mencionados, se debe considerar que el sufrimiento que experimentan las personas, que han atravesado diversas situaciones de conflicto (en las que se considera con especial relevancia el derivado de situaciones en el marco del conflicto armado colombiano), las hace proclives a sufrir afectación en su salud mental. Agudelo-Vélez (2018) afirma que:

Los conflictos aquejan la salud mental, no solo por la exposición directa o vicaria al trauma, sino por el impacto a nivel de la afectación de las condiciones de vida, los cambios en los estilos productivos, la modificación e, incluso, precarización del empleo, la dificultad para acceder a la satisfacción de las necesidades básicas y el aumento de la pobreza. (p.2)

Si bien los anteriores testimonios muestran la afectación directa del conflicto sobre los niños, las niñas y sus familias, uno de los aspectos relevantes, al que reiteradamente el talento humano hace referencia, es al hecho de que las familias han adoptado prácticas de crianza en las que el maltrato es visto como una forma adecuada de corregir a los niños, y las formas violentas de dirimir los conflictos hacen parte de la cotidianidad en las familias; todo lo anterior es atribuido, según el talento humano, a que los padres de ahora crecieron en un país que ha enfrentados por décadas distintos tipos de conflictos internos, por lo cual la violencia es interpretada como algo normal. Es así como el talento humano explica tales conductas como la naturalización de la violencia. 
En relación con lo antes mencionado, algunos investigadores han estudiado el efecto que tiene sobre los seres humanos enfrentar, de manera colectiva, situaciones que producen niveles elevados de dolor y sufrimiento; de este modo han considerado el concepto de trauma histórico, definido como el trauma colectivo infligido a un grupo de personas que comparten una identidad o afiliación grupal específica (etnia, nacionalidad y afiliación religiosa), se caracteriza por la transmisión generacional de eventos traumáticos que generan diversas respuestas psicológicas y sociales (Evans-Campbell, 2008).

La interpretación que hace el talento humano de las conductas que se adoptan en muchas familias no está alejada de la concepción que tienen diversos investigadores, a raíz de los estudios que han desarrollado con población colombiana.

Durante todo este tiempo, los niños y niñas han sido vícti $\neg$ mas sensiblemente afectadas por la orfandad (al ser asesina $\neg$ dos sus padres), y por el reclutamiento forzado, con los cua $\neg$ les su infancia se ve cercenada por la violencia como cultura que naturaliza las prácticas de crianza y socialización en las familias y en las instituciones. Porque en 50 años de guerra, los niños se han convertido en padres y abuelos que han heredado la desesperanza a sus hijos y sus nietos. (Granada y Ortiz, 2018, p.146)

Si se analiza el concepto de trauma histórico, este se puede asociar con la realidad que evidencia el talento humano en las formas de interacción dentro de muchas familias y comunidades con las que ellos trabajan en sus procesos de formación y acompañamiento. Los testimonios presentados a continuación, de profesionales psicosociales, maestras y auxiliares pedagógicas, son las expresiones del talento humano en torno a lo que se ha venido discutiendo.

"En Colombia hemos naturalizado la violencia de una manera que ya es parte de nuestra cotidianidad, entonces desde que nacemos, hasta que estamos en la tercera edad, todo el tiempo es naturalizada la violencia, desde la crianza, la educación, en la calle, en general en todo sentido se ha naturalizado (...), porque eso es lo que siempre nos han enseñado, como que es necesaria la violencia, es necesario el golpe, es necesario el grito, todo el tiempo, en la crianza, en la educación”.

"Todo este conflicto armado ha hecho que se normalice y se tipifique la violencia, o sea que se tome como que algo es normal, y digamos que no se cuente como maltrato si yo se lo estoy haciendo a mi hijo porque le estoy enseñando que la letra con sangre entra y que tiene que aprender o aprender".

"Igual pienso yo que son cadenas no, que independientemente que a nosotros no nos haya tocado como tal el conflicto, viene de atrás y las familias como que van tomando ese tipo de comportamientos y eso va trascendiendo a la familia independiente uno no esté inmerso en eso, eso se expande y se extiende (...), ya uno lo vuelve aceptable (...)”.

"Porque muchos de esos maltratadores cuando fueron niños, fueron víctimas primero y vieron cómo sus padres o sus madres eran maltratados o maltrataban y de una manera u otra lo normalizan y creen que ese es el deber ser y cuando son adultos muchas veces la manera de comportarse es repetir lo que vieron en sus padres, maltratando o siendo víctimas".

"Otro punto que también se me hace como importante es considerar la normalización de la violencia, como que ya estamos tan acostumbrados a que tal fue víctima del desplazamiento, de la violencia, que le mataron, que le violaron, que secuestraron, que como que ya lo dejamos al margen porque eso es común ¿sí? y digamos, muchas veces, a nuestras sesiones y eso llegan mamitas con mucha historia por detrás que nosotros no podemos llegar a considerar qué es y muchas veces son personas conflictivas en el espacio porque no han podido expresar esa emoción en ningún momento". 
La naturalización de la violencia y su transmisión intergeneracional, podría entonces ser atribuida a que muchos de los padres de hoy crecieron en una sociedad que ha experimentado dolor y sufrimiento prolongado a causa de enfrentar situaciones de violencia, enmarcada, aunque no en todos los casos, en el conflicto colombiano. No obstante, es importante mencionar que pueden existir diversos factores asociados a las conductas y las dinámicas adoptadas en las familias, que influyen en el desarrollo de los vínculos afectivos, las pautas que adoptan para la crianza de los hijos, las formas en que se comunican y cómo expresan sus emociones y abordan los conflictos. No obstante, es de vital importancia, sobre todo teniendo en cuenta el objetivo del presente trabajo, que se considere la indudable influencia que ha tenido en las personas, crecer en una sociedad que ha enfrentado diversos tipos de conflictos, incluido el conflicto armado, durante tantas décadas. Si bien no se ampliará aquí los efectos de tal consideración, sí es importante mencionar que uno de los objetivos del presente trabajo es precisamente proponer un marco de competencias para el talento humano, que contribuya a disminuir la posibilidad de que se continúen naturalizando dinámicas nocivas de interacción familiar, que afectan las condiciones para garantizar el desarrollo integral de los niños y las niñas.

\section{La disminución de los factores asociados con el establecimiento de dinámicas violentas dentro de las familias y en los contextos escolares, así como en la prevención de la transmisión interge- neracional de dichas dinámicas}

Como se mencionaba en el apartado anterior, la familia es el primer contexto de socialización de los niños y las niñas. Es en este contexto, y por medio de la interacción con sus padres, que se inicia el desarrollo de la personalidad. De acuerdo con Rodríguez (2007), la familia se constituye como el más importante entorno de socialización, por lo cual es el principal agente encargado de la transmisión de normas, valores y modelos de comportamiento. No obstante, de acuerdo con Mestre (2017), "El segundo contexto más potente en el proceso de socialización y educación de los menores es la escuela” (p.120).

En estos dos contextos, familia y escuela, los niños y las niñas, sientan las bases del comportamiento que guiará las interacciones con sus pares y la manera como afrontarán los conflictos. Algunos serán más empáticos, mantendrán relaciones más armónicas con sus pares, les brindarán ayuda y adoptarán con mayor frecuencia formas pacíficas de dirimir los conflictos. Este tipo de conductas han sido denominadas por diversos autores como conductas prosociales (Rodríguez, 2007; Cuervo, 2010; Mestre, 2017). Se entiende la conducta prosocial como una competencia que contribuye a establecer espacios de socialización menos violentos, además que previene la transmisión de conductas violentas de manera intergeneracional (Granada y Ortiz, 2018). 
Siendo la familia el principal contexto de socialización, ha sido interés determinar qué caracteriza a las familias que educan hijos que se distinguen por mostrar una conducta prosocial. Se ha encontrado que los estilos de crianza influyen en la manera como los niños autorregulan la conducta y entablan relaciones sociales (Mestre, 2017). De acuerdo con Cuervo (2010), "el comportamiento prosocial y el comportamiento agresivo son los extremos de una dimensión modulada por procesos cognitivos y emocionales de signo contrario, en los que los estilos de crianza contribuyen a su desarrollo" (p.116). Un adecuado desarrollo socioafectivo se da cuando se establece un estilo democrático de crianza (Cuervo, 2010). Diversos estudios coinciden en definir el estilo de crianza democrático como aquel en el cual los padres establecen un adecuado equilibrio entre el afecto y la disciplina, además instauran normas coherentes y brindan apoyo emocional; de acuerdo con Mestre (2007), este tipo de estilo de crianza promueve el desarrollo de la conducta prosocial.

Por otro lado, siendo el entorno escolar el segundo contexto más importante de socialización de los niños y las niñas, es un entorno propicio para que estos aprendan a ser empáticos con sus pares, a cooperar con ellos y a solucionar los conflictos de maneras dialogadas. Por lo tanto, es relevante resaltar el rol del talento humano que trabaja con primera infancia en la enseñanza de conductas prosociales.

Ahora bien, el talento humano reconoce y acepta la responsabilidad que tiene de formar y acompañar a las familias, a los niños y a las niñas, en el establecimiento de conductas que prevengan el uso de la violencia y contrarresten su naturalización y transmisión generacional. Los testimonios aquí presentados, de profesionales psicosociales, maestras y auxiliares pedagógicas, así lo evidencian:

\footnotetext{
"¿Qué puedo hacer yo? Continuar con la sensibilización a las familias para que se deje de tomar la violencia como algo inherente al ser humano, en donde entendamos que somos seres humanos y que no necesariamente tenemos que ser violentos (...), como que se unifique ese discurso de la no violencia, porque a veces como maestras, como profesionales, seguimos impulsando que el golpe está bien, que el grito está bien y seguimos naturalizándola, entonces es como empezar a hacer conciencia de mi ejercicio como agente educativo, qué estoy transmitiendo a esas familias y si estoy perpetuando que se siga naturalizando esa violencia (...), muchas veces nosotros a veces como profesionales y como agentes educativos somos quienes vulneramos".

“(...) Entonces, siento también que nuestro trabajo como psicosociales es como generar que esa normalización de la violencia disminuya, no acostumbrarnos a que es normal que nos violen, nos maten, nos secuestren, sino retomar otra vez de cuidarnos los unos a los otros, el simple hecho de saber que hay una redes de apoyo, que si se fortalecieran teniendo en cuenta que eso no es normal, que se están vulnerando derechos, podría generar una transformación, un impacto social, entonces sentiría que eso es un factor muy importante, el hecho de disminuir esa normalización de la violencia con nuestros usuarios, con nuestras familias".
}

Todo lo anterior permite concluir que el talento humano que trabaja con primera infancia, familias y comunidades, tiene la importante labor de formar y acompañar a las familias en el establecimiento de pautas de crianza y estilos parentales que promuevan conductas prosociales en los niños y las niñas, además de continuar esta labor en los entornos escolares, contribuyendo a generar espacios donde se pongan 
en práctica dichas conductas, de manera que se favorezca el establecimiento de una cultura de paz y se trabaje en prevenir la naturalización y transmisión generacional de conductas violentas.

\section{Construyendo la línea de tiempo. Diálogo entre el concepto y la evidencia encontrada. Las competencias del talen to humano}

La actividad denominada "Construyendo la línea de tiempo" surgió como un ejercicio de recolección de información y puntos de vista acerca del conflicto colombiano y partió de una pregunta central: ¿Qué significa ser competentes en el tiempo histórico del conflicto colombiano? Como respuesta se propuso co-construir unas estructuras conceptuales de tiempo, que serán cada vez más complejas, estructuras para la comprensión del tiempo histórico. La línea de tiempo es quizá la estructura esencial para la comprensión del tiempo que permite crear una secuencia de eventos, independiente de la relación que existe entre ellos.

Es posible construir una línea del tiempo del conflicto. En el caso de los participantes del proyecto, personas dedicadas al cuidado y educación inicial de la primera infancia, al igual que puede pasar con la mayoría de colombianos, el ejercicio de reconstrucción de la biografía del conflicto dejó en la mayoría una sensación de falta de claridad en el orden exacto en que han sucedido los hechos que hacen parte de él, y muchos coincidieron en decir que los sucesos más antiguos del conflicto son los que pueden ubicar con menos precisión, puesto que nacieron y se criaron después de que estos acontecimientos tuvieran lugar.

"Lo que pasa es que todo fue muy hacia allá, hace mucho tiempo, entonces todo como que se nos revolvió".

"Yo no tengo casi conocimiento de esto, porque yo no nací en ese tiempo y la verdad no me he interesado".

"Todos son (hechos) conocidos pero la relación entre ellos (fue lo difícil)".

No obstante, es posible construir un relato de lo que ha sido este conflicto "echando mano" de las memorias de protagonistas más directos de él; tal es el caso de los datos provenientes de relatos de padres o abuelos que sirvieron para ubicar y rememorar los acontecimientos más lejanos del conflicto, al mismo tiempo que cada persona hacía uso de su conocimiento teórico del conflicto, así como de experiencias más directas con hechos de violencia que fueron de más reciente aparición.

\footnotetext{
"Mis abuelitos nos contaban mucho de cómo llegaban y mataban con peinillas (...) que mataban a familias completas, si digamos usted era conservador, la guerra entre ellos (liberales y conservadores) hacía que digamos llegaran y acabaran con todo ".

"Cuando eso (el Bogotazo), mi mamá duró como tres días allá metida en el internado aguantando hambre porque no podían salir. Ella dice que apenas se asomaban a las ventanas y veían correr a la gente".

"El hermano de mi mami fue asesinado en la puerta de la casa por los paramilitares, ellos vivían en Guaduas (...) y él fue asesinado por ser opositor".

"Yo lo que tengo así de recuerdo es más que todo lo de Garzón, que yo estaba enferma y preciso pasaron los videos de él (cuando lo asesinaron)”.
} 
Esta síntesis histórica del conflicto colombiano, además, permite reconocer que nuestro país está atravesado por una historia de violencia en la cual también se han visto inmersos los niños, niñas y adolescentes, y en ese sentido los participantes del proyecto, como talento humano que trabaja con primera infancia que ha sido afectada por el conflicto colombiano, señala la importancia de conocer acerca de este (causas, factores de permanencia y consecuencias), alrededor de cinco razones principales:

\section{- Conocer sobre el conflicto colombiano para ser conservadores y transmi- sores de la memoria histórica del país y contribuir así a la construcción de paz desde la infancia.}

"Considero que es muy importante desde el ámbito profesional y personal contribuir a la construcción y fortalecimiento de la memoria histórica, en virtud que desde las familias se pueden llegar a mitigar ciertas situaciones de violencia o conflicto, las cuales han llegado a trascender de generación en generación".

"Desde el rol docente, la historia colombiana es un factor clave al trabajar con diferentes familias, niñas, niños quienes traen un pasado el cual se pudo ver afectado por el conflicto armado, por ello es importante saber de este tema, su principal causa y las acciones a seguir para la construcción de paz desde la infancia".

"Normalmente nosotros no conocemos muy bien nuestra historia, pero en la niñez tampoco la presentamos de ninguna manera (...) de pronto algunos que vienen desplazados saben por qué fueron desplazados, pero aun así no saben la historia más a fondo de por qué se presentó ese conflicto (..) es importante porque nosotros podemos tener más conocimiento para transmitirlo con las personas que trabajamos y esas mismas personas transmitirán a otros y de esa manera se creará como una cadena en la cual tengamos al menos conocimiento de nuestro país".

- Conocer sobre el conflicto colombiano para dimensionar lo que ha tenido que vivir un niño expuesto a un episodio de conflicto y entender su comportamiento y contexto de desarrollo.

"Es primordial, ya que esto es una herramienta que permite entender el origen de los conflictos de las familias y los comportamientos, así mismo permite a los agentes educativos ponerse en el lugar de estas personas y desarrollar acciones acertadas".

"Es indispensable también porque es la forma de saber cómo la docente se comporta con el niño, porque no es lo mismo yo saber que el niño viene de un conflicto de un desplazamiento forzado a que viene de un terrorismo (...) O sea, no es lo mismo tratar a un chico así a un chico que viene con drogadicción o con habitabilidad de calle o que viene con maltrato intrafamiliar, o sea, son casos muy diferentes que para las docentes es superimportante conocer. Te pongo un ejemplo, tenía un niño que me decía «me van a disparar, profe, agáchese», entonces (es importante) para comenzar a conocer esa situación (a la cual estuvieron expuestos), porque hay niños que lo traen muy arraigado y a raíz de todo ese proceso yo sé que tal persona de tal universidad hizo esto y le funcionó porque vio situaciones así, entonces las profes pueden decir, bueno: hagamos una experiencia de tal forma y si yo conozco la historia sé qué hacer".

- Conocer sobre el conflicto colombiano para contribuir a la transformación de la realidad de las familias.

"Considero que sí es pertinente no solamente tener una conciencia crítica frente a la realidad que enfrentamos a diario, sino que en cierta medida hay cosas que al ver uno dice, bueno, pasó, 
pero si nos damos cuenta todavía siguen ocurriendo pero de diferente manera. Pero la idea no es seguir en lo mismo, sino (pensar) de qué manera a través de esta historia yo puedo, en cierta medida, empoderar o contribuir al empoderamiento de las familias; que conozcan su historia, de qué manera, con lo que tienen, pueden también transformar esos espacios, esos escenarios en los que se encuentran, entonces yo creo que desde mi profesión sí le aporto mucho a la transformación social, por eso creo que sí es importante (conocer) qué hemos vivido, qué se puede mejorar y hacia dónde queremos llegar".

"Para futuros casos o para los presentes, todo este conocimiento nos serviría porque nosotras no somos formadoras, pero somos orientadoras. Y (en) lo que nos ayudaría es como a tratar de orientar a las personas para ayudarles a tener una visión diferente a la contaminación que ya traen (...) y buscar una solución para futuras generaciones o para los niños que tenemos acá, entonces nos sirve es como para orientar".

"Claro que sí se debe ser competente para poder brindar una información precisa al beneficiario que requiere el apoyo como para encontrar una solución para observar el cambio".

"Porque somos líderes políticas, no solo en conocer las leyes de la primera infancia o las rutas de atención cuando una mujer es agredida en la casa, más allá de eso, acá también estamos fortaleciendo en las sesiones ese poder político que tenemos nosotros como ciudadanos en el momento de elegir algo, entonces (por ejemplo) cuando fue el proceso de las elecciones (les decíamos a los usuarios) como bueno: hay que salir a votar, no por X, no por $\mathrm{Y}$, sino es el derecho de decir yo hice mi aporte de que yo quería esto porque creo en sus propuestas. Entonces cómo voy a incentivar algo si realmente ni siquiera sé la historia, (tener la capacidad de analizar): este (candidato) me está proponiendo tal cosa, eso que me está proponiendo es a raíz de esto y tiene como consecuencia esto".

\section{- Conocer sobre el conflicto colombiano para adaptar las prácticas que se llevan a cabo con población afectada por ese tipo de violencia.}

"Yo creo que también (sirve conocer sobre el conflicto), para analizar todos los efectos y todo el conflicto que también se tiene interno, porque por más que se perdone o se quiera olvidar ciertos sucesos, el conflicto interno queda ahí, entonces para iniciar un proceso pedagógico que nosotros hacemos acá, un proceso de acompañamiento que realizan las psicólogas y los trabajadores sociales, hay que también conocer un poco de historia para saber en qué se enfoca uno, cómo trabajarlo. Porque (por ejemplo), no podemos trabajar algo de colombianidad cuando no nos sentimos totalmente orgullosos de todo lo que se está exportando de Colombia hacia el exterior, porque no es así. Y sentirnos orgullosos totalmente de ser colombianos tampoco es así, porque no nos sentimos orgullosos de nuestra historia, nos sentimos orgullosos de la fauna, de la flora y de la cantidad de talento que ha surgido de los colombianos, pero sentirnos orgullosos de ser colombianos y de todas estas consecuencias del conflicto, realmente no (..) entonces (debemos pensar cómo) tocar el orgullo de ser colombiano ¿cómo lo debemos tocar?, y ¿cómo tocarlo hacia los niños?”

"Es importante conocer la historia social de cada uno de los niños para trabajar en ellos pedagógicamente, reconociendo su valor y sus derechos”.

"Considero muy necesario para conocer y abordar a los niños, niñas y sus familias y así realizar un trabajo donde se garanticen sus derechos”.

\section{- Conocer sobre el conflicto colombiano como marco de análisis para identificar otros conflictos y actuar sobre ellos.}

"Es pertinente no solo intervenir, sino también evaluar las consecuencias que pueden dejar las situaciones de violencia o conflicto, en virtud de que esos efectos no se conviertan más adelante en posibles causas que desencadenen otros conflictos".

"Sí, se deben tener conocimientos, prácticas y valores en el conflicto en Colombia, ya que 
de este conflicto se derivan muchas situaciones de conflicto en las familias de las niñas y los niños".

"Es muy importante conocer, así sea a grosso modo, el conflicto colombiano, para aprender a dar solución a esos conflictos (y) conocer las causas (de otros conflictos), (por ejemplo), bueno: si el papá (de un niño del CDI) es consumidor (pensar en) ¿cuál es su contexto sociocultural? ¿Qué lo llevó a eso?, no solo juzgarlo y (decidir que) al niño hagámoslo a un lado y tratémoslo un poco diferente. Entonces sí es importante conocer esas causas para aprender a aplicarlas a unas causas (de los conflictos) de las familias en el CDI (..) El conflicto armado tiene unas consecuencias, trae unas causas, se le han planteado unas soluciones, (entonces) lo mismo se puede aplicar (con los niños)".

"Si uno es consciente de que eso (un conflicto cotidiano) es un problema que está afectando a la vida de los niños, entonces si nosotras somos conscientes de que eso es un conflicto, pues se va a buscar una solución (...) Si hay un conflicto, entonces hay una búsqueda de solución y una búsqueda de mejora (...) porque si de pronto se dejan pasar las cosas entonces se sigue afectando, entonces no hay conflicto y no hay solución".

"Para tener más prevención, como (para saber cómo) evitar llegar a un conflicto grande sería importante tener ese conocimiento (causas, factores y efectos del conflicto colombiano)".

Se puede concluir que en el entralazamiento de voces enmarcadas en un relato con unas mínimas coordenadas históricas les permitieron a los participantes una cierta perspectiva de causas, factores y efectos y una claridad, entonces, sobre el propósito y el sentido de los conocimientos, prácticas y valores en torno al conflicto colombiano.

\section{Los orígenes, las múltiples causas y factores de permanencia de los distintos tipos de conflicto a los que están expuestos los niños y sus familias.}

La propuesta que se realiza de las competencias del talento humano que trabaja con población afectada por el conflicto, en relación con los orígenes, las múltiples causas y factores de permanencia de los distintos tipos de conflicto a los que están expuestos los niños y sus familias, está en concordancia con la concepción que se tiene del talento humano como actor que acompaña, realiza procesos de formación y brinda espacios para que las familias reflexionen, entre otros aspectos, sobre sus prácticas de crianza, de manera que se sientan (las familias) mejor preparadas y con mayores herramientas para promover el desarrollo integral de los niños y las niñas, estableciendo prácticas de crianza no violentas y mecanismos de resolución pacífica de los conflictos, que a su vez repercutan en el adecuado manejo de estos en los contextos escolar y social.

Ahora bien, teniendo en cuenta los testimonios recogidos del talento humano acerca de las situaciones que más cotidianamente deben afrontar en la atención de las familias, los niños y la comunidad, se plantean, además de las competencias para identificar y analizar las diversas causas y factores de permanencia de los conflictos que competen más a un ámbito social, competencias específicas relacionadas con la identificación, análisis y afrontamiento de los conflictos a nivel intrafamiliar y escolar. 
A continuación, se presentan algunos testimonios del talento humano que dan cuenta de las problemáticas que evidencia, en relación con el desarrollo de los conflictos intrafamiliares, que desencadenan en conductas violentas, muchas veces alimentadas por las dinámicas de inequidad de género entre las parejas.

"La situación es también maltrato intrafamiliar, hombre que maltrata a su pareja, entonces ¿las causas cuáles son? Primero, por mala comunicación, el machismo, normalización de la situación y baja autoestima, depresión y dependencia".

"Yo digo que todo está ligado como a las tradiciones o lo cultural de nosotros, entonces digamos la violencia dentro de un hogar (...), en general, siempre se ve es al hombre golpeando a la mujer y la violencia económica es bastante fuerte y más en los estratos bajos".

"Porque yo también soy desplazada cuando me toca irme de mi casa y de mi pueblo, porque mi esposo me golpea, me violenta, le pega a mis hijos, ahí soy desplazada, no porque la guerrilla me sacó corriendo y todo eso, también soy desplazada desde ese espacio, desde esa circunstancia y desde esa situación".

"Los factores son: creencias sociales, creencias transgeneracionales, manipulación y presión social, entonces creencias sociales como dicen (...), pero por decir, a veces, dicen que la mujer tiene que ser sumisa a su esposo, entonces porque tengo que ser sumisa a mi esposo tengo que aguantarme, pues los golpes, los maltratos, tengo que aguantarme muchas cosas (...) maltratos físicos y psicológicos solamente, porque uno tiene que ser sumisa a su esposo y sus hijos tienen que ver ese ejemplo (...), manipulación, entonces, manipulación es por decir que hay parejas donde el esposo manipula a su esposa como: si usted se va de la casa yo le puedo hacer algo a usted o le puedo hacer algo a su familia, entonces uno muchas veces dice, jhuy!, pero es que usted sí es bruta, ¿no?, usted por qué se queda con ese tipo, pero usted por qué le aguanta, pero uno realmente no sabe qué está pasando de puertas para adentro, y también las creencias sociales, muchas veces las mujeres por mantener como ese ideal, ¿no?, que la mujer debe tener su esposo, o los niños deben tener papá y mamá, tienden a aguantarse un ambiente familiar de violencia, de maltrato por solo socialmente tener como el esquema normal de familia, entonces se tiende a aguantar toda esa situación de violencia generalmente".

\section{Nivel individual}

En el nivel individual las competencias se enmarcan en el reconocimiento de la historia violenta del país, su repercusión en las dinámicas de violencia dentro de las instituciones educativas, centros de atención y las familias, lo que conlleva la necesidad de desarrollar conocimientos y prácticas que posibiliten espacios de reconciliación, re-significación de las experiencias violentas, así como espacios que promuevan la reflexión sobre las prácticas de crianza que perpetúan las conductas violentas, como forma de dirimir los conflictos. 
Tabla 3.1 Competencias de la categoría las múltiples causas y factores de permanencia de los distintos tipos de conflicto a los que están expuestos los niños y sus familias, incluido el conflicto armadoNivel individual.

\begin{tabular}{|c|c|c|}
\hline Conocimientos & Prácticas & Valores \\
\hline $\begin{array}{l}\text { - Conocimiento sobre la mul- } \\
\text { tiplicidad de causas y factores } \\
\text { de permanencia que pueden } \\
\text { desencadenar distintos tipos } \\
\text { de conflictos, a los que están } \\
\text { expuestos los niños y sus fa- } \\
\text { milias, incluido el conflicto } \\
\text { armado. } \\
\text { - Conocimiento sobre las es- } \\
\text { trategias que promueven el } \\
\text { desarrollo de una conducta } \\
\text { prosocial y favorecen la sana } \\
\text { convivencia a nivel familiar y } \\
\text { escolar, a la vez que permiten } \\
\text { abordar de manera pacífica } \\
\text { los conflictos y prevenir el } \\
\text { uso de la violencia como for- } \\
\text { ma de dirimirlos, entre ellas: } \\
\text { empatía, ayuda mutua, co- } \\
\text { municación asertiva, manejo } \\
\text { de emociones y estrategias de } \\
\text { mediación para la resolución } \\
\text { de los conflictos... } \\
\text { - Re-conocimiento de los de- } \\
\text { rechos de los niños. }\end{array}$ & 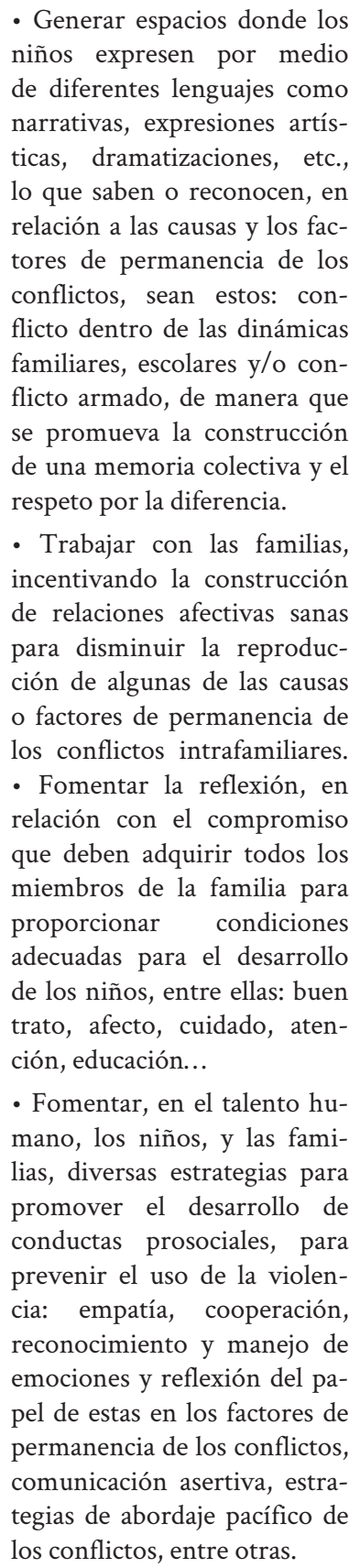 & 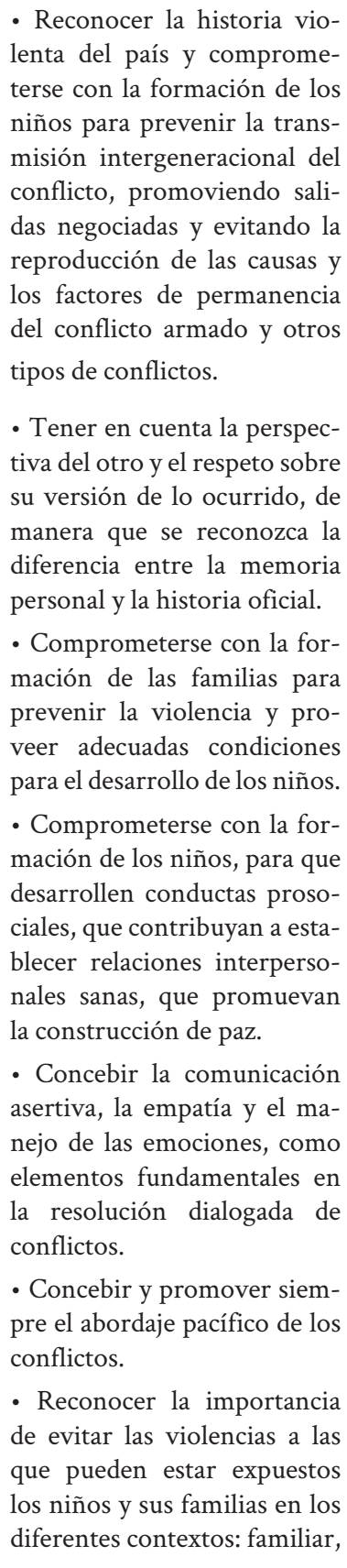 \\
\hline
\end{tabular}




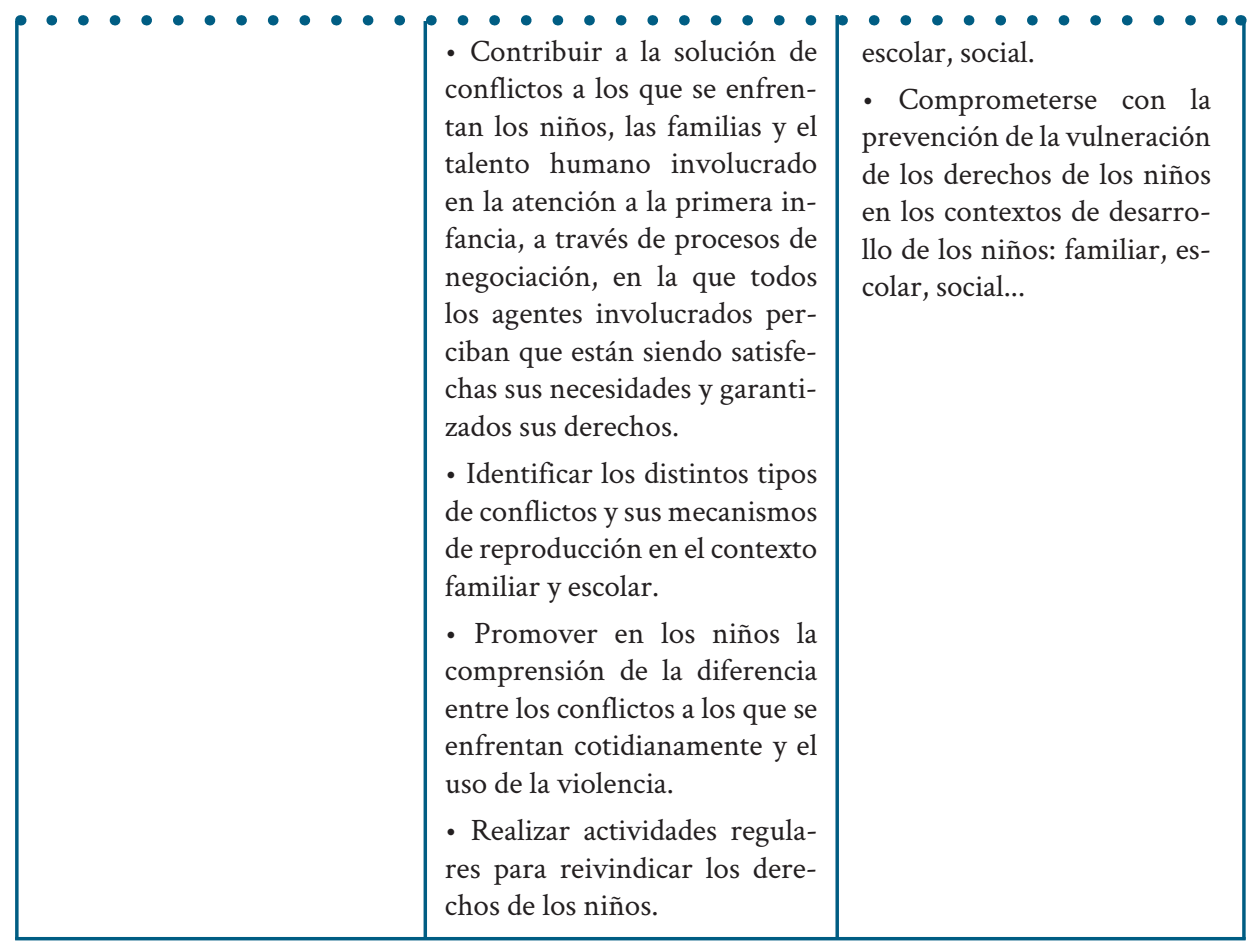

\section{Nivel institucional}

El papel de las instituciones, en el esquema de competencias propuesto, se prioriza en el reconocimiento de los niños como sujetos de derechos, con lo cual se establece la necesidad de desarrollar competencias que contribuyan al diseño de planes, para identificar y analizar los mecanismos de reproducción de los conflictos, al punto de llevar estos a niveles violentos. Contempla también las competencias necesarias para apoyar la generación de espacios para reivindicación de derechos y generación de espacios propicios para el diálogo, la reflexión y la concertación, en los cuales se involucre a los diferentes actores: familias, niños, niñas, comunidad y talento humano.

Tabla 3.2 Competencias de la categoría las múltiples causas y factores de permanencia de los distintos tipos de conflicto a los que están expuestos los niños y sus familias, incluido el conflicto armado -

\section{Nivel institucional.}

\section{Conocimientos}

- Re-conocimiento de los derechos del niño, así como de las formas en las que han sido vulnerados en los diversos contextos, incluido en el contexto del conflicto arma-

\section{Prácticas \\ Valores}

- Realizar actividades regulares para reivindicar los derechos de los niños.

- Favorecer espacios de diálogo y concertación para resolver los conflictos.
- Adoptar un enfoque basado en el reconocimiento de los niños como sujetos de derechos, que abarque la plena participación en la vida social y cultural de su comunidad. 


\begin{tabular}{|c|c|c|}
\hline $\begin{array}{l}\text { do colombiano (reclutamien- } \\
\text { to forzado, desplazamiento, } \\
\text { violencia sexual, abandono, } \\
\text { etc...). } \\
\text { - Conocimiento de los meca- } \\
\text { nismos de identificación, re- } \\
\text { producción y resolución de los } \\
\text { conflictos a los que se enfren- } \\
\text { tan los niños. } \\
\text { - Conocimiento de los distin- } \\
\text { tos tipos de violencias y las } \\
\text { diferentes formas en que se } \\
\text { normalizan y reproducen. }\end{array}$ & $\begin{array}{l}\text { - Establecer con la participa- } \\
\text { ción de los diferentes actores } \\
\text { (talento humano, los niños y } \\
\text { sus familias), rutas y protoco- } \\
\text { los para resolver los conflictos. } \\
\text { - Identificar los diferentes ti- } \\
\text { pos de conflictos y sus factores } \\
\text { de permanencia. } \\
\text { - Analizar los conflictos que se } \\
\text { presentan en el contexto fami- } \\
\text { liar y escolar. } \\
\text { - Abordar, mediante acciones } \\
\text { preventivas y de manera in- } \\
\text { terdisciplinaria, las violencias } \\
\text { que se puedan presentar den- } \\
\text { tro de las familias y de la ins- } \\
\text { titución. } \\
\text { - Construir protocolos de } \\
\text { atención de los casos de vio- } \\
\text { lencias dentro de las familias y } \\
\text { de la institución. }\end{array}$ & $\begin{array}{l}\text { - Adoptar un enfoque de re- } \\
\text { solución de conflictos basado } \\
\text { en el diálogo, de manera que } \\
\text { se prioricen las formas nego- } \\
\text { ciadas de dirimir los conflictos } \\
\text { por encima del uso de la fuer- } \\
\text { za. } \\
\text { - Concebir los conflictos como } \\
\text { una oportunidad de creci- } \\
\text { miento y de encuentro. } \\
\text { - Reconocer la importancia de } \\
\text { orientar a los padres, para que } \\
\text { modifiquen los esquemas que } \\
\text { conducen a reproducir distin- } \\
\text { tos tipos de violencia y con- } \\
\text { diciones desfavorables para el } \\
\text { desarrollo de los niños. } \\
\text { - Valorar la importancia de } \\
\text { trabajar para prevenir cual- } \\
\text { quier tipo de violencia, en pro } \\
\text { de lograr condiciones de vida } \\
\text { favorables para los niños y sus } \\
\text { familias. }\end{array}$ \\
\hline
\end{tabular}

\section{Nivel interinstitucional}

Las competencias propuestas en este nivel se plantean concibiendo que la articulación de diversas instituciones puede apoyar los procesos de construcción de memoria histórica, la reivindicación de las víctimas y contribuir a no perpetuar o heredar la violencia como mecanismo para la solución de los conflictos.

Tabla 3.3 Competencias de la categoría las múltiples causas y factores de permanencia de los distintos tipos de conflicto a los que están expuestos los niños y sus familias, incluido el conflicto armado -

Nivel interinstitucional.

Conocimientos
Prácticas

- Conocimiento sobre las entidades y grupos que preservan la memoria histórica (comisión de la verdad, centro de memoria, archivos).

- Conocimiento sobre las funciones del sistema integral de verdad, justicia y reparación.

- Conocimiento sobre sistemas de prevención de violencias y no repetición de los

Valores

- Realizar ferias y eventos, con la cooperación de diversas entidades, para reivindicar la memoria de quienes han sido víctimas del conflicto.

- Solicitar y usar material didáctico de los distintos centros de memoria histórica, para realizar actividades pedagógicas con los niños y sus familias.

- Intercambiar experiencias
- Asumir la memoria y la verdad históricas como una compleja y múltiple construcción colectiva.

- Concebir la prevención de las violencias y la no repetición de los conflictos como un compromiso interinstitucional en la construcción de paz. 


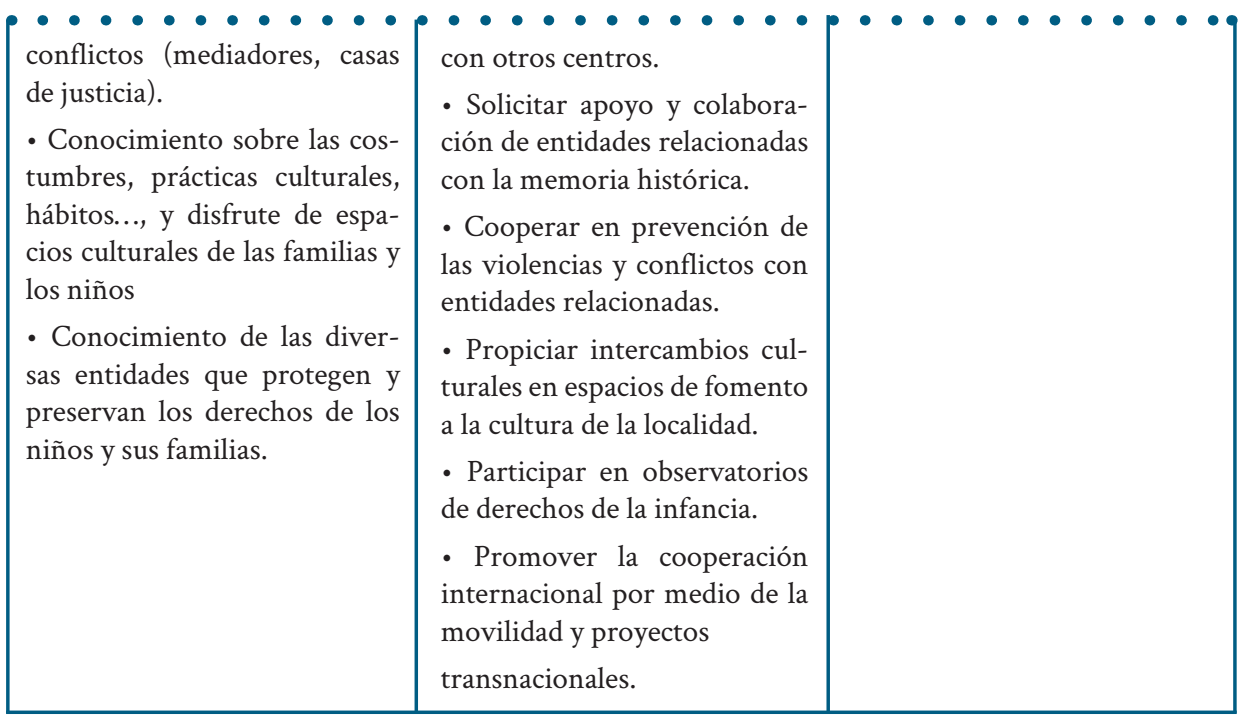

\section{Nivel de gobernanza}

Las competencias aquí propuestas parten del reconocimiento sobre qué es el nivel de gobernanza, quien tiene las facultades para desarrollar una política en la que se contemple la formación sistemática del talento humano, como especialista en la identificación y análisis de los conflictos y las violencias. Formación que repercuta en la generación de cambios en las dinámicas familiares, escolares y sociales, que contribuya a disminuir los mecanismos mediante los cuales las conductas violentas se perpetúan y se transmiten a nivel intergeneracional.

Tabla 3.4 Competencias de la categoría las múltiples causas y factores de permanencia de los distintos tipos de conflicto a los que están expuestos los niños y sus familias, incluido el conflicto armado -

Nivel de gobernanza.

Conocimientos

- Conocimiento de las políticas nacionales y regionales de memoria histórica.

- Conocimiento del sistema integral de verdad, justicia y reparación y su relación con los sistemas de atención a la primera infancia.

- Conocimiento del Acuerdo final para la terminación del Conflicto y la construcción de una paz estable y duradera y todos los documentos que de él emanen, en especial aque-

Prácticas

Valores

- Proporcionar acceso equitativo a la verdad integral sobre las violencias y los diferentes conflictos, incluido el conflicto armado.

- Co-construir, con todos los grupos de interés, un marco pedagógico que garantice el abordaje de la verdad histórica alrededor de las violencias y diferentes conflictos.

- Realizar conmemoraciones, reconocimientos, homenajes públicos y mecanismos de re-
- Entender el derecho a la verdad como base de la justicia, la democracia y la paz.

- Reconocimiento del concepto de participación como eje en la construcción de una paz estable y duradera.

- Comprometerse con la divulgación de acciones a desarrollar en los contextos familiar y escolar, para contribuir con la no repetición del conflicto armado y con los pilares de la justicia transicional de verdad, justicia, 


\begin{tabular}{|c|c|c|}
\hline $\begin{array}{l}\text { llos relacionados con la pobla- } \\
\text { ción infantil afectada. } \\
\text { - Conocimiento de los ins- } \\
\text { trumentos de participación } \\
\text { económica y política contem- } \\
\text { plados en dicho acuerdo, como } \\
\text { preventivos de nuevas violen- } \\
\text { cias y conflictos. } \\
\text { - Conocimiento de los meca- } \\
\text { nismos de reproducción de los } \\
\text { conflictos y la violencia a nivel } \\
\text { escolar y familiar, de manera } \\
\text { que se construya con políticas } \\
\text { que favorezcan acciones para } \\
\text { disminuir dichos mecanismos. }\end{array}$ & $\begin{array}{l}\text { paración simbólica. } \\
\text { lento humano en acciones que } \\
\text { favorezcan: } \\
\text { - La contribución para la no re- } \\
\text { petición del conflicto armado. } \\
\text { - El desarrollo de acciones que } \\
\text { minimicen los mecanismos de } \\
\text { reproducción de los conflictos } \\
\text { a nivel familiar y escolar. }\end{array}$ & $\begin{array}{l}\text { reparación y no repetición de } \\
\text { dicho conflicto. } \\
\text { - Comprometerse con la for- } \\
\text { mación del talento humano } \\
\text { en conocimientos y acciones } \\
\text { a desarrollar con los niños y } \\
\text { sus familias, para el aborda- } \\
\text { je y resolución pacífica de los } \\
\text { conflictos, de modo que no se } \\
\text { escalen hasta niveles de vio- } \\
\text { lencia. }\end{array}$ \\
\hline
\end{tabular}

\section{Los efectos de los distintos tipos de conflicto sobre los niños y sus familias, incluye conflicto armado y otros tipos de conflictos.}

\section{Nivel individual}

Todo este proceso de planificar colectivamente y trabajar juntos para mejorar las relaciones con la comunidad que rodea la primera infancia afectada por el conflicto colombiano, pasa primero por un esfuerzo individual del talento humano para lograr procesos tanto de reintegración como de apoyo que incluyan la reconciliación y proporcionen a los niños apoyo psicosocial. Esto sin una apuesta de los individuos es inútil e incompleto, puesto que solo desde el compromiso individual se pueden encadenar esfuerzos colectivos. En las relaciones persona a persona, agente - niño, familias, hay elementos básicos que suelen soslayarse. En 2006, por ejemplo, el Comité de los Derechos del Niño celebró un "Día del debate general sobre el derecho del niño a ser escuchado" (Lázaro, 2016). Es deseable comenzar por conocer el básico derecho de los niños a ser escuchados. Por tanto, una práctica como escuchar -que surge del conocimiento de la escucha activa en el contexto de la reparación o restitución de derechos- es una competencia fundamental (Castro y Olano, 2018).

Escuchar las experiencias individuales de los niños y las familias víctimas de diversos tipos de conflicto en las dinámicas familiares, escolares y/o conflicto armado, y propiciar que se plasmen mediante la literatura, el arte y otros recursos, la afectación directa o indirecta que han experimentado, de manera que se promueva la resignificación, la reconciliación y superación de las secuelas. Se pretende, además, que la comprensión de los efectos genere empatía por el otro y contribuya a buscar salidas negociadas y a disminuir los factores que generan y reproducen dichos conflictos.

Todo esto tiene que traducirse en los valores individuales éticos del comprometerse con el abordaje de la memoria de un pasado violento que ha afectado a los niños y sus familias, desde las distintas disciplinas que conforman el talento humano que trabaja con esta población. 
Tabla 3.5. Competencias de la categoría los efectos de los distintos tipos de conflicto, incluido el conflicto armado, sobre los niños y sus familias - Nivel individual.

\begin{tabular}{|c|c|c|}
\hline Conocimientos & Prácticas & Valores \\
\hline $\begin{array}{l}\text { - Conocimiento sobre la mul- } \\
\text { tiplicidad de efectos que han } \\
\text { tenido los distintos tipos de } \\
\text { conflicto, incluido el conflic- } \\
\text { to armado, sobre el desarro- } \\
\text { llo del niño y el bienestar de } \\
\text { su familia. }\end{array}$ & $\begin{array}{l}\text { Escuchar las experiencias } \\
\text { individuales, de los niños y las } \\
\text { familias víctimas de diversos } \\
\text { tipos de conflicto en las diná- } \\
\text { micas familiares, escolares y/o } \\
\text { conflicto armado, y propiciar } \\
\text { que se plasmen mediante la } \\
\text { literatura, el arte y otros re- } \\
\text { cursos, la afectación directa o } \\
\text { indirecta que han experimen- } \\
\text { tado, de manera que se pro- } \\
\text { mueva la resignificación, la } \\
\text { reconciliación y superación de } \\
\text { las secuelas. Se pretende, ade- } \\
\text { más, que la comprensión de } \\
\text { los efectos genere empatía por } \\
\text { el otro y contribuya a buscar } \\
\text { salidas negociadas y a dismi- } \\
\text { nuir los factores que generan y } \\
\text { reproducen dichos conflictos. } \\
\text { - Brindar soluciones acordes } \\
\text { con las necesidades de las víc- } \\
\text { timas del conflicto. }\end{array}$ & $\begin{array}{l}\text { - Comprometerse con el abor- } \\
\text { daje del pasado violento que } \\
\text { ha afectado a los niños y sus } \\
\text { familias, desde las distintas } \\
\text { disciplinas que conforman el } \\
\text { talento humano que trabaja } \\
\text { con esta población. }\end{array}$ \\
\hline
\end{tabular}

\section{Nivel institucional}

Las instituciones educativas y centros de atención en Colombia están insertos en unas particularidades étnicas, culturales, geográficas específicas. Sin embargo, las prácticas institucionales, desde las más elementales como puede ser la alimentación, están marcadas por una consigna de productividad económica, y vale la pena debatir si se puede considerar o concebir la misma solución o competencia para todo el talento humano, sin tener en cuenta las historias y trayectorias de vida particulares, muchas de ellas ancladas en la tierra y el campo, otras tantas vinculadas a tradiciones étnicas y culturales ajenas a las lógicas de producción urbana. Por tanto, el conocimiento profundo de las tradiciones culturales y étnicas de cada región donde el talento humano se establezca es de alta prioridad.

Desarrollar prácticas inclusivas que faciliten la socialización de creencias, costumbres y tradiciones de los niños que han sido desarraigados de su cultura a causa del conflicto armado u otro tipo de conflicto, de manera que se fomente la empatía y 
el respeto a la diferencia. Analizar con los niños y sus familias las diferencias entre conflictos y violencia -siendo los primeros inherentes al ser humano-, deben ser abordados siempre de manera negociada para que se conviertan en oportunidades pedagógicas. Mostrar mediante testimonios de quienes han sido víctimas del conflicto armado, la afectación que estos han tenido en diferentes niveles, de manera que se fomente la empatía por el otro y la construcción de alternativas para abordar sus efectos.

Todo esto con el objetivo final de reconocer que cada niño y su familia tienen una historia en la que pueden existir secuelas, por afectación directa o indirecta a raíz de distintos tipos de conflictos. Reconocer la importancia de respetar y mantener la cultura (creencias, costumbres, tradiciones...), de los niños y las familias que sufren el desarraigo cultural, a consecuencia de distintos tipos de conflicto, incluido el conflicto armado. Y finalmente, reconocer la importancia de abordar de manera interdisciplinaria las violencias a las que pueden estar expuestos los niños y sus familias en los diferentes contextos: familiar, escolar, social.

Tabla 3.6. Competencias de la categoría los efectos de los distintos tipos de conflicto, incluido el conflicto armado, sobre los niños y sus familias - Nivel institucional.

Conocimientos

\section{Prácticas}

\section{Valores}

- Conocimiento sobre la cultura (creencias, costumbres, tradiciones...) de los niños y las familias que han sido víctimas de distintos tipos de conflicto, incluido el conflicto armado.

- Conocimiento de estrategias de abordaje de las violencias a las que están expuestos los niños y sus familias, como consecuencia de los conflictos que se presentan en el contexto escolar y familiar.
- Desarrollar prácticas inclusivas que faciliten la socialización de creencias, costumbres y tradiciones de los niños que han sido desarraigados de su cultura, a causa del conflicto armado u otro tipo de conflicto, de manera que se fomente la empatía y el respeto a la diferencia.

- Analizar con los niños y sus familias las diferencias entre conflictos y violencia -siendo los primeros inherentes al ser humano-, deben ser abordados siempre de manera negociada para que se conviertan en oportunidades pedagógicas.

- Mostrar mediante testimonios de quienes han sido víctimas del conflicto armado, la afectación que estos han tenido en diferentes niveles, de manera que se fomente la empatía por el otro y la construcción de alternativas para abordar sus efectos.
- Reconocer que cada niño y su familia tienen una historia en la que pueden existir secuelas, por afectación directa o indirecta a raíz de distintos tipos de conflictos.

- Reconocer la importancia de respetar y mantener la cultura (creencias, costumbres, tradiciones...) de los niños y las familias que sufren el desarraigo cultural, a consecuencia de distintos tipos de conflicto, incluido el conflicto armado.

- Reconocer la importancia de abordar de manera interdisciplinaria, las violencias a las que pueden estar expuestos los niños y sus familias en los diferentes contextos: familiar, escolar, social. 


\section{Nivel interinstitucional}

Cuando las instituciones trabajen entre sí, se configuran sistemas que las abarcan y les permiten dialogar (Urban, 2015). Del enfoque sistémico surge la consideración y conocimiento del Sistema Integral de Verdad, Justicia y no repetición (SIVJNR), que es el conjunto de mecanismos para garantizar los derechos de las víctimas a la verdad, la justicia, la reparación y la no repetición estipulados en el Acuerdo para la Terminación del Conflicto y la Construcción de una Paz Estable y Duradera, firmado entre el Gobierno Nacional de Colombia y las FARC.

Es importante que el talento humano conozca que el Sistema tiene un enfoque territorial, diferencial y de género, que corresponde a las características particulares de victimización

en cada territorio y por cada población, con especial protección y atención a las mujeres, los niños y las niñas víctimas del conflicto armado.

Así, es deseable un conocimiento básico de entidades y procedimientos interinstitucionales relacionados con este enfoque. Es muy importante la capacidad de comunicar y gestionar sobre programas interinstitucionales, saber identificar las familias víctimas de distintos tipos de conflicto, incluido el conflicto armado, y conducirlas en una ruta de atención interinstitucional y cómo el sistema tiene previsto apoyarlos. Todo esto con el fin último de asumir las diferentes violencias y conflictos a los que han estado expuestos los niños y sus familias desde una perspectiva de reparación y acceso a la verdad, de manera que se promueva la reconciliación y la no repetición (Tonche y Umaña, 2017).

Tabla 3.7. Competencias de la categoría los efectos de los distintos tipos de conflicto, incluido el conflicto armado, sobre los niños y sus familias - Nivel interinstitucional.

\begin{tabular}{|c|c|c|}
\hline Conocimientos & Prácticas & Valores \\
\hline $\begin{array}{l}\text { - Conocimiento general sobre } \\
\text { los procedimientos de la Jus- } \\
\text { ticia Especial para la Paz, con } \\
\text { énfasis en aquellos relaciona- } \\
\text { dos con la población infantil } \\
\text { afectada. } \\
\text { - Conocimiento de entidades } \\
\text { y procedimientos interinsti- } \\
\text { tucionales relacionados con } \\
\text { el desplazamiento forzado y la } \\
\text { sustitución de cultivos. }\end{array}$ & $\begin{array}{l}\text { - Informar sobre programas in- } \\
\text { terinstitucionales de proyectos } \\
\text { productivos y sustitución de } \\
\text { cultivos ilícitos. } \\
\text { - Identificar las familias vícti- } \\
\text { mas de distintos tipos de con- } \\
\text { flicto, incluido el conflicto ar- } \\
\text { mado, y conducirlas en una ruta } \\
\text { de atención interinstitucional. }\end{array}$ & $\begin{array}{l}\text { - Asumir las diferentes violen- } \\
\text { cias y conflictos a los que han } \\
\text { estado expuestos los niños y } \\
\text { sus familias desde una pers- } \\
\text { pectiva de reparación y acceso } \\
\text { a la verdad, de manera que se } \\
\text { promueva la reconciliación y } \\
\text { la no repetición. }\end{array}$ \\
\hline
\end{tabular}




\section{Nivel de gobernanza}

Sin duda, el Acuerdo final para la terminación del conflicto y la consolidación de una paz estable y duradera, o simplemente el Acuerdo de paz con las Farc, ha sido el hecho político que más ha trascendido en los últimos años (Moncayo, 2015). Sin embargo, lo que debió ser un consenso nacional para la terminación de un conflicto de más de cincuenta años, no se tradujo tan fácilmente en realidades y transformaciones regionales. Es por ello que las competencias enmarcadas en este nivel tienen mucho que ver con la capacidad de transformar, de convertir una realidad política nacional en realidades locales y regionales.

La principal herramienta con que cuentan los actores y agentes de paz es la política pública. Por tanto, toda transformación debe partir de un conocimiento de las políticas de atención, asistencia y reparación integral a las víctimas de las violencias y los conflictos, incluido el conflicto armado. Conocimiento general de la ley de víctimas y restitución de tierras. Por tanto, debe insistirse en apoyar la capacitación del talento humano en la política pública sobre atención a víctimas por medio de inducción y desarrollo profesional continuo de todo el talento humano (practicantes, asistentes, líderes de los centros de desarrollo infantil, modalidades familiares e institucionales y otras instituciones educativas), y promover la movilidad del talento humano, especialista en atención a las víctimas del conflicto, a las regiones más afectadas por este.

Todo esto debe partir de reconocer que en Colombia hubo un conflicto armado de más de 50 años que se está superando y que hay un escenario de violencia donde están anidando por lo menos otros cinco conflictos más. Reconocer, además, todos los derechos de las víctimas que estos conflictos pasados y presentes dejan y la construcción colectiva de memoria histórica en Colombia. Para ello, en el nivel de gobernanza es deseable adoptar un enfoque integral de atención, asistencia y reparación integral a las víctimas de diversos tipos de conflicto o violencias, incluido el conflicto armado, para promover políticas de reconocimiento de las víctimas de las violencias y los diferentes conflictos, como un asunto que compete a toda la sociedad.

Tabla 3.8. Competencias de la categoría los efectos de los distintos tipos de conflicto, incluido el conflicto armado, sobre los niños y sus familias - Nivel de gobernanza.

\begin{tabular}{|c|c|c|}
\hline Conocimientos & Prácticas & Valores \\
\hline $\begin{array}{l}\text { - Conocimiento de las políticas } \\
\text { de atención, asistencia y repa- } \\
\text { ración integral a las víctimas de } \\
\text { las violencias y los conflictos, } \\
\text { incluido el conflicto armado. } \\
\text { - Conocimiento general de la } \\
\text { ley de víctimas y restitución de } \\
\text { tierras. }\end{array}$ & $\begin{array}{l}\text { - Apoyar la capacitación del ta- } \\
\text { lento humano en la política pú- } \\
\text { blica sobre atención a víctimas } \\
\text { por medio de: } \\
\text { - Inducción y desarrollo } \\
\text { profesional continuo de } \\
\text { todo el talento humano } \\
\text { (practicantes, asistentes, lí- }\end{array}$ & $\begin{array}{l}\text { - Reconocer los derechos de } \\
\text { las víctimas y de la construc- } \\
\text { ción de memoria histórica en } \\
\text { Colombia. } \\
\text { - Adopción de un enfoque } \\
\text { integral de atención, asisten- } \\
\text { cia y reparación integral a las } \\
\text { víctimas de diversos tipos de }\end{array}$ \\
\hline
\end{tabular}




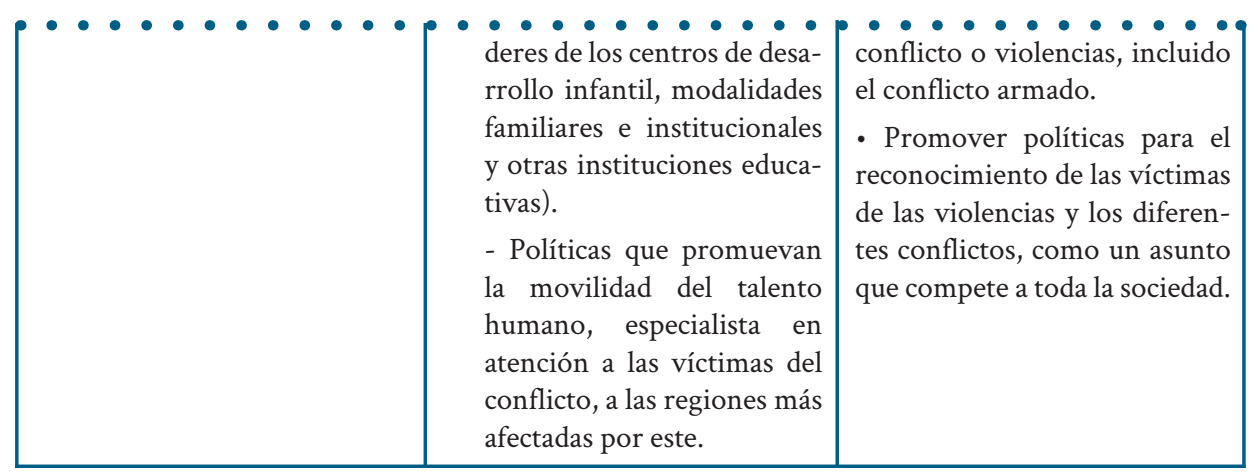

\section{Conclusiones}

Es innegable que la historia violenta del país ha influido en los mecanismos adoptados por los sujetos para hacer frente a situaciones de conflicto en los distintos ámbitos: social, institucional y familiar. En relación con el conflicto colombiano o conflicto armado se está a medio camino, ya que se corre el riesgo de repetir patrones de violencia y generar nuevas conflictividades que heredarán las niñas, los niños y los jóvenes, los actores protagónicos en el presente y futuro del país. La responsabilidad de los adultos es enorme, en ellos recae la ardua labor de contribuir al inicio del establecimiento de una cultura de paz, precedida por un espíritu comprensivo e interpretativo que va más allá del seguimiento de un enfoque mono-causal o meramente explicativo, generando un ambiente en el que los niños y los jóvenes se formen y que disminuya la posibilidad de la transmisión de la violencia de manera intergeneracional, como mecanismo para dirimir los conflictos.

\section{Referencias}

Agudelo-Vélez, D. (2018). Presentación. Impacto del conflicto y la violencia sobre la salud mental: del diagnóstico a la intervención. Revista de Estudios Sociales, 66, 2-8. Recuperado de: https:// journals.openedition.org/revestudsoc/28019

Calvino, I. (2012). Seis propuestas para el próximo milenio (Vol. 2). Madrid: Siruela.

Campos, J., Cardona, J., Bolaños, I., y Cuartero, M. E. (2015). La fatiga por compasión en la práctica de la mediación familiar: hipótesis para una investigación. En M. Morelli y D. De Luise (Eds.), Voci Dal X Congresso mondiale di mediazione. Una via verso la cultura della pace e la coesione sociale, Génova, Italia. Recuperado de: https://www.researchgate.net/profile/Jose_Campos_Vidal/ publication/279288785_La_Fatiga_por_Compasion_en_la_Practica_de_la_Mediacion_Familiar_Hipotesis_para_una_investigacion/links/55917abe08aed6ec4bf83b86.pdf

Castro, X., y Olano, J. (2018). Reparación y escucha del sujeto-víctima: discursos y prácticas en la intervención psicosocial con víctimas del conflicto armado en Colombia. Revista Colombiana de Ciencias Sociales, 9(1), 85-108.

Comisión Intersectorial para la Primera Infancia [CIPI]. (s.f.). Lineamiento técnico de formación y acompañamiento a familias de niños y niñas en la primera infancia. Recuperado de: https:// cutt.ly/LeP8sIt

Cuartero, M., Riera, J., y Casado, T. (2016). La fatiga por compasión: la consecuencia de trabajar con personas que sufren. Recuperado de: https://cutt.ly/7eP49j7 
Cuervo, A. (2010). Pautas de crianza y desarrollo socioafectivo en la infancia. Diversitas: Perspectivas en Psicología, 6(1), 111-121. Recuperado de: https://www.redalyc.org/pdf/679/67916261009. pdf

Evans-Campbell, T. (2008). Historical trauma in American Indian/Native Alaska communities: A multilevel framework for exploring impacts on individuals, families, and communities. Journal of interpersonal violence, 23(3), 316-338.

Figley, C. (Ed.). (1995). Compassion fatigue. Nueva York, EE. UU.: Taylor \& Francis.

González, J. (2004). Empatía y ecpatía. Revista psiquis, 6, 243-245. Recuperado de: http://www.psicoter.es/art/04_25_n06_A01.pdf

Freund, J. (2014). La esencia de lo político. Signos Universitarios, 6(12), 11-19.

Granada, P., y Ortiz, L. (Ed.). (2018). Crianza para la paz. Bogotá, Colombia: Universidad Pedagógica Nacional; Fundación Centro Internacional de Educación y Desarrollo Humano, CINDE; COLCIENCIAS; Universidad de Manizales. Recuperado de: http://ceanj.cinde.org.co/programa/ Archivos/publicaciones/Coleccion_virtual/3_CRIANZA_PARA_LA_PAZ.pdf

Lázaro, P. (2016). El Derecho del niño a ser escuchado en juzgados de familia: un estudio desde la perspectiva de jueces y consejeros técnicos. Tesis de pregrado Psicología. Universidad de Chile. Recuperado de: http://repositorio.uchile.cl/handle/2250/165709

Pizarro, E. (2015). Una lectura múltiple y pluralista de la historia. Comisión de historia del conflicto y sus víctimas. Revista Academia Libre, (12), 151-213.

Mestre, V. (2017). Desarrollo prosocial: crianza y escuela. Revista Mexicana de Investigación en Psicología, 6(2), 115-134. Recuperado de: https://www.medigraphic.com/pdfs/revmexinvpsi/mip2014/mip142b.pdf

Oquendo, C. (2019). Hay 5 conflictos armados hoy en Colombia. El País. Recuperado de: https:// elpais.com/internacional/2019/07/20/colombia/1563649226_997490.html

Ospina, M., Alvarado, S., y Fajardo, M. (2018). Subjetividades políticas de la primera infancia en contextos de conflicto armado: Narrativas colectivas de agencia. Psicoperspectivas, 17(2), 115-127.

Pécaut, D. (2015). Un conflicto armado al servicio del status quo social y político. Contribución al entendimiento del conflicto armado colombiano, 1-53.

Rodríguez, A. (2007). Principales modelos de socialización familiar. Foro de educación, 5(9), 91-97. Recuperado de: https://www.redalyc.org/pdf/4475/447544584007.pdf

Stewart, J. G. (2003). Towards a single definition of armed conflict in international humanitarian law: A critique of internationalized armed conflict. International Review of the Red Cross, 85(850), 313-350.

Tonche, J., y Umaña, C. (2017). Sistema Integral de Verdad, Justicia, Reparación y No Repetición: un acuerdo de justicia irestaurativa? Revista Derecho del Estado, (38), 223-241.

Useche, Ó., y Gutiérrez, T. (2017). En defensa de la vida. Balances y perspectivas del post-acuerdo colombiano. Polisemia, 13(24), 7.

Valcárcel, J. (2007). Concepto de conflicto armado interno y seguridad jurídica. Prolegómenos. Derechos y Valores, 10(19), 107-121.

Wills, M. (2015). Los tres nudos de la guerra colombiana. Comisión Histórica del Conflicto y sus Víctimas: Contribución al entendimiento del conflicto armado en Colombia. Recuperado de: http:// www.humanas.unal.edu.co/observapazyconflicto/files/5714/6911/9376/Version_final_informes_CHCV.pdf 
$\mathrm{E}$ ste capítulo tiene por objeto la reflexión sobre la atención que se brinda a la primera infancia desde las políticas públicas, en el marco de un sistema competente, especialmente la atención que se realiza con los menores de 5 años que han sido afectados directa o indirectamente por el conflicto colombiano. El capítulo inicia con una presentación de conceptos centrales sobre política pública y políticas públicas para la primera infancia en Colombia, para luego centrarse en los elementos de política pública, que a criterio de quienes participaron en la investigación, resultan necesarios para garantizar una adecuada atención a la primera infancia, tales como la integralidad, los sistemas de información, el monitoreo, la planeación y el presupuesto, todos ellos vitales para la competencia del sistema en sus diferentes niveles. Esto se hace partiendo del diálogo entre estos conceptos y los hallazgos encontrados en los participantes del estudio.

\section{Sobre el concepto de política pública}

Un país se desarrolla en la medida en que utiliza las herramientas necesarias para detectar cuáles son las principales problemáticas que le están aquejando en un momento determinado y brinda alternativas de solución, estratégicas y sostenibles, con el fin de dar manejo a dichas problemáticas.

Para Aguilar (2006), la tendencia mundial es que se pueda restablecer la naturaleza pública y asegurar un gobierno de calidad institucional, informativa y analítica -que tome decisiones con base en hechos fuertes y estudios rigurosos- y un gobierno de calidad gerencial, capaz de llevar a la práctica las decisiones que ha tomado. El tema hoy en el mundo es la calidad y no solamente el número de acciones del Estado. Cuando menciona restablecer la naturaleza pública, Aguilar (2006) hace referencia a que la actuación gubernamental sea legal y busque el beneficio público. Para este autor es necesario restablecer la deliberación y la corresponsabilidad ciudadana en los asuntos públicos, buscando su aporte para la identificación de los problemas sociales, la forma de abordarlos y la identificación de alternativas para cualificar las acciones institucionales, sociales e individuales que se requieren.

Con la promulgación de la Constitución Política en 1991 y la denominación Estado Social de Derecho, devienen para Colombia debates políticos, técnicos y académicos sobre los derechos humanos y los roles y responsabilidades del Estado, la sociedad y la familia en su garantía. Esto, sumado a los múltiples pactos que fueron adoptados en dicha década, como la Convención de los Derechos del Niño, favorecen que la infancia emerja como grupo poblacional relevante, que amerita una legislación y políticas particulares, acordes con las problemáticas y realidades que viven niños y niñas en el país.

Ahora bien, un tema se convierte en asunto de política pública cuando diversos actores construyen una visión compartida de reconocimiento del problema y este es incorporado a la agenda política. Para que un problema, entre tantos que existen en una sociedad, sea considerado materia de política pública, debe ser construido como 
cuestión pública, es decir, transformarse en un problema público. En efecto, las políticas públicas engloban el conjunto de procesos mediante los cuales las demandas sociales se transforman en opciones políticas y en decisiones públicas, gracias a la acción combinada de organizaciones, individuos situados estratégicamente y grupos que creen que pueden y debe hacerse algo y están en condiciones de promover la incorporación de su demanda en la agenda pública de problemas socialmente vigentes (Suárez, 1989). Así pues, podemos decir que la política pública es una herramienta que permite intervenir problemáticas sociales que afectan el bienestar de grupos sociales particulares.

Para facilitar la comprensión de las políticas públicas, autores como Meny y Thoenig (1992) propusieron el modelo del ciclo de política pública, en el que se presentan las políticas como fases secuenciales y ordenadas, tal como desde una mirada racional se esperaría que ocurriera. Desde este modelo se esperaría, entonces, que una vez se identifica una problemática social -ojalá relevante-, se procede con decidir las mejores opciones para resolverla, decisiones sobre las que se diseñan planes, programas y proyectos que puedan implementarse con esquemas de monitoreo y evaluación con el fin de contar con información que favorezca la solución de las problemáticas y la cualificación de la acción pública. Si bien es un modelo tentador para los diseñadores de política, y aún más para analistas, no es cierto que así suceda realmente, pues en cada una de las fases -que no se dan de manera ordenada y secuencial- existen tensiones, conflictos, confrontaciones de intereses e interpretaciones y disputas de recursos que ameritan lecturas amplias, complejas y demandantes por parte de los actores desde los diferentes niveles de planeación e implementación. A pesar de la advertencia anterior, resulta bastante útil usar las fases de ciclo analíticamente y comprender lo que sucede con determinadas problemáticas sociales asociadas a momentos determinados de una política.

Partiendo de lo anterior, uno de los aspectos más importantes del ciclo es la definición del problema. Los problemas de política no están dados, se construyen, hay que señalar los componentes cruciales del problema desde lógicas particulares, determinar hipótesis sobre sus causas y consecuencias y los aspectos sobre los que se deben centrar las acciones de Estado para su solución. Así, la construcción de un problema apuesta por una solución para entrar en una arena en la que se juegan otras posibles lecturas del problema y las maneras de tramitarlo.

Aguilar (2012) plantea que la política pública tiene dimensiones: una jurídica, que debe asegurar su legalidad mediante la compatibilidad con la Constitución Política y el cuerpo legislativo vigente; una segunda dimensión, que hace referencia a la economía, pues indica que la política pública debe respetar una racionalidad económica y finos análisis y cálculos de costo-eficacia de los recursos públicos; una dimensión organizacional, en la que es necesario identificar o desarrollar organizaciones gubernamentales, no gubernamentales o comunitarias para operativizar las acciones propuestas, y para esto es necesario conocer y contar con las estructuras y siste- 
mas que existen, su normatividad, distribución de la autoridad, división del trabajo, equipamiento tecnológico, cultura organizacional y sentido de la responsabilidad; de allí que sea fundamental analizar la estructura del Estado y la capacidad de sus organizaciones para asegurar el logro de la política. Y, por último, está la dimensión política, que hace referencia a que para evitar que una política sea automáticamente rechazada deber ser susceptible de obtener consenso, confianza y apoyo social.

Ahora bien, y ¿por qué los niños, niñas y adolescentes son políticamente prioritarios? El Departamento Nacional de Planeación, Ministerio de Educación Nacional, Ministerio de Protección Social e Instituto Colombiano de Bienestar Familiar (2007), indican que hasta hace poco los niños no eran sujetos de política, sino objetos de asistencia social. Darle la prioridad política que requiere la infancia se ha ido ganando con el tiempo con base en tres justificaciones: 1) ética, ya que el desarrollo y la protección de los niños nos dignifica como sociedad y garantiza nuestro desarrollo actual y futuro; 2) jurídica, dados los compromisos legales adquiridos en torno a la garantía de derechos de los niños y niñas y 3) política, ya que la acción del Estado se hace más efectiva, porque las inversiones con esta población son más benéficas para sentar bases de desarrollo y cambio social.

\section{Las políticas públicas para primera infancia en Colombia}

Como se planteó previamente, una de las dimensiones de la política pública es la jurídica, y esto implica que no solo se eviten acciones que van por fuera de los marcos legislativos avalados, sino que se responda a solicitudes expresas realizadas por la ley al ejecutivo del Estado. Un ejemplo de ello es lo indicado como esperado para la infancia colombiana por el Código de la Infancia y la Adolescencia, Ley 1098 de 2006, en el que se establece qué debe entenderse por políticas públicas de infancia y adolescencia, los principios rectores que deben guiar al Estado para garantizar la protección integral de sus derechos, y establece los responsables en el ámbito nacional, departamental y municipal, de movilizar las políticas de infancia y adolescencia en el país (Ver primer capítulo del tercer libro de la Ley).

Aun cuando el marco normativo para niñez y adolescencia en Colombia indica que las políticas públicas deben darse en coherencia con un enfoque de derechos y territorial, la tradición y las dinámicas propias de la política social en el país no lo han favorecido, revistiendo gran complejidad por la necesidad de implementar acciones integrales y articuladas a partir de sistemas fragmentados, inequitativos y sectorizados.

El país ha avanzado en documentos que presentan cada vez con mayor claridad las intenciones y orientaciones sobre la infancia, facilitando con ello la comprensión de complejidad y hasta cierto punto las tensiones y contradicciones a las que se enfrenta la puesta en marcha de acciones integrales, situadas y respetuosas con la diversidad. $\mathrm{Su}$ formulación puede detectarse en múltiples instrumentos de carácter oficial y, en otros casos, a partir de análisis derivados de las prácticas que se generan en di- 
ferentes niveles del territorio nacional, de allí la necesidad de contar con lecturas comprensivas, no lineales y abiertas a la complejidad de un mundo que no cuenta con únicas miradas y órdenes preestablecidos.

A pesar de rastrearse acciones institucionales intencionadas para la primera infancia en el país desde hace por lo menos 70 años, es desde la primera década del siglo XXI en la que se empiezan a gestar iniciativas para primera infancia de corte integral e interinstitucional; sin duda, estas propuestas han debido sortear dificultades como las planteadas en el aparte anterior.

Torrado, Gaitán, Bejarano y Torrado (2017), en el texto la política pública para la primera infancia frente a la desigualdad social en Colombia, señalan que aun cuando es posible identificar como logros de política para la primera infancia los CONPES 115 de 2008 y el 123 de 2009, en los que se definieron directrices para la destinación de recursos públicos para la atención integral en los diferentes niveles de gobierno, además de brindar claridades con respecto a la responsabilidad de las autoridades en la prestación de los servicios y sentar las bases para fortalecer acciones intersectoriales, continúa siendo un reto la autonomía en el diseño de las modalidades de atención y la descentralización de los servicios, la integración de programas nacionales que se implementan a nivel local y la articulación con las iniciativas comunitarias.

Con el fin de dar respuesta a parte de los retos identificados, Colombia ha generado diversas propuestas, entre las que se encuentra la estrategia nacional de atención integral De cero a Siempre, estrategia que orientó una serie de acciones planificadas de carácter nacional y territorial, dirigidas a promover y garantizar el desarrollo infantil desde la gestación hasta los cinco años. Las bondades de estas iniciativas han sido muchas, pero quisiéramos resaltan la promulgación de la ley 1804 de 2016 (Congreso de la República de Colombia, 2016), la cual garantiza en nuestro país un piso de exigibilidad con el que antes no se contaba.

La Ley 1804 de 2016 hace explícita la necesidad de políticas que garanticen el Desarrollo Integral de la Primera Infancia en el marco de la Doctrina de la Protección Integral, el fortalecimiento del marco institucional para el reconocimiento, garantía y protección de los derechos de niños, niñas y gestantes y el restablecimiento en caso de vulneración. Precisa la ley la necesidad de un trabajo intersectorial que articule acciones intencionadas y efectivas que aseguren en cada entorno las condiciones para la promoción y potenciación del desarrollo infantil, así mismo, la necesidad de atención "prioritaria" a quienes por diversas condiciones, debido a su cultura, pertenencia étnica, contexto, condiciones, dimensiones particulares o afectaciones transitorias, puedan estar en riesgo, como es el caso que expone este libro: la población afectada por el conflicto colombiano.

Con respecto a esto, la ley explicita que para la población a ser atendida de forma prioritaria con recursos oficiales de carácter nacional o local, se concertarán los esquemas de atención de las autoridades gubernamentales del orden nacional y lo- 
cal en los escenarios del Consejo de Política Social municipal y departamental, en consonancia con el análisis de situación de derechos y de servicios consignado en la Ruta Integral de Atenciones (RIA), esperando que con ello se puedan generar esquemas específicos de atención integral.

\section{Las políticas públicas para primera infancia y el conflicto colombiano}

Como se evidenció en los capítulos previos, las dinámicas del conflicto en Colombia han generado una serie de retos particulares para la atención de niños y niñas en sus primeros años y, claro está, para las políticas que la sustentan.

Desde hace más de diez años, un estudio realizado por la Organización de Estados Iberoamericanos y Save the Children (2009), en zonas afectadas por el conflicto armado colombiano, identificó la necesidad de que a nivel de política pública: 1) se incluyera el tema de primera infancia en los debates permanentes sobre conflicto armado colombiano, visibilizando estrategias explícitas para hacer seguimiento y monitoreo a su situación, 2) se fortaleciera la capacidad de las autoridades locales y de los programas de atención a la primera infancia, principalmente en zonas especialmente afectadas por el conflicto, generando acciones específicas para atender y prever los efectos en la vida de los niños y sus familias, 3) se diseñaran e implementaran programas con aval y financiación de los niveles departamental y municipal, y 4) se cualificaran los sistemas de seguimiento, monitoreo y control de las políticas destinadas a este fin.

Con respecto a las necesidades señaladas por la Organización de Estados Iberoamericanos y Save the Children (2009), los avances que ha realizado el país tanto a nivel legislativo como ejecutivo han sido limitado; sin embargo, se reconoce que los avances en las acciones de políticas para la primera infancia y la Ley 1804, han sentado las bases para el desarrollo de propuestas claras, intencionadas y de cada vez mayor especificidad, entre las que -sin duda- se deben encontrar las de cualificación del talento humano que trabaja con primera infancia.

Con base en lo anterior, en el resto del capítulo se presenta la propuesta de competencias construidas tomando como insumo principal la información brindada por los equipos de talento humano y los expertos que participaron en esta investigación, y que, a su vez, puede sentar bases para una propuesta de cualificación del talento humano que trabaja con primera infancia en todos los niveles del sistema, en lo relacionado con políticas públicas.

\section{La políticas públicas para la primera infancia afectada por el conflicto colombiano: diálogo en tre conceptos y evidencias}

Para incluir las opiniones y vivencias de los miembros de los equipos de talento humano en la tarea de definir las competencias sobre políticas públicas se utilizó la 
metodología de estudio de casos. Haciendo uso de ella, por grupos, los participantes expusieron el curso de atención de un caso con el cual hubiesen trabajado en su institución, usando para ello la metáfora denominada río del tiempo. Por medio de esta metáfora se profundizó en las herramientas y recursos disponibles a la llegada del caso a sus manos (nacimiento del río), los obstáculos de distinto tipo que debieron sortear durante la atención de este, así como los apoyos recibidos durante la atención (curso medio y afluentes), y las trasformaciones o el impacto que tuvieron sus acciones sobre las vidas de las personas con y para las que trabajaron en ese caso (desembocadura).

Por medio de esa estrategia se propició la reflexión sobre la relación entre políticas públicas, derechos y prestación de servicios para la atención, educación y cuidado de la primera infancia, así como propuestas de mejora a la actual política. Todo esto alrededor de tres categorías que se desarrollarán a continuación:

- Concepción de política pública.

- Integralidad de las políticas públicas para la primera infancia y prestación de servicios.

- Planificación y asignación de recursos.

\section{Competencias relacionadas con la concepción de política pública}

Las políticas públicas, como se empezó a exponer al inicio del capítulo, son medios provisionales que entremezclan y expresan tanto los ideales políticos trascendentales de los derechos humanos (libertad, igualdad, solidaridad, dignidad), como las posibilidades institucionales del momento (los medios organizacionales, la cultura y las costumbres), y los intereses individuales y colectivos de los grupos sociales y étnicos. Estas políticas también son la expresión del reconocimiento previo de una problemática social que se ha transformado en un problema político, al cual se responde mediante posibles soluciones que se construyen entre tensiones e intereses sociales, económicos y políticos (Roth, 2007).

Por lo anterior, las competencias de esta dimensión se centran en la concepción de política pública, entendida como la relación que se establece entre las personas que trabajan en el ámbito de primera infancia y las políticas públicas que han sido formuladas para la población con la que trabajan. Se entiende, además, que esta concepción se compone de la interpretación propia sobre lo que es una política pública en el contexto colombiano y los conocimientos, prácticas y valores en torno a las políticas y legislación vigente para primera infancia, familia y víctimas de conflicto.

De acuerdo con lo anterior, la concepción de política pública se centra en el sujeto (nivel individual), independientemente de si es quien presta los servicios, los gestiona, los administra o los crea y no se puede atribuir a una institución (nivel institucional), a las relaciones entre instituciones (nivel interinstitucional) o a la intervención del Estado (nivel gobernanza), sino a las personas que trabajan en cada uno de estos niveles del sistema. 
En el caso de los conocimientos sobre la legislación y políticas públicas vigentes para infancia, familia y víctimas de situaciones de conflicto, decimos que este conocimiento es parte de una competencia que se moldea según el nivel; así, por ejemplo, en el nivel individual otorga a los prestadores de servicios y con otros roles dentro de la atención, cuidado y educación para la primera infancia, una mirada amplia sobre la incidencia, alcance y responsabilidad de sus acciones, mientras que en el nivel de gobernanza, tener este conocimiento permite evaluar las políticas públicas vigentes dentro de estos marcos de política y legislación y/o crear planes, programas o estrategias que sean acordes con esas disposiciones.

En consecuencia, puesto que la concepción de política pública es una forma subjetiva e interpretativa de relación con las políticas públicas, la propuesta de competencias para esta categoría se centra en el nivel individual y pretendemos incluir en él las competencias de aquellas personas que están en contacto con las políticas públicas en todas sus fases: desde la planeación hasta la ejecución y evaluación; lo que además abarca al resto de niveles del sistema competente (institucional, interinstitucional y gobernanza). No obstante, también se realizó un esquema de competencias específico para el nivel de gobernanza, puesto que es un nivel de amplio peso en la gestación de las políticas públicas y, por lo tanto, creemos que vale la pena construir unas competencias propias a ese nivel.

\section{Nivel individual}

En los escenarios de educación inicial participan varias personas que desempeñan roles distintos; algunos están relacionados con la administración de los servicios (p. ej. coordinador, auxiliar administrativo), y otros son más cercanos a la atención directa de las niñas, niños y familias (p. ej. agente educativo, auxiliar pedagógico, profesional psicosocial, profesional de la salud).

No obstante, sin importar el tipo de rol, las personas que trabajan en escenarios de educación inicial pueden ser vistos como ejecutores de política pública, pues son quienes en última instancia materializan en su quehacer las disposiciones de las políticas públicas para la primera infancia. Además, debido a su práctica directa y diaria con los niños, familias y comunidad, tienen una visión privilegiada acerca de las fortalezas, debilidades y potencialidades de las acciones de política pública diseñadas para esta población, pudiendo ser así no solamente ejecutores de la política, sino también participantes activos en su construcción o mejora, y en este sentido cobra especial importancia la manera de entender la política pública.

De acuerdo con esto, fue posible evidenciar cómo los miembros de los equipos de talento humano reconocen varios aspectos claves que definen lo que son las políticas públicas, así, por ejemplo, señalan a estas como medios o herramientas gubernamentales para dar solución a las necesidades de la población y su materialización por medio de proyectos en cabeza del Estado; además, resaltan su papel en la garantía de derechos e identifican su función en la atención de problemáticas sociales específicas. Dos testimonios que están en la línea de lo anterior son los siguientes: 
"Es un conjunto de acciones articuladas por el estado, encaminadas a intervenir una situación o problema, las cuales son implementadas mediante proyectos, teniendo en cuenta el contexto o grupo poblacional”.

"Una política pública es una garantía (para) que se cumplan los derechos que tenemos como ciudadanos en cuanto a la salud, educación, etc.”.

Así mismo, como parte de la concepción de política pública, se destaca la necesidad de conocer sobre legislación y políticas públicas vigentes para la atención de la población menor de cinco años con el fin de enmarcar sus acciones dentro de estas disposiciones, pues los mismos miembros de los equipos de talento humano consideran que tener conocimiento en esta materia constituye un marco de referencia que garantiza atenciones de calidad; de ahí su importancia de estar familiarizados con ello, tal como lo dejan ver los siguientes testimonios:

"Es necesario tener conocimientos frente al conflicto en las diferentes zonas, así como en políticas públicas, rutas de atención y de desarrollo del posconflicto”.

“Es importante para así poder ofrecer un trabajo óptimo y de calidad”.

"Importante para que podamos tener mayor capacidad de análisis ante estos casos".

"Es importante tener los conocimientos para poder dar respuesta a algún caso que llegue al CDI para ser orientado”.

"Si nosotras como agentes educativas y tenemos estos conocimientos, los podemos transmitir a las familias beneficiarias del programa”.

Según lo anterior, las competencias propuestas para el nivel individual en la categoría de concepción de política pública son las siguientes:

Tabla 4.1. Competencias relacionadas con la concepción de política públicaNivel individual.

\section{Conocimientos}

Prácticas

Valores
- Conocimiento de las políticas públicas vigentes que inciden en la atención de la primera infancia y sus características (contradictorias, no lineales e incididas por la comprensión particular de las personas).

- Conocimiento de la legislación vigente sobre infancia y familia.

- Conocimiento sobre las disposiciones de la política pública local, regional y nacional en relación con la atención de víctimas del conflicto armado
- Actuar responsable y comprometidamente en cualquiera de los escenarios de política pública en los que se enmarquen sus prácticas profesionales.

- Enmarcar sus acciones en las disposiciones de la política pública vigente.

- Hacer acompañamiento a los beneficiarios en los procesos de atención que se inician dentro de la institución $\mathrm{y}$ en otras instituciones.
- Asumir con ética las acciones y gestiones que debe realizar en la fase de política pública en que se encuentre (identificación de problemas, formulación, decisión, implementación, evaluación). 


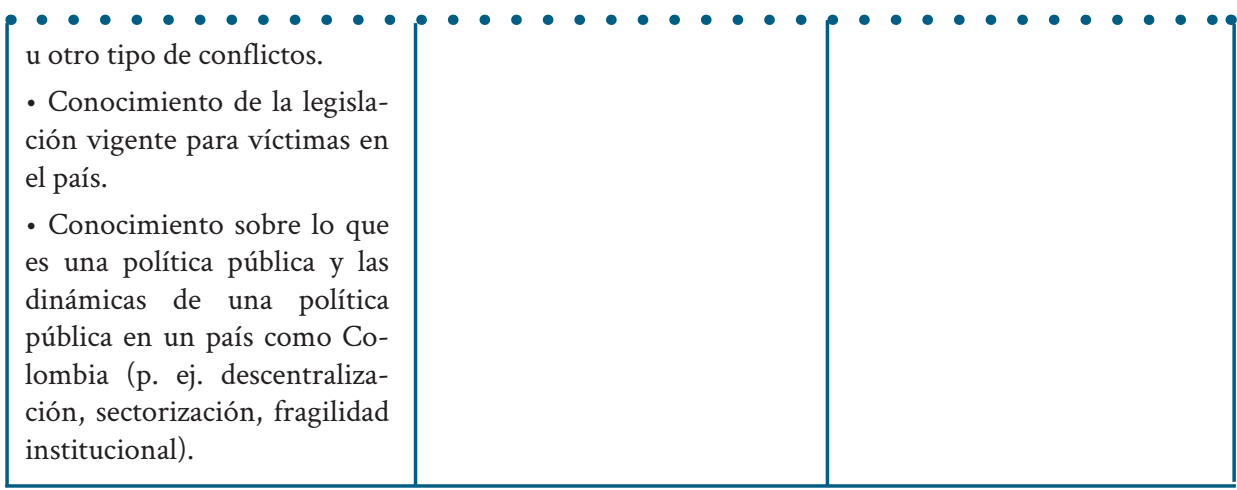

\section{Nivel de gobernanza}

Las concepciones que circulan en este nivel permiten identificar la necesidad de conocer en detalle las diferentes responsabilidades que se demarcan desde el legislativo y el ejecutivo entre el gobierno nacional, departamental y local y, además, reiteran los participantes, como ya lo han hecho otros autores (Durán y Torrado, 2017), las demandas que se tienen, sobre todo en términos prácticos, sobre la integralidad, la intersectorialidad y el trabajo interinstitucional.

También fue posible identificar una concepción arraigada frente a la forma en que se hacen las políticas nacionales, resaltando la tendencia a homogeneizar problemas y soluciones sin la consulta y participación adecuada de los territorios, lo que sin duda genera, a criterio de los participantes, soluciones ideales que demandan procesos de lucha por la creación de condiciones materiales que permitan el cumplimiento de tales ideales, lo que minimiza, o incluso lleva a la renuncia, a iniciativas locales y comunitarias que puedan tener mayor aceptación y potencial de transformación, sobre todo en temas relacionados con el conflicto colombiano.

La primera infancia vive hoy las contradicciones y tensiones naturales de establecer políticas para diferentes formas de ser, hacer y valorar en relación con los derechos de los niños, por lo tanto, hay una oportunidad latente de llevar la formulación de políticas y su implementación en el diálogo local y territorial; esto implica, necesariamente, que las políticas lleguen a ser estrategias concretas, situadas, y no descontextualizadas o con un alcance predominantemente técnico. La orientación política, que para algunos participantes es por ahora más una intención que una realidad, sobre la necesidad de acciones integrales e intersectoriales, con alianzas territoriales, abre una ventana de oportunidad, que sin duda no está exenta de debate y tensión, y para ello consideramos puede ser pertinente cualificar a los equipos frente a los siguientes conocimientos, prácticas y valores.

Con base en lo anterior, las competencias propuestas para el nivel de gobernanza en cuanto a concepción de política pública son las siguientes: 
Tabla 4.2. Competencias relacionadas con la concepción de política pública - Nivel de gobernanza.

\begin{tabular}{|c|c|c|}
\hline Conocimientos & Prácticas & Valores \\
\hline $\begin{array}{l}\text { - Conocimiento de la legisla- } \\
\text { ción vigente sobre infancia y } \\
\text { familia. } \\
\text { - Conocimiento de la legisla- } \\
\text { ción vigente para víctimas en } \\
\text { el país. } \\
\text { - Conocimientos sobre la si- } \\
\text { tuación de garantía de dere- } \\
\text { chos de población infantil y el } \\
\text { estado de la prestación de ser- } \\
\text { vicios para la garantía de sus } \\
\text { derechos. } \\
\text { - Conocimientos sobre la si- } \\
\text { tuación de garantía y repara- } \\
\text { ción de derechos de población } \\
\text { víctima del conflicto. } \\
\text { - Conocimiento de las acciones } \\
\text { que se puede gestionar en el } \\
\text { marco de las políticas públicas } \\
\text { vigentes y aquellas que se de- } \\
\text { ben gestionar. } \\
\text { - Conocimientos del Estado, el } \\
\text { Gobierno y de administración } \\
\text { pública. } \\
\text { - Conocimientos sobre inci- } \\
\text { dencia política - advocacy. }\end{array}$ & $\begin{array}{l}\text { - Identificar necesidades social- } \\
\text { mente relevantes de la primera } \\
\text { infancia y población víctima de } \\
\text { conflictos que ameriten accio- } \\
\text { nes de política pública. } \\
\text { - "Construir" problemas que } \\
\text { afecten a la garantía de los de- } \\
\text { rechos de la primera infancia y } \\
\text { población víctima de conflictos, } \\
\text { que sean susceptibles de poner- } \\
\text { se en agenda para debates de } \\
\text { política pública. } \\
\text { - Analizar roles y responsa- } \\
\text { bilidades institucionales para } \\
\text { promover acciones integrales y } \\
\text { viables de implementación para } \\
\text { la garantía de los derechos de la } \\
\text { primera infancia y la población } \\
\text { víctima de conflictos. } \\
\text { - Evaluar las propuestas que } \\
\text { son susceptibles de convertirse } \\
\text { en acciones de política pública } \\
\text { para la primera infancia o po- } \\
\text { blación víctima de conflictos. }\end{array}$ & $\begin{array}{l}\text { - Velar por políticas de pri- } \\
\text { mera infancia y población } \\
\text { víctima de conflictos que res- } \\
\text { pondan coherentemente a los } \\
\text { postulados de la Constitución } \\
\text { Política de Colombia (Estado } \\
\text { Democrático, descentralizado } \\
\text { y Social de Derecho). }\end{array}$ \\
\hline
\end{tabular}

\section{La integralidad de las políticas públicas para la primera infan- cia y la prestación de servicios}

La integralidad puede ser entendida como una característica deseable de las políticas públicas para la primera infancia, pues tiene que ver con la capacidad de las mismas para garantizar la realización de todos los derechos de los niños y niñas entre los 0 y 5 años. Implica que la realización plena de un derecho dependa de la realización de los demás derechos, la adopción de medidas de protección integral para ellos y la prestación de servicios integrales durante la atención (Durán, 2017).

Esta concepción integral de las políticas públicas es contraria a la arquitectura institucional sectorial que caracteriza nuestro país para la garantía de derechos, puesto que propende por la integración de sectores, agentes, planes y programas en torno a un objetivo común (Molina, Torres y Moromizato, 2013), y de base adopta un enfoque de derechos, ya que concibe la atención a la primera infancia como un asunto de inclusión social y equidad, y no desde la postura de contención social o caridad (Durán, 2017). 
En el país, la actual Política de Estado para el Desarrollo Integral de la Primera Infancia de Cero a Siempre es quizás la apuesta más grande que se ha hecho en los últimos años en materia de atención a esta población, y fue construida bajo esta concepción de integralidad (Congreso de la República de Colombia, 2016). Con este panorama como antesala, a continuación se analiza por nivel el conjunto de competencias propuesto que está relacionado con la integralidad de las políticas públicas para la primera infancia y la prestación de servicios.

\section{Nivel individual}

Derivados de los testimonios de los participantes de la investigación, en el nivel individual las competencias propuestas se construyeron en torno a tres aspectos centrales que tienen que ver con la realización de prácticas conjuntas entre los miembros del equipo de atención de la institución según las necesidades de los niños, niñas y familias, la actuación en el marco de rutas de atención establecidas y la gestión activa de los miembros del equipo ante dificultades en el proceso de atención.

Sobre el primer aspecto, los participantes señalan que su trabajo se enmarca en acciones interdisciplinarias, es decir, que la atención no se realiza de forma aislada, sino contando con el apoyo del resto del equipo de acuerdo con las particularidades de cada caso. Así, las experiencias relatadas indican que el proceso de atención de (o para) las madres gestantes, madres, niños y niñas implica la participación de un equipo pedagógico, un equipo psicosocial y un equipo nutricional como realizadores principales de la atención. De esta manera, las maestras y auxiliares pedagógicas llevan a cabo visitas familiares y sesiones educativas grupales en las que se abordan temas relacionados con el cuidado, la crianza y el desarrollo infantil. Los profesionales de apoyo psicosocial brindan orientación, especialmente a las madres, y el equipo de nutrición y de salud vela por el adecuado estado nutricional y físico de madres gestantes, niñas y niños.

Acerca del segundo aspecto, este se refiere a la activación de rutas de atención tendientes a la gestión de servicios a cargo de otras instituciones. Esta activación consiste en la derivación de los usuarios a estos servicios, e incluye el seguimiento al proceso que cada uno lleva dentro de ellos. Algunas de las rutas mencionadas fueron las siguientes: ruta para trámite de documentos de identificación, ruta para la atención de casos de violencia intrafamiliar, ruta para el acceso a servicios de salud y ruta para el direccionamiento de servicios de salud.

Por su parte, en el tercer aspecto, varias experiencias relatadas indican que los miembros del equipo de atención no únicamente activan las rutas de atención, sino que realizan acompañamiento de los casos y gestión con funcionarios de otras instituciones para lograr el acceso efectivo de los usuarios a los servicios que requieren en el momento, es decir, se propende por una atención oportuna.

De esta manera, se considera que las competencias que deben promoverse con el talento humano en este nivel son las siguientes: 
Tabla 4.3. Competencias relacionadas con la integralidad de las politicas públicas para la primera infancia y la prestación de servicios - Nivel individual.

\begin{tabular}{|c|c|c|}
\hline Conocimientos & Prácticas & Valores \\
\hline $\begin{array}{l}\text { - Conocimiento de los ser- } \\
\text { vicios a los que pueden acce- } \\
\text { der los usuarios dentro de su } \\
\text { institución y en otras insti- } \\
\text { tuciones afines, así como los } \\
\text { medios para acceder a todos } \\
\text { estos servicios. } \\
\text { - Conocimiento sobre los } \\
\text { roles y responsabilidades de } \\
\text { cada uno de los actores y los } \\
\text { procesos de direccionamien- } \\
\text { to a otras modalidades de su } \\
\text { institución y en otras institu- } \\
\text { ciones para complementar la } \\
\text { atención. } \\
\text { - Conocimiento de las rutas } \\
\text { establecidas para la atención } \\
\text { integral, la manera de acti- } \\
\text { varlas y los procesos que se } \\
\text { deben seguir. }\end{array}$ & $\begin{array}{l}\text { - Prestar los servicios corres- } \\
\text { pondientes a su rol, teniendo } \\
\text { en cuenta las particularidades } \\
\text { de cada caso (p. ej. necesidades, } \\
\text { fortalezas, debilidades, recur- } \\
\text { sos disponibles). } \\
\text { - Resolver los problemas que } \\
\text { surgen durante la prestación } \\
\text { del servicio y la gestión inte- } \\
\text { rinstitucional que entorpecen } \\
\text { la garantía de derechos de ni- } \\
\text { ños, niñas y familias. } \\
\text { - Acordar planes interdiscipli- } \\
\text { narios con los otros miembros } \\
\text { del equipo de atención (maes- } \\
\text { tra, auxiliar pedagógica, profe- } \\
\text { sional psicosocial, profesional } \\
\text { de la salud), en los que se defi- } \\
\text { na el papel de cada uno ante un } \\
\text { caso en cuestión. } \\
\text { - Prestar los servicios corres- } \\
\text { pondientes a su rol, teniendo } \\
\text { en cuenta los objetivos globa- } \\
\text { les de atención definidos por el } \\
\text { equipo interdisciplinario. } \\
\text { - Activar, gestionar, mejorar } \\
\text { y/o participar en la construc- } \\
\text { ción de rutas (en caso que no } \\
\text { existan) que favorezcan el ac- } \\
\text { ceso de los beneficiarios a los } \\
\text { servicios que se requieran con } \\
\text { otras instituciones (p. ej. a tra- } \\
\text { vés de la ruta adecuada, en los } \\
\text { tiempos y bajo los criterios de } \\
\text { la institución a la que se le de- } \\
\text { manda el servicio). }\end{array}$ & $\begin{array}{l}\text { - Comprometerse con la } \\
\text { prestación de servicios opor- } \\
\text { tunos que sean ofertados, } \\
\text { teniendo en cuenta las parti- } \\
\text { cularidades de cada caso (cul- } \\
\text { tura de servicio). } \\
\text { - Fomentar el trabajo colabo- } \\
\text { rativo interdisciplinar en el } \\
\text { manejo de los casos durante } \\
\text { el proceso de atención. } \\
\text { - Buscar siempre la interac- } \\
\text { ción adecuada entre los ser- } \\
\text { vicios prestados por las dis- } \\
\text { tintas instituciones. }\end{array}$ \\
\hline
\end{tabular}

\section{Nivel institucional}

En este nivel se identificó, además de la necesidad de habilidades de gestión interinstitucional, el papel de las instituciones en la priorización de acciones para poblaciones en condiciones de vulnerabilidad, así como en el fomento de la corresponsabilidad en la garantía de derechos de los niños, niñas y familias.

En este sentido, los aportes de los participantes que orientaron las competencias 
configuradas para este nivel, en cuanto a integralidad de las políticas públicas para la primera infancia y la prestación de servicios, resaltan la necesidad de que las instituciones a las que pertenecen los equipos de atención mantengan y establezcan alianzas con otras instituciones que les permitan dar un mayor alcance a sus prácticas.

“(...) que se evidenciaran más las instituciones, que nos dieran a conocer qué otras redes de apoyo dentro de la localidad y pues fuera de la localidad como para también orientar esas familias".

Por otro lado, otros aportes que aplican para el nivel institucional del sistema indican la importancia de concientizar a las familias de su papel activo en la garantía de los derechos de los niños desde el abordaje del núcleo familiar o de cuidado.

“(...) porque ¿qué es lo que busca nuestro programa? fortalecer a las familias, brindarles herramientas para que sean ellas mismas quienes a partir de las herramientas que nosotros les brindamos, ellas sean quienes solucionen sus conflictos y sean capaces de salir adelante por sí solas, eso es lo que buscamos como modalidad".

"Lo que decíamos acá, este programa debería medirse por una superación de necesidades, porque también entramos a una zona de confort de que "allá me dan entonces tengo 1, 2, 3 y voy y los vinculo y son desplazados", que hay una zona de confort donde yo ya tengo la posibilidad, tengo conocimiento previo, sé las rutas de atención, sé por dónde generar ingresos dentro de mi familia, es cómo la superación de necesidades nos hace cambiar esa mentalidad jsí? Si yo ya tengo un ingreso, ya tengo un trabajo "démosle la oportunidad a otra persona que en realidad está empezando y lo necesita”, pero a veces vemos a mamás que tienen un bebé, luego tienen otro bebé... Ahorita no tenemos niños de dos años, entonces papás furiosos "que vamos a demandar, que ICBF nos está quitando los derechos", pero también es cómo hacerle entender a la familia que su niño ya terminó un proceso en este medio familiar y necesita otro proceso".

"(Un obstáculo para la atención) es la falta de voluntad, no todas (las madres) tienen disposición con ciertas cosas: compromiso. Puede que la mamá lo necesite mucho, pero si ya es falta de voluntad, ya sea madrugar para recibir la sesión o recibirnos en el encuentro familiar, eso sería un obstáculo".

De igual forma, se identificó un rol crucial de las instituciones en la priorización de servicios para los participantes que se enfrentan a vulneración de derechos o están en riesgo de ello. Un ejemplo recurrente fue la priorización de la atención para migrantes venezolanos y de niños y niñas expuestos a situaciones de riesgo como el maltrato intrafamiliar. Situaciones que configuran un foco de conflictos distinto al de las situaciones propias del conflicto armado y que ahora parecen ser más frecuentes en los escenarios de educación inicial, según los relatos de los participantes. Algunos de los testimonios que reflejan estas situaciones son los siguientes:

"Priorizar la legalización de documentos (de identificación), priorizando la atención de la salud, porque ahí sí es bastante demorado el proceso de esta ruta, donde Planeación (Distrital) les hace una visita, luego viene el cargue del puntaje, después la legalización del puntaje para adquirir un servicio de salud totalmente gratuito de parte del Estado (...) porque un niño con riesgo de desnutrición que le salga la salud en 3, 4 meses, no, por eso pasan casos terribles en los que se mueren los niños por falta de atención (...) y más cuando estamos hablando de ser garantes de los derechos de la primera infancia”.

"A veces hay, como son personas desplazadas que vienen de otro lado, problema para que les activen acá (en Bogotá) la salud, no hay esa prioridad que tanto dicen para mujeres embaraza- 
das o niños menores, no la hay, el proceso es muy demorado".

“(...) cuando se ve la vulneración de derechos, principalmente cuando son los niños ahí sí se activa la ruta, o sea se hace un denuncio anónimo o se hace un llamado de atención a la familia, digamos acá también el psicólogo tiene el tiempo de escucha, que digamos no solo se activan las rutas para maltrato, sino hay diferentes situaciones en las que se pueden activar las rutas (...) igual cuando hay vulneración de derechos, cuando el niño no tiene EPS, que no hayan controles de crecimiento y desarrollo, (...) cuando no lo registran rápido, todo ese tipo, es más que todo cuando hay vulneración de derechos que se activan las rutas de atención (...) Las nutricionistas también hacen un reporte a ICBF y a la EPS cuando el niño está en desnutrición".

Tomando en cuenta lo anterior, para este nivel las competencias que deben promoverse son:

Tabla 4.4. Competencias relacionadas con la integralidad de las politicas públicas para la primera infancia y la prestación de servicios - Nivel institucional.

Conocimientos

- Conocimiento de las acciones que se puede gestionar en el marco de las políticas públicas vigentes y aquellas que se deben gestionar.

- Conocimiento de las instituciones que hacen parte de la red de atención integral, sus roles y responsabilidades (por ley, por política pública).

- Conocimiento de los servicios que oferta cada institución y las rutas de acceso a los mismos, para toda la población y los que se ofertan de manera exclusiva para población en situación de vulnerabilidad.

- Conocimiento de los principios de garantía y corresponsabilidad del enfoque de Derechos.
- Priorizar acciones pertinentes para la atención de población en condiciones de vulnerabilidad y víctimas de conflictos.

- Incorporar instrumentos de caracterización de los niños y sus familias en lo relacionado con el nivel de afectación que han tenido a raíz del conflicto armado u otro tipo de conflictos para brindarles atención diferencial.

- Dar solución oportuna a problemas derivados de la atención dentro de la propia institución y aquellos inherentes a la gestión interinstitucional.

- Garantizar el cumplimiento de las acciones estipuladas por ley y las políticas públicas, asegurando la prestación de los servicios, la infraestructura, el personal y recursos necesarios para responder de manera coherente con dichos compromisos.

- Incorporar estrategias tendientes a concientizar a las familias sobre su rol ac-
- Adoptar un enfoque integral de atención que incluya acciones sobre los niños, sus padres, cuidadores y/o acudientes (cuando sea necesario), con el fin de asegurar condiciones óptimas de desarrollo del niño por medio del bienestar de todo su núcleo familiar o de cuidado.

- Comprender que uno de los fines de la atención integral es promover la garantía plena de derechos de la primera infancia por parte del Estado y la corresponsabilidad de las partes, entre ellas la familia o cuidadores.

- Velar por que los participantes de los servicios comprendan sus derechos y los mecanismos de garantía y exigibilidad. 


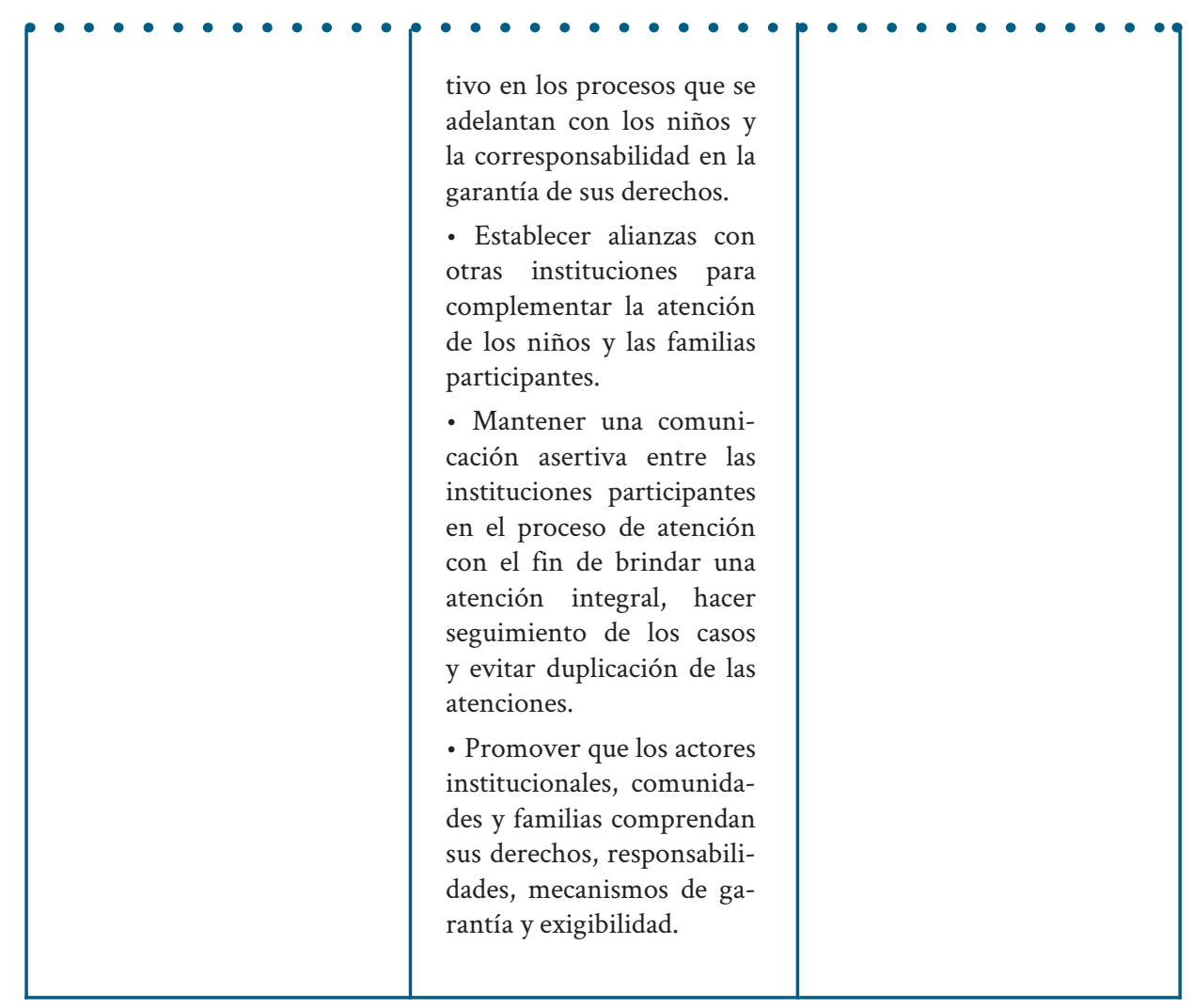

\section{Nivel interinstitucional}

En el ámbito interinstitucional se identificaron competencias relacionadas con el funcionamiento en red del conjunto de instituciones que tienen responsabilidad directa en el trabajo con la primera infancia: entidades de salud, educación, recreación y cultura, principalmente, y también las competencias que permiten la integración de sectores para alcanzar objetivos compartidos.

De este nivel se destacan las competencias relacionadas con la coordinación de acciones en las que participan estas entidades/instituciones de distintos sectores y que tienen que ver con la gestión y trabajo cooperativo entre ellas. Este trabajo cooperativo y no competitivo se prioriza en las relaciones interinstitucionales, puesto que asegura, entre otras cosas, la toma de liderazgo y trabajo mancomunado en temas relevantes para más de una entidad/institución, la optimización de los procesos de focalización de la atención y la no duplicación de acciones o servicios similares en la población (Durán, 2017).

Las competencias construidas para este nivel en relación con integralidad de las políticas públicas y prestación de servicios son las siguientes. 
Tabla 4.5. Competencias relacionadas con la integralidad de las políticas públicas para la primera infancia y la prestación de servicios - Nivel interinstitucional.

\begin{tabular}{|c|c|c|}
\hline Conocimientos & Prácticas & Valores \\
\hline $\begin{array}{l}\text { - Conocimiento sobre cómo } \\
\text { realizar gestión interinstitu- } \\
\text { cional y planes de acción para } \\
\text { la promoción de la primera } \\
\text { infancia. } \\
\text { - Conocimiento sobre nego- } \\
\text { ciación y manejo de conflic- } \\
\text { tos que puedan suscitarse por } \\
\text { las dinámicas institucionales. } \\
\text { - Conocimientos del Estado, } \\
\text { el gobierno y de administra- } \\
\text { ción pública. }\end{array}$ & $\begin{array}{l}\text { - Disponer ámbitos o escena- } \\
\text { rios que favorezcan el diálogo } \\
\text { y la puesta en marcha de ac- } \\
\text { ciones interinstitucionales (p. } \\
\text { ej. alianzas del tercer sector, } \\
\text { CPS, mesas intersectoriales). } \\
\text { - Atender con prontitud, y de } \\
\text { manera sistémica, a las difi- } \\
\text { cultades que se presentan en } \\
\text { la atención integral por fallos } \\
\text { propios de los esquemas de } \\
\text { atención sectorial y la foca- } \\
\text { lización para el acceso a los } \\
\text { recursos. } \\
\text { - Resolver los problemas de } \\
\text { manera estructural, haciendo } \\
\text { las gestiones que sean nece- } \\
\text { sarias para movilizar recursos } \\
\text { que desbordan la capacidad } \\
\text { institucional } \\
\text { - Priorizar acciones perti- } \\
\text { nentes para la atención de } \\
\text { población en condiciones de } \\
\text { vulnerabilidad y víctimas de } \\
\text { conflictos. }\end{array}$ & $\begin{array}{l}\text { - Garantizar la resolución de } \\
\text { problemas derivados de las } \\
\text { lógicas sectoriales ante las de- } \\
\text { mandas de atención integral } \\
\text { que requiere la población in- } \\
\text { fantil, sus familias y las vícti- } \\
\text { mas de conflictos. }\end{array}$ \\
\hline
\end{tabular}

\section{Nivel gobernanza}

Las competencias de este nivel están estrechamente relacionadas con las funciones estipuladas para los distintos sectores que integran la Comisión Intersectorial de Primera Infancia (CIPI; Departamento Administrativo de la Presidencia de la República, 2011) en relación con la implementación, monitoreo y evaluación de las acciones de política pública para esta población.

No obstante, se intentó rescatar, en clave de competencias (conocimientos, prácticas y valores), las percepciones de los miembros de los equipos de talento humano participantes en la investigación.

De este modo, se destaca la opinión bastante recurrente acerca de las estrategias de seguimiento a los programas que actualmente realizan las entidades a cargo, pues muchas de las personas entrevistadas tienen la percepción de que los formatos administrativos por medio de los que se hace control y seguimiento afectan la calidad de la labor de servicio con los usuarios, puesto que restan tiempo efectivo de atención 
con los niños, niñas y familias y promueven una lógica cuantitativa que sesga los resultados de impacto y calidad de los programas a los datos numéricos de cobertura.

De ahí que se sugiriera, entre otras competencias, para el nivel de gobernanza lo siguiente: optimizar los recursos de seguimiento y evaluación para minimizar la sobrecarga administrativa para los agentes educativos, así como la integralidad de actores/prácticas (cualitativas/cuantitativas) y concepciones de la calidad de los programas en aras de la garantía de los derechos de la población infantil, y aquella que ha sido víctima del conflicto.

Algunos de los aportes de los participantes que están en la línea de lo anterior son los siguientes:

"una falencia que se ve es que hay mucha papelería, el trabajo se evalúa en papelería y a veces por hacer papelería de pronto uno tiene las ideas, pero no se pueden ejecutar porque no queda tiempo, entonces aquí no hay esa presencia de ver qué se está haciendo sino solo con papel y eso es lo que da cuenta del trabajo, entonces un cambio que nosotros opinamos sería eso, como cambiar los métodos de auditoría, de revisión, para llevar mejor las acciones, tener más acciones porque a veces no queda el tiempo, es solo escribir, escribir, escribir, entonces es como eso, nos evalúan es con la cantidad de papeles que entregamos".

"Yo digo que nosotros, las entidades, perpetuamos el asistencialismo con la burocracia, cuando a uno le piden pasar un informe o lo que sea, primero es la cantidad y después la calidad, el problema es que al sistema le importa más la burocracia que la calidad y eso lo lleva a uno corriendo, porque si usted sabe que usted tiene qué hacer, tiene el taller regio, pero tiene que hacer tanto, tanto, tanto ¿qué escoge? Así somos todos por el sistema y creo que es la primera falla, por eso perpetuamos el asistencialismo, porque vienen las mamás y uno es: no se les olvide firmar, la firma, la firma; es así".

De esta manera, el esquema de competencias en esta categoría para el nivel de gobernanza es el que se presenta enseguida.

Tabla 4.6. Competencias relacionadas con la integralidad de las politicas públicas para la primera infancia y la prestación de servicios - Nivel de gobernanza.

\begin{tabular}{|c|c|c|}
\hline Conocimientos & Prácticas & Valores \\
\hline $\begin{array}{l}\text { - Conocimiento de los prin- } \\
\text { cipios de garantía y corres- } \\
\text { ponsabilidad del enfoque de } \\
\text { derechos. } \\
\text { - Conocimiento de los roles y } \\
\text { responsabilidad de cada nivel } \\
\text { de gobierno. } \\
\text { - Conocimiento de los instru- } \\
\text { mentos de evaluación, moni- } \\
\text { toreo y seguimiento que debe } \\
\text { realizar el nivel nacional para } \\
\text { verificación de cumplimiento } \\
\text { de ley y políticas. }\end{array}$ & $\begin{array}{l}\text { - Formular acciones de go- } \\
\text { bierno que, sin dejar de lado la } \\
\text { garantía de los derechos de la } \\
\text { población infantil en general, } \\
\text { y aquella que ha sido víctima } \\
\text { de conflictos, promuevan la } \\
\text { corresponsabilidad de familias, } \\
\text { cuidadores y comunidad. } \\
\text { - Verificar la inclusión de los } \\
\text { temas de infancia y población } \\
\text { víctima del conflicto en los di- } \\
\text { ferentes instrumentos de polí- } \\
\text { tica en el nivel departamental, }\end{array}$ & $\begin{array}{l}\text { - Fomentar la corresponsabili- } \\
\text { dad de la garantía de los dere- } \\
\text { chos de los niños, con enfoque } \\
\text { diferencial. } \\
\text { - Exigir que los gobiernos } \\
\text { locales implementan las ac- } \\
\text { ciones que se exigen para in- } \\
\text { fancia y población víctima del } \\
\text { conflicto. } \\
\text { - Adoptar una visión sistémica } \\
\text { (multifactorial) de la calidad } \\
\text { de los programas en aras de la } \\
\text { garantía de los derechos de la }\end{array}$ \\
\hline
\end{tabular}




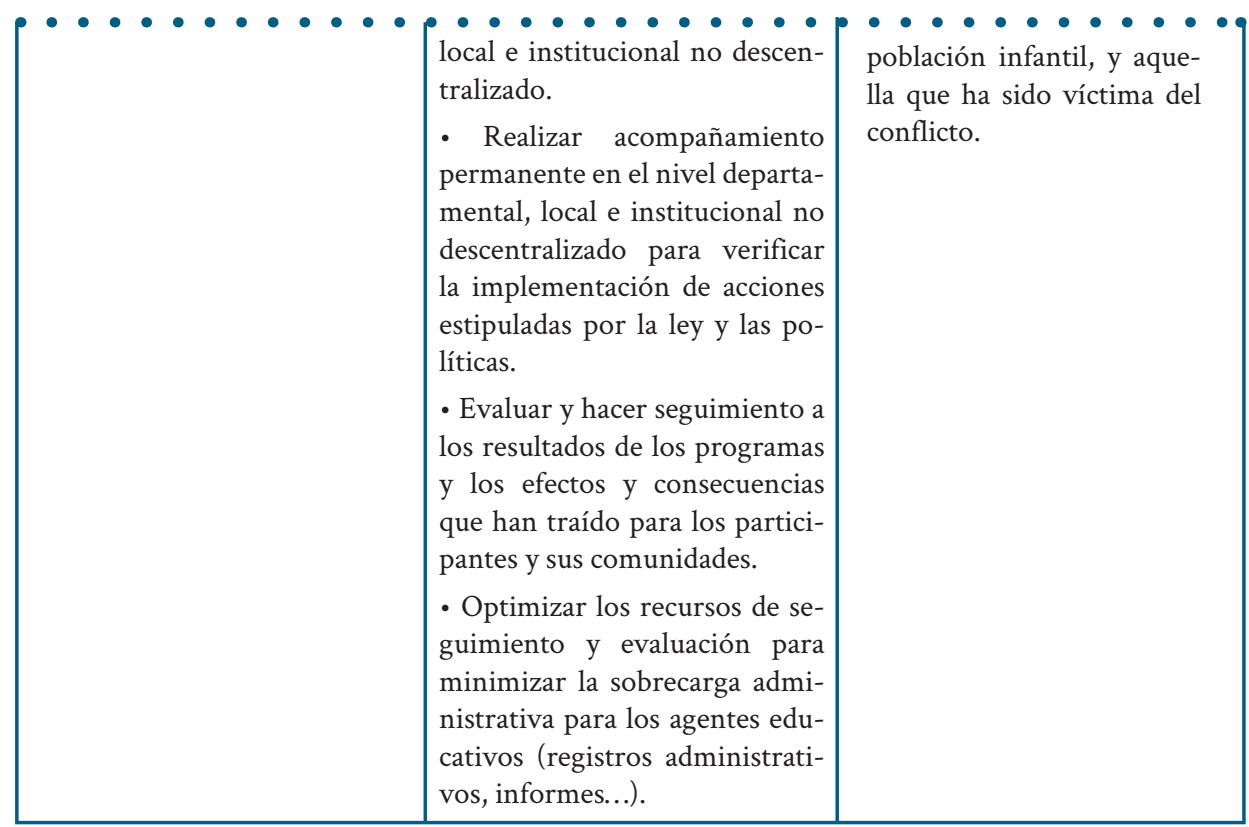

\section{La planeación de políticas y asignación de recursos}

Con respecto a esta categoría, es importante señalar lo expuesto por UNICEF (2018), frente a los presupuestos para la niñez. Indica la agencia que la Convención sobre los Derechos del Niño en su artículo 4 explicita que, para dar cumplimiento efectivo a los derechos, los Estados deben ejecutar todas las medidas administrativas y legislativas necesarias, adoptando medidas hasta el máximo de los recursos de que dispongan; y agrega en la Observación General $N^{\circ} 19$, que esto implica un cambio en la forma en que dichos Estados planifican, ejecutan y supervisan los presupuestos a favor de este grupo poblacional. En Colombia muchos son los retos, no solo por la ampliación y sostenibilidad de partidas presupuestales para la infancia, sino también por el monitoreo y seguimiento que se hace a las ya destinadas, combatiendo de manera contundente la corrupción y malversación de recursos.

Tal como se presentó al comienzo del texto, la Ley 1804 señala que el Gobierno nacional debe proyectar y garantizar los recursos para la implementación de la política para la Primera Infancia, con base en las metas de cobertura y gestión que se definan en el marco de la Comisión Intersectorial para la Atención Integral de la Primera Infancia, además del presupuesto que deben destinar para este fin las entidades del orden nacional y territorial para la atención integral. Exige la ley que se deben reglamentar los esquemas de financiación y cofinanciación entre la Nación y el territorio, además de una gestión intencionada de fuentes financieras complementarias a los recursos de la Nación.

Señala Garnier (2000), que el presupuesto es una herramienta fundamental para que el gobierno destine los recursos necesarios para poner en marcha los compromisos 
derivados de las políticas públicas, y para esto se hace indispensable articular procesos de planificación y lecturas detalladas de presupuesto.

Comprender un presupuesto es de vital importancia, ya que permite identificar las prioridades de política y cómo el gobierno redistribuye los recursos que toma de la sociedad. Ahora, no es solo saber leer presupuestos y conocer la forma en que se estructuran, es conocer los mecanismos a partir de los cuales se organizó la planificación que le sustentan, cómo se definieron los montos y su destinación y cómo hacer ajustes en caso de que los mismos no se adecuen consistentemente a las necesidades identificadas en los territorios e instituciones.

La construcción de un presupuesto conlleva a un proceso de alta complejidad, ya que implica contar con conocimiento amplio de los recursos con los que se cuenta, que vale la pena aclarar, no solo son económicos, sino, además, los compromisos legales y de política que de base ya puedan tener estos recursos, así como las distintas necesidades y expectativas que las instituciones y beneficiarios tengan con dichos recursos. En palabras de Aguilar (2006) implica entonces tener en consideración las dimensiones jurídicas, economía, organizacional y política de las políticas públicas.

Hablar de presupuesto lleva al concepto de planeación, que al menos desde la lógica con la que se planifica en Colombia, es entendido como un proceso racional que exige decidir cómo, con qué y con quién hacer frente a una situación o problemática, teniendo que elegir entre múltiples opciones aquellas que sean compatibles con los medios disponibles.

Siguiendo a Roth (2018), la planeación viene de una tradición racional que gira en torno a los mecanismos para tomar decisiones eficientes y eficaces, reduciendo al máximo la incertidumbre. Sin duda, no es la única manera de planear, pero esta es la opción con la que actualmente trabajan la mayoría de los Estados, incluido Colombia, y que resulta de alta relevancia para la comprensión de cómo activar un sistema de atención competente con base en las estructuras de acción del Estado que lo contiene. A pesar de dificultades como la incapacidad de integrar nuevos elementos, la planificación también goza de bondades como su apoyo en la toma de decisiones; la reducción de la incertidumbre puede minimizar la incoherencia en la acción pública, favorece la identificación de contradicciones, ayuda a cotejar la capacidad real y presupuestal frente a las múltiples demandas, aumenta la capacidad de prospección y hace transparente el proceso de seguimiento de la acción estatal a partir de la generación de información, sistemas e indicadores.

Para que un sistema de atención a la primera infancia sea competente es indispensable que en sus distintos niveles se puedan garantizar conocimientos, prácticas y valores frente a la planeación, así como en el presupuesto, sobre todo por la complejidad del trabajo con población afectada por distintos tipos de conflicto, entre ellos el armado.

Una parte importante de las dificultades con las que se enfrente la política de pri- 
mera infancia se debe a estos temas, de allí la urgencia de reflexionar sobre las necesidades de cualificación de talento humano en los diferentes niveles del sistema. A continuación, presentamos la propuesta construida con base en los aportes brindados por los integrantes de los equipos de talento humano frente a las necesidades de conocimientos, prácticas y valores en torno a la categoría de planeación y asignación de recursos.

\section{Nivel individual}

A partir del trabajo con los equipos de talento humano, pero también con los expertos que acompañaron el proceso de validación de las competencias, pudimos identificar que aun cuando los equipos del talento humano conocen las necesidades de la población con la que trabajan y son conscientes de las dificultades con las que se pueden encontrar al trabajar con ellos con la calidad requerida, por falta de recursos, algunos de ellos económicos, no era del todo claro para los equipos cómo se pueden gestionar nuevos recursos institucionales, gubernamentales, privados o incluso internacionales. En otras palabras, es claro que los recursos son escasos para las necesidades identificadas con la población atendida, pero no se cuenta en todas las instancias con los conocimientos ni prácticas para conseguir nuevos recursos, hacer lecturas amplias para identificar en dónde pueden estar los cuellos de botella para hacer las solicitudes de reasignaciones presupuestales y ajustes a las actividades que las sustentan, o las herramientas de incidencia para solicitar ajustes reales en la planeación o el presupuesto.

Si bien es claro que a nivel individual son distintos los roles y responsabilidades que tienen los diferentes integrantes de los equipos del talento humano, en términos generales todos podrían desarrollar competencias que les permitan hacer lecturas comprensivas de los recursos con los que se cuentan, los criterios con los que se distribuyen frente a las necesidades identificadas, los compromisos a los que pueden estar atados parte de dichos recursos y las formas con los que se podrían activar o liberar los recursos humanos, comunitarios, financieros o físicos con los que se cuenta o los que se puede contar. Más abajo, algunos testimonios de los participantes que apoyan lo anterior:

\footnotetext{
"Hace poquito abrieron los jardines y se ven perjudicados una cantidad de niños y es por eso, ¿por qué no está el presupuesto?”.

"Hay un momento donde dicen que es sostenible, eso es también lo que hay que mirar, de pronto estos programas así del Estado, ellos tienen que tener un presupuesto, yo me imagino que ellos ya deben tener el presupuesto para el próximo año. Y algo que no pasa por ejemplo a nivel distrital, por ejemplo, los de Integración, que ellos cuando se acaba el presupuesto pues tienen que parar todo, paran jardines, cierran jardines porque no hay la nueva contratación o el nuevo presupuesto, entonces acá habla que tienen que ser sostenibles".
}

Consideramos, entonces, que las competencias que pueden trabajarse en los esquemas de cualificación del talento humano a nivel individual sobre presupuestos son: 
Tabla 4.7. Competencias relacionadas con la planeación de políticas y asignación de recursosNivel individual.

\begin{tabular}{|c|c|c|}
\hline Conocimientos & Prácticas & Valores \\
\hline $\begin{array}{l}\text { - Conocimientos básicos } \\
\text { para la construcción de pre- } \\
\text { supuestos participativos que } \\
\text { respondan a las necesidades e } \\
\text { intereses de las comunidades y } \\
\text { los territorios, específicamen- } \\
\text { te aquellos vinculados con el } \\
\text { conflicto colombiano. } \\
\text { - Conocimientos sobre los } \\
\text { recursos destinados directa } \\
\text { e indirectamente a primera } \\
\text { infancia y conflicto en el or- } \\
\text { den territorial, institucional, } \\
\text { familiar y comunitario, sus } \\
\text { condiciones y mecanismos de } \\
\text { obtención. }\end{array}$ & $\begin{array}{l}\text { - Discutir sobre las necesidades } \\
\text { propias de la comunidad en la } \\
\text { que se trabaja (y que están li- } \\
\text { gadas con la prestación de los } \\
\text { servicios propios de su rol), en } \\
\text { los espacios gubernamentales } \\
\text { y comunitarios diseñados para } \\
\text { tal fin. } \\
\text { - Participar activamente y con } \\
\text { criterio en los espacios insti- } \\
\text { tucionales de construcción de } \\
\text { presupuesto, toma de decisio- } \\
\text { nes acerca de la distribución, } \\
\text { manejo de los recursos en la } \\
\text { institución u organización a la } \\
\text { que pertenece y en los esque- } \\
\text { mas de veeduría-auditoría, se- } \\
\text { gún corresponda. }\end{array}$ & $\begin{array}{l}\text { - Darle importancia a su rol en } \\
\text { la gestión de transformación } \\
\text { social dentro de la comunidad } \\
\text { en la que trabaja. }\end{array}$ \\
\hline
\end{tabular}

\section{Nivel institucional e interinstitucional}

Si bien son niveles distintos, a continuación se presentan articuladamente los conocimientos, prácticas y valores con los que debe contar el sistema de atención a la primera infancia para garantizar los recursos apropiados para la efectiva consecución de las metas propuestas. Es claro que aun cuando cada institución tiene unas metas particulares a la luz de sus roles y responsabilidades, la atención integral para la primera infancia requiere de acciones conjuntas frente a objetivos compartidos que exigen un mayor diálogo y disposición de las instituciones para actuar en conjunto; así, sin perder la especificidad es indispensable aunar esfuerzos, recursos y gestiones, más aún por la complejidad en la atención de población víctima del conflicto colombiano.

Es importante aclarar que si estos niveles no generan las condiciones para una planeación y asignación de recursos acorde con las necesidades de la población con la que trabajan, será muy difícil que desde el nivel individual los equipos del talento humano puedan resolver las dificultades identificadas; es decir, la acción individual está sujeta a las ampliaciones que se logren desde el nivel institucional e interinstitucional dada su capacidad de incidencia en instancias en las que se toman decisiones de alcance nacional y territorial. Ahora bien, estos niveles, sin duda, podrán tomar mejores decisiones que acompañan la comprensión de las dinámicas institucionales por parte de sus equipos, pues son ellos quienes tienen contacto directo con la 
población y viven en carne propia las dificultades inherentes de la implementación de la política, generando para ello espacios de participación para conocer sus necesidades, pero sobre todo sus propuestas. Los siguientes testimonios dejan ver la importancia de lo anterior.

"Nota de campo. Al preguntarles a las agentes (que presentaron el caso de la ruta nutricional en el CDI modalidad familiar), qué proponen, estas señalaron con énfasis la necesidad de mejorar los presupuestos de todos los servicios de atención a la primera infancia. Establecen las agentes que la dificultad es no contar con un presupuesto suficiente para atender y ayudar a todas las familias, pero especialmente a aquellas que no logran ser priorizadas".

"Y pues lo que nosotros cambiaríamos en la política pública es, de pronto, más inversión, porque, digamos, sí vemos que nos exigen cierta cualificación, cierto grado de estudio y los sueldos no, no pagan bien. Entonces sí exigen ciertas competencias o ciertos perfiles, pues así mismo deberían invertir en ellos".

De acuerdo con lo expuesto, las competencias para los niveles institucional e interinstitucional en la categoría de planeación y asignación de recursos serían las desarrolladas en la siguiente tabla.

Tabla 4.8. Competencias relacionadas con la planeación de políticas y asignación de recursos - Nivel institucional e interinstitucional.

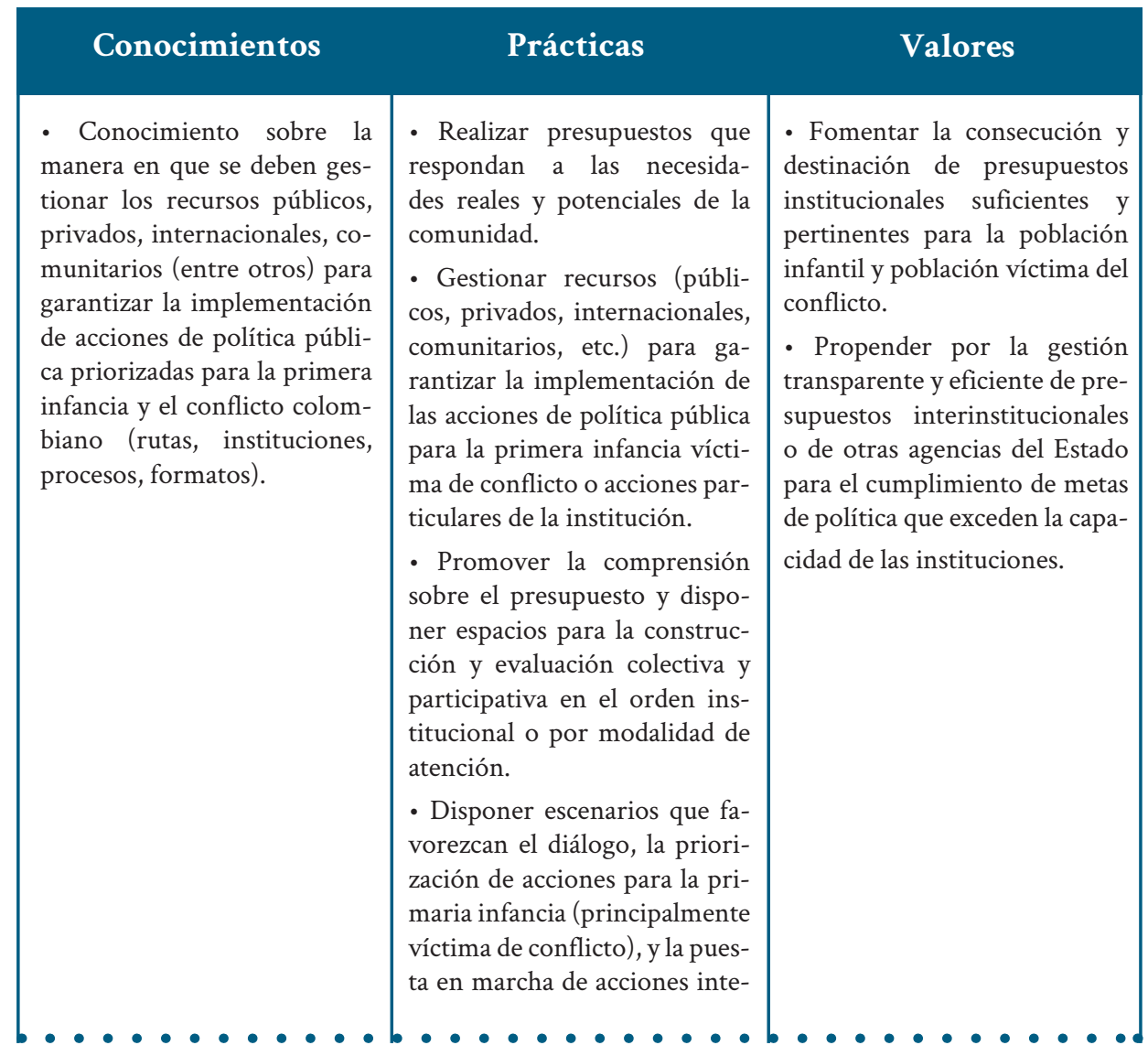




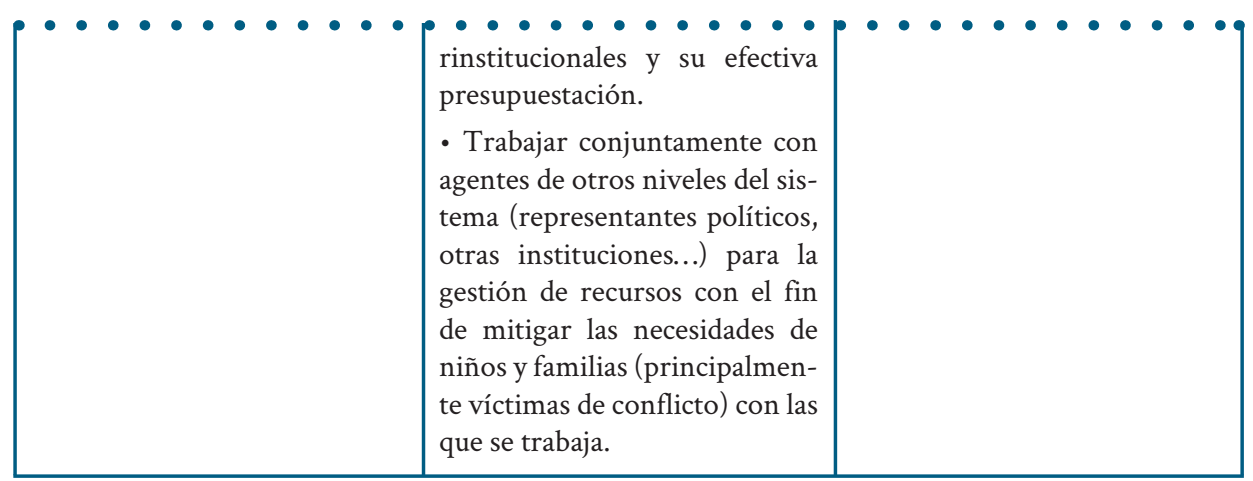

\section{Nivel de gobernanza}

Este nivel es de vital importancia dado el nivel de impacto que puede tener en las condiciones que dificultan que el sistema sea realmente competente. A partir del diálogo con los equipos de talento humano y con los expertos del orden nacional se pueden identificar los conocimientos, prácticas y valores que se necesitan desde el nivel que genera los encuadres sobre los que se ponen en marcha las políticas y acciones para la primera infancia.

La voluntad política, la claridad frente a los compromisos adquiridos, el diálogo efectivo entre los diferentes niveles territoriales y con autonomía en la gestión, así como la generación de mecanismos de monitoreo y seguimiento fueron aspectos señalados en las mesas de trabajo para la inclusión en el esquema de competencias que se presenta enseguida para el nivel de gobernanza en relación con la planeación y asignación de recursos.

Tabla 4.9. Competencias relacionadas con la planeación de politicas y asignación de recursosNivel de gobernanza.

\section{Conocimientos}

- Conocimientos sobre seguimiento, monitoreo y evaluación de los recursos destinados a primera infancia y conflicto, así como su incidencia e impacto en las condiciones de vida de los niños y sus familias.

- Conocimiento sobre la manera de hacer auditoría y veeduría, con alta incidencia de la sociedad y las comunidades, a los recursos destinados y asignados a primera infancia y

\section{Prácticas}

Valores

- Priorizar, y blindar, recursos de orden nacional, departamental y local para población en condición de vulnerabilidad y víctimas de conflictos para los problemas identificados.

- Garantizar la inclusión del tema de primeria infancia y víctimas en los Planes de Desarrollo (según nivel territorial), partidas presupuestales $\mathrm{y}$ esquemas de monitoreo y seguimiento explícitos.

- Explicitar las formas en que
- Garantizar presupuestos (en los diferentes niveles territoriales) para el cumplimiento de metas de política que exceden la capacidad de las instituciones.

- Visibilizar los recursos culturales, comunitarios y familiares y valorarlos como activos de importancia en la construcción de presupuestos para la población infantil y víctima del conflicto. 


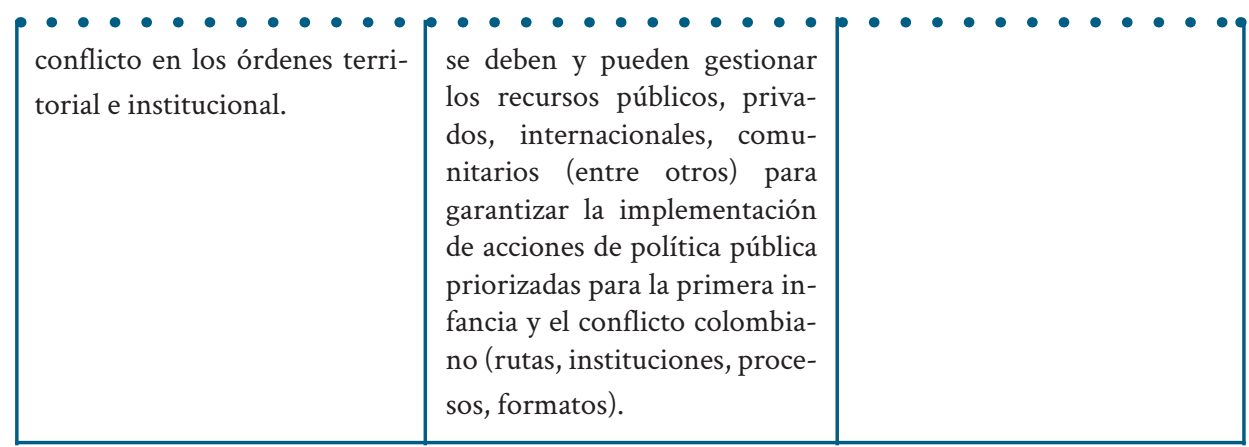

\section{Conclusiones}

La primera infancia es un tema relevante de política pública en el país; a lo largo de los años se han ido adoptando enfoques o concepciones distintas acerca de las niñas y niños, sus derechos y su protección, lo que ha ido moldeando estas políticas y las acciones derivadas de ellas. Una de estas concepciones es la de integralidad de los niños como sujetos y de sus derechos, y es el enfoque con el que actualmente se quiere sustentar todas las acciones de política pública para la primera infancia en Colombia.

Aunque como consecuencia de lo anterior se han definido unas bases sobre las cuales diseñar e implementar acciones de política pública para la población menor de 5 años, lo que se valora como un gran avance, varios autores y los participantes de esta investigación coinciden en que aún son muchos los retos por afrontar, principalmente aquellos que tienen que ver con cómo trabajar con y por la primera infancia, principalmente aquella que ha sido víctima del conflicto colombiano, de forma articulada, integral e intersectorial en una estructura institucional que no lo facilita y a la que le cuesta la puesta en marcha de acciones que logren poner en diálogo las necesidades de la nación y las propias de los territorios y las comunidades.

Como aporte para hacer frente a estos retos se propuso un esquema de competencias que recoge la voz de distintos actores que trabajan en varios ámbitos de la educación inicial y atención para la primera infancia. Tales competencias se estructuraron en torno a la concepción de política pública, prestación de servicios, planeación y asignación de recursos, y por medio de ellas se quiso visibilizar el papel de los actores de cada nivel del sistema.

Se apuesta a que este esquema de competencias sirva para hacer frente a aquellas situaciones que imponen las dinámicas derivadas del conflicto colombiano, un reto más para las políticas de primera infancia, tal como lo reveló hace algunos años un estudio en zonas afectadas por el conflicto, hecho por la Organización de Estados Iberoamericanos y Save de Children (2009), en el que se observaron falencias en la gestión de recursos y puesta en marcha de iniciativas propias en esos territorios.

De esta manera, se quiso exponer en este capítulo las competencias (conocimientos, 
prácticas y valores), que a la luz de los hallazgos del estudio que se presenta en todo el libro, permitan analizar necesidades locales, identificar soluciones, poner sobre la mesa temas relacionados con la primera infancia, gestionar recursos y mantener las estrategias diseñadas o proponer mejoras a las existentes, especialmente cuando se trata de mejorar los servicios y acciones que se llevan a cabo con la primera infancia afectada por el conflicto colombiano.

Entendemos que esta tarea no es algo que se logre en solitario, y por eso se especifican competencias en cada nivel del sistema, resaltando especialmente aquellas del nivel individual, pues a veces el asunto de políticas públicas tiende a verse como algo alejado de lo personal, como un asunto que le compete más al Estado.

\section{Referencias}

Aguilar, L. (2006). Aspectos centrales de una política pública. Memorias del Segundo Foro Internacional Movilización por la Primera Infancia. Bogotá, Colombia.

Aguilar, L. (2012). Política pública: una visión panorámica. La Paz, Bolivia: Programa de Naciones Unidas para el Desarrollo. Recuperado de: https://cutt.ly/ee8CMre

Congreso de la República de Colombia. (2016). Ley 1804 de 2016. Por la cual se establece la política de Estado para el desarrollo integral de la primera infancia de cero a siempre y se dictan otras disposiciones. Bogotá, Colombia: Congreso de la República de Colombia.

Departamento Administrativo de la Presidencia de la República. (2011). Decreto 4875 de 2011. Por el cual se crea la Comisión Intersectorial para la Atención Integral de la Primera Infancia -AIPI- y la Comisión Especial de Seguimiento para la Atención Integral a la Primera Infancia. Bogotá, Colombia: Departamento Administrativo de la Presidencia de la República.

Departamento Nacional de Planeación, Ministerio de Educación Nacional, Ministerio de Protección Social, Instituto Colombiano de Bienestar Familiar. (2007). Marco para las Políticas Públicas y Lineamientos para la Planeación del Desarrollo de la Infancia y la Adolescencia en el Municipio -Guía para Alcaldes-. Bogotá, Colombia: Departamento Nacional de Planeación. Recuperado de: https://cutt.ly/2e8VQ2d

Durán, E. (2017). Integralidad y políticas locales de infancia y adolescencia. En E. Durán y M. Torrado (Eds.). (2017). Políticas de infancia y adolescencia ¿Camino a la equidad? (221-252). Bogotá, Colombia: Colección Centro de Estudios Sociales -CES-, Universidad Nacional de Colombia.

Durán, E, y Torrado, M. (Eds.). (2017). Políticas públicas de infancia y adolescencia ¿Camino a la equidad? Bogotá, Colombia: Colección Centro de Estudios Sociales -CES-, Universidad Nacional de Colombia.

Garnier, L. (2000). Función de coordinación de planes y políticas. Santiago de Chile, Chile: Instituto Latinoamericano y del Caribe de Planificación Económica y Social, ILPES. Recuperado de: https://cutt.ly/ze8B43H

Meny, I., y Thoenig, J. (1992). Las políticas públicas. Barcelona, España: Ariel.

Molina, H., Torres, A., y Moromizato, R. (2013). Áreas críticas para la gestión de políticas integrales de desarrollo infantil. Banco Interamericano de Desarrollo. Recuperado de: https://cutt.ly/ je8BGHc

Organización de Estados Iberoamericanos y Save the Children. (2009). Colombia: huellas del conflicto en la primera infancia. Bogotá, Colombia. Recuperado de: https://cutt.ly/pe8Vkkz

Roth, A. (2007). Enfoques y teorías para el análisis de políticas públicas, cambio de la acción pública y transformaciones del Estado. En: J. Jolly y J. Cuervo (Eds.), Ensayos sobre políticas públicas. Bogotá, Colombia: Universidad Externado de Colombia. 
Roth, A. (2018). Políticas públicas: formulación, implementación y evaluación. Bogotá, Colombia: Ediciones Aurora.

Suárez, F. (1989). Problemas sociales y problemas de programas sociales masivos. Santiago de Chile, Chile: Comisión Económica para América Latina y el Caribe. Recuperado de: https://cutt. ly/De8VwLB

Torrado, M., Gaitán, M., Bejarano, D., y Torrado, M. (2017). La política pública para la primera infancia frente a la desigualdad social en Colombia. En: E. Durán y M. Pacheco (Eds.), Políticas de infancia y adolescencia ¿Camino a la equidad? Bogotá, Colombia: Colección Centro de Estudios Sociales -CES-, Universidad Nacional de Colombia.

UNICEF. (2018). Presupuesto para la niñez. Recuperado de: https://cutt.ly/ae8B0bu 


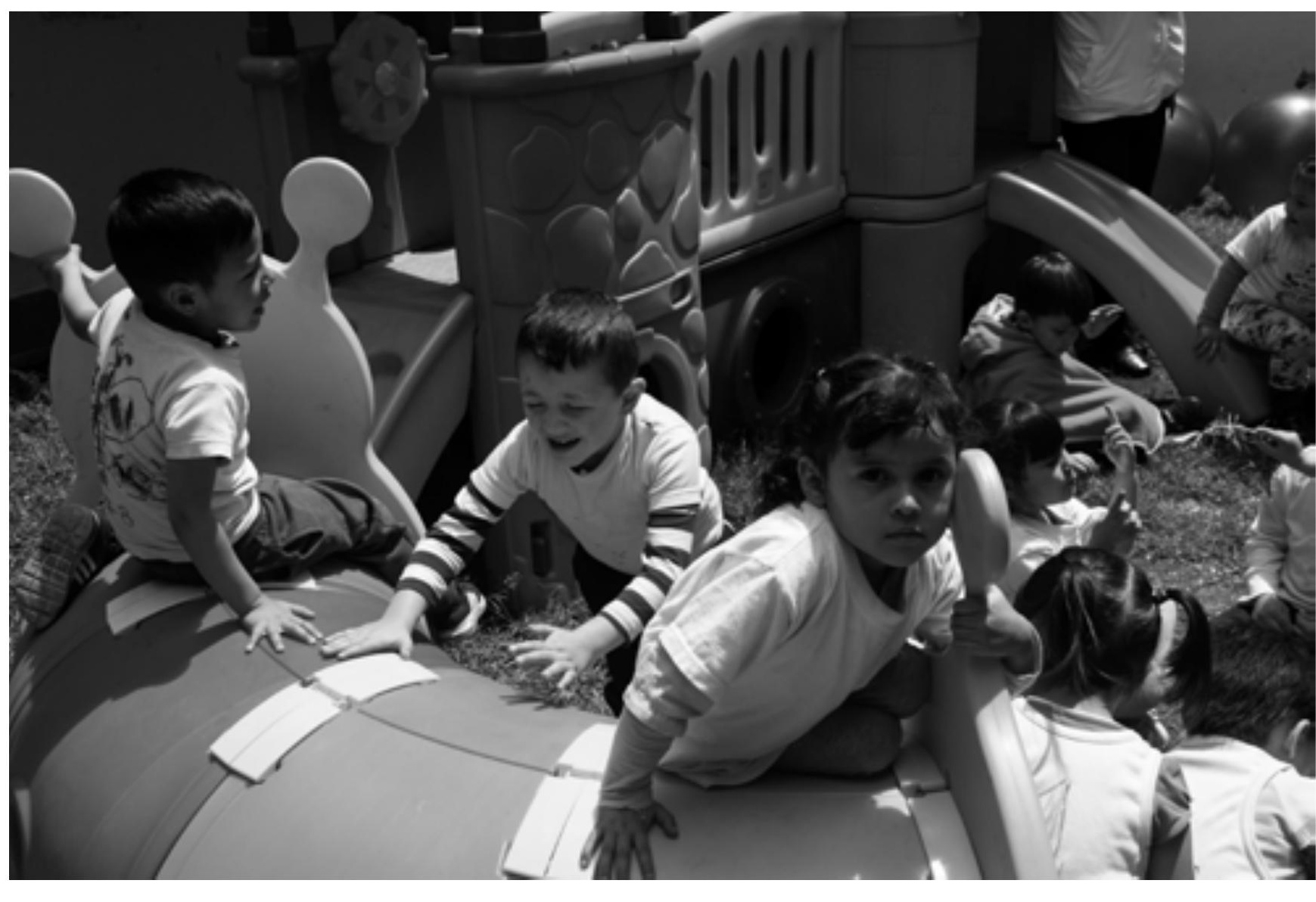




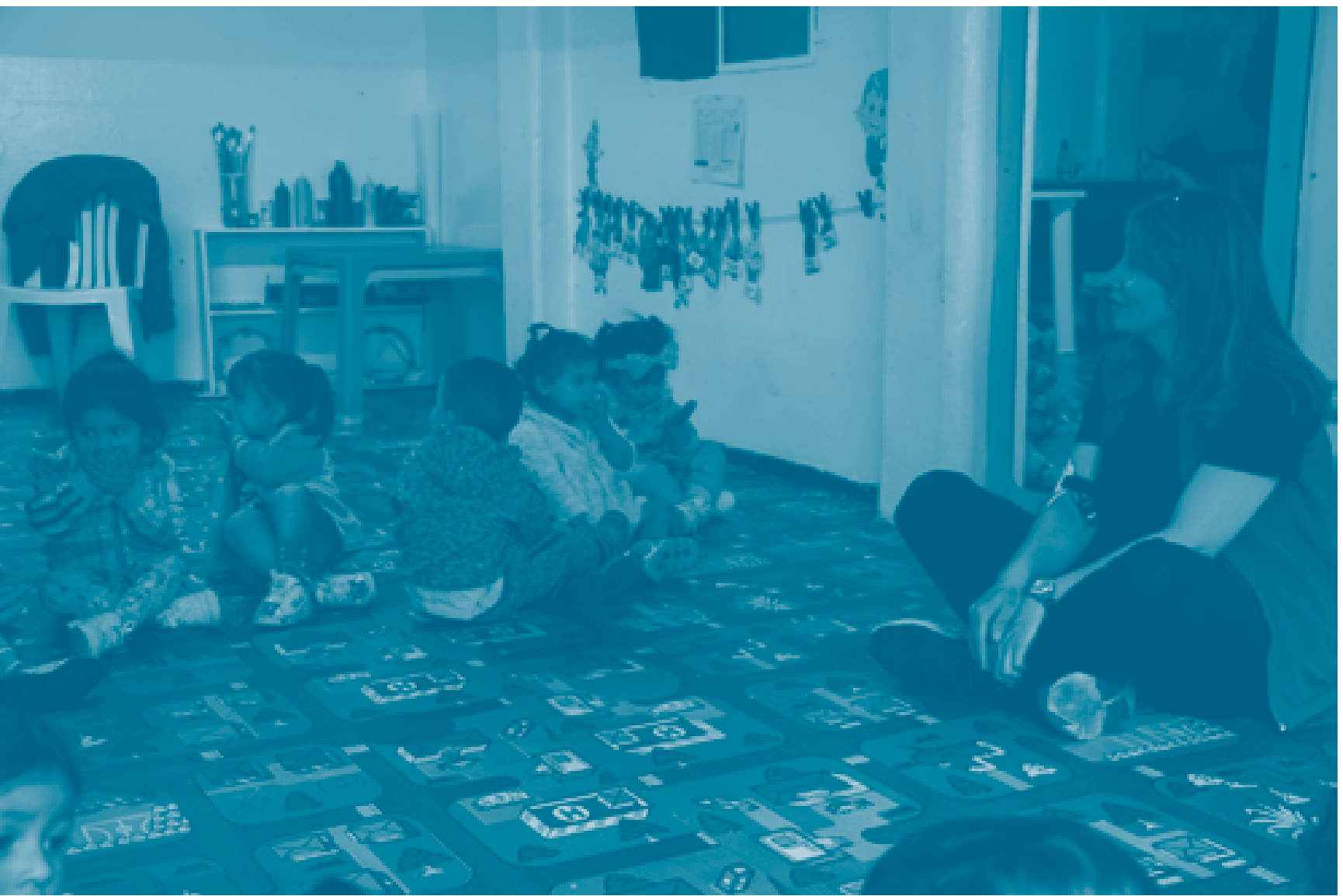

Capítulo 5.

El conflicto en Colombia y su impacto en la calidad de vida de la primera infancia: entornos para la promoción del bienestar y el desarrollo infantil 
$\mathrm{E}$ ste capítulo se interesa por el impacto del conflicto en la calidad de vida, particularmente en los entornos que promueven el bienestar y el desarrollo infantil. El capítulo inicia presentando los elementos nucleares para el trabajo de los profesionales que atienden a niñas y niños afectados por el conflicto desde una perspectiva de sistema competente. Se presentarán las categorías identificadas en el estudio, en los niveles descritos por Urban, Vandenbroeck, Van Laere, Lazzari y Peeters (2012), en un diálogo entre el concepto y la evidencia. Por último, se determinarán las conclusiones de este análisis.

\section{Sobre el concepto de calidad de vida}

La calidad de vida es entendida como la percepción individual de la propia posición en la vida, dentro del contexto del sistema cultural y de valores en que se vive y en relación con objetivos, esperanzas, normas y preocupaciones (OMS, 2019; Orley y Saxena, 1996). Es un concepto de construcción cultural, variable e impreciso. Se relaciona con el sistema de valores y consiste en la sensación de bienestar que puede ser experimentada por las personas y que representa la suma de sensaciones objetivas y subjetivas personales (Cardona y Agudelo, 2005).

Diversos estudios coinciden en definir la calidad de vida mediante distintos factores o dimensiones de bienestar de la persona; por ejemplo, el estudio internacional de MERCER (2018), analiza la calidad de vida a nivel mundial en 39 factores, agrupados en categorías que refieren a los distintos entornos de la persona: natural, social, cultural, económico, político, educativo, entre otros. En el ámbito nacional, la Encuesta Nacional de Calidad de Vida (Departamento Administrativo Nacional de Estadística [DANE], 2017), nos habla de características físicas de la vivienda, servicios del hogar, salud, cuidado de niños menores de 5 años, educación, fuerza de trabajo y diferentes variables socioeconómicas como elementos importantes para entender las diferentes condiciones de bienestar de las personas.

De acuerdo con Verdugo, Arias, Gómez y Schalock (2009), la calidad de vida es:

Una categoría multidimensional, compuesta por las mismas dimensiones para todas las personas, que está influida tanto por factores ambientales como personales, así como por su interacción, y que se mejora a través de la autodeterminación, los recursos, la inclusión y las metas en la vida. (p.18)

Este enunciado, relacionado con las definiciones internacionales y nacionales expuestas anteriormente, permite entender la calidad de vida como una categoría con múltiples dimensiones, algunas de estas referidas, como lo señala la OMS, a los distintos entornos, y otras, referidas a variables que afectan el desarrollo de la persona.

\section{Calidad de vida de la primera infancia: elementos nucleares para su comprensión}

Si bien el concepto presentado de calidad de vida aplica para todas las personas, en la primera infancia se aprecian mayores énfasis en unas dimensiones que en otras, 
especialmente en la idea de la necesidad de satisfacción de condiciones básicas que salvaguarden la vida del niño, como condiciones de salud y nutrición, y que promueven su bienestar, por medio de la educación y la recreación.

En general, los estudios sobre este tema en la primera infancia parecen tomar dos direcciones: por un lado, hacia variables relacionadas con la atención y, por otro, hacia las condiciones en las que habitan los sujetos. Sobre la primera categoría, resalta la importancia, en buena parte de los estudios, de la atención en salud, principalmente oral o respiratoria, el cuidado de enfermedades y la atención en casos de discapacidad (Davey et al., 2013; Dhillon, Logani, Agarwal, y Mathur, 2014; Easton, Landgraf, Casamassimo, Wilson, y Ganzberg, 2008; Peters, Mahajan, Bawa, Sahu, y Rao, 2014). En esa misma línea, en la primera infancia son fundamentales los escenarios de atención para mejorar la calidad de vida de los niños, las niñas y sus familias. Por ejemplo, Balcells-Balcells, Giné, Guàrdia-Olmos, Summers y Mas (2019), muestran la relevancia de mejorar las condiciones de vida de las familias, especialmente de aquellas con personas con discapacidad. Así, es clave el acompañamiento de los profesionales y la extensión de los apoyos de los centros de intervención infantil, los cuales tiene un impacto positivo en la calidad de vida de dichas familias. Otras variables de interés, como lo señalan Schalock y Verdugo (2012), refieren a la discapacidad y la inclusión, estas, apoyadas en las familias y su calidad de vida, lo que coincide con un número importante de estudios (Bertelli, Bianco, Rossi, Scuticchio, y Brown, 2011; Bhopti, Brown, y Lentin, 2016; Purcell, Turnbull, y Wood, 2006). Así, se resalta la relación necesaria entre el individuo, la familia y la institución de apoyo (García-Grau, McWilliam, Martínez-Rico, y Morales-Murillo, 2019).

Por otro lado, y de manera específica como condición en la que habitan los sujetos, aparecen diferentes variables socioeconómicas y contextuales. Por ejemplo, desde una perspectiva de deprivación, Wong, Wang y Xu (2015) muestran cómo los niños en condiciones de pobreza tienen peores índices de calidad de vida, con efectos diversos dependiendo del género. Igualmente, hay estudios que señalan la disminución de la calidad de vida de los niños que habitan en contextos de violencia (Vega-Arce y Núñez-Ulloa, 2017).

Desde esta perspectiva, en este estudio la calidad de vida es comprendida desde una serie de entornos que promueven unas condiciones de bienestar y desarrollo en diferentes dimensiones del individuo en su relación con la familia y las instituciones de atención, educación y promoción del desarrollo infantil.

\section{Impactos del conflicto en la calidad de vida}

Las referencias al impacto del conflicto en la calidad de vida de niños y niñas son amplias. Así, los efectos más comunes reportados en la literatura suelen referirse a las dimensiones emocional y psicológica. Por ejemplo, se señala la prevalencia de problemas emocionales, como ansiedad, depresión, síntomas de estrés postraumático y angustia psicológica, en niños y adolescentes refugiados de guerra en Bélgica 
y EEUU (Derluyn y Broekaert, 2007; González, Monzón, Solís, Jaycox, y Langley, 2016). Estos problemas socioemocionales parecen guardar relación con problemas de ajuste escolar y social.

A través de un estudio longitudinal realizado en 15 países, distintos investigadores encontraron que reacciones de estrés postraumático, ansiedad, depresión y síntomas somáticos, son muy frecuentes entre niños y adolescentes que sobreviven a conflictos armados y desastres naturales, en contraste con la prevalencia de estos síntomas en niños y adolescentes de la misma edad en entornos favorecidos (Fisher et al., 2011). En la misma línea, Dimitry (2012), en una revisión sistemática de 71 estudios sobre la salud mental de niños y adolescentes en áreas de conflicto armado en medio oriente, muestra que el número de experiencias traumáticas derivadas del conflicto armado se correlaciona proporcionalmente con la prevalencia de problemas emocionales.

Relacionado con lo anterior, se encuentran estudios que señalan el impacto del conflicto en el bienestar emocional de los niños. Por ejemplo, Ison-Zintilini y Morelato-Giménez (2008), muestran que, a edades más tempranas, el maltrato infantil tiene un mayor impacto en el desarrollo. Aunque hacía el final de la infancia el pronóstico para desarrollar habilidades sociales en estos niños aumenta, el afrontamiento emocional se suele dar desde el miedo y la ansiedad. En Colombia, el estudio de Hewitt et al. (2014), realizado con niños y adolescentes expuestos al conflicto armado en una zona rural del país, señala altos indicadores de afectaciones psicológicas, conductas internalizadas y externalizadas en rango clínico, problemas somáticos, estrés postraumático y consumo de alcohol.

Por su parte, Vega-Arce y Núñez-Ulloa (2017), evidencian que los conflictos y experiencias adversas, en un sentido amplio, el cual incluye maltrato infantil, abuso sexual, violencia intrafamiliar, entre otras categorías, generan impactos importantes en la dimensiones de salud, desarrollo y rendimiento escolar de los niños, mediante un espectro amplio de dificultades, como problemas de atención, retrasos generalizados del desarrollo, asma, obesidad, fracaso escolar y problemas de aprendizaje.

De igual forma, el conflicto también afecta los imaginarios sociales de los niños sobre la guerra y la paz. Por ello, los niños que viven en escenarios de guerra y conflicto suelen representar la paz como vivir una vida normal, ir al colegio, jugar en el patio o salir a la calle, mientras que, para sus pares en contextos sin guerra, se relaciona con ideas abstractas, tales como la camaradería, la armonía, la felicidad, entre otras (Özer, Oppedal, Şirin y Ergün, 2018).

El conflicto suele estar representado por estados afectivos en tensión, y suele caracterizarse por la vulneración de los derechos y por la afectación a las necesidades básicas (Vanegas, Bonilla y Camacho, 2011). Como es apenas lógico, el conflicto afecta de manera importante la garantía de los derechos de los niños y las niñas. Como lo señalan Durán y Torrado-Pacheco (2014), los niños, las niñas y adoles- 
centes, víctimas de la violencia, especialmente desplazados, son altamente vulnerables. Cuando estos niños pierden la escuela, parte o toda la familia, la red social de apoyo y otras condiciones de protección, "quedan expuestos a diferentes formas de explotación" (p.107).

A su vez, los casos de trabajo y reclutamiento forzado generan en los niños problemas de adaptación social, rabia, temor, desesperanza, soledad y angustia (Andrade, Angarita, Perico, Henao y Zuluaga, 2011), promueven la aparición de conductas agresivas y generan segregación y disociación familiar (Andrade, 2010). En general, como lo señalan Vera-Márquez, Palacio, Maya y Holgado (2015), el conflicto conduce a una reducción significativa de la satisfacción de las necesidades básicas de niños y niñas.

\section{El trabajo del talento humano para mejorar la calidad de vida de niños y niñas}

Son variados los estudios que reconocen la importancia del contexto educativo y del talento humano para la atención de niños afectados por el conflicto. Por ejemplo, Betancourt, Meyers-Ohki, Charrow y Tol (2013), y Jordans, Tol, Komproe y De Jong (2009), muestran que en los estudios existentes sobre intervenciones de niños y jóvenes en contextos de conflicto, buena parte de ellas evaluadas positivamente, se dan en su mayoría en contextos escolares. Es por esto por lo que el profesional que acompaña al niño en estas instituciones juega un papel fundamental. En estos estudios se resalta la importancia de las capacidades individuales para proveer apoyo, especialmente emocional, a niños y niñas, dado que dicho apoyo promueve el sentido psicológico de comunidad (Vera-Márquez et al., 2015). Lo anterior concuerda con el estudio de Oliveira, Fearon, Belsky, Fachada y Soares (2015), en el que se insiste en la importancia de la calidad del cuidado y de la relación emocional entre el cuidador y el niño, o con el estudio de Lacunza y Contini (2009), sobre la importancia de mejorar el clima familiar y las pautas de crianza para promover las habilidades sociales de niños y niñas que viven en escenarios de conflicto y pobreza.

Otras investigaciones señalan la priorización de los vínculos afectivos familiares y del apoyo de la red social como posibilidades para tejer resiliencia y para construir nuevos sentidos de vida (Vanegas et al., 2011); a esto se le suma la necesidad de fortalecer la identidad social, la cual se pierde por los procesos de aculturación, resultado de los procesos del conflicto.

\section{La calidad de vida desde la primera infancia como condiciones de bienestar y desarrollo en diferentes entornos: diálogos entre conceptos y evidencias}

A continuación, se presenta el esquema de competencias identificado a partir de la revisión de la literatura y del diálogo entre dicha revisión y el ejercicio de indagación realizado tanto con profesionales como con expertos que trabajan con primera 
infancia, las cuales se ubican en las siguientes categorías, referidas a los diferentes entornos de promoción de calidad de vida, desde una perspectiva relacional. Dichas categorías son:

- Entornos que promueven el bienestar físico y material.

-Entornos que promueven el bienestar psicológico y emocional.

- Entornos que promueven el bienestar familiar y comunitario.

- Entornos que promueven el desarrollo personal e interpersonal.

- Entornos que promueven el desarrollo social y cultural.

\section{Los entornos que promueven el bienestar físico y material}

Elementos que componen los entornos físicos y materiales son recurrentes en los discursos de los profesionales y expertos que trabajan con primera infancia. En estos elementos, se suele hacer referencia a ambientes que promueven la salud física, el peso y la talla adecuada, una buena nutrición, controles de vacunación, condiciones de higiene adecuadas, momentos de sueño y de recreación, entre otras cuestiones. También es común la referencia al espacio vital del niño, en la necesidad de contar con ambientes seguros y protectores. A continuación, se presenta lo identificado en esta dimensión en cada uno de los niveles comprensivos:

\section{Nivel individual}

Entre las prácticas del talento humano para promover el bienestar físico se menciona el control del peso y de la talla del niño; igualmente, se hace mención del uso trimestral de una escala que permite evaluar dicho peso y talla, para saber si este desarrollo es el esperado para la edad. Esto también se realiza al ingreso del niño, por primera vez, a la institución. Es por ello por lo que estos controles y valoraciones son importantes entre las estrategias de atención. A partir de dichas mediciones, se hacen remisiones (si no existe una profesional de apoyo en nutrición en la institución), o se pasa directamente a la nutricionista (cuando la institución cuenta con esta profesional). Un ejemplo en un testimonio:

"Peso, talla, salud física, nutrición, condiciones de higiene, prevención y promoción en salud. ¿Cómo desde mi labor puedo mitigar? ¡Total!, las condiciones naturales de su contexto no le afectaban. No estaba invisibilizado, pero cuando llegaron a otro lugar sus condiciones cambiaron".

Otros elementos que se relacionan con las condiciones de bienestar físico tienen que ver con el acceso a una serie de recursos; así, se torna relevante el acceso a los alimentos, al servicio de salud y a la recreación. Desde la perspectiva del profesional, estos aspectos suelen verse desmejorados por efectos de la violencia. Lo anterior guarda relación con lo señalado por Durán y Torrado-Pacheco (2014), quienes, al referirse a los derechos a la supervivencia, denuncian que "el consumo de alimentos en las familias desplazadas se ve francamente disminuido. La ayuda alimentaria, cuando llega, es insuficiente, presentándose una alta vulnerabilidad nutricional, con problemas de desnutrición aguda y un aumento de la desnutrición crónica”(p.103). 
Así, la calidad de vida en la primera infancia guarda una relación estrecha con unas condiciones nutricionales, las cuales entran en interacción con otras dimensiones de promoción del bienestar, como aquellas relacionadas con el afecto; por ejemplo, el alimento puede ser importante si se mezcla con un componente afectivo. Aquí es clave señalar que, para los profesionales que atienden a niños y niñas, el afecto no se restringe a la madre y la familia, sino que también, y desde una perspectiva de entorno vital, se hace evidente en la institución educativa, principalmente en la práctica de la maestra en la cual es posible aprovechar los distintos momentos para la satisfacción emocional del niño, por ejemplo, al momento de la alimentación o en los momentos previos al sueño.

Por otra parte, se percibe que las condiciones de higiene de los niños también se ven afectadas por las dificultades de acceso a un baño o al agua, resultado de los desplazamientos y de las nuevas condiciones de vivienda. Relacionado con lo anterior, se mencionan algunas consecuencias de la reducción económica sobre la consecución de implementos de aseo e higiene, como los pañales, lo que hace que los niños estén "más expuestos a enfermedades".

La recreación, por otro lado, es un componente importante de los entornos que promueven el bienestar de niños y niñas. Si bien esta puede guardar una estrecha relación con el bienestar físico y material, es claro que interviene en otros entornos de promoción de bienestar, como el psicológico o emocional, o el de desarrollo personal o cultural. Así, para el profesional, la violencia afecta el espacio vital del niño, "reduciendo su hábitat"; a su vez, esta violencia puede generar una pérdida de libertades, la cual se traduce en un menoscabo del espacio para la recreación.

Por ello, de acuerdo con los profesionales, el conflicto afecta, principalmente, la "estabilidad" de los niños. Esta estabilidad es entendida en varios sentidos: económico, emocional y social. Lo económico se relaciona con unas condiciones físicas y materiales del hogar y con las condiciones de vivienda. El desplazamiento puede conducir a la pérdida del hogar, lo que, a su vez, se traduce en una inestabilidad en las condiciones de habitabilidad o del entorno vital del niño. Al respecto, sobre el hábitat del niño, se torna importante reconocer las condiciones de este, el acceso a unos recursos para vivir cómodamente y para evitar la reducción de dicho ambiente, lo que podría entrar en diálogo con una perspectiva ecológica o ecosistémica. Al respecto, el siguiente testimonio:

"Los niños son invisibles. No son participantes. Se destierran de sus viviendas y llegan a otro contexto y de ahí no sale."

Los testimonios de los profesionales corroboran los planteamientos de Durán y Torrado-Pacheco (2014), al indicar que:

La mayoría de la población desplazada vive en barrios informales. Gran parte de ellos ubicados en zonas de alto riesgo de desastres naturales. Sus casas son construidas con materiales de mala calidad y pisos de tierra, facilitando la infestación de plagas. (p.102) 
Dicho esto, es un contexto propicio para las situaciones de hacinamiento y proclive a las enfermedades, donde, generalmente, los servicios de salud son bastante complejos. A continuación, la tabla de competencias identificadas en los entornos que promueven el bienestar físico y material en este nivel.

Tabla 5.1. Competencias en entornos que promueven el bienestar físico y material Nivel individual.

\section{Conocimientos}

\section{Prácticas}

\section{Valores}

- Conocimientos sobre condi- - Valorar el estado de salud del ciones para la promoción de la salud física, prevención de la enfermedad y cuidado de niños y niñas.

- Conocimientos sobre formas de valorar el estado de salud infantil.

- Conocimientos sobre formas de seguimiento al desarrollo del niño o niña.

- Conocimientos de cuidado infantil y protección social.

- Conocimientos sobre rutas de atención en salud (articuladas con la Ruta Integral de Atenciones - RIA).

- Conocimientos sobre la estrategia de Atención Integrada de Enfermedades Prevalentes de la Infancia AIEPI.

- Conocimientos sobre identificación del riesgo y signos de alarma, especialmente en casos de ERA (Enfermedad Respiratoria Aguda) y EDA (Enfermedad Diarreica Aguda).

- Conocimientos sobre condiciones de los entornos de vida de los niños y sus familias. niño por medio de prácticas pertinentes y oportunas de promoción de la salud y prevención de la enfermedad, y de mecanismos ajustados a la realidad del niño y su familia.

- Hacer seguimiento al desarrollo infantil (control y valoración del peso y talla, estado nutricional del niño, lactancia, estado de vacunación, entre otros), y apoyarse en las familias para esto.

- Proporcionar una alimentación acorde con las necesidades nutricionales de cada niño o niña y revisar las formas de alimentación en el hogar.

- Remitir a redes de atención en salud cuando sea necesario.

- Realizar prácticas de higiene y cualificar a los padres en las mismas.

- Realizar prácticas basadas en la actividad física que promuevan la motricidad del niño o niña.

- Hacer seguimiento a los momentos de sueño y de buen dormir del niño.

- Aprovechar los espacios recreativos para promover una buena salud física y mental del niño.

- Aprovechar los saberes ancestrales para la promoción de la salud y la prevención de la enfermedad.

- Realizar prácticas de promoción de la salud y prevención de
- Adoptar una perspectiva de vida saludable del niño, de promoción de la salud y prevención de la enfermedad infantil, basada en el seguimiento, la observación y el acompañamiento.

- Promover el derecho de los niños a espacios para la recreación y el sueño.

- Promover las prácticas de cuidado y atención, basadas en la familia, para la recuperación, mantenimiento y protección de la salud del niño en el hogar.

- Comprometerse con el bienestar y el desarrollo infantil.

- Adoptar una perspectiva relacionada con una sana alimentación.

- Promover el acceso del niño a ambientes seguros y saludables.

- Valorar el espacio vital como esencial para el desarrollo y el bienestar infantil.

- Garantizar el derecho a la salud como derecho fundamental.

- Asumir una perspectiva ecosistémica sobre el espacio vital del niño, que permita, en los casos de desplazamiento, reflexionar sobre la recuperación de la vivienda y sobre las nuevas configuraciones de los espacios vitales en nuevos entornos. 


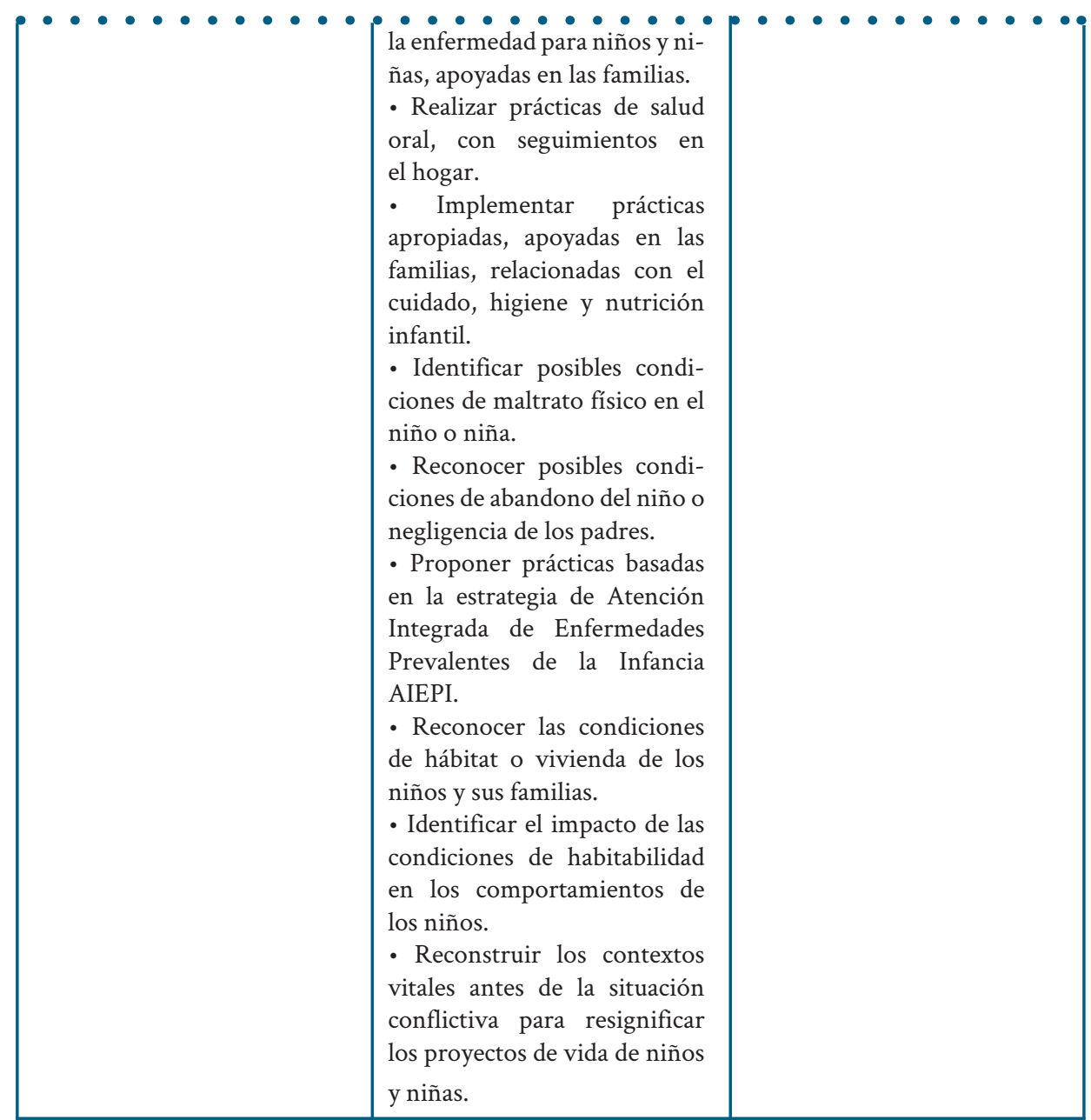

\section{Nivel institucional}

Desde la institución, en la promoción del bienestar físico y material, particularmente en las condiciones de higiene, se menciona que en las instituciones se trabajan sesiones educativas para padres, en las que se tratan temas como el lavado de manos para la prevención de enfermedades, se orienta sobre vacunación, se supervisa la asistencia a controles de crecimiento y desarrollo, y se vigila la asistencia a terapias de estimulación temprana. De igual forma, se resalta el apoyo institucional para brindar los complementos alimenticios o nutricionales que los niños necesitan, entre estos, bienestarina ${ }^{10}$, compotas, papillas, entre otros.

\footnotetext{
${ }^{10}$ Complemento alimentario producido por el Instituto Colombiano de Bienestar Familiar (ICBF), de alto valor nutricional, el cual consiste en una mezcla de harinas y/o féculas de cereales (trigo, maíz), harina de soya y leche entera en polvo, con vitaminas y minerales.
} 


\begin{tabular}{|c|c|c|}
\hline Conocimientos & Prácticas & Valores \\
\hline $\begin{array}{l}\text { - Conocimientos sobre con- } \\
\text { diciones institucionales para } \\
\text { la promoción de la salud y la } \\
\text { prevención de la enfermedad } \\
\text { de niños y las niñas. } \\
\text { - Conocimientos instituciona- } \\
\text { les sobre rutas de atención en } \\
\text { salud (articuladas con la Ruta } \\
\text { Integral de Atenciones - RIA). } \\
\text { - Conocimientos instituciona- } \\
\text { les sobre la estrategia de Aten- } \\
\text { ción Integrada de Enfermeda- } \\
\text { des Prevalentes de la Infancia } \\
\text { AIEPI. } \\
\text { - Conocimientos sobre nor- } \\
\text { mativas para la generación de } \\
\text { espacios seguros y protectores. } \\
\text { - Conocimientos sobre aten- } \\
\text { ción a la diversidad. }\end{array}$ & $\begin{array}{l}\text { - Trabajar con padres en la } \\
\text { promoción de un cuidado res- } \\
\text { ponsable dirigido a la identi- } \\
\text { ficación de signos de alarma } \\
\text { (EDA, ERA), higiene, lavado de } \\
\text { manos, vacunación, lactancia, } \\
\text { asistencia a controles de creci- } \\
\text { miento y desarrollo y a terapias } \\
\text { de estimulación temprana. } \\
\text { - Proveer una alimentación } \\
\text { acorde con las necesidades nu- } \\
\text { tricionales de cada niño o niña, } \\
\text { apoyada en las familias. } \\
\text { - Proporcionar acceso a espa- } \\
\text { cios adecuados para la expre- } \\
\text { sión corporal, la motricidad, la } \\
\text { recreación y el uso del tiempo } \\
\text { libre de niños y niñas. } \\
\text { - Proporcionar acceso a espa- } \\
\text { cios para aseo e higiene. } \\
\text { - Proporcionar acceso a espa- } \\
\text { cios que promuevan la salud } \\
\text { ambiental. } \\
\text { - Promover la seguridad de los } \\
\text { espacios de trabajo con los ni- } \\
\text { ños. } \\
\text { - Proveer espacios que promue- } \\
\text { van la atención a la diversidad y } \\
\text { que permitan la inclusión. } \\
\text { - Proveer oportunidades para } \\
\text { fesionales, y entre estos y las } \\
\text { familias. }\end{array}$ & $\begin{array}{l}\text { - Adoptar una perspectiva } \\
\text { de vida saludable del niño. } \\
\text { - Adoptar una perspectiva } \\
\text { de promoción de la salud y } \\
\text { prevención de la enferme- } \\
\text { dad infantil, basada en el se- } \\
\text { guimiento, la observación y } \\
\text { el acompañamiento. } \\
\text { - Promover el acceso del } \\
\text { niño a ambientes seguros y } \\
\text { saludables. } \\
\text { - Garantizar el derecho a la } \\
\text { salud como derecho funda- } \\
\text { mental. }\end{array}$ \\
\hline
\end{tabular}

\section{Nivel interinstitucional}

Este nivel se evidencia fuertemente en la atención en salud, mediante el ejercicio de las redes existentes para la dicha atención; y en nutrición, específicamente entre las entidades que brindan servicios de acompañamiento nutricional, entre los que se incluye la alimentación. Así, es común en los discursos la mención al tránsito de un tipo de institución a otra, y la construcción de redes de apoyo que le permiten a las familias la consecución de un estado de equilibro económico, el cual, a su vez, se va a relacionar con el desarrollo de capacidades para cubrir las necesidades alimenticias de los niños. 
Tabla 5.3. Competencias en entornos que promueven el bienestar físico y material Nivel interinstitucional.

\begin{tabular}{|c|c|c|}
\hline Conocimientos & Prácticas & Valores \\
\hline $\begin{array}{l}\text { - Conocimientos sobre redes } \\
\text { de cooperación para la aten- } \\
\text { ción integral a la primera in- } \\
\text { fancia (conocimientos sobre } \\
\text { redes para la atención en sa- } \\
\text { lud). } \\
\text { - Conocimientos sobre for- } \\
\text { mas para el desarrollo de las } \\
\text { familias y de las comunidades, } \\
\text { de sus espacios de ocio, de } \\
\text { encuentro significativo y de } \\
\text { labores económicamente pro- } \\
\text { ductivas. } \\
\text { - Conocimientos transdiscipli- } \\
\text { narios para la atención integral } \\
\text { a la primera infancia. } \\
\text { - Conocimientos interinstitu- } \\
\text { cionales sobre la estrategia de } \\
\text { Atención Integrada de Enfer- } \\
\text { medades Prevalentes de la In- } \\
\text { fancia, AIEPI. }\end{array}$ & 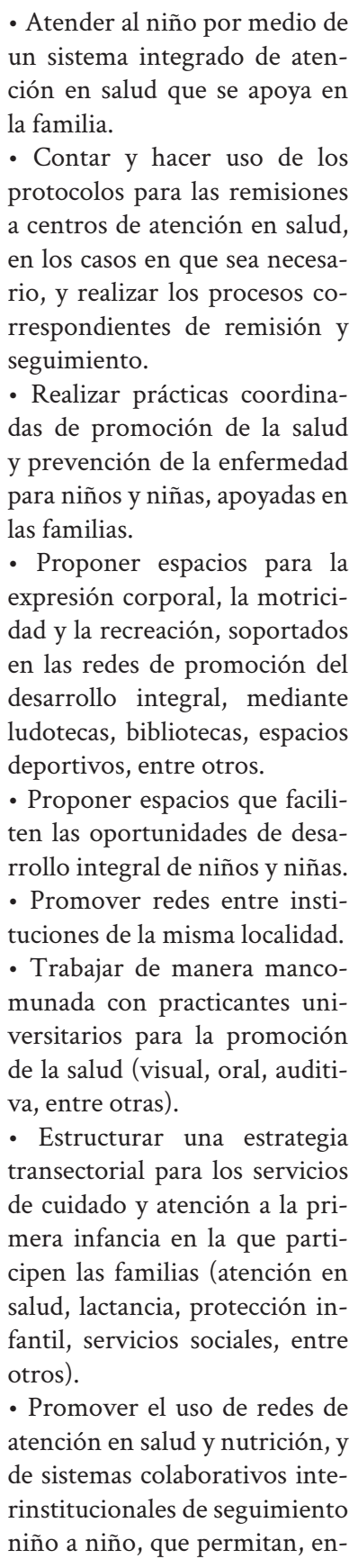 & $\begin{array}{l}\text { - Adoptar una perspectiva de } \\
\text { atención integral en salud in- } \\
\text { fantil basada en el apoyo fami- } \\
\text { liar. } \\
\text { - Adoptar una perspectiva de- } \\
\text { mocrática y de respeto por la } \\
\text { diversidad y la discapacidad. } \\
\text { - Asumir una aproximación de } \\
\text { colaboración en la educación y } \\
\text { para el cuidado de la primera } \\
\text { infancia, con el propósito de } \\
\text { fomentar la cohesión social. } \\
\text { - Promover el acceso del niño } \\
\text { a ambientes seguros y saluda- } \\
\text { bles. } \\
\text { - Garantizar el derecho a la } \\
\text { salud como derecho funda- } \\
\text { mental. }\end{array}$ \\
\hline
\end{tabular}




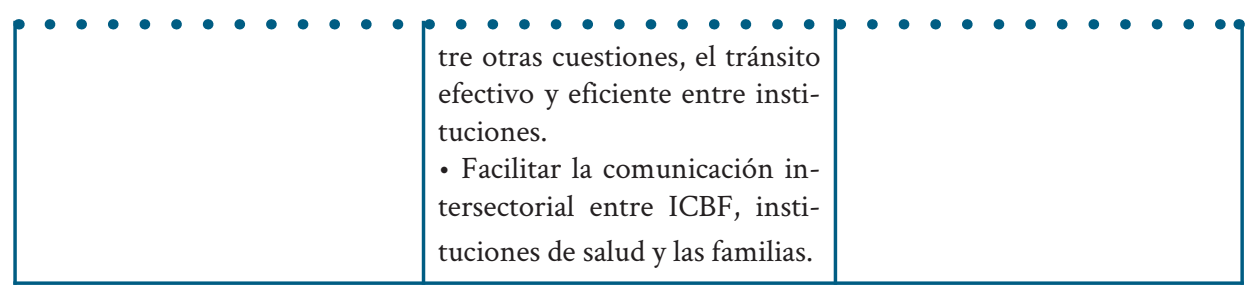

\section{Nivel de gobernanza}

De forma similar al nivel anterior, en este se suele hacer referencia a las condiciones sociales que permiten que el niño sea atendido por un sistema de salud, de forma amplia, particularmente luego de ser víctima del conflicto. Lo anterior puede guardar relación con la existencia y activación de unas rutas de atención al niño por entidades locales o regionales, como Bienestar Familiar (ICBF), comisarías de familia, por entidades prestadoras del servicio de salud mediante el régimen subsidiado (Sistema de Selección de Beneficiarios Para Programas Sociales - SISBEN), o por medio de las Entidades Promotoras de Salud (EPS).

En alimentación, por ejemplo, se ve la importancia de la administración municipal, la alcaldía, con programas o entidades prestadoras del servicio de atención a niños y niñas. Así, por ejemplo, los hogares comunitarios, o las modalidades familiares, se tornan importantes para este acompañamiento y garantía del derecho a la alimentación, al igual que los jardines infantiles.

Tabla 5.4. Competencias en entornos que promueven el bienestar físico y material Nivel de gobernanza.

\section{Conocimientos}

Prácticas

\section{Valores}

- Conocimiento de políticas que promueven la atención integral de niños y niñas.

- Conocimientos sobre dotación adecuada de instituciones para la atención integral.

- Conocimientos normativos para el establecimiento de ambientes seguros y protectores.

- Conocimientos sobre la estrategia de Atención Integrada de Enfermedades Prevalentes de la Infancia, AIEPI.
- Dotar adecuadamente a las instituciones que atienden a niños de primera infancia con el fin de proveer un acceso equitativo generalizado a una atención educativa y de cuidado de calidad, especialmente para niños con un trasfondo socioeconómico desventajoso, con discapacidad o víctimas del conflicto.

- Contar con sistemas o marcos de seguimiento a la calidad de las instituciones que atienden a población víctima del conflicto, y al monitoreo y evaluación de estas.
- Garantizar los derechos de los niños para desarrollar todo su potencial mediante educación y aprendizaje exitosos.

- Promover el acceso del niño a ambientes seguros y saludables.

- Garantizar el derecho a la salud como derecho fundamental.

- Garantizar el derecho a una buena alimentación, a la lactancia y a la supervivencia infantil, por medio de mecanismos de entidades locales como alcaldías, hogares comunita- 


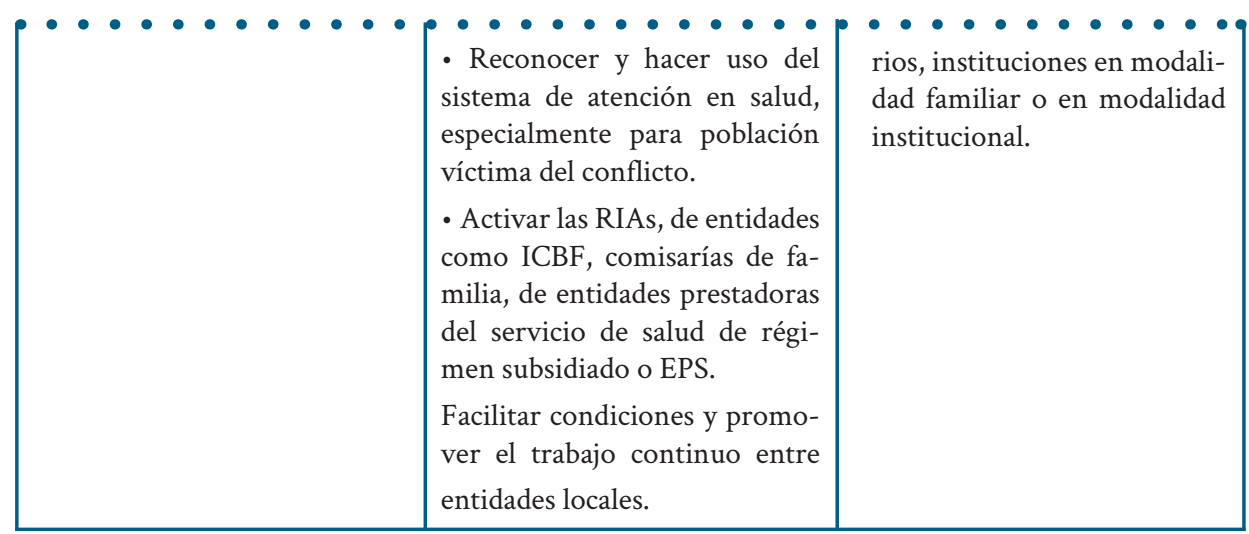

Los entornos que promueven el bienestar psicológico y emocional

Como se vio anteriormente en la revisión de la literatura, los estudios tienden a señalar a esta dimensión como una de las más relevantes para la población objetivo. Es evidente que el conflicto suele dejar marcas en la corporalidad del niño, en su emocionalidad y en su mente. Frente a esto podríamos traer las palabras de Skliar (2017), cuando habla de "una experiencia de la fragilidad, porque se trata de un saber en el cuerpo" (p.83); es una búsqueda continua que se resarce en el propio interior del niño o de la niña; aspectos que van más allá del contexto y de lo material.

Humberto Maturana (1994) refiere que la escuela es un espacio en el que se entrecruzan emociones, y su manejo debilita o potencializa el conflicto; así pues, esta condición demanda un papel importante del profesional quien, por medio de estrategias educativas, busca formas que le permiten contener estas narraciones cargadas de experiencias y emociones, soportadas en los planes educativos, y de cara a la transformación social desde la escuela. A continuación se presenta su manifestación en los distintos niveles de análisis.

\section{Nivel individual}

En este nivel es común que se realicen seguimientos a las condiciones de los niños y a sus comportamientos. Si bien estos procedimientos los realiza el profesional psicosocial (psicólogo o trabajador social), estos se encuentran apoyados por la maestra y las observaciones que realiza sobre los comportamientos del niño dentro del aula, en las visitas a las familias, o por medio de las preguntas que realiza durante la entrevista; de allí que las capacidades de observación y de cuestionamiento (las capacidades para hacer preguntas), se tornen relevantes para la identificación primaria de las condiciones psicosociales, satisfechas o no, del niño o niña. Al respecto, se refiere lo siguiente:

"Hay que pedir valoraciones médicas. Hay que hacer talleres de resiliencia y establecer comunidades de autoayuda".

De acuerdo con las maestras, las condiciones que afectan el bienestar psicológico y 
emocional pueden tener efectos normalmente negativos en el desempeño del niño; a su vez, estas condiciones pueden verse afectadas o agravadas por las situaciones económicas actuales de las familias, por las condiciones de vivienda o de alimentación, o por contextos de abandono o de negligencia de los padres, como se señala en el siguiente testimonio:

"Yo tengo un caso de un niño que tiene mucha gente al lado, pero ni el papá ni la mamá lo atienden y vive atendido por diferentes personas".

Decimos que los niños y las niñas de escenarios de educación inicial pueden estar en medio de un conflicto que no termina; al ser desterrados de su hogar, son perseguidos por la violencia, en medio de la pobreza y la precariedad de las condiciones de vida de sus padres; aspectos que afectan su salud mental y condicionan emociones y comportamientos. Sobre las prácticas de algunos profesionales, se menciona el lugar fundamental de la psicóloga o psicólogo para la intervención de traumas derivados del conflicto, referidos estos como miedos de los niños, rencores, predisposiciones hacia los otros, agresividad y aislamiento, causados por los hechos violentos. Se reconoce también la importancia del acompañamiento psicológico para que el niño desarrolle estrategias de afrontamiento. En otras palabras, siguiendo a Gopnik (2009), "cuando aún son pequeños, los niños muestran algunos de los mismos impulsos de ira y venganza que tienen los adultos"(p.224), hecho que amerita un acompañamiento profesional.

Entre estas competencias de acompañamiento también aparecen aquellas referidas a la observación de posibles casos de maltrato, al reporte de estos y el seguimiento en el hogar, no solo del maltrato físico, sino también aquel que resulte de condiciones de descuido del niño. Se reconoce que el reporte de estos casos puede ser complejo, por lo que las prácticas relacionadas suponen charlas y otros recursos formales e informales sobre maltrato infantil, sobre legislaciones y sobre derechos afines a estos temas.

Así, las características actuales de los y las usuarias de los centros de desarrollo infantil y, en general, de las instituciones de educación inicial y preescolar, obligan al profesional, especialmente al agente educativo, a ampliar su perspectiva de su labor educativa, hacia la atención y la orientación. Por ello, se dice que hoy en día no basta con saber de una disciplina, ni ser multidisciplinario, sino que supone el actuar con comprensión emocional (Mora, 2006).

Lo social, en el contexto de las condiciones de bienestar emocional, por su parte, hace referencia al entorno en el que se mueve el niño frente a los demás sujetos. Esto implica unas condiciones que conducen al niño a sentirse amado y querido, de tal forma que se encuentre cómodo y satisfecho en el entorno en el que se encuentra. Es por ello por lo que se insiste en que el trabajo sobre las emociones es central para garantizar el bienestar del niño. Así, por ejemplo, los profesionales suelen hacer mención del trabajo sobre la autoestima, por medio de prácticas de juego, de la música, del arte y, en general, mediante la estimulación y actividades motrices. 
Estas estrategias, como la pintura y el trazo, también pueden ser utilizadas por los profesionales psicosociales para el diagnóstico infantil.

Lo emocional, además, refiere a las condiciones de soporte afectivo del niño y a la capacidad de este de expresar afecto. Sobre el manejo de emociones, los profesionales hacen énfasis en el trabajo con la lúdica y con los cuentos (como por ejemplo, “el monstruo de los colores”, Llenas, 2014), canciones o audiocuentos, títeres o por medio del manejo de siluetas.

Los profesionales también suelen hacer mención a los procesos de gestación en las usuarias, y a la importancia de los vínculos durante dicho proceso con sus hijos. Para estos profesionales, la exposición a situaciones de violencia y de vulnerabilidad afecta de manera significativa a estos niños y niñas, incluso desde el vientre materno, por lo que se tornan relevantes los conocimientos sobre elementos que promueven el bienestar emocional de los niños antes del nacimiento. Más aún si tenemos en cuenta lo referido por Durán y Torrado-Pacheco (2014), en cuanto que "las niñas $y$ adolescentes desplazadas tienen índices mucho más altos de embarazo y maternidad, en comparación con otros grupos de su misma edad en el país” (p.103). A continuación, las competencias identificadas en este nivel:

Tabla 5.5. Competencias en entornos que promueven el bienestar psicológico y emocional Nivel individual.

\begin{tabular}{|c|c|c|}
\hline Conocimientos & Prácticas & Valores \\
\hline $\begin{array}{l}\text { - Conocimientos sobre con- } \\
\text { diciones que promueven una } \\
\text { buena salud mental y emocio- } \\
\text { nal en la primera infancia. } \\
\text { - Conocimientos sobre es- } \\
\text { trategias de promoción de la } \\
\text { salud mental de niños, niñas y } \\
\text { familias víctimas del conflicto. } \\
\text { - Conocimientos sobre rutas } \\
\text { integrales de atención y pro- } \\
\text { tocolos dirigidos a la atención } \\
\text { en salud mental de niños, ni- } \\
\text { ñas y sus familias. } \\
\text { - Conocimientos sobre resi- } \\
\text { liencia y estrategias de afron- } \\
\text { tamiento. } \\
\text { - Conocimientos sobre con- } \\
\text { diciones que promueven la } \\
\text { autoestima infantil. } \\
\text { - Conocimientos sobre com- } \\
\text { petencias emocionales en ni- } \\
\text { ños: expresión, comprensión }\end{array}$ & $\begin{array}{l}\text { - Realizar observaciones sien- } \\
\text { do sensibles a las alteraciones } \\
\text { comportamentales de niños y } \\
\text { niñas. } \\
\text { - Trabajar conjuntamente en- } \\
\text { tre profesionales educativos, } \\
\text { psicosociales y familias, para } \\
\text { la observación y seguimiento a } \\
\text { condiciones y comportamien- } \\
\text { tos de los niños, especialmente } \\
\text { en casos de población víctima } \\
\text { de conflicto. } \\
\text { - Observar y acompañar las } \\
\text { diferentes manifestaciones y } \\
\text { reacciones de los niños cuyos } \\
\text { hogares han sido afectados por } \\
\text { el conflicto. } \\
\text { - Redireccionar casos que re- } \\
\text { quieran una atención profunda } \\
\text { a unidades de atención especia- } \\
\text { lizadas. } \\
\text { - Promover la resiliencia y es- } \\
\text { trategias de afrontamiento en }\end{array}$ & $\begin{array}{l}\text { - Asumir una perspectiva basa- } \\
\text { da en la construcción, promo- } \\
\text { ción y mantenimiento de una } \\
\text { cultura de paz. } \\
\text { - Adoptar una perspectiva } \\
\text { de promoción de la salud y } \\
\text { prevención de la enfermedad } \\
\text { infantil, basada en el segui- } \\
\text { miento, la observación y el } \\
\text { acompañamiento. } \\
\text { - Reconocer la importancia de } \\
\text { la superación de la adversidad. } \\
\text { - Reconocer la importancia del } \\
\text { afrontamiento de las situacio- } \\
\text { nes conflictivas. } \\
\text { - Asumir una perspectiva de } \\
\text { derecho de los niños y niñas a } \\
\text { gozar de salud mental. } \\
\text { - Asumir una perspectiva de } \\
\text { protección integral de los ni- } \\
\text { ños y sus familias. }\end{array}$ \\
\hline
\end{tabular}




\begin{tabular}{|c|c|c|}
\hline $\begin{array}{l}\text { y regulación de las emociones } \\
\text { en la primera infancia. } \\
\text { - Conocimientos sobre el vín- } \\
\text { culo afectivo madre-hijo (cui- } \\
\text { dador-niño). } \\
\text { - Conocimientos sobre formas } \\
\text { de operar desde el Progra- } \\
\text { ma de Atención Psicosocial } \\
\text { y Salud Integral a Víctimas - } \\
\text { PAPSIVI. }\end{array}$ & $\begin{array}{l}\text { los niños y sus familias, apoya- } \\
\text { das estas en prácticas pedagógi- } \\
\text { cas o en las actividades rectoras } \\
\text { de la primera infancia. } \\
\text { - Promover la comunicación } \\
\text { asertiva. } \\
\text { - Resignificar los proyectos de } \\
\text { vida de los niños y sus familias. } \\
\text { - Identificar condiciones de } \\
\text { maltrato psicológico y emocio- } \\
\text { nal en el niño. } \\
\text { - Realizar prácticas de satisfac- } \\
\text { ción emocional en momentos } \\
\text { de alimentación. } \\
\text {-Promover espacios para la re- } \\
\text { creación que faciliten el bienes- } \\
\text { tar emocional. } \\
\text { - Promover interacciones entre } \\
\text { niños y adultos cercanos que } \\
\text { fortalezcan su vínculo afectivo } \\
\text { y su apego seguro. } \\
\text { - Promover la autoestima in- } \\
\text { fantil por medio de prácticas } \\
\text { pedagógicas enriquecidas, basa- } \\
\text { das en el juego, las expresiones } \\
\text { emocionalima del conflicto. } \\
\text { culicas y las actividades mo- } \\
\text { trices. } \\
\text { - Realizar prácticas para la pro- } \\
\text { moción de competencias emo- } \\
\text { cionales en niños (expresión, } \\
\text { comprensión y regulación), } \\
\text { mediante estrategias pedagógi- } \\
\text { cas enriquecidas. }\end{array}$ & $\begin{array}{l}\text { - Asumir una perspectiva re- } \\
\text { lacionada con alimentación } \\
\text { afectiva. } \\
\text { - Comprometerse con brindar } \\
\text { afecto, acompañamiento, apo- } \\
\text { yo y soporte emocional. } \\
\text { - Actuar con comprensión } \\
\text { emocional. } \\
\text { - Adoptar una perspectiva re- } \\
\text { flexiva sobre el cuerpo afecta- } \\
\text { do por el conflicto. }\end{array}$ \\
\hline
\end{tabular}

\section{Nivel institucional}

Institucionalmente los profesionales suelen referirse a un acompañamiento psicológico o psicosocial a niños y niñas. Estas prácticas están dirigidas al seguimiento al niño que ha sido víctima de la violencia, con estrategias que le permitan sobrellevar la situación. También aparece la atención psicosocial dirigida al trabajo sobre los miedos generados por el conflicto (estrés postraumático).

Igualmente, se menciona la importancia del redireccionamiento del niño a una uni- 
dad de atención especializada en casos de problemas psicológicos; es decir, hacer remisiones de niños con dificultades derivadas de la exposición a condiciones de violencia, con el fin de que se le realicen terapias de apoyo. Entre estas prácticas se menciona el trabajo para generar o aumentar la resiliencia del niño. Los profesionales recomiendan que este ejercicio se realice por medio de cuentos como "Tito y Pepita” (Low, 2011), y del trabajo basado en la comunicación asertiva.

Tabla 5.6. Competencias en entornos que promueven el bienestar psicológico y emocional Nivel institucional.

\begin{tabular}{|c|c|c|}
\hline Conocimientos & Prácticas & Valores \\
\hline $\begin{array}{l}\text { - Conocimientos sobre con- } \\
\text { diciones que promueven una } \\
\text { buena salud mental y emocio- } \\
\text { nal en la primera infancia. } \\
\text { - Conocimientos sobre es- } \\
\text { trategias de identificación de } \\
\text { problemas de salud mental de } \\
\text { niños y sus familias víctimas } \\
\text { del conflicto. } \\
\text { - Conocimientos sobre rutas } \\
\text { integrales de atención diri- } \\
\text { gidas a la atención en salud } \\
\text { mental. } \\
\text { - Conocimientos sobre resi- } \\
\text { liencia y estrategias de afron- } \\
\text { tamiento. } \\
\text { - Conocimientos sobre condi- } \\
\text { ciones que promueven la au- } \\
\text { toestima infantil. } \\
\text { - Conocimientos institucio- } \\
\text { nales sobre el Programa de } \\
\text { Atención Psicosocial y Salud } \\
\text { Integral a Víctimas - PAPSIVI. }\end{array}$ & $\begin{array}{l}\text { - Proporcionar las condicio- } \\
\text { nes para un seguimiento a po- } \\
\text { sibles casos de abandono. } \\
\text { - Proporcionar las condicio- } \\
\text { nes para un acompañamiento } \\
\text { psicosocial al niño y su familia. } \\
\text { - Promover el desarrollo de } \\
\text { comunidades de ayuda y au- } \\
\text { toayuda. } \\
\text { - Brindar las posibilidades } \\
\text { para el desarrollo de la perso- } \\
\text { nalidad, en donde se permita, } \\
\text { de manera libre, la expresión } \\
\text { emocional y afectiva del niño } \\
\text { o niña. } \\
\text { - Realizar actividades para la } \\
\text { promoción y mejoramiento } \\
\text { del vínculo afectivo. } \\
\text { - Realizar prácticas apoyadas } \\
\text { en la relación familia-institu- } \\
\text { ción educativa para promover } \\
\text { la salud mental. } \\
\text { - Promover la autoestima, la } \\
\text { resiliencia y las estrategias de } \\
\text { afrontamiento de los niños y } \\
\text { sus familias. }\end{array}$ & $\begin{array}{l}\text { - Asumir una perspectiva ba- } \\
\text { sada en la construcción, pro- } \\
\text { moción y mantenimiento de } \\
\text { una cultura de paz. } \\
\text { - Comprometerse con brindar } \\
\text { afecto, acompañamiento, apo- } \\
\text { yo y soporte emocional. } \\
\text { - Asumir una postura reflexiva } \\
\text { sobre el afecto durante el em- } \\
\text { barazo y la maternidad. } \\
\text { - Asumir una perspectiva de } \\
\text { derecho de los niños y niñas a } \\
\text { gozar de salud mental. }\end{array}$ \\
\hline
\end{tabular}

\section{Nivel interinstitucional}

En este nivel se mencionan las Rutas Integrales de Atención para la Primera Infancia (RIA) y el PAPSIVI. 
Tabla 5.7. Competencias en entornos que promueven el bienestar psicológico y emocional Nivel interinstitucional.

\begin{tabular}{|c|c|c|}
\hline Conocimientos & Prácticas & Valores \\
\hline $\begin{array}{l}\text { - Conocimientos sobre RIAs } \\
\text { para el seguimiento a casos de } \\
\text { maltrato o de cualquier vulne- } \\
\text { ración. } \\
\text { - Conocimientos interinstitu- } \\
\text { cionales sobre el Programa de } \\
\text { Atención Psicosocial y Salud } \\
\text { Integral a Víctimas - PAPSIVI. }\end{array}$ & $\begin{array}{l}\text { - Promover la atención in- } \\
\text { tegral en salud mental en los } \\
\text { territorios. } \\
\text { - Promover la identificación } \\
\text { de casos de maltrato o vulne- } \\
\text { ración infantil. } \\
\text { - Establecer rutas de trabajo } \\
\text { entre instituciones prestado- } \\
\text { ras de servicios de salud men- } \\
\text { tal y las familias, para la aten- } \\
\text { ción psicosocial. }\end{array}$ & $\begin{array}{l}\text { - Asumir una perspectiva ba- } \\
\text { sada en la construcción, pro- } \\
\text { moción y mantenimiento de } \\
\text { una cultura de paz. } \\
\text { - Concebir la educación y el } \\
\text { cuidado como integrados, } \\
\text { con el fin de confluir todas las } \\
\text { necesidades del niño en una } \\
\text { perspectiva holística e inte- } \\
\text { grada del desarrollo del niño. } \\
\text { - Asumir una perspectiva de } \\
\text { derecho de los niños y niñas a } \\
\text { gozar de salud mental. }\end{array}$ \\
\hline
\end{tabular}

\section{Nivel de gobernanza}

En este nivel se mencionan distintas estrategias para la atención psicosocial en territorio.

Tabla 5.8. Competencias en entornos que promueven el bienestar psicológico y emocional Nivel de gobernanza.

\section{Conocimientos}

Prácticas

- Conocimientos sobre RIAs para el seguimiento a casos de maltrato o de cualquier vulneración.

- Conocimientos en las rutas de acceso a los servicios de salud mental en cada territorio.

- Conocimientos sobre el Programa de Atención Psicosocial y Salud Integral a Víctimas PAPSIVI.

\section{Valores}

- Atender de manera integral a los niños, niñas y las familias víctimas en los territorios.
- Asumir una perspectiva basada en la construcción, promoción y mantenimiento de una cultura de paz.

- Concebir la educación y el cuidado como integrados, con el fin de confluir todas las necesidades del niño en una perspectiva holística e integrada del desarrollo del niño.

- Asumir una perspectiva de derecho de los niños y niñas a gozar de salud mental.

\section{Entornos que promueven el bienestar familiar y comunitario}

Para los profesionales, la calidad de vida de niños y niñas afectados por el conflicto se ve trastocada por los cambios en los espacios vitales, por las transformaciones en las relaciones familiares y por los ajustes y desajustes en las estructuras comu- 
nitarias. Los tránsitos, por ejemplo, de niños y niñas desplazados por la violencia, transforman el capital social que se ha construido a través de los años por medio de interacciones y vivencias. Estos, se pierden de un momento a otro, borrando historias y llevándose seguridades, desbordando al niño y arrasándolo emocionalmente.

En este sentido, el lugar de las instituciones de atención y educación es central. De acuerdo con Díaz (2011):

Si comprendemos el concepto de calidad educativa, como aquella que considera no solo las demandas y expectativas sociales, sino también las demandas y expectativas de los estudiantes, es imperativo que las instituciones de educación formal acojan y respondan a las distintas necesidades de la población estudiantil (p.49).

A continuación, lo encontrado en cada uno de los niveles de esta categoría.

\section{Nivel individual}

Para entender el bienestar familiar, se parte de reconocer que la calidad de vida se construye en sociedad, entre familias que habitan un territorio y comparten un estilo de vida; por eso, como señalan Cardona y Agudelo (2005), "desde lo colectivo o público es fundamental determinar el contexto cultural en el que vive, crece y se desarrolla un individuo, pues en él se concentra un capital humano"(p.89), que, si bien pareciera que se destruye o abandona al paso de la violencia, no deja de ser parte de los recuerdos, de lo sagrado y de los sueños de los niños y niñas.

Así, las organizaciones de familias deben generar la visión y la pasión por la transformación, tanto para las propias organizaciones como para los proveedores de servicios y los gobiernos. "Se trata de algo demasiado importante como para dejarlo librado al azar" (Inclusion Internacional, 2012, p.122). Transformación que se gesta en el hogar en la manera como se "mira" a sí mismo los valores y las prácticas que finalmente determinan su participación social y el permanecer en estado de víctima o tomar otra posición, y así, desde el agenciamiento familiar, cambiar la situación de todos y cada uno de los individuos que componen la familia, en clave de bienestar, como se señala en los siguientes testimonios:

"Lo que pasa es que la familia misma se victimiza".

"Hay que entender que la familia es la que debe establecer nuevas pautas".

"Lo único que les interesa es recoger el bono, y a veces el bono lo utilizan para cerveza y no para lo que necesitan sus hijos, por lo que las niñas y los niños quedan desprotegidos, y ahí un mal manejo de los recursos por parte de los padres de familia”.

Para los profesionales, la "unidad familiar" es una estrategia que permitiría sobrellevar las situaciones conflictivas y de violencia armada, lo que coincide con lo mencionado por el Ministerio de Educación Nacional [MEN], en cuanto que "la familia, como actor fundamental en el desarrollo de sus hijos e hijas, debe fortalecerse para promover su desarrollo integral a partir de sus particularidades y de los contextos en que se encuentra" (MEN, 2014b, p.28). En este fortalecimiento juegan un papel importante las agentes educativas, quienes deben contar con los conocimientos y estrategias para poder 
identificar las verdaderas necesidades de los niños, niñas y sus familias y, desde allí, planear la atención, orientación y formación de estos.

El desplazamiento y la violencia también afectan las prácticas de cuidado infantil por parte de las familias. Así, los padres se ven en la necesidad de buscar nuevas formas de trabajo que pueden conducir al descuido del niño. Por ello, se pasa de un cuidado permanente en las zonas rurales a un posible descuido en la ciudad.

En términos de lo comunitario, las narraciones de los profesionales demuestran una escuela donde convergen todas las situaciones sociales, tratando de entrar allí, incluso, problemáticas de orden intrafamiliar que, si bien han de ser asumidas desde lo educativo, afectan tanto el ejercicio educativo como a la persona que ejerce esta labor de acogida y desarrollo. Así, en palabras de González (2016), "el maestro sigue siendo un agente central en el sistema social y, en ese sentido, también es víctima de la violencia que destila el sistema" (p.34). A pesar de esto, su rol sigue siendo central, como observa en el siguiente testimonio:

"Como docente lo que tengo que hacer es acercarme a las familias; es indagar cuáles eran sus condiciones y preguntarles: ¿qué quieren? ¿Qué necesitan? ¿En qué les puedo ayudar?”

Los saberes adquiridos por los profesionales, por medio de la experiencia propia en familia, de su posible rol materno, se convierten en elementos importantes para compartir, mediante el diálogo de saberes, como estrategia de fortalecimiento de la labor como agentes educativos.

Tabla 5.9. Competencias en entornos que promueven el bienestar familiar y comunitarioNivel individual.

\section{Conocimientos}

\section{Prácticas}

Valores
- Conocimientos sobre condiciones de pobreza y diversidad de las familias.

- Conocimientos sobre trabajo con padres y comunidades locales.

- Conocimientos sobre crianza, cuidado y autocuidado.
- Reconocer las necesidades de las familias.

- Generar redes de apoyo para atender problemáticas familiares diversas.

- Analizar las necesidades de las familias para un trabajo efectivo con padres.

- Analizar las necesidades de las comunidades locales para un trabajo efectivo con grupos menos favorecidos o en situación de desventaja.

- Establecer relaciones con padres basadas en la comprensión mutua, la verdad y la cooperación.

- Establecer comunicaciones y
- Adoptar una aproximación democrática e inclusiva para la educación de los niños y sus familias, con el propósito de mantener la cohesión social.

- Promover el fortalecimiento familiar como estrategia de cohesión social y de superación de situaciones conflictivas derivadas de la violencia. 


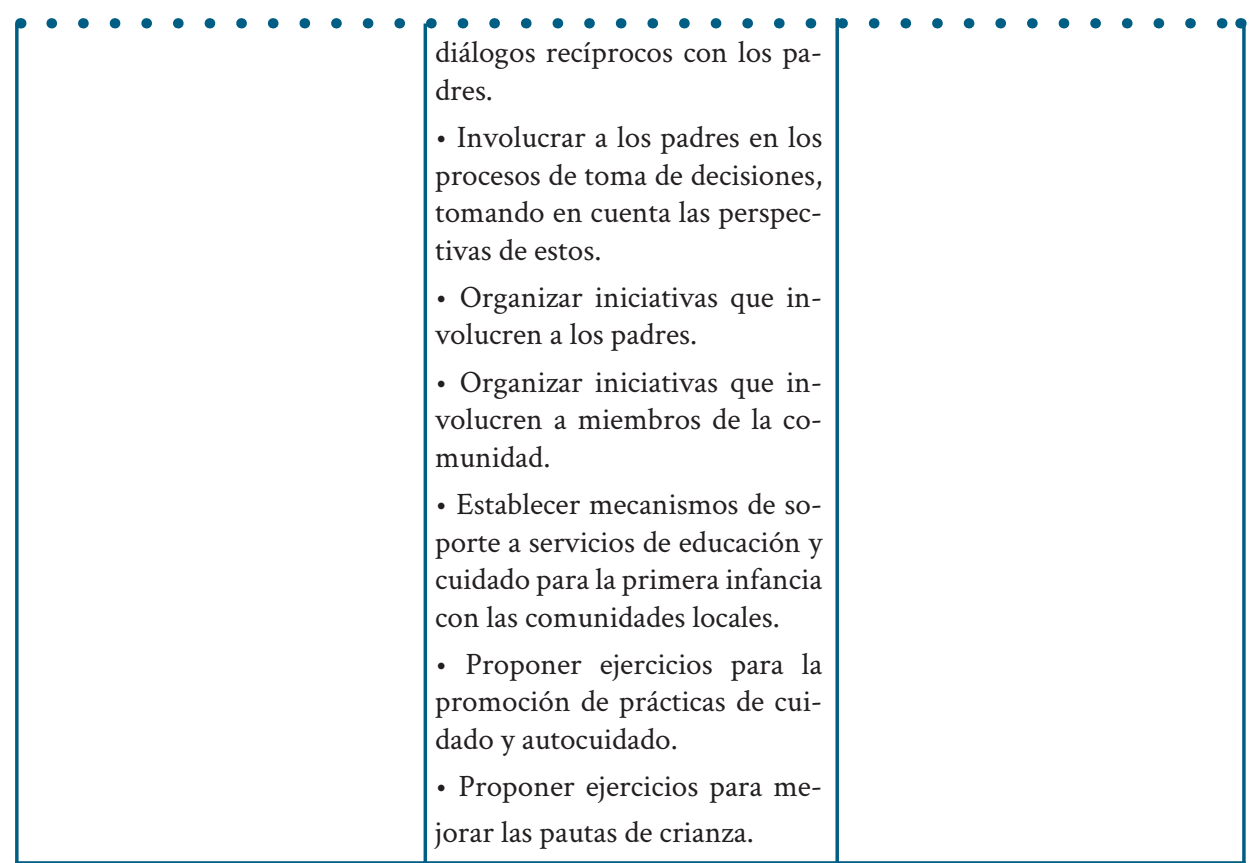

\section{Nivel institucional}

En este nivel las instituciones promueven las condiciones de bienestar al garantizar los cupos de acceso a los servicios que ofrecen y al realizar los tradicionales talleres para padres. Igualmente, es común la referencia al apoyo de la institución en el redireccionamiento de las familias a entidades que pueden ampararlas, en los casos en los que no puedan cumplir con los requisitos para el acceso a los servicios de atención de la institución, como se señala en los siguientes testimonios:

"Familias en Acción, el Instituto Colombiano de Bienestar Familiar (ICBF), la Secretaría [Distrital] de Integración Social (SDIS), las Juntas de Acción Comunal (JAC), los CDI, las Casas de Justicia. A estos lugares pueden acudir y pedir ayuda".

"Solicitar ayuda con las directivas. Acercarse a una fundación y pedir ayuda y hacer talleres de padres para sensibilizarlos".

"Desde la institución educativa se hacen los talleres de padres. Esa ha sido la estrategia".

Tabla 5.10. Competencias en entornos que promueven el bienestar familiar y comunitarioNivel institucional.

\section{Conocimientos}

\section{Prácticas} Valores
- Conocimientos sobre condiciones de pobreza y diversidad de las familias.

- Conocimientos sobre condiciones de los entornos
- Favorecer la constitución de redes de apoyo para las familias, que faciliten un equilibrio

\begin{tabular}{l|l} 
económico de estas. & - Adoptar una aproximación \\
- Proponer ejercicios para la & democrática e inclusiva para la
\end{tabular} 


\begin{tabular}{|c|c|c|}
\hline 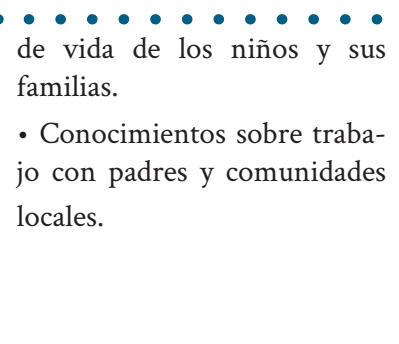 & $\begin{array}{l}\text { promoción de prácticas de cui- } \\
\text { dado y autocuidado. } \\
\text { - Proponer ejercicios para me- } \\
\text { jorar las pautas de crianza. } \\
\text { proponer protocolos para la } \\
\text { procción del niño, en el que }\end{array}$ & $\begin{array}{l}\bullet \bullet \bullet \bullet \\
\text { educación de los niños y sus } \\
\text { familias, con el propósito de } \\
\text { mantener la cohesión social. } \\
\text { - Promover el fortalecimiento } \\
\text { familiar como estrategia de } \\
\text { cohesión social y de supera- } \\
\text { ción de situaciones conflicti- } \\
\text { vas derivadas de la violencia. }\end{array}$ \\
\hline
\end{tabular}

\section{Nivel interinstitucional}

En este nivel se hace referencia al compromiso de las redes de apoyo con las familias que atraviesan condiciones difíciles y al trabajo articulado para la atención y garantía de derechos de niños y niñas.

Tabla 5.11. Competencias en entornos que promueven el bienestar familiar y comunitarioNivel interinstitucional.

\begin{tabular}{|c|c|c|}
\hline Conocimientos & Prácticas & Valores \\
\hline $\begin{array}{l}\text { - Conocimientos sobre re- } \\
\text { des de participación de las } \\
\text { familias para la atención } \\
\text { infantil. } \\
\text { - Conocimientos sobre en- } \\
\text { tidades, programas y pro- } \\
\text { yectos para la garantía de } \\
\text { los derechos de los niños y } \\
\text { sus familias. }\end{array}$ & $\begin{array}{l}\text { - Proponer ejercicios de diálo- } \\
\text { go entre la institución y la fa- } \\
\text { milia para el acompañamiento, } \\
\text { cuidado y protección del niño } \\
\text { o niña. } \\
\text { - Proponer acciones de aten- } \\
\text { ción al niño y su familia adap- } \\
\text { tadas a las necesidades de estos. } \\
\text { - Proponer un trabajo con las } \\
\text { mesas sectoriales e intersecto- } \\
\text { riales para la articulación de } \\
\text { los servicios. } \\
\text { - Trabajar bajo un sistema in- } \\
\text { tegrado de información que } \\
\text { permita la consulta sobre la } \\
\text { atención y la eficiencia en la } \\
\text { misma. }\end{array}$ & $\begin{array}{l}\text { - Comprometerse con la } \\
\text { vida de las familias en condi- } \\
\text { ciones difíciles. }\end{array}$ \\
\hline
\end{tabular}

\section{Nivel de gobernanza}

En este nivel se reconoce que las políticas que emergen de la demanda de atención a las necesidades de las víctimas del conflicto, o producto secundario de algunas de sus causas/consecuencias, no van más allá de lo material, dejando de lado la reconstrucción de la vida, necesaria para procesos de resiliencia y resignificación individual, familiar y social. Es por ello por lo que, siguiendo a Durán y Torrado-Pacheco (2014), urge la revisión de las políticas públicas dirigidas a la infancia y la adolescencia para que trascienda su tradicional asistencialismo, avanzando hacia la construcción de 
un modelo equitativo de acceso a servicios sociales que garanticen universalmente derechos. Se requieren, en este sentido, acciones profundas para la transformación de las realidades, pensadas desde y hacia los sujetos.

Tabla 5.12. Competencias en entornos que promueven el bienestar familiar y comunitario Nivel de gobernanza.

\begin{tabular}{|l|l|l|}
\hline \multicolumn{2}{|c|}{ Conocimientos } \\
\begin{tabular}{|l|l|l|}
\hline - Conocimientos de estrate- \\
gias comprehensivas para en- \\
frentar la pobreza.
\end{tabular} & $\begin{array}{l}\text { - Promover la organización } \\
\text { familiar para la educación y } \\
\text { cuidado infantil. }\end{array}$ & $\begin{array}{l}\text { • Comprometerse con el dere- } \\
\text { cho de las familias. }\end{array}$ \\
- Trascender el asistencialismo \\
hacia un modelo equitativo de \\
acceso a servicios sociales que \\
garanticen los derechos. \\
- Proponer rutas de atención \\
que respondan a los contextos \\
diversos y a las necesidades de \\
los territorios.
\end{tabular}

\section{Entornos que promueven el desarrollo personal e interpersonal}

En esta categoría se ubican las competencias relacionadas con los entornos que promueven el desarrollo infantil, tanto personal como interpersonal. Los profesionales suelen resaltar acá la importancia de la estimulación del niño y el desarrollo de competencias ciudadanas, especialmente dirigidas a la convivencia. A continuación, lo encontrado en cada nivel.

\section{Nivel individual}

En este nivel se señala una serie de condiciones de los entornos que promueven el desarrollo infantil, algunas de estas se articulan con los referentes existentes para potenciar el desarrollo del niño, como las actividades rectoras de la primera infancia, presentadas por el MEN en su serie de orientaciones: juego, exploración del medio, literatura y arte, que posibilitan los aprendizajes infantiles (MEN, 2014a).

Así, se observa que el encuentro pedagógico, pensado en la vía del desarrollo del niño, debe ir más allá de los contenidos de las asignaturas. Se debe partir de reconocer, en las escuelas, las existencias de cada persona, muchas veces narradas no solamente desde lo oral, sino a través de los silencios, a través del cuerpo. Cabe aquí la cita de Skliar (2017), en la que se señala "no ser impunes cuando hablamos del otro. No ser inmunes cuando el otro nos habla” (p.83), lo que guarda relación con el siguiente testimonio:

\footnotetext{
"Yo tengo el caso de un niño colombo-venezolano. Su mamá cambia de pareja cada rato, y su papá tiene pareja, y yo he visto cómo su proceso es lento. Tiene un proceso de un niño de cinco
} 
años y no tiene procesos de atención”.

"Pienso que es una tarea del docente, desde el reconocimiento de la historia, abordar las problemáticas en las aulas de clase y resolver las situaciones desde el aula, y sensibilizar a los niños sobre las problemáticas de los otros”.

Este ejercicio de acompañamiento al desarrollo implica, para el profesional, visibilizar la demanda, ser consciente de sí mismo y del otro, y tratar de verse como un ser humano auténtico; de la misma manera al otro, el cual no es una producción o representación propia. Lo anterior exige una apertura del profesional para descubrir la existencia del otro en sí mismo y en medio de la comunidad.

Tabla 5.13. Competencias en entornos que promueven el desarrollo personal e interpersonalNivel individual.

\begin{tabular}{|c|c|c|}
\hline Conocimientos & Prácticas & Valores \\
\hline $\begin{array}{l}\text { - Conocimientos de varios } \\
\text { aspectos del desarrollo del } \\
\text { niño (desde una perspectiva } \\
\text { holística-integral: motora, } \\
\text { cognitiva, social, emocio- } \\
\text { nal, creativa...). } \\
\text { - Conocimientos sobre } \\
\text { promoción del desarrollo } \\
\text { infantil. } \\
\text { - Conocimientos para la } \\
\text { promoción de la solución } \\
\text { pacífica de los conflictos. }\end{array}$ & $\begin{array}{l}\text { - Observar al niño con el fin } \\
\text { de identificar sus potenciali- } \\
\text { dades de desarrollo. } \\
\text { - Documentar el progreso } \\
\text { sistemático del niño con el fin } \\
\text { de redefinir, de manera cons- } \\
\text { tante, las prácticas educativas. } \\
\text { - Realizar ejercicios de } \\
\text { promoción del desarrollo } \\
\text { infantil. } \\
\text { - Fomentar la resolución pa- } \\
\text { cífica de los conflictos. } \\
\text { - Promover la conciencia de } \\
\text { sí y del otro, como partes de } \\
\text { una comunidad. }\end{array}$ & $\begin{array}{l}\text { - Promover las potencialida- } \\
\text { des del niño con el fin de faci- } \\
\text { litar su participación en la vida } \\
\text { de la institución. } \\
\text { - Promover la democracia, la } \\
\text { solidaridad, la ciudadanía acti- } \\
\text { va, la creatividad y la realiza- } \\
\text { ción personal. } \\
\text { - Promover el reconocimiento } \\
\text { del ser. } \\
\text { - Promover la resolución pací- } \\
\text { fica de los conflictos y la con- } \\
\text { ciliación. }\end{array}$ \\
\hline
\end{tabular}

\section{Nivel institucional}

Para entender las competencias relacionadas con el desarrollo personal e interpersonal en este nivel, se parte de reconocer el escenario de la violencia en la institución: el escenario escolar cobija múltiples prácticas violentas que van más allá de las situaciones de agresividad verbal, física o psicológica que podemos observar en las relaciones de algunos miembros de la comunidad educativa. Por ello, existe una serie de normas y condiciones que vulneran al que desea entrar y, a título del poder institucional, invisibilizan los derechos. Por ello, cobra vigencia lo señalado por González (2016), en términos de que "la violencia tradicional es ejercida por los maestros y por la institución escolar sobre los alumnos, y su justificación se encuentra en la misma concepción autoritaria de la educación” (p.27), lo cual urge una resignificación de los manuales de convivencia y demás políticas institucionales, a la luz de los derechos humanos, de los niños y niñas, de las personas en condición de discapaci- 
dad, de las comunidades indígenas, entre otras. Esto, pensando en las escuelas como territorios de paz, como espacios seguros y garantes de derechos. Así, el estar juntos se convierte en principio y base de la escuela o los lugares de desarrollo. Aprender juntos y superar las barreras propias del proceso de crecimiento y desarrollo, lo cual, en el marco de la violencia producto del conflicto, juega un papel fundamental.

Tabla 5.14. Competencias en entornos que promueven el desarrollo personal e interpersonal Nivel institucional.

\begin{tabular}{|c|c|c|}
\hline Conocimientos & Prácticas & Valores \\
\hline $\begin{array}{l}\text { - Conocimientos de varios } \\
\text { aspectos del desarrollo del } \\
\text { niño (desde una perspectiva } \\
\text { holística-integral: motora, } \\
\text { cognitiva, social, emocional, } \\
\text { creativa...). }\end{array}$ & $\begin{array}{l}\text { - Proveer espacios para el de- } \\
\text { sarrollo integral del niño. } \\
\text { - Fomentar la resolución pa- } \\
\text { cífica de los conflictos. } \\
\text { - Promover la conciencia de sí } \\
\text { y del otro, como parte de una } \\
\text { comunidad. }\end{array}$ & $\begin{array}{l}\text { - Promover las potencialida- } \\
\text { des del niño con el fin de faci- } \\
\text { litar su participación en la vida } \\
\text { de la institución. } \\
\text { - Promover la democracia, la } \\
\text { solidaridad, la ciudadanía acti- } \\
\text { va, la creatividad y la realiza- } \\
\text { ción personal. } \\
\text { - Promover la resolución pací- } \\
\text { fica de los conflictos y la con- } \\
\text { ciliación. }\end{array}$ \\
\hline
\end{tabular}

\section{Nivel de gobernanza}

En este nivel resalta el reconocimiento de derechos y el reconocimiento de la situación de la educación y cuidado en diferentes contextos.

Tabla 5.15. Competencias en entornos que promueven el desarrollo personal e interpersonal Nivel de gobernanza.

\begin{tabular}{|c|c|c|}
\hline Conocimientos & Prácticas & Valores \\
\hline $\begin{array}{l}\text { - Conocimientos de los de- } \\
\text { rechos de los niños y sus } \\
\text { familias. } \\
\text { - Conocimientos de la situa- } \\
\text { ción de la educación y cuida- } \\
\text { do en la primera infancia en } \\
\text { el contexto local, regional, } \\
\text { nacional e internacional. }\end{array}$ & $\begin{array}{l}\text { - Proveer espacios para el } \\
\text { desarrollo integral del niño, } \\
\text { con sensibilidad contextual y } \\
\text { territorial. } \\
\text { - Promover la identidad per- } \\
\text { sonal del niño. }\end{array}$ & $\begin{array}{l}\text { - Promover las potencialida- } \\
\text { des del niño con el fin de fa- } \\
\text { cilitar su participación en la } \\
\text { vida de la institución. } \\
\text { - Promover la democracia, la } \\
\text { solidaridad, la ciudadanía ac- } \\
\text { tiva, la creatividad y la reali- } \\
\text { zación personal. } \\
\text { - Promover la resolución } \\
\text { pacífica de los conflictos y la } \\
\text { conciliación. }\end{array}$ \\
\hline
\end{tabular}




\section{Los entornos que promueven el desarrollo social y cultural}

Este último conjunto de competencias se relaciona con los entornos que promueven el desarrollo social y cultural infantil. Para buena parte de los profesionales, este, al igual que el bienestar físico y psicológico, se torna relevante, especialmente por la necesidad de mantenimiento o recuperación de las condiciones culturales previas al conflicto o desplazamiento, o por la necesidad de efectuar procesos de inclusión social y atención a la diversidad de esta población en los nuevos espacios educativos.

\section{Nivel individual}

Desde este nivel es importante reconocer el desprendimiento cultural que viven niños y niñas y sus familias, el cual va más allá de cambiar de ambiente o habilidades para integrarse. Dicho desprendimiento conduce a una pérdida del capital humano, misma que referencian Cardona y Agudelo (2005), cuando advierten que la persona vive, crece y se desarrolla en un contexto cultural cargado de significados que él o ella ha tejido con el apoyo de los demás, y que le permite valorar la vida cotidiana. Los niños y niñas y sus familias, que por medio de actos violentos son expulsados de su cultura y deben someterse a un nuevo proceso de enculturación o endoculturación (Sola-Morales, 2012), se ven enfrentados al despojo de su capital humano y cultural, a costa de un proceso de integración social a veces insatisfactorio, como se señala en el siguiente testimonio:

"A ese niño no le preguntan qué quiere y lo trasladan a otro espacio en el que llega estigmatizado y para mí esto es un tipo de violencia”.

Entender este capital humano es importante, y el profesional juega un rol fundamental en dicho proceso. Así, por ejemplo, tener en cuenta las historias de vida, cómo viven los estudiantes, es vital para una planeación educativa que responda a las verdaderas necesidades de los niños, las niñas y sus familias, lo que coincide con la popular frase de Ospina (1999), de que "todo proyecto histórico que pretenda erradicar los males sin conocer su fuente está condenado al fracaso” (p. 60). Por ello, seguir con una atención educativa vacía de contenido humano, social, político y económico, cuestiona las capacidades y valores de los profesionales y agentes educativos, lo cual guarda relación con lo mencionado en los siguientes testimonios:

"Nadie sabe de la vida de las niñas y los niños, y las maestras son las que tienen que saber qué hacen".

"Subestimamos a los niños y creemos que ellos no comprenden las problemáticas de los otros niños".

Otro elemento que aparece de forma importante es el efecto que tiene la violencia y el desplazamiento en la adquisición y la práctica cultural. El capital cultural del niño y su familia se ve afectado, se ve transformado por los nuevos espacios en los que deben transitar luego del desplazamiento. Este nuevo espacio cultural es visto como distinto, como se menciona en los siguientes testimonios:

\footnotetext{
"Le pregunté a una mamá venezolana si ya matriculó a sus niñas cerca y dijeron que no, que
} 
les tocaba en la Balsa o en Bojacá, que eran donde recibían de todo".

La expresión «reciben de todo» es bastante común en el medio educativo, de manera despectiva, por no decir violenta, donde se "sabe" que hay lugares o instituciones donde pueden entrar ciertas personas y otras no; peor aún, hay ciertos lugares para aquellos que se agrupan en su diferencia más marcada, haciendo territorios permitidos y barreras invisibles, que se valen de las actitudes para mantenerse en el tiempo.

Por ello, es importante entender que el profesional es un agente político, que hace parte del ejercicio de la garantía de derechos y que, mediante la educación y el cuidado, debe procurar la defensa de los derechos de los niños y las niñas, lo cual permite y facilita el ejercicio verdadero de una corresponsabilidad, desde la consciencia del rol que desempeñan y su impacto en la vida de sus estudiantes o de los sujetos de atención y cuidado.

Otros elementos que se cruzan en este nivel tienen que ver con las condiciones de inclusión/exclusión, igualdad/desigualdad, que se perpetúan mediante las prácticas de los profesionales. Según Rettberg (2003):

La dificultad de delimitar la definición de construcción de paz para el postconflicto refleja una tensión entre una visión minimalista de los retos del postconflicto (reducido a la superación de las secuelas específicas del conflicto como, por ejemplo, la reconstrucción de la infraestructura destruida) y una visión maximalista (enfocada en parar la guerra y generar las condiciones propicias para fomentar el desarrollo económico, político y social del país en cuestión, para superar las causas así llamadas «estructurales» de los conflictos, como, por ejemplo, la pobreza, la inequidad y la exclusión que estas generan). (p.17)

De fondo, se plantea una discusión alrededor de la igualdad versus la desigualdad, base fundamental para hablar de desarrollo cultural, en cuanto a los valores relacionados con el acceso del niño a la cultura, ser reconocido, como aparece en el testimonio del profesional que menciona ir "más allá de un etiquetamiento sociocultural, económico $y /$ o político”.

"Al hacer la investigación en el aula, tienen niños con muchas diferencias y problemáticas y el bienestar no solo es para los niños que tienen barreras de aprendizaje, sino que se tiene que ver lo cultural".

Es de recordar que el niño es el actor central en las situaciones de violencia, tan afectado como invisible. Los profesionales pueden perder a los niños y niñas de vista, asegurando, con ello, un futuro de violencia al dejarlos a su suerte y sin ningún tipo de garantías de ley. Es por ello por lo que, como lo mencionan Cussiánovich y Márquez (2002), "el enfoque de derechos nos convoca a tener al niño, a la niña como tal, como referente insoslayable. Es lo que la Convención sobre los Derechos del Niño consagra como el principio de interés Superior del Niño" (p.66). Es, en palabras de Skliar (2017), "no ser impunes cuando hablamos del otro. No ser inmunes cuando el otro nos habla” (p.83); dos condiciones fundamentales para todo agente educativo: la necesidad del respeto y de reconocimiento. Ser conscientes de una educación en la cual se es a través del otro. 
Los profesionales, así, suelen hacer énfasis en no tener ningún tipo de discriminación, ni de prácticas excluyentes. Mencionan reconocer la apertura al otro que llega sin más pretensiones que ser parte de una comunidad. Sin embargo, esto se cruza con las necesidades de diagnóstico que rompen con los ideales de no estigmatización, como aparece en los siguientes testimonios:

"Ya no se mira el diagnóstico del niño. Si no puede caminar, de una vez se le pone una silla de ruedas, y así no controle esfínteres se lo llevan a la profesora. «el niño no habla bien. No importa. Así llévenselo a la profesora». Se está pasando por encima de las situaciones”.

"Si yo le exijo a la mamá un diagnóstico para que el niño se sienta cómodo, esto se convierte en dificultades con la mamá, pero lo que yo quiero es que él avance y se sienta bien”.

"La docente no sabe cómo manejar esto y yo me siento en cero para manejar esta gama de posibilidades de las niñas y los niños”.

Tabla 5.16. Competencias en entornos que promueven el desarrollo social y cultural Nivel individual.

\section{Conocimientos}

- Conocimientos sobre formas de participación infantil.

- Conocimientos sobre trabajo en contextos de diversidad (aproximaciones en contra de sesgos y prejuicios, diálogo intercultural, identidad, entre otros).

- Conocimientos sobre formas de acceso del niño a la cultura.

- Conocimientos sobre formas de participación infantil en actividades sociales y culturales.

- Conocimientos sobre discapacidad en primera infancia.

- Conocimientos sobre planes de ajustes razonables (PIAR), y sus formas de realización.

\section{Prácticas}

- Conocer al niño, su historia de vida y su contexto social y cultural.

- Reconocer la diversidad y proponer estrategias para la inclusión.

- Facilitar diálogos interculturales soportados en la participación de los padres.

- Promover espacios para la recreación que permitan la expresión de la herencia cultural.

- Valorar e incentivar la expresión infantil por medio de múltiples lenguajes (pintura, danza, narraciones, entre otros).

- Hacer accesible al niño a la herencia cultural de las comunidades locales, a la vez que a la herencia cultural de la humanidad (arte, drama, música, danza, deporte, entre otros).

- Incentivar en el niño la capacidad tanto para participar en la producción cultural como para expresarse a sí mismo.

- Involucrar al niño en proyectos de base comunitaria (festivales, eventos culturales, entre otros) y valorar sus con-
Valores

- Adoptar una aproximación basada en derechos para la educación y el cuidado en la primera infancia, en la cual, los derechos del niño para la ciudadanía incluyan su participación completa en la vida social y cultural de su comunidad.

- Promover la democracia, la solidaridad, la ciudadanía activa, la creatividad y la realización personal.

- Adoptar una perspectiva que reconozca y dé cuenta de la individualidad del niño y que, a la vez, permita el ejercicio igualitario de los derechos.

- Adoptar una aproximación democrática e inclusiva que valore la diversidad y la discapacidad.

- Asumir un enfoque diferencial.

- Asumir la inclusión como mecanismo eficiente para la construcción de una sociedad más democrática, tolerante y respetuosa de las diferencias.

- Asumir la educación como un derecho de todos. 


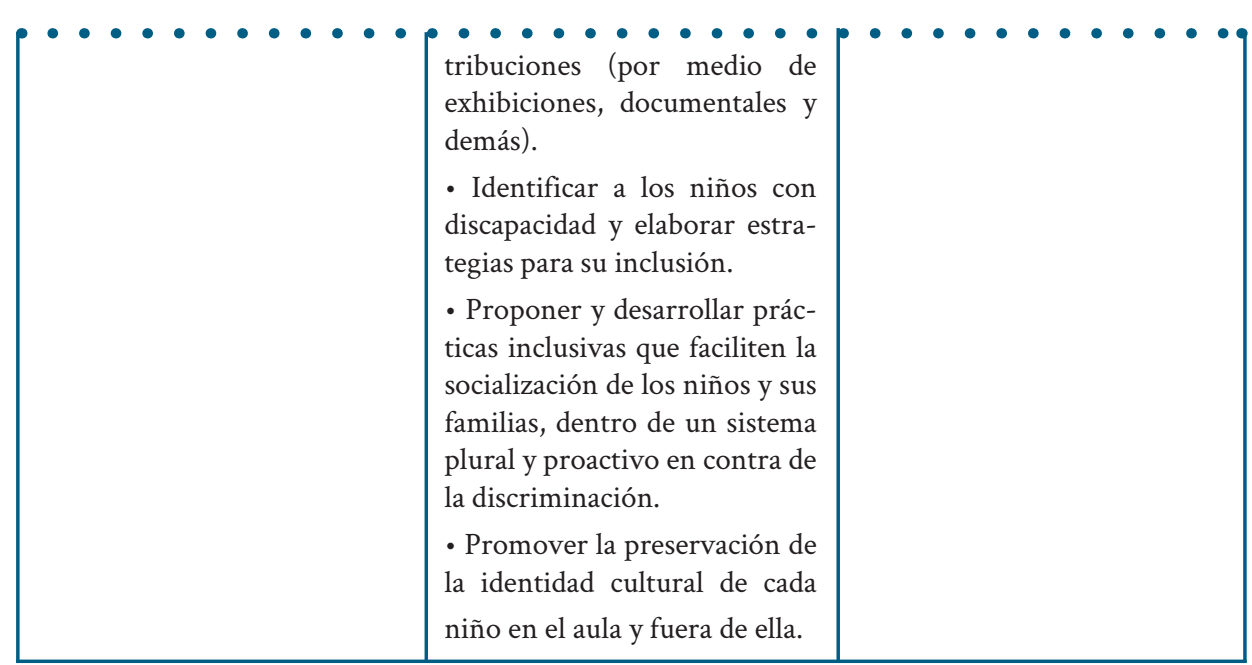

\section{Nivel institucional}

En este nivel se reconoce el lugar de la institución para promover la inclusión y la atención a la diversidad. Sin embargo, los testimonios parecen señalar las faltas y los problemas morales que se juegan en las instituciones con estas intenciones:

"La institución educativa no tiene la capacidad para reconocer la diferencia de cada uno. Llegan al aula estigmatizados".

La corresponsabilidad del Estado, la familia y la sociedad, se constituye en una oportunidad para la escuela. En palabras de Magendzo y Toledo (2011), "en toda intervención resulta indispensable que la comunidad escolar, en su conjunto, reconozca la existencia y gravedad de la problemática” (p.16). Con cierta sorpresa se ve cómo, en las intervenciones de los profesionales, se cuestiona una «doble moral» de las instituciones educativas, por parte de algunos docentes y directivos docentes, quienes condicionan el acceso, la participación y la permanencia de los estudiantes, siempre y cuando sus formas de ser, pensar y hacer estén dentro de lo esperado y normado en cada espacio escolar, so pena de ser excluidos del mismo, como se señala en el siguiente testimonio:

"En mi colegio se habla de diversidad e inclusión, pero hay un fenómeno [desde donde se dice]: «bienvenidos, hermanos venezolanos!», pero eso se hace es para tener más alumnos, pero no reconociendo su diferencia, y esto solo queda en el discurso”.

En general, se olvida el hecho de que las escuelas son un lugar donde se puede pensar en la paz. En donde muchas de ellas se han constituido como territorios de paz, dando ejemplo a la comunidad entera. Como señalan Durán y Torrado-Pacheco (2014), son lugares donde se construye y se aplica la mirada de no violencia, que contrasta con lo que se vive en la vida social. De esta manera, el ejercicio de los profesionales está llamado a resignificar sus prácticas lejos de la violencia, en un ambiente de proximidad, escucha y reconocimiento, todo esto como política educativa hecha realidad en las aulas. 
Por ello, hoy en día las instituciones están llamadas a un proceso de transformación de sus políticas, prácticas y cultura. Se les invita a pasar de la educación tradicional a una educación inclusiva. El reto, según el MEN (2007), es entender que la inclusión implica la construcción una sociedad más democrática, tolerante y respetuosa de las diferencias, entendiendo la diversidad como esencia de las comunidades educativas. Sin embargo, se reconoce que existen prácticas que no permiten el reconocimiento del ser, dado que, por medio de estas, se determina quién es el otro, se lo condena y se le limita a una forma de ser y a un espacio a habitar. Siguiendo a Lévinas (2002), "la ética es una óptica" (p.50), una forma de mirar al otro a la distancia sin dejarse afectar, sin dejarse tocar, que nos hace insensibles o, como diría Foucault (1996):

Es como si experimentásemos una repugnancia singular en pensar la diferencia, en describir los alejamientos y las dispersiones, en desintegrar la forma tranquilizadora de lo idéntico o (...) Es como si tuviésemos miedo de pensar al otro en el tiempo de nuestro propio pensamiento (p.19-20).

Aunque, en palabras de Skliar (2017), no se trata de abogar por hacer, de todo esto, una suerte de paraíso de lo políticamente correcto, sino comprender cuánto afectamos y somos afectados en la convivencia cotidiana, y cómo todo ello trae y perpetúa las dinámicas de la violencia en Colombia.

Tabla 5.17. Competencias en entornos que promueven el desarrollo social y cultural Nivel institucional.

\begin{tabular}{|c|c|c|}
\hline Conocimientos & Prácticas & Valores \\
\hline $\begin{array}{l}\text { - Conocimientos sobre aten- } \\
\text { ción a la diversidad. } \\
\text { - Conocimientos sobre planes } \\
\text { de ajustes razonables (PIAR), y } \\
\text { su ejecución. } \\
\text { - Conocimientos institucio- } \\
\text { nales sobre preservación de la } \\
\text { identidad cultural. }\end{array}$ & $\begin{array}{l}\text { - Ofrecer oportunidades es- } \\
\text { pecializadas para la educación } \\
\text { intercultural. } \\
\text { - Facilitar el acceso a espacios } \\
\text { para la recreación que permi- } \\
\text { tan la expresión de la herencia } \\
\text { cultural. } \\
\text { - Promover la preservación de } \\
\text { la identidad cultural de cada } \\
\text { niño en el aula. } \\
\text { - Realizar acciones para pro- } \\
\text { porcionar y fomentar el acceso } \\
\text { equitativo a los recursos socia- } \\
\text { les y culturales. } \\
\text { - Promover la participación } \\
\text { de las familias y la comunidad } \\
\text { para corregir las desigualdades } \\
\text { sociales estructurales. } \\
\text { - Asumir una perspectiva de } \\
\text { "aprender juntos" y de supera- } \\
\text { ción colectiva de las barreras } \\
\text { sociales e institucionales. }\end{array}$ & $\begin{array}{l}\text { - Adoptar una perspectiva de- } \\
\text { mocrática y de respeto por la } \\
\text { diversidad y la discapacidad. } \\
\text { - Pensar la institución como } \\
\text { territorio de paz, como un es- } \\
\text { pacio seguro para los niños y } \\
\text { las niñas, y como garante de } \\
\text { derechos. } \\
\text { - Reconocer la diferencia y } \\
\text { erradicar la estigmatización. } \\
\text { - Promover la ciudadanía, } \\
\text { como ejercicio activo y parti- } \\
\text { cipativo de niños y niñas que } \\
\text { conocen su contexto y que res- } \\
\text { petan y reconocen a los otros. }\end{array}$ \\
\hline
\end{tabular}




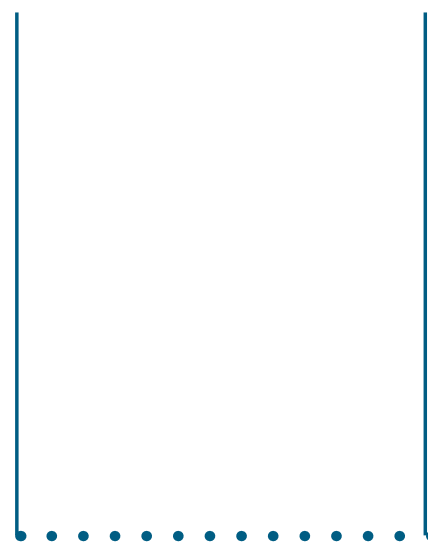

- Revisar las normativas institucionales existentes para favorecer los procesos de inclusión educativa.

- Promover condiciones de acceso, participación y permanencia de niños y niñas en la institución.

- Promover prácticas de conocimiento conjunto y co-construcción de sentidos y saberes, por medio de la escucha y el reconocimiento del otro.

\section{Nivel interinstitucional}

Aquí se habla de los conocimientos, prácticas y valores interinstitucionales que reconocen el pensamiento, las habilidades y capacidades diversas.

Tabla 5.18. Competencias en entornos que promueven el desarrollo social y cultural Nivel interinstitucional.

Conocimientos

- Conocimientos sobre el desarrollo de capacidades en los niños y las niñas.

Prácticas Valores

- Promover, desde los colectivos de atención a la primera infancia, prácticas sociales que reconozcan el pensamiento, las capacidades y habilidades de niños y niñas.
- Adoptar una perspectiva democrática y de respeto por la diversidad y la discapacidad.

- Asumir una postura basada en el deseo de vivir y de superar las huellas del conflicto.

- Comprometerse con las familias y sus niños con discapacidad.

\section{Nivel de gobernanza}

Este último nivel está relacionado con la garantía de los derechos en un sentido amplio, lo cual implica una posición frente a [o una creación de] una "cultura de la igualdad”, que reconozca el conflicto, que permee las prácticas y transforme las políticas. En palabras de Rousseau:

En lugar de destruir la desigualdad natural, el fundamento constituye, para esa desigualdad física que la naturaleza puede haber establecido entre los hombres, una igualdad que es moral y legítima, por la que los hombres, que pueden ser desiguales en fuerza con inteligencia, se convierten en iguales por convención y por derecho legal. (Rousseau, citado por Guibet y Romañach, 2010, p.97)

A continuación, algunos testimonios que señalan el lugar del Estado frente a lo anterior: 
"No es que todo sea gratuidad, pero hay cosas que tienen que solventar el Estado, porque son nuestros impuestos los que están siendo invertidos".

"La victimización sí se puede cambiar. Hay cosas que son del sistema y hay cosas que son del Estado".

Tabla 5.19. Competencias en entornos que promueven el desarrollo social y cultural Nivel de gobernanza.

\begin{tabular}{|c|c|c|}
\hline Conocimientos & Prácticas & Valores \\
\hline $\begin{array}{l}\text { - Conocimientos de estrategias } \\
\text { comprehensivas para enfrentar } \\
\text { las inequidades socioculturales. } \\
\text { - Conocimientos de la diversi- } \\
\text { dad en todas sus formas, y de } \\
\text { prácticas antidiscriminatorias. }\end{array}$ & $\begin{array}{l}\text { - Reconocer las narraciones } \\
\text { de los actores del conflicto, de } \\
\text { las víctimas, para conocer los } \\
\text { contextos sociales y culturales } \\
\text { vividos. } \\
\text { - Buscar los mecanismos gu- } \\
\text { bernamentales para la preser- } \\
\text { vación de la identidad cultural } \\
\text { del niño. }\end{array}$ & $\begin{array}{l}\text { - Asumir un enfoque de de- } \\
\text { rechos. } \\
\text { - Garantizar el derecho de los } \\
\text { niños a una participación en } \\
\text { sociedad. } \\
\text { - Reconocer al niño más allá } \\
\text { de etiquetamientos sociocul- } \\
\text { turales, económicos y/o po- } \\
\text { líticos. } \\
\text { - Adoptar una perspectiva } \\
\text { "equilibrada", que reconozca } \\
\text { y dé cuenta de la individuali- } \\
\text { dad del niño y que, a la vez, } \\
\text { permita el ejercicio igualita- } \\
\text { rio de los derechos. } \\
\text { - Promover el respeto e in- } \\
\text { clusión de la diversidad. }\end{array}$ \\
\hline
\end{tabular}

\section{Conclusiones}

En este capítulo hemos visto la importancia de reconocer las condiciones para una calidad de vida, por medio de entornos basados en las familias, que promueven el bienestar y el desarrollo infantil, pensando en el ejercicio del profesional que atiende a niños y niñas víctimas del conflicto, y en un sistema competente para dicha atención. Se rescata, en este ejercicio comprensivo, la importancia de los entornos que mantienen o promueven unas condiciones de bienestar físico y material, principalmente de salud y nutrición, de gestionar o de poner en funcionamiento las redes existentes de atención en salud, de generar dispositivos para el acompañamiento, la observación y el seguimiento al niño, y en la promoción de ambientes seguros y protectores.

En los entornos que promueven el bienestar psicológico y emocional, resalta la atención psicosocial y la promoción de la resiliencia. Resultan importantes para este proceso las competencias emocionales de los profesionales, y el acompañamiento y observación de los niños en distintos escenarios, para reconocer necesidades de apoyo tanto psicológico como emocional. Estos procesos pueden encontrar soporte en las actividades rectoras de la primera infancia, especialmente en el uso de cuentos 
y en el trabajo mancomunado con las familias.

En los entornos que promueven el bienestar familiar y comunitario, se resalta el papel de la familia, el profesional, la institución educativa y las instituciones de apoyo, para dar soporte y ayuda para la configuración del espacio vital infantil, lo cual implica una preocupación genuina por el niño y unas rutas de atención claras y contextualizadas en los territorios.

Por último, en las condiciones de desarrollo personal, interpersonal, social y cultural, se resalta el reconocimiento y mantenimiento de las condiciones culturales de los niños y niñas, y los ejercicios de inclusión educativa y social, en donde el profesional tiene un papel importante.

Es de esperar que este panorama resulte útil tanto para los profesionales que trabajan promoviendo condiciones para la atención a la primera infancia-condiciones cuya expectativa es el mejoramiento de la calidad de vida de niños y niñas- como para los tomadores de decisiones, especialmente en aquellas competencias que aparecen en el nivel de gobernanza en los distintos entornos.

\section{Referencias}

Andrade, J. (2010). Mujeres, niños y niñas, víctimas mayoritarias del desplazamiento forzado. Orbis. Revista Científica Ciencias Humanas, 6(16), 28-53.

Andrade, J., Angarita, L., Perico, L., Henao, N., y Zuluaga, Y. (2011). Desplazamiento forzado y conflicto armado. Niños y niñas vulnerados en sus derechos humanos. Orbis. Revista Científica Ciencias Humanas, 7(20), 51-78.

Balcells-Balcells, A., Giné, C., Guàrdia-Olmos, J., Summers, J., \& Mas, J. (2019). Impact of supports and partnership on family quality of life. Research in Developmental Disabilities, 85, 50-60. https://doi.org/10.1016/j.ridd.2018.10.006

Bertelli, M., Bianco, A., Rossi, M., Scuticchio, D., \& Brown, I. (2011). Relationship between individual quality of life and family quality of life for people with intellectual disability living in Italy. Journal of Intellectual Disability Research, 55(12), 1136-1150. https://doi.org/10.1111/j.13652788.2011.01464.x

Betancourt, T., Meyers-Ohki, S., Charrow, A., \& Tol, W. (2013). Interventions for children affected by war: An ecological perspective on psychosocial support and mental health care. Harvard Review of Psychiatry, 21(2), 70-91. https://doi.org/10.1097/HRP.0b013e318283bf8f

Bhopti, A., Brown, T., \& Lentin, P. (2016). Family quality of life: A key outcome in early childhood intervention services - A scoping review. Journal of Early Intervention, 38(4), 191-211. https:// doi.org/10.1177/1053815116673182

Cardona, D., y Agudelo, H. (2005). Construcción cultural del concepto calidad de vida. Revista Facultad Nacional de Salud Pública, 23(1), 79-90.

Cussiánovich, A., y Márquez, A. (2002). Hacia una participación protagónica de los niños, las niñas y adolescentes. Lima, Perú: Save The Children.

Davey, M., Trinder, J., Embuldeniya, U., Biggs, S., Anderson, V., Nixon, G., ... Walter, L. M. (2013). Sleep disordered breathing in early childhood: Quality of life for children and families. Sleep, 36(11), 1639-1646. https://doi.org/10.5665/sleep.3116

Departamento Administrativo Nacional de Estadística. (2017). Encuesta Nacional de Calidad de Vida (ECV). Bogotá, Colombia. Recuperado de: http://www.dane.gov.co/files/investigaciones/boletines/mmm/bol_emm_ene18.pdf 
Derluyn, I., \& Broekaert, E. (2007). Different perspectives on emotional and behavioural problems in unaccompanied refugee children and adolescents. Ethnicity and Health, 12(2), 141-162. https:// doi.org/10.1080/13557850601002296

Dhillon, J., Logani, A., Agarwal, R., \& Mathur, V. (2014). Development and validation of oral health-related early childhood quality of life tool for North Indian preschool children. Indian Journal of Dental Research, 25(5), 559. https://doi.org/10.4103/0970-9290.147078

Díaz, C. (2011). Nuevos conceptos, viejas representaciones: el reto de de-construir la normalidad. Paulo Freire. Revista de Pedagogía Crítica, 10(9), 47-56.

Dimitry, L. (2012). A systematic review on the mental health of children and adolescents in areas of armed conflict in the Middle East. Child: Care, Health and Development, 38(2), 153-161. https:// doi.org/10.1111/j.1365-2214.2011.01246.x

Durán, E., y Torrado-Pacheco, M. C. (2014). Reflexiones sobre la infancia y adolescencia, conflicto, postconflicto y construcción de paz. En E. Durán (Ed.), Infancia y Adolescencia en Colombia: Transitando Hacia la Paz (95-119). Bogotá, Colombia: Observatorio sobre Infancia/Universidad Nacional de Colombia.

Easton, J., Landgraf, J., Casamassimo, P., Wilson, S., \& Ganzberg, S. (2008). Evaluation of a generic quality of life instrument for early childhood caries-related pain. Community Dentistry and Oral Epidemiology, 36(5), 434-440. https://doi.org/10.1111/j.1600-0528.2007.00417.x

Fisher, J. (2011). Mental health and psychosocial consequences of armed conflict and natural disasters. International Journal of Social Psychiatry, 57(S1), 57-78. https://doi. org/10.1177/0020764010397324

Foucault, M. (1996). La arqueología del saber. México: Fondo de Cultura Económica.

García-Grau, P., McWilliam, R., Martínez-Rico, G., y Morales-Murillo, C. (2019). Child, family, and early intervention characteristics related to family quality of life in Spain. Journal of Early Intervention, 41(1), 44-61. https://doi.org/10.1177/1053815118803772

González, A., Monzón, N., Solís, D., Jaycox, L., \& Langley, A. K. (2016). Trauma exposure in elementary school children: description of screening procedures, level of exposure, and posttraumatic stress symptoms. School Mental Health, 8, 77-88. https://doi.org/10.1007/s12310-015-9167-7

González, J. (2016). Escuela, conflicto y paz. Bogotá, Colombia: IDEP.

Gopnik, A. (2009). El filósofo entre pañales. Madrid: Planeta.

Guibet, C., \& Romañach, J. (2010). Diversity ethics. An alternative to Peter Singer's ethics. Dilemata. Revista Internacional de Éticas Aplicadas, 2(3), 95-116.

Hewitt, N., Gantiva, C. A., Vera, A., Cuervo, M., Hernández, N., Juárez, F., y Parada, A. (2014). Afectaciones psicológicas de niños y adolescentes expuestos al conflicto armado en una zona rural de Colombia. Acta Colombiana de Psicología, 17(1), 79-89. https://doi.org/10.14718/ ACP.2014.17.1.9

Inclusión Internacional. (2012). Comunidades inclusivas = co-munidades más fuertes: Informe mundial sobre el Artículo 19: El derecho a vivir y ser incluido en la comunidad. Londres.

Ison-Zintilini, M., y Morelato-Giménez, G. (2008). Habilidades socio-cognitivas en niños con conductas disruptivas y víctimas de maltrato. Universitas Psychologica, 7(2), 357-367.

Jordans, M., Tol, W., Komproe, I., \& De Jong, J. (2009). Systematic review of evidence and treatment approaches: psychosocial and mental health care for children in war. Child and Adolescent Mental Health, 14(1), 2-14. https://doi.org/10.1111/j.1475-3588.2008.00515.x

Lacunza, A., y Contini, N. (2009). Las habilidades sociales en niños preescolares en contextos de pobreza. Ciencias Psicológicas, 3(1), 57-66.

Lévinas, E. (2002). Totalidad e infinito. Salamanca: Ediciones Sígueme.

Llenas, A. (2014). El monstruo de colores. Barcelona: Editorial Flamboyant.

Low, A. (2011). Tito y Pepita. Bogotá, Colombia: Ediciones B.

Magendzo, A., y Toledo, M. (2011). Bullying: avanzando hacia el pluralismo explicativo. Revista Internacional Magisterio, (53), 16-23.

Maturana, H. (1994). La democracia es una obra de arte. Bogotá, Colombia: Magisterio.

MEN. (2007). Educación para todos. Recuperado de: https://www.mineducacion.gov.co/1621/arti- 
cle-141881.html

MEN. (2014a). Cualificación del talento humano que trabaja con primera infancia. Documento $\mathrm{n}^{\circ} 19$. Serie de Orientaciones Pedagógicas para la Educación Inicial en el Marco de la Atención Integral. Bogotá: Ministerio de Educación Nacional.

MEN. (2014b). Modalidades y condiciones de calidad para la educación inicial. Documento n 50 . Serie de orientaciones para favorecer la calidad de la educación inicial en el marco de la atención integral. Bogotá: Ministerio de Educación Nacional.

MERCER. (2018). Calidad de vida. Recuperado de: https://www.latam.mercer.com/newsroom/2018-calidad-de-vida-internacional.html

Mora, F. (2006). ¿Enferman las mariposas del alma? Madrid: Alianza Editorial.

Oliveira, P., Fearon, R., Belsky, J., Fachada, I., \& Soares, I. (2015). Quality of institutional care and early childhood development. International Journal of Behavioral Development, 39(2), 161-170. https://doi.org/10.1177/0165025414552302

OMS. (2019). WHOQOL: Measuring Quality of Life. Recuperado de: https://www.who.int/healthinfo/survey/whoqol-qualityoflife/en/

Orley, J., y Saxena, S. (1996). ¿Qué es calidad de vida? Foro Mundial de La Salud, 17, 385-387.

Ospina, W. (1999). ¿Dónde está la franja amarilla? Bogotá, Colombia: Norma.

Özer, S., Oppedal, B., Şirin, S., \& Ergün, G. (2018). Children facing war: their understandings of war and peace. Vulnerable Children and Youth Studies, 13(1), 60-71. https://doi.org/10.1080/174 50128.2017.1372652

Peters, N., Mahajan, J., Bawa, M., Sahu, P., \& Rao, K. (2014). Factors affecting quality of life in early childhood in patients with congenital hydrocephalus. Child's Nervous System, 30(5), 867-871. https://doi.org/10.1007/s00381-013-2335-x

Purcell, M., Turnbull, A., \& Wood, C. (2006). Linking early childhood inclusion and family quality of life: Current literature and future directions. Young Exceptional Children, 9(3), 10-19.

Rettberg, A. (2003). Diseñar el futuro: Una revisión de los dilemas de la construcción de paz para el postconflicto. Revista de Estudios Sociales, (15), 15-28.

Schalock, R., y Verdugo, M. (2012). El cambio en las organizaciones de discapacidad. Estrategias para superar sus retos y hacerlo realidad. Guía de liderazgo. Madrid: Alianza Editorial.

Skliar, C. (2017). Pedagogías de las diferencias (Notas, fragmentos, incertidumbres). Buenos Aires: Noveduc.

Sola-Morales, S. (2012). La dialéctica entre las narrativas mediáticas identitarias y los procesos de identificación. Universitat Autònoma de Barcelona.

Urban, M., Vandenbroeck, M., Van Laere, K., Lazzari, A., \& Peeters, J. (2012). Towards competent systems in early childhood education and care. Implications for policy and practice. European Journal of Education, 47(4), 508-526. https://doi.org/10.1111/ejed.12010

Vanegas, J., Bonilla, C., \& Camacho, L. (2011). Significado del desplazamiento forzado por conflicto armado para niños y niñas. Fundamentos en Humanidades, 24(2), 163-189.

Vega-Arce, M., y Nuñez-Ulloa, G. (2017). Experiencias adversas en la infancia: revisión de su impacto en niños de 0 a 5 años. Enfermería Universitaria, 14(2), 124-130. https://doi.org/10.1016/j. reu.2017.02.004

Vera-Márquez, A., Palacio, J., Maya, I., y Holgado, D. (2015). Identidad social y procesos de adaptación de niños víctimas de violencia política en Colombia. Revista Latinoamericana de Psicologia, 47(3), 167-176. https://doi.org/10.1016/j.rlp.2015.06.006

Verdugo, M., Arias, B., Gómez, L., y Schalock, R. (2009). Escala GENCAT de calidad de vida. Manual de aplicación. Barcelona: Institut Ctalá d'Asstència i Serveis Socials y Departamento de Acción Social y Ciudadanía de la Generalitat de Catalunya.

Wong, Y., Wang, T., \& Xu, Y. (2015). Poverty and quality of life of Chinese children: From the perspective of deprivation. International Journal of Social Welfare, 24(3), 236-247. https://doi. org/10.1111/ijsw.12115 


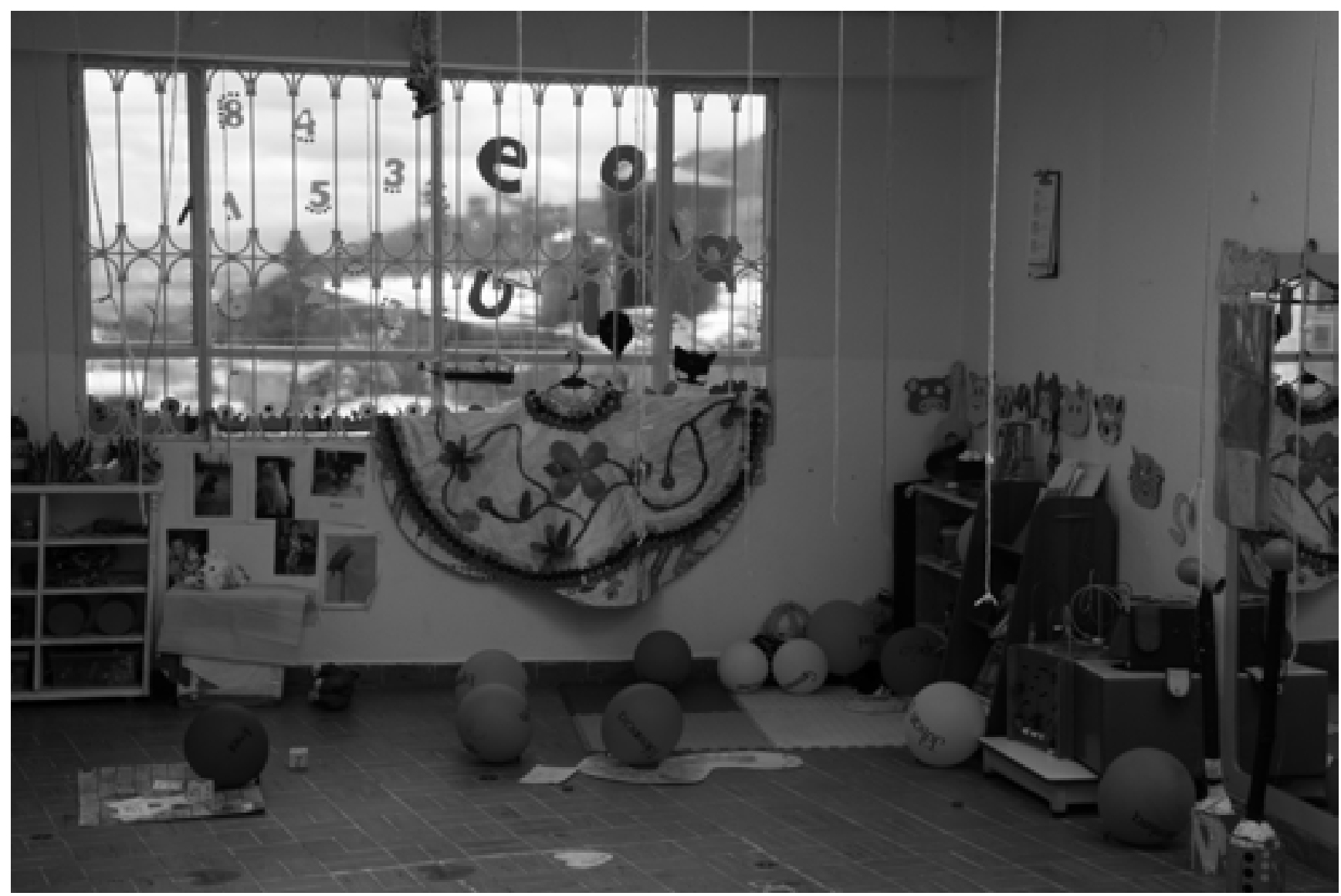




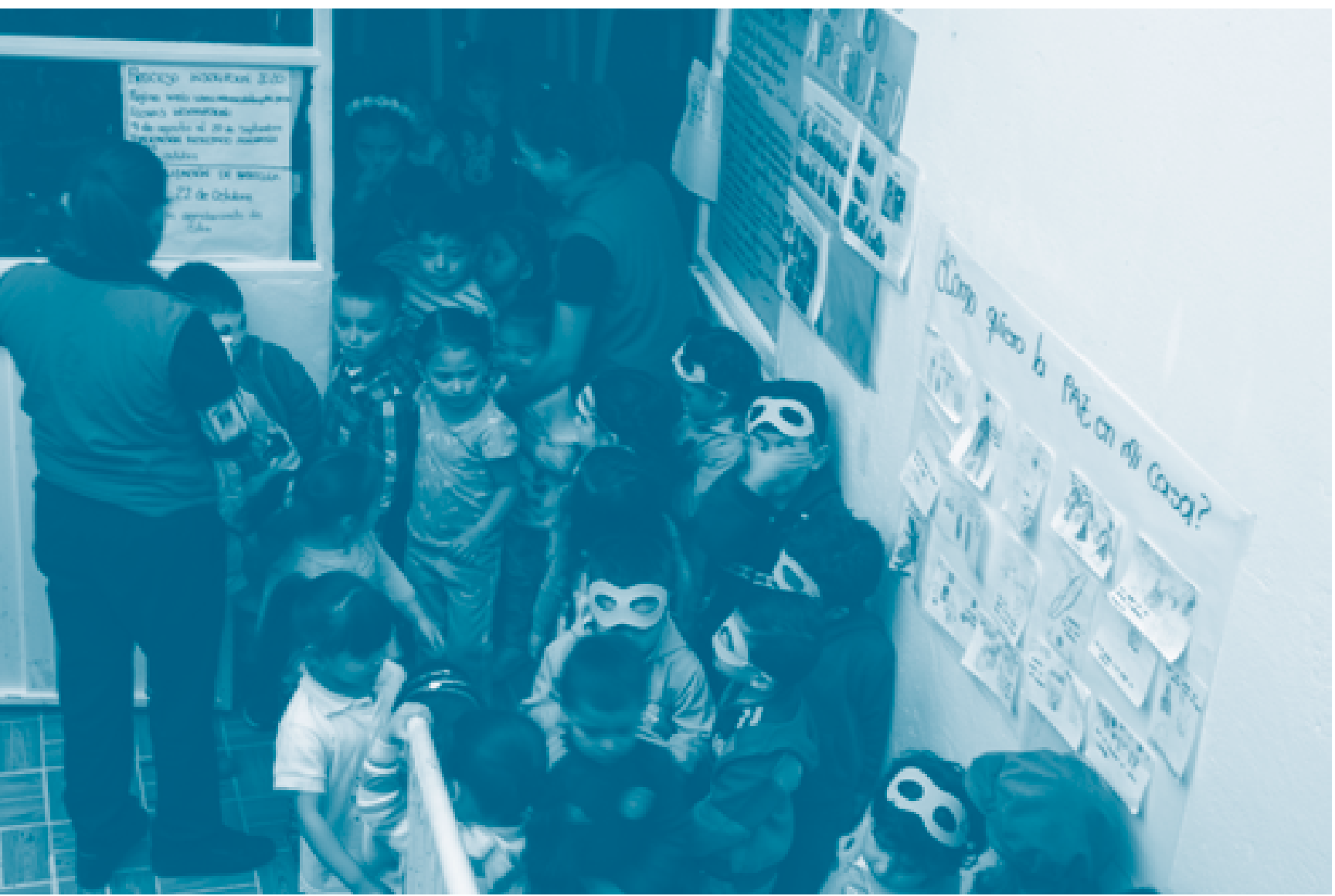

Capítulo 6.

Acciones educativas para promover una cultura de paz en la primera infancia 
$\mathrm{E}$ propósito de este capítulo es socializar los conocimientos, prácticas y valores sobre las acciones educativas que se pueden promover en la primera infancia en el marco de un sistema competente que responda a una educación para la paz y al fortalecimiento de capacidades de las niñas y los niños afectados por el conflicto colombiano.

El capítulo presenta inicialmente la fundamentación teórica sobre la naturaleza de las acciones educativas, luego profundiza sobre el sentido de la educación en la primera infancia desde una perspectiva de construcción de paz, la importancia de la formación docente y las condiciones para garantizar el derecho a la educación de calidad en torno al conflicto, que son, además, las tres grandes categorías por medio de las que se conciben las acciones educativas para promover la paz. Por cada una de estas categorías, se presentan las competencias asociadas a los resultados de lo hallado en el estudio con el talento humano y expertos en el nivel individual, institucional, interinstitucional y de gobernanza.

\section{Naturaleza de las acciones educativas}

En primera instancia, para hacer una aproximación teórica sobre las acciones educativas, se abordará primero lo que es una acción. El Diccionario de la Real Academia Española (DRAE), define el término acción como "Hecho, acto u operación que implica actividad, movimiento o cambio y normalmente un agente que actúa voluntariamente, en oposición a quietud o acción no física” ${ }^{2}$. Precisamente, en el lenguaje cotidiano en castellano, acción denota movimiento, algo opuesto a la quietud o a la pasividad.

Sin embargo, en el consenso de diferentes visiones teóricas que han conceptualizado y guiado la investigación sobre la acción, como la psicología genética, la psicología de la Gestalt y la psicología histórico-cultural, la acción es un acto que tiene dos dimensiones: orientación y ejecución (Piaget, 1969; Köhler, 1959; Leontiev, 1981; Montealegre, 2005). De este modo, toda acción se compone de una dimensión de ejecución mediante contemplación, interpretación o transformación de una realidad, y de orientación, dada por el pensamiento o la dirección que la persona le da a dichos actos (Piaget, 1969; Köhler, 1959; Leontiev, 1981; Montealegre, 2005).

La acción se alimenta también de los objetos del medio sobre los cuales se aplica. De allí, se hace más sofisticada, y puede incluso volver sobre su propia manera de ejecutarse, es decir, hacerse cada vez más consciente, controlada y susceptible de dirección intencional hacia un determinado fin (Flavell, 1999; Karmiloff-Smith, 1994; Piaget, 1969). Por lo tanto, la acción se diferencia del movimiento o del procedimiento en que incluye un plan, su ejecución y la evaluación de sus resultados.

${ }^{2}$ Diccionario de la Real Academia Española, DRAE. Consultado en: https://dle.rae.es/?id=0KZwLbE 
Su definición coincide, entonces, con el control mediante la metacognición (Flavell, 1999; Mateos, 2009).

De acuerdo con lo anterior, la acción es entonces un acto con orientación, procedimientos o formas de ejecución propios y procesos de revisión de esta, tanto en el momento como posteriormente (Flavell, 1999; Karmiloff-Smith, 1994; Mateos, 2009; Piaget, 1969). Las acciones, por orientarse a los objetos y hacia otras personas, son flexibles para cambiar y adaptarse al entorno. Por tanto, las acciones se aprenden y también pueden ser orientadas, guiadas y enseñadas por otros, es decir, puede haber acciones educativas de diferentes tipos.

La acción educativa es una acción enmarcada en la formación de personas o en propósitos educativos. En ese sentido, la acción educativa se puede dirigir hacia el desarrollo del ser (construcción de aspectos que pasan a ser parte de la personalidad o la identidad de la persona) o del saber hacer (consolidación de conocimientos o saberes que permiten razonar y actuar de una manera determinada) (Runge-Peña y Muñoz-Gaviria, 2012). Las acciones educativas hacen referencia a los actos que llevan a cabo distintos actores relacionados con la formación de los niños y la actividad guiada que se realiza con ellos, con actores adultos como los padres, los cuidadores, los profesores y otros profesionales que laboran en las instituciones educativas (Koivula, Gregoriadis, Rautamies y Grammatikopoulos, 2017).

Las acciones educativas suelen tener un componente cultural interiorizado mediante la socialización que no necesariamente es consciente, junto con un componente de asimilación práctica o de lo elaborado en la experiencia. En algunos casos, tienen también un componente de conceptualización del acto educativo, en el caso de los educadores formales (Bruer, 1997; Dimaté-Rodríguez, 2017). Por esta razón, las acciones educativas se clasifican en incidentales e intencionales. A su vez, las acciones educativas intencionales se dividen en acciones educativas intencionales informales o no formales, y en acciones educativas intencionales formales (Russ, Sherin y Sherin, 2016). Las acciones educativas incidentales son acciones educativas que se desarrollan en prácticas asumidas, naturalizadas y no cuestionadas dentro de los grupos que las desarrollan (Bronfenbrenner, 1994). Las acciones educativas intencionales son acciones educativas desarrolladas mediante su desarrollo deliberado y deliberadamente orientado a un objetivo o fin explícito de aprendizaje, que se busca hacer claro para quien enseña y para quien aprende (Russ et al., 2016). Como se enunció, se dividen en dos:

- Acciones educativas intencionales informales o no formales, definidas como prácticas cotidianas de enseñanza, inmersión y enculturación de personas dentro de grupos, formas de pensar, formas de actuar y creencias, que se dan en marcos de actividades cotidianas y situadas en contextos específicos, sin que haya una asignación fija, especializada o pre-especificada de roles entre quienes enseñan y quienes aprenden (Bronfenbrenner, 1994).

- Acciones educativas intencionales formales, definidas como prácticas de enseñanza institucionalizadas que pueden tener mucho en común con las informales o no formales (Russ et.al., 2016), pero en las cuales hay una asignación fija, especializada y especificada de roles entre quienes en- 
señan y quienes aprenden (Bruer, 1997), en torno a campos de saber y de actuación que social y políticamente se han establecido como importantes y con privilegio sobre otros (Stenhouse, 1998).

La acción educativa incidental pone en marcha actividades en las que se hace partícipe a la persona y esta incorpora conocimientos, prácticas y valores por el solo hecho de participar en los grupos que la promueven (Bronfenbrenner, 1994). La acción educativa intencional informal o no formal y la acción educativa intencional formal orientan explícita y deliberadamente, es decir, enseñan a sus miembros con el fin de poder avanzar en una ejecución cada vez más diestra de las prácticas privilegiadas (Guzmán, Ghitis y Ruiz, 2018).

Desde otro punto de vista, en las acciones educativas incidentales y en las acciones educativas intencionales informales o no formales, los agentes que enseñan no están establecidos previamente y pueden rotarse sus roles dentro de actividades de enseñanza que son parte de los contextos situados de su actividad, como parte de la inserción a los más nuevos en su tradición y en su forma de pensamiento colectivamente compartido (Leontiev, 1981). En otro sentido, en las acciones educativas intencionales formales, los agentes que educan son designados institucionalmente con este fin y con esta misión de la enseñanza y orientación de personas (Russ et.al., 2016). La siguiente tabla puede sintetizar estas relaciones.

Tabla 6.1. Relación entre disposición de los agentes y tipo de enseñanza en los diferentes tipos de acciones educativas.

\begin{tabular}{|c|c|c|}
\hline & $\begin{array}{l}\text { Agentes no fijos, } \\
\text { dados por necesidad } \\
\text { de enseñar u orientar }\end{array}$ & $\begin{array}{l}\text { Agentes designados } \\
\text { institucionalmente } \\
\text { para enseñar }\end{array}$ \\
\hline $\begin{array}{l}\text { Enseñanza implícita y } \\
\text { no consciente, apren- } \\
\text { dizaje implícito y no } \\
\text { consciente }\end{array}$ & Acción educativa incidental & \\
\hline $\begin{array}{l}\text { Enseñanza y aprendizaje } \\
\text { explícitos, conscientes y } \\
\text { orientados a un fin }\end{array}$ & $\begin{array}{l}\text { Acción educativa intencional } \\
\text { informal o no formal }\end{array}$ & $\begin{array}{l}\text { Acción educativa intencional } \\
\text { formal }\end{array}$ \\
\hline
\end{tabular}

De este modo, las acciones educativas incidentales forman personas por su participación en contextos de interacciones y prácticas espontáneas, en las cuales desarrollan saber, prácticas y valores privilegiados consciente o inconscientemente por el grupo o los grupos en los cuales participa la persona que se forma (Bronfenbrenner, 1994). Las acciones educativas intencionales informales o no formales forman personas mediante la participación de estas en interacciones o prácticas diseñadas para enseñarles algo o para hacerles aprender algo, dentro de prácticas de este tipo que son comunes dentro de los grupos y los diferentes contextos (Leontiev, 1981). Finalmente, las acciones educativas intencionales formales también forman perso- 
nas mediante la participación de estas en interacciones o prácticas diseñadas para enseñarles algo o para hacerles aprender algo, pero dentro de campos de saber que se han privilegiado previamente y por medio de agentes que han sido designados institucionalmente con la función de enseñar en estos campos (Russ et al., 2016; Stenhouse, 1998).

Estos tres tipos de acciones educativas son las que se ponen en marcha en la educación para la paz y para la resolución de conflictos. Las acciones educativas en primera infancia, dentro del marco de las competencias del talento humano que labora en educación inicial con población afectada por el conflicto colombiano, hacen referencia a trabajos en el aula y a sus labores de apoyo en la educación para la paz en el escenario de la educación inicial.

Partiendo de esta contextualización previa, que permitió reflexionar sobre la naturaleza de las acciones educativas que se realizan con la primera infancia, en lo que resta del capítulo se desarrollarán tres conceptos o macro categorías -con sus respectivas categorías-, que en lo que tiene que ver con acciones educativas y construcción de paz, se consideran centrales en un proceso de cualificación del talento humano que trabaja en escenarios de educación inicial con población afectada por el conflicto.

En la Tabla 6.2. se observa la distribución de estos conceptos como una guía para su lectura. Igualmente, en el texto se encontrará una propuesta de competencias por nivel del sistema, que está ligada a cada macro categoría presentada en esta tabla.

Tabla 6.2. Macro categorias y categorías del concepto de acciones educativas para promover una cultura de paz en la primera infancia.

\begin{tabular}{|l|l|}
\hline \multicolumn{1}{c|}{$\begin{array}{c}\text { Concepto/ } \\
\text { macro categoría }\end{array}$} & \multicolumn{1}{c|}{ Categorías } \\
\hline $\begin{array}{l}\text { Sentido de la educación } \\
\text { en la primera infancia } \\
\text { desde una perspectiva de } \\
\text { construcción de paz }\end{array}$ & $\begin{array}{l}\text { Desarrollo integral y creación de oportunidades para el } \\
\text { ejercicio pleno de la ciudadanía. }\end{array}$ \\
\hline $\begin{array}{l}\text { Formación de educado- } \\
\text { res para promover la } \\
\text { educación para la paz }\end{array}$ & $\begin{array}{l}\text { - Análisis, reflexión y evaluación continua del contexto. } \\
\text { que promueven la educación para la paz. } \\
\text { - Formación para la democracia y ciudadanía. } \\
\text { • Fortalecimiento de capacidades personales. }\end{array}$ \\
\hline $\begin{array}{l}\text { Condiciones para ga- } \\
\text { rantizar el derecho a la } \\
\text { educación de calidad }\end{array}$ & Trabajo articulado entre instituciones con garantía de calidad. \\
\hline
\end{tabular}

\subsection{Sentido de la educación en la primera infancia desde una perspectiva de construcción de paz}

En este apartado es importante mencionar que el sentido de la educación inicial 
es fundamental para la configuración de un modelo de competencias para agentes educativos que trabajan con niños víctimas del conflicto, y por qué se debe orientar hacia la perspectiva de construcción de paz.

Es fundamental que los agentes comprendan que las acciones educativas en primera infancia, al ser incidentales, intencionales no formales e intencionales formales, se inscriben en un campo de oportunidades. Son las mismas oportunidades de las cuales pueden gozar los niños durante su desarrollo en la primera infancia. Lo característico de la primera infancia sea, tal vez, ser un periodo de la vida en el cual el desarrollo y el aprendizaje están todavía muy cerca. Por lo tanto, las oportunidades de desarrollo del niño en primera infancia son también, en general, oportunidades de aprendizaje y el aprendizaje, a su vez, promueve el desarrollo.

De igual manera, es importante resaltar que es en esta etapa donde se logra generar el despliegue de todas las dimensiones del ser humano, el fortalecimiento para el desarrollo de estructuras de autocontrol, regulación, desarrollo y potenciación que son "las bases del desarrollo posterior y se adquieren las habilidades personales y sociales que van a determinar su futuro" (Gutiérrez y Ruiz, 2012, p.108). Como se expone en las Orientaciones Pedagógicas para la Educación Inicial en el Marco de la Atención Integral (Guía 20), el propósito de la educación inicial centra su propuesta en el desarrollo y atención de la primera infancia porque es el momento en que los niños:

\footnotetext{
Aprenden a convivir con otros seres humanos, a establecer vínculos afectivos con pares y adultos significativos [...] a relacionarse con el ambiente natural, social y cultural; a conocerse, a ser más autónomos, a desarrollar confianza en sí mismos, a ser cuidados y a cuidar a los demás, a sentirse seguros, partícipes, escuchados, reconocidos [...] a descifrar las lógicas en las que se mueve la vida, a solucionar problemas cotidianos (Guía 20, 2014 p.12).
}

Por tanto, si los agentes educativos que atienden a la primera infancia conocen y se apropian del sentido de la educación, reflexionan sobre su quehacer y logran enfocar su acción hacia una perspectiva de construcción de paz, promueven una calidad de vida que incide y contribuye a la consolidación y potenciación de las capacidades de los niños. Por esta razón, en esta sección se aborda el desarrollo integral y la creación de oportunidades para el ejercicio pleno de la ciudadanía, así como las grandes líneas de propuesta pedagógica acordes con tal desarrollo.

\section{Desarrollo integral y creación de oportunidades para el ejerci- cio pleno de la ciudadanía}

El desarrollo integral hace referencia a concebir el desarrollo de los niños como integrado por las múltiples dimensiones: físico-orgánicas, intelectuales, socioemocionales, afectivas, y sociales. En general, descansa en la idea de que los seres humanos, en la mayor parte de nuestra actividad, tenemos intervención de todos los aspectos anteriormente mencionados (Bandura, 1986; Dweck, 2015). Dicho desarrollo se da en interacción entre lo que la persona trae consigo, y su relación con diferentes esferas de su entorno. Por lo tanto, implica una relación entre la persona, sus procesos 
y la relación con esas esferas, inscritos en el paso del tiempo (Bronfenbrenner, 1994; Gifre-Monreal y Guitart, 2013).

Esto, visto desde el desarrollo en la primera infancia, nos muestra que hay un despliegue de grandes capacidades de orden intelectual, lingüístico, cognitivo y del organismo en un tiempo relativamente breve en comparación con otros periodos de la vida. Diferentes evidencias científicas muestran que la actividad enriquecida del niño en este periodo tiene incidencia en desempeños sociales e intelectuales posteriores y es una base de seguridad afectiva y de prevención de trastornos y enfermedades, con mayor probabilidad de tener efectos duraderos en comparación con planes e intervenciones que se realizan en otros periodos de la vida de las personas (Mustard, 2007). Por lo tanto, las intervenciones guiadas, de las cuales hacen parte las acciones educativas, son cruciales para cualquier campo del desarrollo en la primera infancia.

Lo anterior nos lleva a considerar que las intervenciones guiadas y las acciones educativas son un importante campo de oportunidades para todos los niños. De esta manera, se da la opción de sentar una base de oportunidades para todos los niños como fin social no negociable, dentro del cual se pueden dirigir las diferentes dinámicas y acciones de los adultos para el logro de este fin (Sen, 2000).

De acuerdo con hallazgos de investigaciones, en el desarrollo de los niños y niñas durante la primera infancia, y en aprendizajes específicos que suceden en esta etapa, muchos avances en la evolución de capacidades en los niños se dan en espacios de interfase. Dichos espacios se caracterizan por ser interacciones del adulto con el niño que, con mayor frecuencia, logran conectar las capacidades que el niño ya tiene, con otras nuevas o que apenas se encuentran en proceso de adquisición (Arias-Velandia y Flórez-Romero, 2011). Las oportunidades que los niños tienen en su desarrollo y su aprendizaje en la primera infancia son más ricas cuando cuentan con mayor probabilidad de tener o generar estos espacios de interfase (Arias-Velandia y Flórez-Romero, 2011).

El espacio de interfase que más se liga al desarrollo y al aprendizaje de competencias para la paz y la ciudadanía, corresponde con las actividades en las cuales los niños comienzan a atribuir estados mentales a los demás y a juzgarlos como estados de creencia, plan, intención o deseo, diferentes de otros tipos de estados en las personas, es decir, actividades en las que se pone en marcha la capacidad de teoría de la mente en los niños (Flórez-Romero, Arias-Velandia y Torrado Pacheco, 2011; Posada-Gilède y Parales-Quenza, 2012; Wellman, Cross y Watson, 2001). En ese sentido, las bases de capacidades para la ciudadanía incluyen ideas, acciones y sentimientos de empatía, que demandan conocer lo que los demás sienten o piensan en determinada situación, la consideración de esa situación y el juicio sobre si la consecuencia de los actos de estas personas son justas o no, lo cual incluye capacidades de consideración de los límites y trato válido con las demás personas en colectivo (subyacentes al manejo y resolución de conflictos, de las normas de convivencia y 
la participación), y fortalecimiento de capacidades ligadas al sentido de la valía de los propios sentimientos, del cuidado y del concepto y sentido de valía de sí mismo (Chaux, 2012; Ruiz-Cardozo, Ñañez-Rodríguez y Capera-Figueroa, 2019).

\section{Lineamientos generales de propuesta pedagógica para la crea- ción de oportunidades}

Lo planteado en el apartado anterior supone un importante reto para los profesores y educadores que laboran en escenarios de la primera infancia. En primer lugar, esta creación de oportunidades para el desarrollo y el aprendizaje implica los siguientes aspectos:

- Análisis y reflexión sobre el contexto del niño, que incluya tanto el de las familias, las comunidades, los medios y sus ideas socialmente compartidas, como el sentido de las propias opciones y oportunidades para desarrollar la propia carrera como educador inicial.

- Conocimientos del profesor sobre la actividad pedagógica de formación ciudadana, en cultura de paz y para el afrontamiento del conflicto.

- Competencias requeridas para manejar con los niños el contenido implicado en la actividad pedagógica de formación ciudadana, en cultura de paz y para el afrontamiento del conflicto.

- Condiciones de trabajo con los niños para la realización de su derecho a la educación.

En las dos secciones siguientes (6.3 y 6.4) se desarrollarán estos aspectos.

A continuación, se relacionan las competencias de los diferentes niveles en la categoría de sentido de la educación en la primera infancia desde una perspectiva de construcción de paz.

\section{Competencias que promueven sentido de la educación en la pri- mera infancia desde una perspectiva de construcción de paz.}

\section{Nivel individual}

Todo agente educativo que trabaje para la primera infancia afectada por el conflicto colombiano requiere orientar sus procesos con una intencionalidad. Para ello, se deben generar ambientes de aprendizaje, apropiación de contenidos, estrategias, momentos pedagógicos, actividades y recursos, así como generación de interacciones, experiencias y reflexiones del proceso de los niños para la construcción de paz y la resolución de conflictos.

Algunos testimonios de los agentes educativos con relación a este nivel mencionan lo siguiente:

Apropiación de contenidos: "Para ser sujetos de paz y seres más sociables y felices, que permitan distinguir entre las buenas y malas acciones". "A través de observaciones, indagaciones y diálogo, las experiencias de los niños le permiten a uno conocer su opinión”.

Interacciones, experiencias y reflexiones de los niños para la construcción de paz: "Hay que enseñarles a los niños a respetar las desigualdades, que tiene el pelo de este color, el que se viste de esta manera, es necesario que respete a los otros, respeto a la vida". "Se trabaja en rutina diaria el respeto de las normas de ciudadanía, pedir la palabra, conservar la derecha 
para caminar, pedir permiso, hacer la fila, a veces entre ellos mismos se corrigen. Son actividades diarias, cotidianas, todos los días se trabajan”.

Con los testimonios de agentes educativos mencionados anteriormente, en el nivel individual las competencias propuestas se centran en identificar, encontrar las características propias que le dan un sentido de ser a la educación infantil, centradas en conocimientos, prácticas y valores hacia la creación de oportunidades para un pleno ejercicio de la ciudadanía.

Tabla 6.3. Competencias que promueven sentido de la educación en la primera infancia desde una perspectiva de construcción de paz - Nivel individual.

\begin{tabular}{|c|c|c|}
\hline Conocimientos & Prácticas & Valores \\
\hline $\begin{array}{l}\text { - Conocimiento de las formas } \\
\text { de expresiones artísticas y } \\
\text { lenguajes propios de la prime- } \\
\text { ra infancia. }\end{array}$ & $\begin{array}{l}\text { - Promover acciones, activida- } \\
\text { des que propongan movimien- } \\
\text { to, gestos, manipulación de los } \\
\text { objetos y por medio de diferen- } \\
\text { tes expresiones que manifiesten } \\
\text { su experiencia, aprendizajes, } \\
\text { problematizando actividades li- } \\
\text { gadas a pensar sobre el conflicto } \\
\text { y la construcción de paz. } \\
\text { - Desarrollar actividades que } \\
\text { promuevan las destrezas que se } \\
\text { requieren para fortalecer la co- } \\
\text { municación, el trabajo colabo- } \\
\text { rativo y la empatía con los otros } \\
\text { en los niños y sus familias. } \\
\text { - Promover y fortalecer accio- } \\
\text { nes que fomenten las compe- } \\
\text { tencias socioemocionales de } \\
\text { escuchar, conversar, leer, escri- } \\
\text { bir y recrear diversos lenguajes } \\
\text { expresivos. } \\
\text { - Favorecer la vinculación afec- } \\
\text { tiva, promover el desarrollo del } \\
\text { lenguaje, incentivar la imagina- } \\
\text { ción, desplegar la creatividad, } \\
\text { ampliar la visión de mundo } \\
\text { (Flórez y Torrado, 2013). }\end{array}$ & $\begin{array}{l}\text { - Valoración del sentido de } \\
\text { las acciones educativas arti- } \\
\text { culadas para fortalecer el de- } \\
\text { sarrollo integral y promover } \\
\text { la construcción de la paz. }\end{array}$ \\
\hline
\end{tabular}

\section{Nivel institucional}

En este nivel de competencias se espera que trabajen de manera articulada las instituciones y sus agentes que laboran en ellas. Como bien lo manifiesta (Urban et al., 2012), el desarrollo de las competencias de los profesionales también es responsabilidad de los equipos profesionales. Por esta razón los criterios que se tuvieron en cuenta para este nivel de competencia institucional, con relación a las acciones 
educativas y competencias del docente, se focalizan en la generación de ambientes significativos, la articulación del trabajo en equipo (psicosocial, nutricionista, coordinador, docentes), conocer las situaciones de los niños que llegan a las instituciones y la promoción de programas y proyectos en la primera infancia para la construcción de paz. Algunos testimonios de los agentes educativos con relación a este nivel mencionan:

Programas, proyectos para la atención integral a la primera infancia: "Desde el CDI tenemos un proyecto pedagógico que se llama Jugando y explorando voy valorando, entonces nuestras sesiones educativas van hacia implementar y recuperar los valores en el hogar, una de las actividades que nosotros realizamos independiente del tema, siempre estamos hablando de eso".

"Nada más cuando uno llama a los niños de uno a uno para entregarles el refrigerio, hacemos venir al bebé, primero para que identifiqué a quién se está llamando, luego ellos van hacia nuestro lugar y nosotros le entregamos nuestro refrigerio”.

Tabla 6.4. Competencias que promueven sentido de la educación en la primera infancia desde una perspectiva de construcción de paz - Nivel institucional

Conocimientos
Prácticas

- Generar oportunidades de expresión y aprendizaje, problematizando actividades ligadas a pensar sobre el conflicto y la construcción de paz.

- Propiciando formas de expresiones artísticas (dibujo, escultura, dramatización, danza, relatos orales, relatos escritos) y lenguajes propios de la primera infancia (juego, literatura, artes), que usan los niños para expresar su experiencia frente a guerra, paz y asuntos relacionados.

- Adelantar actividades basadas en el conocimiento de temas relacionados con el desarrollo de los niños en la primera infancia.

- Poner en práctica estrategias de disciplina positiva.

- Generar oportunidades a los niños para entrar en contacto con bienes culturales; la música, lengua escrita, expresión $\mathrm{y}$ actividades que fortalezcan

\section{Valores}

- Reconocer la importancia de formar en comprensión sobre el conflicto y la construcción de paz.

- Valorar la importancia de potenciar el desarrollo infantil.

- Reconocer la importancia de pautas y modelos de buen trato a los niños.

- Comprender que cada niño es diferente, y que se requiere de una adaptación de sus propuestas pedagógicas a las particularidades de cada uno y de su contexto. 


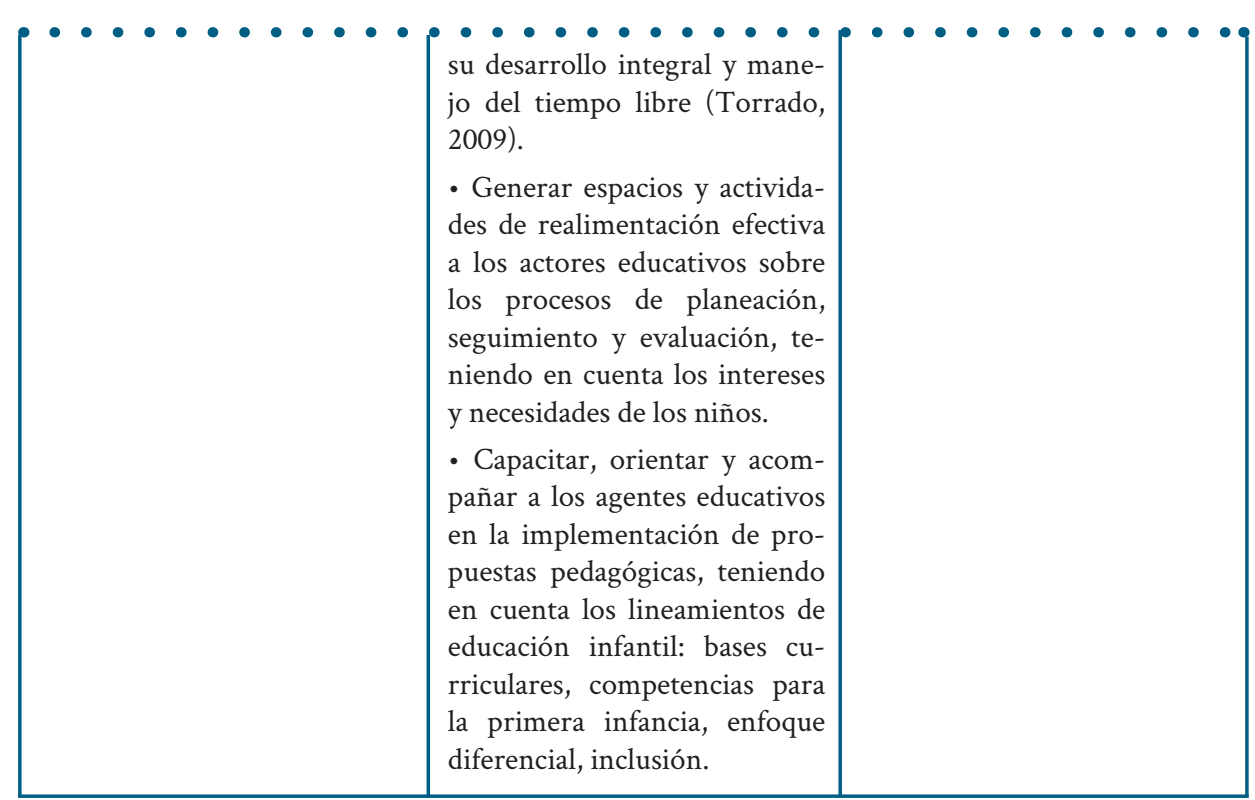

\section{Nivel interinstitucional}

Este nivel corresponde a las alianzas con otras instituciones, para responder a las necesidades del contexto y de los niños. A continuación, se relacionan las categorías. Se espera que las diferentes instituciones se coordinen en la generación de lineamientos, planes, rutas, acciones educativas que propicien el trabajo articulado en la educación de la primera infancia que propicie una cultura de paz. Algunas de las referencias de los agentes educativos con relación a este nivel mencionan:

Lineamientos, planes, rutas protocolos de atención a la primera infancia: "Todos los que atienden a los niños y estén relacionados con la garantía de sus derechos deben conocer claramente los procesos y protocolos de atención”.

Tabla 6.5. Competencias que promueven sentido de la educación en la primera infancia desde una perspectiva de construcción de paz - Nivel interinstitucional.

\section{Conocimientos}

- Conocer programas, planes actividades que propendan por potenciar el desarrollo integral en los diferentes espacios o entornos en los que interactúan los niños.

\section{Prácticas}

\section{Valores}

- Fomentar la participación de la comunidad en eventos de socialización para la transmisión de conocimiento sobre la prevención y evitar la revictimización en los niños afectados por el conflicto.
- Aprender sobre el ejercicio pleno de la ciudadanía. 


\section{Nivel de gobernanza}

Para garantizar el funcionamiento de este nivel de competencia, se requiere la instancia de la dirección y coordinación de la política pública orientada a la generación de lineamientos del sistema educativo y a la destinación de recursos para la formación del talento humano en temas relacionados con la educación para la paz. Algunas de las referencias de los agentes educativos con relación a este nivel mencionan:

Destinación de recursos a la formación en aspectos de educación para la paz y la superación del conflicto armado: "Nosotros tenemos unos documentos, un buzón de sugerencias, el pacto de convivencia, unas orientaciones para el cumplimiento de las normas, hay unas normas de convivencia”. "También hay un comité de padres que han funcionado para que entre ellos mismos busquen soluciones a las situaciones que se presentan”. "Tenemos veedores que dan cuenta de las situaciones que suceden y entre todas proponen alternativas y si estas se cumplen".

Tabla 6.6. Competencias que promueven sentido de la educación en la primera infancia desde una perspectiva de construcción de paz - Nivel de gobernanza.

\begin{tabular}{|c|c|c|}
\hline Conocimientos & Prácticas & Valores \\
\hline $\begin{array}{l}\text { - Conocer características de la } \\
\text { primera infancia como etapa } \\
\text { crucial del ser humano, que } \\
\text { ayuda a fomentar todo el de- } \\
\text { sarrollo en las personas. }\end{array}$ & $\begin{array}{l}\text { - Generar acompañamiento y } \\
\text { capacitaciones permanentes a } \\
\text { las instituciones, actores edu- } \\
\text { cativos sobre planes, rutas de } \\
\text { atención, leyes, normas y polí- } \\
\text { ticas para la atención integral a } \\
\text { la primera infancia. }\end{array}$ & $\begin{array}{l}\text { - Garantizar las condiciones } \\
\text { para desarrollo integral de los } \\
\text { niños víctimas del conflicto. } \\
\text { - Garantizar y reconocer que } \\
\text { todos los agentes educadores } \\
\text { deben ser partícipes en el de- } \\
\text { sarrollo integral de los niños. }\end{array}$ \\
\hline
\end{tabular}

Formación de educadores para promover la educación para la paz

La comprensión del lugar de los educadores de la infancia para promover la educación para la paz pasa por la comprensión crítica y sistémica de la labor de formación que se desarrolla (Urban, Vandenbroeck, Van Laere, Lazzari y Peeters, 2012). Dicha comprensión crítica, según Urban et al. (2012), es cómo se ve el agente educador como actor individual y cómo ve su articulación con diferentes esferas de la atención y educación a la primera infancia ${ }^{3}$. Específicamente, se refiere a dos aspectos de este agente: su comprensión y acción en torno a sus propias necesidades para hacer mejor su labor de atención y educación a la primera infancia, y su comprensión y

\footnotetext{
${ }^{3}$ Comúnmente, la comprensión crítica implica la capacidad de tomar una posición argumentada con respecto a lo que se conoce. En el sentido en que se plantea desde el marco de fundamentación en los sistemas competentes, se refiere a la visualización del sentido del propio trabajo en primera infancia y a la perspectiva que cada actor tiene para articularse con otros y con otras esferas de la atención integral y educación a la primera infancia (Urban et al., 2012).
} 
acción en torno a esferas, actores y coordinación entre niveles para lograr una mejor atención y educación a la primera infancia.

Para lograr que el agente educativo promueva la educación para la paz debe primero conocer las políticas y los programas, e implementar acciones educativas para la construcción colectiva, la participación de la familia y la comunidad, y que el proceso de formación sea continuo. Con ello se propende que el centro de la intencionalidad en la acción educativa se focalice en la formación de los niños (Política pública por los niños y niñas, desde la gestación hasta los 6 años, 2006. p. 156).

De manera que se requiere que el agente educador permanentemente analice, reflexione y evalúe el contexto de los niños, pero también reconozca sus intereses, necesidades y capacidades, así como en la comunidad de referencia y en él mismo. Tanto como es fundamental que el profesor tenga una apropiación pedagógica y promueva e implemente estrategias educativas que fomenten una cultura de paz desde la formación en valores, convivencia y desarrollo de capacidades. A continuación, se profundizará sobre cada uno de estos aspectos.

\section{Análisis, reflexión y evaluación continua del contexto}

Para mejorar la acción educativa se requieren procesos de evaluación y reflexión constantes por parte del educador, son procesos que deben ser permanentes, de análisis de lo que sucede en el contexto donde está inmerso el niño, lo que ayuda a hacer un proceso de planeación coherente con las realidades y necesidades y a responder de manera contextualizada (Castañeda-Bernal, 2016; Pedraza-Pinto, 2018; Ruiz-Cardozo et al., 2019).

\section{Reconocimiento de necesidades, in tereses y capacidades propias}

Generalmente, "contexto" se refiere a un entorno alrededor de una persona. Sin embargo, desde otro enfoque, cada persona puede ser parte de su mismo contexto: así como recibe influencias del entorno, puede tomar decisiones y cursos de acción que modifican su propio entorno (Bronfenbrenner, 1994).

En concordancia con esto, el educador del nivel inicial puede analizar las necesidades de los entornos de los niños con los cuales labora. Sin embargo, también puede realizar análisis y reflexión sobre su propia actividad como educador (Dimaté-Rodríguez, 2017). En ese sentido, se espera que pueda analizar las condiciones en que se realiza su trabajo, cómo podría mejorar, cómo puede beneficiar con él cada vez más a los niños y otros adultos cercanos a estos, y que pueda, en consonancia, articularse con otros actores, esferas y entidades para lograr el cometido de su trabajo (Urban et al., 2012). En otras palabras: identificarse con su labor, y pensarla como una carrera, que en el caso de quienes son profesores, se busca que se inscriba en un desarrollo profesional docente que le reconozca como profesor y como educador profesional (Dimaté-Rodríguez, 2017).

La investigación de Ruiz-Cardozo et al. (2019), muestra que los profesores de educa- 
ción inicial en una ciudad colombiana, cuando se les indaga por el trabajo de formación en competencias ciudadanas, privilegian mucho más las normas de convivencia que otros aspectos relacionados con dichas competencias, y que, si bien reconocen el valor de la empatía, no logran diferenciar en su discurso su trabajo del que se lleva a cabo en otros niveles de educación formal. Tampoco suelen hacer referencia a su propio rol como actores cívicos con independencia de sus labores como maestros, $y$, por tanto, no se perciben en un papel de modelo cultural de lo que buscan formar en los niños.

Esta evidencia muestra la importancia de insistir en que los profesores sean observadores, y, con ello, analicen y reflexionen sobre el tema de la formación ciudadana, para la paz y para enfrentar el conflicto, dirigiendo su atención a lo que significa esta formación, sus conocimientos docentes para formar en estos temas, y al significado que en sí mismo tiene este problema en el niño, sus adultos cercanos, sus familiares y sus comunidades de referencia, tema que se desarrolla en el siguiente subapartado.

\section{Reconocimiento de necesidades, intereses y capacidades en co- munidades de referencia}

Este aspecto del reconocimiento del contexto se refiere al conocimiento de las comunidades de referencia de las personas que aprenden o que participan de la formación, de sus lógicas y de sus formas de pensar colectivamente compartidas (Urban et al., 2012). Es una manera de desarrollar la acción educativa que privilegia la reflexión (contraste entre lo planeado y lo logrado), en el caso de acciones formales y no formales (Stenhouse, 1998), y la anticipación de rutas y posibles obstáculos en las mismas para avanzar en comprensiones en el caso de acciones educativas intencionales formales (Ruiz-Cardozo et al., 2019), que a su vez implica:

- Articulación entre saberes disciplinares y formas en las que los aprendices avanzan en sus comprensiones (Bruer, 1997; Shulman, 1986).

- Conversión de prácticas con los aprendices en sistematizaciones de las mismas, para desarrollar con ellas conocimientos profesionales de enseñanza (Russ et al., 2016), en el campo de solución de conflictos y educación para la paz (Chaux, 2012).

El conocimiento de la referencia por inmersión es uno de los conocimientos clave en educación inicial (Russ et al., 2016). Los niños están creciendo en múltiples esferas de influencia, por lo cual el trabajo del agente educador en este nivel se extiende también a los padres y adultos al cuidado de los niños (Flórez-Romero, Arias-Velandia, Guzmán-Rodríguez y Restrepo, 2014; Gifre-Monreal y Guitart, 2013; Guzmán-Rodríguez, Ghitis y Ruiz, 2018).

\section{Conocimientos del profesor e implementación de estrategias que promueven la educación para la paz}

Si bien es importante el trabajo en educación para la paz, no puede perderse de vista que este contenido implica dimensiones del ser (Quintana-Cabanas, 1995; Runge-Peña y Muñoz-Gaviria, 2012). Este trabajo abarca también una serie de com- 
petencias del agente educador que no se circunscriben exclusivamente al ámbito de educación para la paz y para afrontar el conflicto, pero que ayudan a hacer las actividades de forma más evolutivamente apropiadas para los niños con los que se labora y con su contexto. Específicamente, se refiere a conocimientos necesarios para planear actividades, desarrollarlas, y dar respuesta oportuna y pertinente a necesidades e inquietudes de los niños (Russ et al., 2016).

Este conocimiento plantea, entonces, la articulación del conocimiento del agente educador sobre sus propias competencias, en relación con su conocimiento de los niños, de su forma de aprender, del contexto de los padres y comunidades de referencia de los niños, y de los diferentes ámbitos de funcionamiento con los que se relaciona su trabajo (Russ et al., 2016). También se refiere a sus capacidades para indagar crítica y reflexivamente su práctica, su relación con los niños y sus padres, y los diferentes aspectos del contexto que afectan o tienen alguna incidencia o relación cercana con su trabajo y con la optimización del mismo en articulación con otros actores de la atención a la primera infancia (Urban, Vandenbroeck, Van Laere, Lazzari y Peeters, 2012). Estos conocimientos abarcan también la capacidad de diseño de prácticas de acuerdo con el conocimiento de los niños (Russ et al., 2016), de lograr inmersión y cercanía con la comunidad de referencia de los niños con miras a conocer sus lógicas (Russ et al., 2016). Estas acciones se clasifican en acciones de justicia y convivencia, y en capacidades personales, que se describen a continuación.

\section{Acciones de justicia y convivencia}

La formación para la democracia y la ciudadanía abarca una dimensión de contenido, es decir, de lo que se busca enseñar, formar o inculcar en los niños sobre conflicto y construcción de paz en educación inicial. Abarca competencias de desarrollo de espacios con disfrute para todos sus participantes, y nociones de defensa de derechos amparados en normas y principios (Chaux, 2012). Esta dimensión hace referencia a los aspectos que constituyen el trabajo en el contenido de la educación para la paz, la democracia y la ciudanía en torno a dos aspectos: acciones de justicia y convivencia, que hace referencia a solución de conflictos, manejo de normas de convivencia y participación, y capacidades personales, que alude a autonomía y autorregulación, cuidado de sí mismo y de los otros, y formas de expresión de estados propios en diferentes medios simbólicos de los niños (Castañeda-Bernal, 2016; Chaux, 2012; Koivula et al., 2017; Rodríguez-Huesa, Flórez-Romero y Gómez-Muñoz, 2016; Singer, De Haan, Van Keulen y Bekkema, 2008). Las primeras se desarrollan en este apartado, y las segundas, en el siguiente.

Las acciones de justicia y convivencia se entienden como la serie de conocimientos y habilidades -cognitivas, emocionales y comunicativas- para la participación de las personas en la construcción de una sociedad democrática, pacífica e incluyente (Rodríguez-Huesa et al., 2016). Abarcan el reconocimiento de los niños y niñas como sujetos de derechos, transformadores de su realidad y la posibilidad del desarrollo de habilidades en torno a la configuración de la identidad, participación, autonomía, 
pensamiento cuidante (Rodríguez-Huesa, Flórez-Romero y Gómez-Muñoz, 2016), resolución de conflictos y convivencia entre los niños (Ruiz-Cardozo et al., 2019). Estos procesos están determinados por las interacciones en los ámbitos educativo, familiar y comunitario (Fernández-Barrera, 2009).

Las acciones educativas de justicia y convivencia se entienden desde la perspectiva de construcción curricular: abarcan la articulación de competencias para afrontar el conflicto y la construcción de paz en articulación del trabajo institucional, la vivencia y las experiencias cotidianas de las comunidades de referencia (Chaux, 2012). Este trabajo se focaliza entonces en el apreciarse a sí mismo y apreciar a los otros como personas, (Castañeda-Bernal, 2016; Chaux, 2012; Koivula et al., 2017; Rodríguez-Huesa et al., 2016; Singer et al., 2008). Las acciones educativas conocidas como acciones de justicia y convivencia, de tipo incidental, intencional informal e intencional formal, se clasifican en la educación para la paz y para la superación del conflicto en los siguientes campos:

- Manejo y resolución de conflictos: manejo de conflictos e infracciones de normas en los niños como parte del trabajo desarrollado en el aula. Con ellas se alude a estrategias de resolución de conflictos, identificación de tipos de conflictos evidenciados en el aula, y diseño de estrategias para su mitigación (Singer et al., 2008).

- Manejo de normas de convivencia: manejo de infracciones de normas en los niños como parte del trabajo desarrollado en el aula. Se refiere a la forma en que el educador maneja las infracciones a las normas y a la convivencia entre los niños, siempre con intención formativa. Son también diferentes intervenciones del profesor para llamar la atención o sancionar el incumplimiento de normas en el aula (Singer et al., 2008).

- Participación: capacidad de tomar decisiones sobre la vida propia o de la comunidad (Hart, 1992, como se citó en Rodríguez-Huesa, Flórez-Romero y Gómez-Muñoz, 2016), que puedan ser reconocidas en el entorno social inmediato. Se expresa conforme al desarrollo del niño- niña, sus interacciones comunicativas por medio de múltiples lenguajes y desarrollo de relaciones basadas en la confianza, el respeto, la solidaridad y la cooperación (Castañeda-Bernal, 2016).

Estas acciones educativas siempre son de naturaleza política, dado que se relacionan con la organización social e inciden directamente en las personas. Cabe aclarar, entonces, que dichas acciones se dan en contextos o entornos con los cuales los niños tienen una interacción directa (la familia, el jardín, las interacciones entre padres y educadores, etc.), así como también tienen relación con otros aspectos con los cuales no tienen interacción directa, pero que pueden afectar su desarrollo y educación (ej., comunidades, vecindarios, condiciones socioeconómicas, pensamiento colectivo compartido en la mentalidad) (Bronfenbrenner, 1994; Gifre-Monreal y Gitart, 2013).

Por lo tanto, la educación para la paz implica modificar la acción o el proceder en las relaciones interpersonales, la regulación de relaciones de justicia y convivencia en sociedad, así como el cambio en la relación con el entorno, mediadas por la solidaridad, tolerancia y la empatía (Ministerio de Educación Nacional, 2017), la cooperación, reconciliación y procesos comunitarios para resolver conflictos de modo no violento (Rodríguez-Huesa et al., 2016). 


\section{Capacidades personales}

Otras acciones educativas para la paz se dirigen también a la valoración de la persona y de esta a las demás personas, a sus propios proyectos y a los espacios de expresión de lo que se siente y se experimenta (Castañeda-Bernal, 2016). Por lo tanto, las acciones educativas incidentales, intencionales informales o no formales, y las intencionales formales, dirigidas a las capacidades personales, se clasifican en los siguientes campos:

- Autoconcepto: imagen y concepto que el niño forma de sí mismo y del valor de quien es y de lo que hace (Dweck, 2015), que se manifiesta mediante la autoexpresión, la reflexión, interlocución y participación independiente y progresiva de niños y niñas, teniendo en cuenta el reconocimiento de sus habilidades, su autoestima y su percepción de felicidad (Buitrago, Escobar y González, 2010). Dentro de esta se incluye el incentivo al trabajo autónomo o desarrollo de intereses propios, donde se incentiva la autorregulación y la autodirección en las actividades y en el aprendizaje (Rodríguez-Huesa et al., 2016), y la formación de vínculos afectivos o formas de apego seguro y de apoyo constante y dirigido al niño desde la familia, los adultos cercanos, y los educadores y el apoyo a su labor en los centros educativos y de atención, que son base comprobada de fortalecimiento de capacidades resilientes (Ruiz-Chávez y Orcasita-Pineda, 2018).

- Cuidado de sí mismo y de los otros: formación del pensamiento sobre el cuidado del otro o pensamiento cuidante (Rodríguez-Huesa et al., 2016). Dicho pensamiento alude a las habilidades relacionales interpersonales y de las personas con entornos u objetos, que se expresa por medio de la apreciación, estima, respeto, cuidado, empatía, compasión y valoración de sí mismo, de los otros o de su entorno (Pineda, 2004, como se citó en Rodríguez-Huesa et al., 2016).

- Expresión simbólica de emociones y situaciones experimentadas: formas de expresión artística (dibujo, escultura, dramatización, danza, relatos orales, relatos escritos) y lenguajes propios de la primera infancia (juego, literatura, artes), que usan los niños para expresar su experiencia sobre los conflictos, la guerra, la paz y la formación ciudadana. Se da mediante oportunidades de expresión y aprendizaje, problematizando actividades ligadas a pensar sobre el conflicto y la construcción de paz (Castañeda-Bernal, 2016).

$\mathrm{Al}$ igual que en el caso anterior, estas acciones educativas siempre son de naturaleza política y se dan en los entornos con los cuales los niños tienen interacción directa y con los cuales no la tienen, pero que de algún modo les afectan (Bronfenbrenner, 1994; Gifre-Monreal y Guitart, 2013).

\section{Competencias para la formación de educadores que promuevan la educación para la paz.}

Las competencias relacionadas con la formación se relacionan con los conocimientos sobre una educación para la paz y su desarrollo en el aula, así como competencias de manejo relacionadas con niños, familias y personas de sus comunidades.

\section{Nivel individual}

En este nivel se identificó que es necesario centrarse en conocimientos, prácticas y valores hacia la comprensión y la importancia del proceso de formación de los agentes educativos que promuevan una cultura de paz, y para lograrlo debe iniciarse 
generando un análisis, reflexión, evaluación continua del contexto, con la intención de identificar intereses y necesidades de los niños, de los mismos agentes educativos y de la comunidad, así como el conocimiento y apropiación de estrategias pedagógicas que promuevan educación para la paz. Algunas de las referencias de los agentes educativos a este tema son las siguientes:

Apropiación de momentos pedagógicos: "En la asamblea se habla de cierto tema o bienvenida, se les explica a los niños estando todos reunidos qué tema se va a trabajar o se refuerza lo que se ha trabajado, reunión para conversar, dialogar". "Se trabaja en la planeación, en esta tenemos unos momentos. El primer momento es de romper el hielo, puede ser con un canto o una dinámica. Momento dos, de reflexión; se lee y se analiza, se usan recursos como el cuento y se dejan muchas enseñanzas. Momento tres, dialogando, construyendo, socializando; se focaliza el tema que se está trabajando".

Prácticas pedagógicas significativas en la primera infancia para la construcción de paz: "El papel o formas de no repetición, educación para la Paz, desde el CDI y el trabajo que realizan con los papás que les han enseñado sobre educación para la paz". "En mi caso, como trabajadora social, fomento mucho la comunicación asertiva, en el caso de las visitas a la casa, al escuchar a las mamás que se quejan de sus esposos, es que no me ayuda, no me colabora, entonces busco y propongo actividades que le permitan a esa familia mejorar sus relaciones". "Realizar cartelera positiva por familiar y de los niños". "Enseñar a los niños a pedir perdón o disculpas". "A los niños hay que fomentarles el buen trato, ser amables, cariñosos, la gratitud, decirles de buena manera las cosas buenas que hay que reforzar".

Estrategias metodológicas para la enseñanza de prácticas encaminadas a la construcción de paz: "Desde el CDI tenemos un proyecto pedagógico que se llama Jugando y explorando voy valorando, entonces nuestras sesiones educativas van hacia implementar y recuperar los valores en el hogar". "Todos los días trabajan las pautas de ciudadanía en los niños, se hace una ronda, el círculo de la palabra, partimos del interés del niño, si se hace un juego se establecen las reglas, a partir de las reglas los niños saben que debe haber un respeto". "Trabajar con los niños rutinas como veo, pienso, me pregunto".

Actividades rectoras de la primera infancia y de la educación inicial: "Se trabaja de esa forma porque el lineamiento es el trabajo con las actividades rectoras: arte, juego, exploración del medio, literatura". "Los niños aprenden a través de estas actividades. Siempre dejando un mensaje, un aprendizaje". "Se han hecho actividades significativas, bonitas, a través de las actividades rectoras donde cada una de mis compañeras se distribuyó una actividad con pintura, textura, juegos y algunos padres quedaron asombrados y decían que ellos no se imaginaban que las profesoras hacen esas cosas tan bonitas".

Uso de recursos pedagógicos, didácticos, materiales se requieren para trabajar con los niños y niñas de la primera infancia. "Se hacen rondas de expresión y se pone en práctica lo que se les ha dicho que hagan las mamás". "Usan pinturas, colores, diferentes materiales, de acuerdo con la edad del bebé para expresar lo que cada niño quiere". "Juego de roles y los niños expresan lo que está pasando con los agentes educativos, los padres, los profesores, uno logra ver cómo los están tratando". "Dramatizados: ahí se puede evidenciar lo que le está pasando a una de las mamás, se socializa el tema y los aportes de una y de la otra". "Uso de cuentos para el desarrollo de las temáticas vistas". "A través del canto y la lectura de cuentos, fomentan a los niños el cuidado del cuerpo. A los niños siempre les dicen las características del libro, autor”. 
Tabla 6.7. Competencias para la formación de educadores que promuevan la educación para la pazNivel individual.

\begin{tabular}{|c|c|c|c|}
\hline Categorías & Conocimientos & Prácticas & Valores \\
\hline $\begin{array}{l}\text { Análisis, } \\
\text { reflexión y } \\
\text { evaluación } \\
\text { continua del } \\
\text { contexto }\end{array}$ & $\begin{array}{l}\text { - Integración de referen- } \\
\text { cias, aspectos y valores } \\
\text { contextuales de los niños } \\
\text { en prácticas de educa- } \\
\text { ción para la paz. } \\
\text { - Conocimiento de pro- } \\
\text { cesos determinados por } \\
\text { medio de las interaccio- } \\
\text { nes en el ámbito educa- } \\
\text { tivo, familiar y comuni- } \\
\text { tario (relaciones consigo } \\
\text { mismo, con los otros, } \\
\text { con el entorno). }\end{array}$ & $\begin{array}{l}\text { - Implementar y abordar } \\
\text { prácticas pedagógicas des- } \\
\text { de la experiencia de los ni- } \\
\text { ños y niñas. } \\
\text { - Reconocer el punto de } \\
\text { vista y conocimientos pre- } \\
\text { vios de los niños y niñas } \\
\text { en diferentes situaciones } \\
\text { cotidianas. } \\
\text { - Generar acciones de par- } \\
\text { ticipación con las familias, } \\
\text { al momento de construir } \\
\text { los planes de trabajo. } \\
\text { - Promover en los niños } \\
\text { el respeto por la diferencia } \\
\text { de todos los demás. } \\
\text { - Generar espacios de tra- } \\
\text { bajo y reconocimiento con } \\
\text { los niños, que le permitan } \\
\text { identificar y valorar las ca- } \\
\text { racterísticas de su región, } \\
\text { de su país y de las personas } \\
\text { con diferentes condicio- } \\
\text { nes o características. }\end{array}$ & $\begin{array}{l}\text { - Reconocer la impor- } \\
\text { tancia de educación para } \\
\text { la paz, acorde con las } \\
\text { necesidades, intereses y } \\
\text { realidades de los niños } \\
\text { y niñas de cada entorno } \\
\text { educativo. } \\
\text { - Reconocer la diver- } \\
\text { sidad humana y de las } \\
\text { personas, entornos, res- } \\
\text { petando las diferencias. }\end{array}$ \\
\hline $\begin{array}{l}\text { Conocimientos } \\
\text { del profesor } \\
\text { e implemen- } \\
\text { tación de } \\
\text { estrategias que } \\
\text { promueven la } \\
\text { educación para } \\
\text { la paz }\end{array}$ & $\begin{array}{l}\text { - Comprender la impor- } \\
\text { tancia de los momentos } \\
\text { pedagógicos como refe- } \\
\text { rente para el fortaleci- } \\
\text { miento de las propuestas } \\
\text { pedagógicas: indagar, } \\
\text { proyectar, vivir la expe- } \\
\text { riencia, valorar el pro- } \\
\text { ceso, teniendo en cuenta } \\
\text { las necesidades e intere- } \\
\text { ses de los niños. } \\
\text { - Conocer diversas es- } \\
\text { trategias y metodologías } \\
\text { para el trabajo en el aula } \\
\text { y fomento de la educa- } \\
\text { ción para la paz. } \\
\text { - Conocimiento y apro- } \\
\text { piación del sentido peda- } \\
\text { gógico de las actividades } \\
\text { rectoras de literatura, }\end{array}$ & $\begin{array}{l}\text { - Generar en las acciones } \\
\text { educativas los momen- } \\
\text { tos pedagógicos que son } \\
\text { necesarios para entregar } \\
\text { a los niños posibilidades } \\
\text { para que se apropien de } \\
\text { los procesos de compren- } \\
\text { sión, aprendizaje y adqui- } \\
\text { sición del conocimiento. } \\
\text { - Implementar en los } \\
\text { procesos de enseñanza y } \\
\text { aprendizaje estrategias y } \\
\text { metodologías que le per- } \\
\text { mitan al niño proponer, } \\
\text { indagar, explorar, partici- } \\
\text { par, ser escuchado y que él } \\
\text { mismo proponga solucio- } \\
\text { nes a las problemáticas. } \\
\text { - Propiciar en los niños } \\
\text { sus propias creaciones }\end{array}$ & $\begin{array}{l}\text { - Comprender la impor- } \\
\text { tancia de los momentos } \\
\text { pedagógicos como refe- } \\
\text { rente para el fortaleci- } \\
\text { miento de las propuestas } \\
\text { pedagógicas. } \\
\text { - Comprender que las } \\
\text { estrategias y metodolo- } \\
\text { gías intencionadas guían } \\
\text { acciones para alcanzar } \\
\text { procesos de aprendizaje } \\
\text { significativos. } \\
\text { - Reconocer que las ac- } \\
\text { tividades y medios de } \\
\text { expresión hacen parte } \\
\text { de la configuración de la } \\
\text { condición humana. }\end{array}$ \\
\hline
\end{tabular}




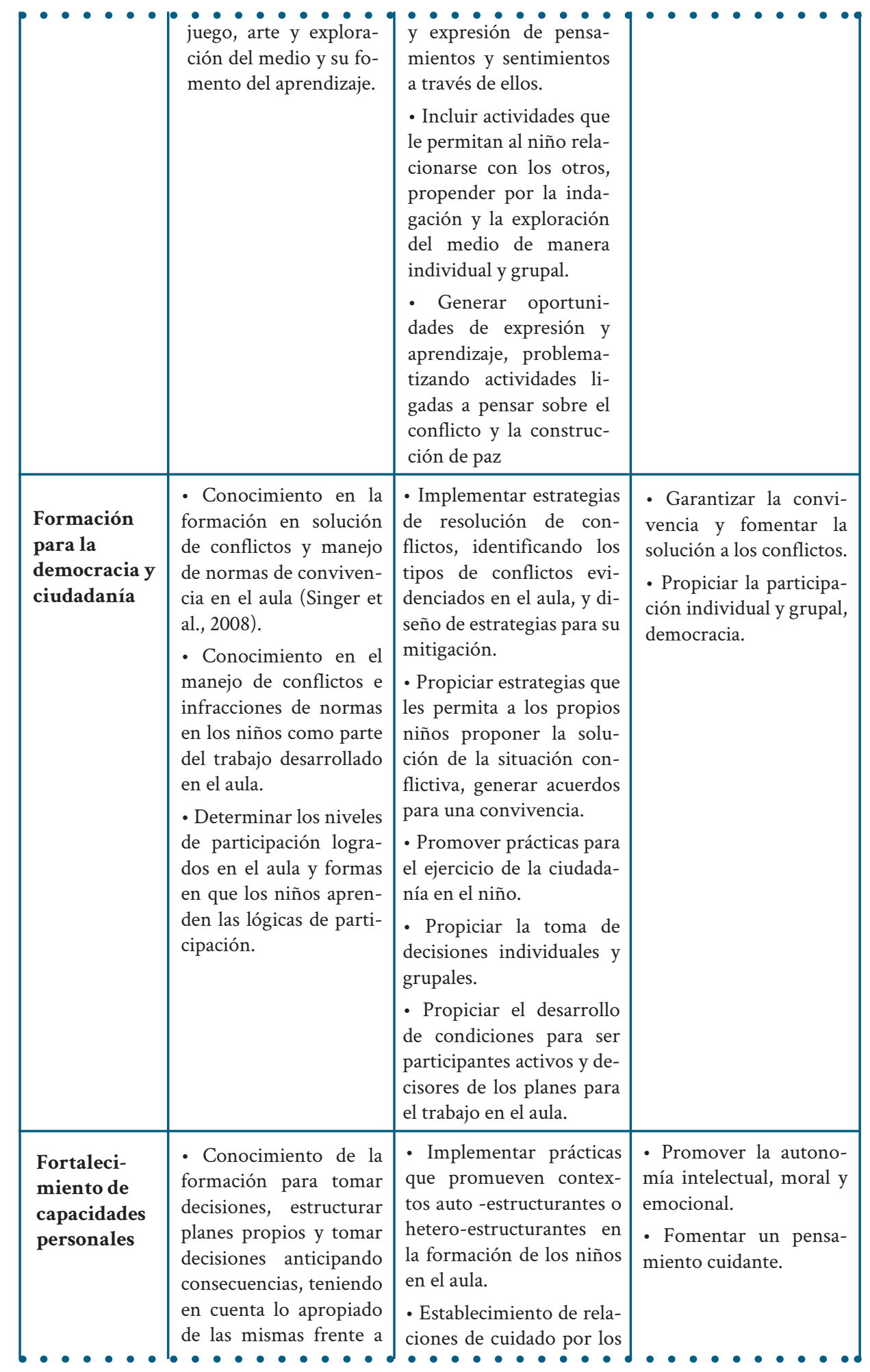




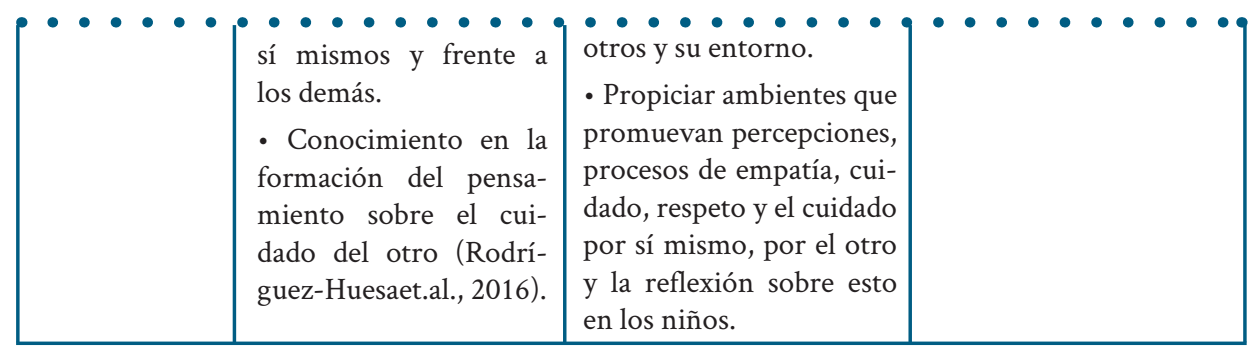

\section{Nivel institucional}

Para este nivel se identificó que es indispensable buscar las formas, mecanismos y estrategias para el trabajo articulado con las instituciones, que se adopten enfoques integrales de atención, de manera que respondan a los intereses y necesidades institucionales, pero que al mismo tiempo se tenga en cuenta a los agentes educativos, padres de familia, docentes y comunidad. A continuación, algunos testimonios de los agentes educativos que se asocian a este nivel:

Situaciones de los niños que llegan a las instituciones: "Por parte de la institución está a disposición nuestro servicio, les decimos: bueno, hoy los esperamos, vamos a revisar tal actividad. Debemos conocer la ficha técnica y caracterización de cada familia". "Dentro de la evaluación hay un proceso que se llama la coevaluación, que nosotras las miramos cómo fueron los resultados, pero en la sesión de evaluación ellas aportan, sugieren, evalúan qué les pareció el tema, si estuvieron motivadas". "Por ejemplo, dentro de la estimulación, las mamás les dicen a los profesores qué les interesa saber sobre este tema... y tomamos esas ideas y al momento de la estimulación uno pone en práctica esos temas". "Son partícipes y una parte activa de lo que de pronto quieren".

Ambientes significativos en la primera infancia para la construcción de paz: "Adecuan los salones con tonos suaves, pasteles, con aromas, con música relajante, en esos espacios se rotan los grupos". "Ambientar diferentes salones para que los niños conocieran diferentes culturas, costumbres, estilos de vida diferentes a los que tienen". "Es importante tener personas que nos den clase de expresión artística, corporal, manejo de voz, entonces si nos dieran esa formación, nosotras podríamos transmitir a las mamás para que ellas lo transmitan a los niños".

Programas, proyectos para la atención integral a la primera infancia " $Y$ les reforzamos ¿Cómo se dice? Gracias, sí. Con cosas tan sencillas ya estamos fomentando valores, entonces cada una en las sesiones lo hacemos tanto en los encuentros en el aula y en la casa".

Tabla 6.8. Competencias para la formación de educadores que promuevan la educación para la pazNivel institucional.

\begin{tabular}{l|l|l|l|} 
Categorías & \multicolumn{4}{c|}{ Conocimientos } & \multicolumn{2}{c|}{ Valores } \\
\hline $\begin{array}{l}\text { Análisis, } \\
\text { reflexión y } \\
\text { evaluación } \\
\text { continua del } \\
\text { contexto }\end{array}$ & $\begin{array}{l}\text { particularidades, valo- } \\
\text { res y creencias que tiene } \\
\text { la familia sobre la ins- } \\
\text { titución, la educación } \\
\text { inicial y las dinámicas } \\
\text { sociales. }\end{array}$ & $\begin{array}{l}\text { Fomentar en los agen- } \\
\text { teducativos la im- } \\
\text { portancia de priorizar } \\
\text { acciones educativas per- } \\
\text { tinentes que incluyan } \\
\text { dentro de sus propuestas } \\
\text { pedagógicas las necesi- } \\
\text { dades e intereses de los }\end{array}$ & $\begin{array}{l}\text { Comprender las diná- } \\
\text { micas de cada contexto } \\
\text { ydecuar las propuestas } \\
\text { danos a intereses de la comunidad. }\end{array}$ \\
\hline
\end{tabular}




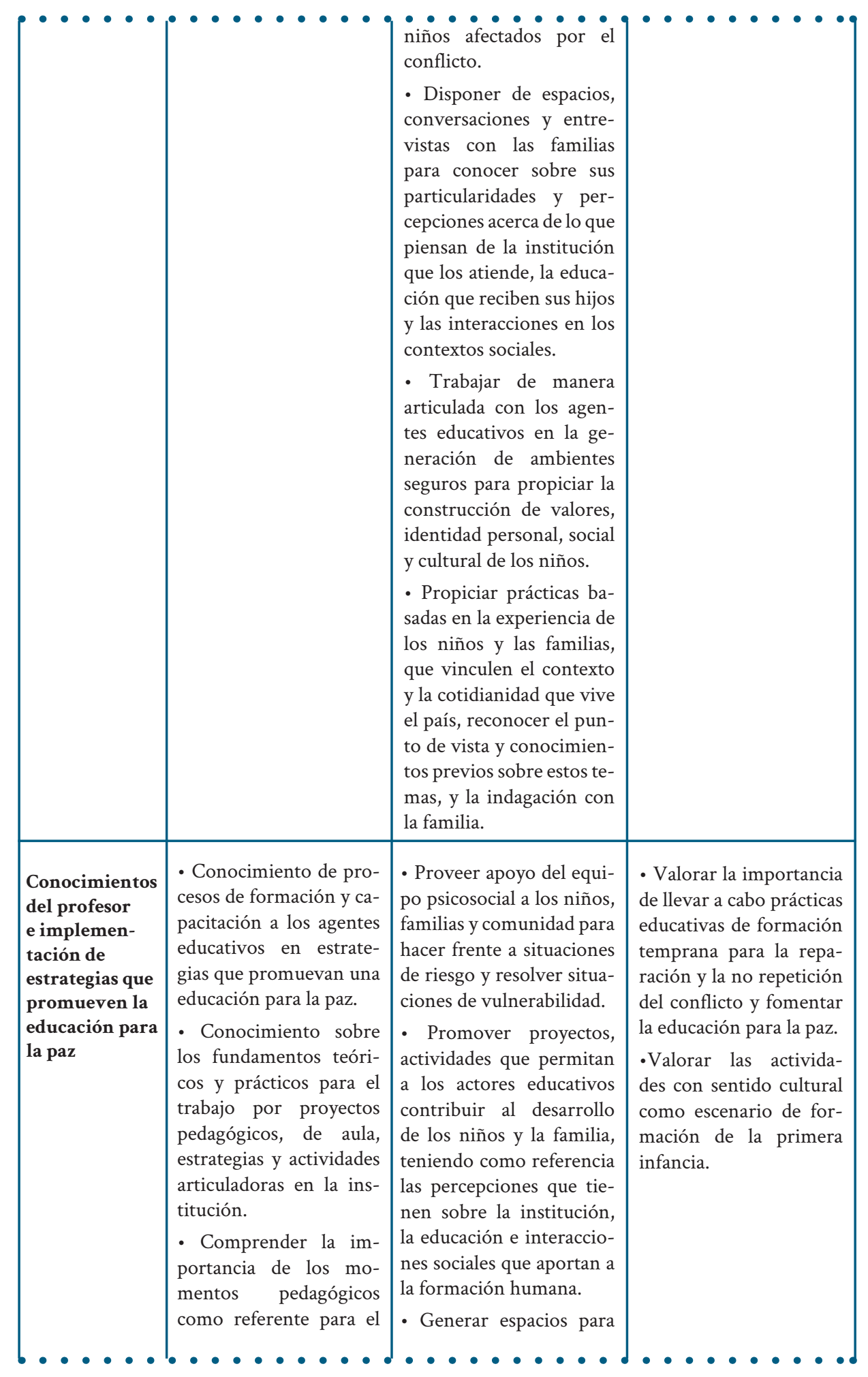




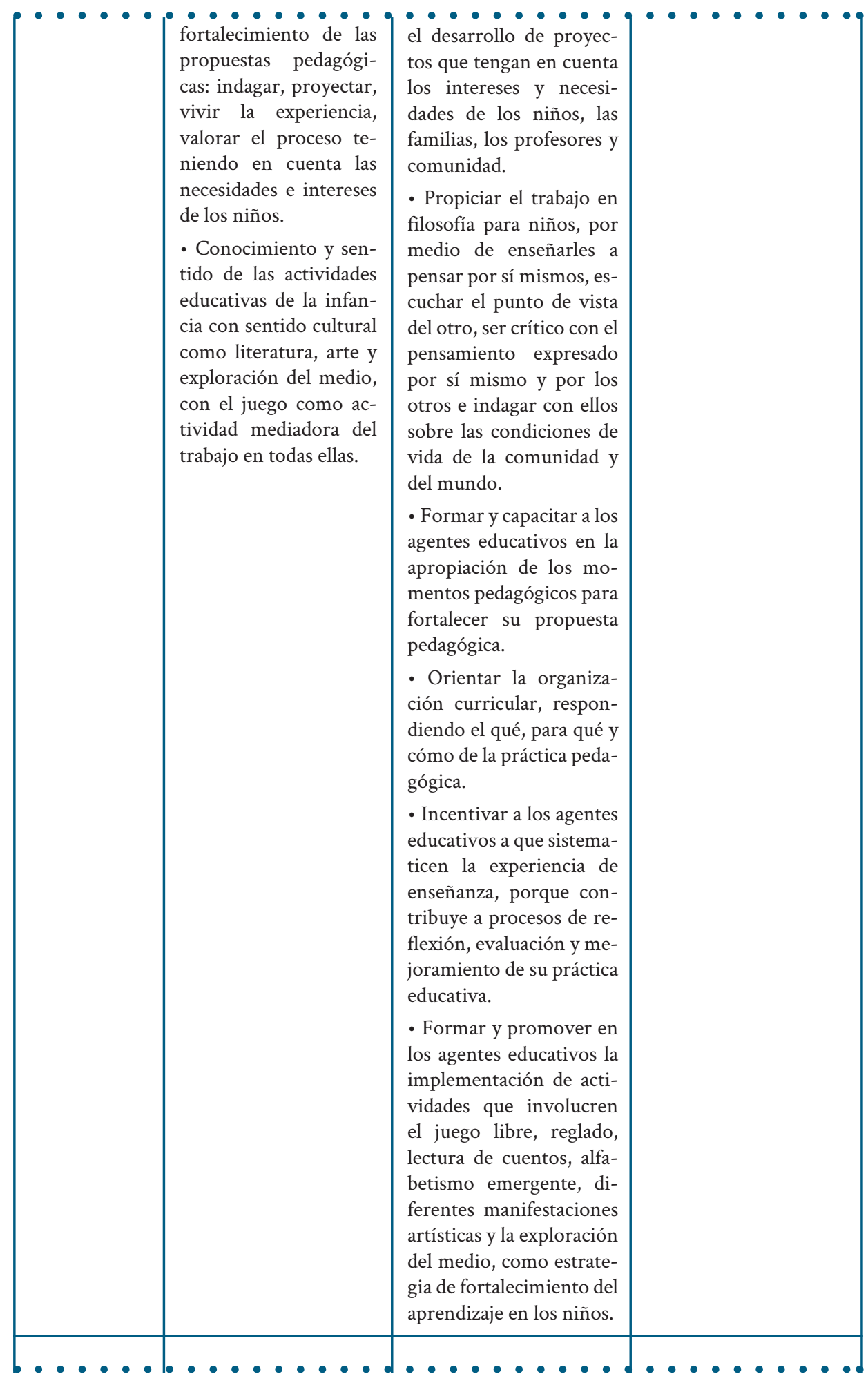




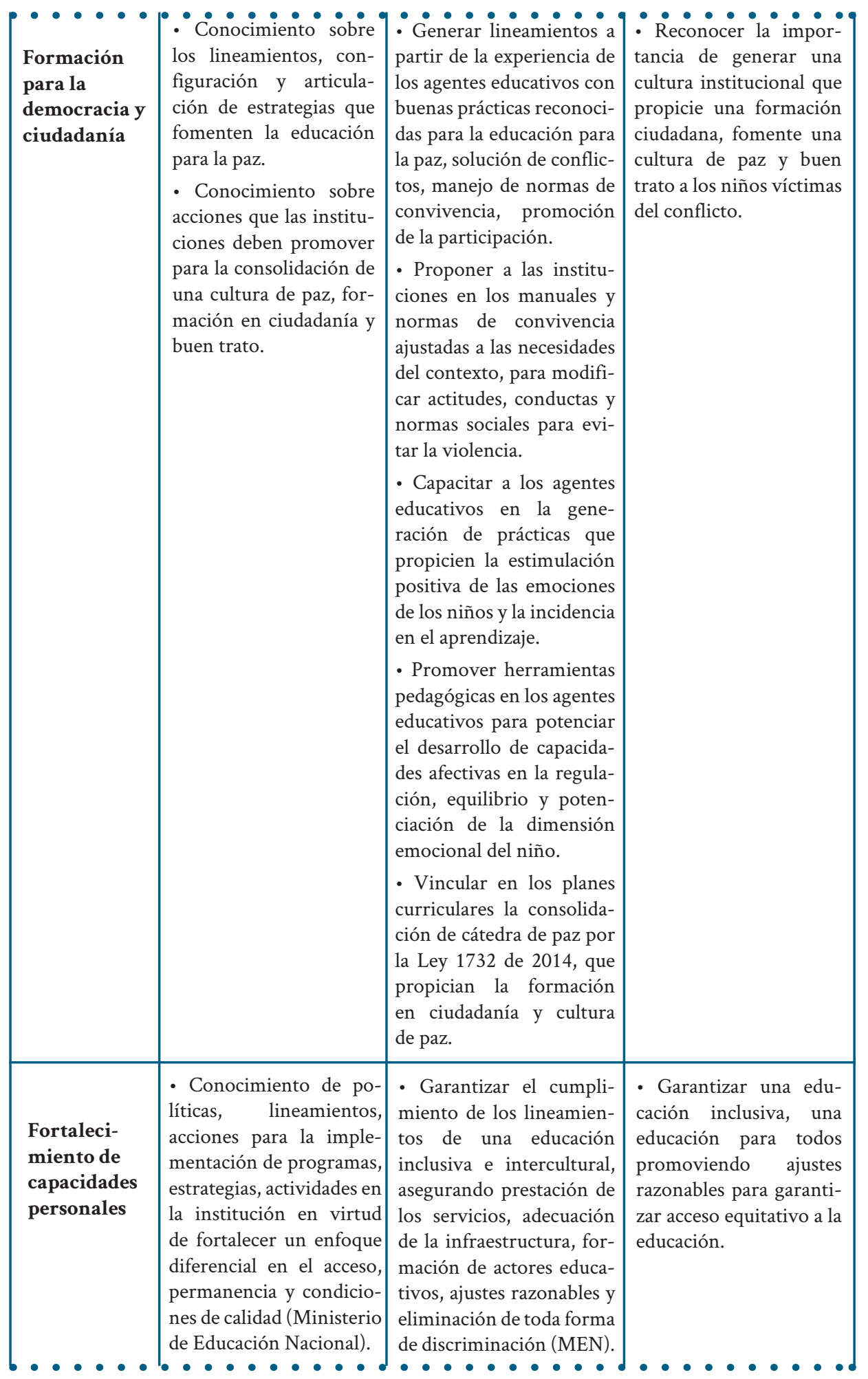




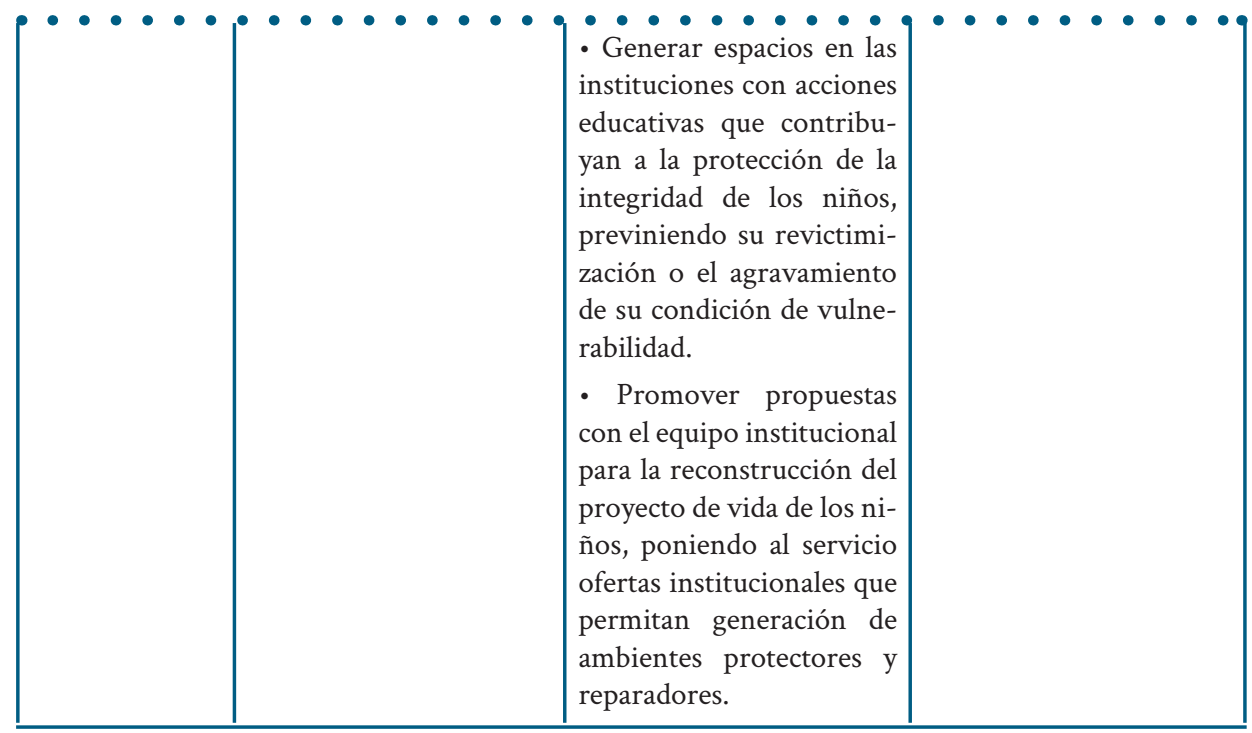

\section{Nivel interinstitucional}

Con relación a las competencias del nivel interinstitucional, se identificó que se requiere propiciar conocimientos, prácticas y valores orientados hacia la generación de redes y trabajo articulado con instituciones que estén promoviendo espacios de socialización que permitan conocer los trabajos que se adelantan sobre el fomento de la educación para la paz, así como la organización, ofertas educativas, programas, contenidos, planes de formación de manera conjunta, relacionados con la promoción de la educación para la paz. Algunas de las referencias de los agentes educativos con relación a este tema son las siguientes:

Acciones educativas articuladas (salidas de campo, salidas pedagógicas, expertos): "Salidas de campo, pedagógicas, posibilidades para que los niños conozcan diferentes lugares, sitios".

\section{Trabajo articulado con otras instituciones:}

"Sería muy bueno no solo contar con la planeación de nosotras, sino que vinieran o fuéramos a una parte donde nos enseñen artes escénicas, y que conociéramos gente que nos apoyen, no solo para las mamás, sino que para nosotras también, para crecer como maestras".

"Es importante tener personas que nos den clase de expresión artística, corporal, manejo de voz, entonces si nos dieran esa formación, nosotras podríamos transmitir a las mamás para que ellas lo transmitan a los niños".

"Surgen preguntas, para lo psicosocial, nutrición, las escuchan, las entienden, y en el buzón de sugerencias ellas opinan y dejan sus mensajes, me gustó el taller y las actividades, por ejemplo, en una actividad de una dinámica les fascinó y las mamás dicen: profe, otra vez esas y se retoma". 


\begin{tabular}{|c|c|c|c|}
\hline Categorías & Conocimientos & Prácticas & Valores \\
\hline $\begin{array}{l}\text { Análisis, } \\
\text { reflexión y } \\
\text { evaluación } \\
\text { continua del } \\
\text { contexto }\end{array}$ & $\begin{array}{l}\text { - Identificar problemas, } \\
\text { dificultades educativas y } \\
\text { de atención que se pre- } \\
\text { sentan en las institucio- } \\
\text { nes y que estén afectan- } \\
\text { do el desarrollo humano } \\
\text { de los niños víctimas del } \\
\text { conflicto. } \\
\text { - Generar informes de } \\
\text { seguimiento sobre pro- } \\
\text { gramas que hayan im- } \\
\text { plementado en la pro- } \\
\text { moción de la paz. }\end{array}$ & $\begin{array}{l}\text { - Abordar problemas que } \\
\text { se están presentando en la } \\
\text { institucionalidad respecto } \\
\text { a la educación, la dignifi- } \\
\text { cación de los niños y pro- } \\
\text { poner acciones que miti- } \\
\text { guen esta vulneración. } \\
\text { - Socializar experiencias } \\
\text { exitosas que pueden ser } \\
\text { referentes para otras ins- } \\
\text { tituciones. }\end{array}$ & $\begin{array}{l}\text { - Reconocer la impor- } \\
\text { tancia de fortalecer el } \\
\text { trabajo articulado de la } \\
\text { institución con otras } \\
\text { instituciones para garan- } \\
\text { tizar una educación con- } \\
\text { textualizada, apropiada } \\
\text { para la primera infancia. }\end{array}$ \\
\hline $\begin{array}{l}\text { Conocimientos } \\
\text { del profesor } \\
\text { e implemen- } \\
\text { tación de } \\
\text { estrategias que } \\
\text { promueven la } \\
\text { educación para } \\
\text { la paz }\end{array}$ & $\begin{array}{l}\text { - Adquirir conocimien- } \\
\text { tos sobre qué es la vio- } \\
\text { lencia (dónde ocurre, } \\
\text { de qué manera, sectores } \\
\text { afectados, identificar } \\
\text { edades y procedencia de } \\
\text { los niños). } \\
\text { - Conocimiento sobre } \\
\text { estrategias para lograr } \\
\text { un trabajo articulado y } \\
\text { óptimo en beneficio de } \\
\text { la comunidad y no de in- } \\
\text { tereses personales. }\end{array}$ & $\begin{array}{l}\text { - Diseñar y planear es- } \\
\text { trategias de intervención } \\
\text { educativa y fijar metas, } \\
\text { tiempo y espacios para ha- } \\
\text { cer seguimiento del pro- } \\
\text { ceso con el fin de dismi- } \\
\text { nuir el índice de violencia } \\
\text { en los entornos cercanos. } \\
\text { - Trabajar colaborativa- } \\
\text { mente y de manera inter- } \\
\text { disciplinaria para diseñar } \\
\text { acciones de trabajo con } \\
\text { los niños y otros actores, } \\
\text { teniendo en cuenta las ne- } \\
\text { cesidades e intereses edu- } \\
\text { cativos. }\end{array}$ & $\begin{array}{l}\text { - Propender por la co- } \\
\text { laboración interdisci- } \\
\text { plinar para asegurar } \\
\text { la atención integral de } \\
\text { los niños. }\end{array}$ \\
\hline $\begin{array}{l}\text { Formación } \\
\text { para la } \\
\text { democracia y } \\
\text { ciudadanía }\end{array}$ & $\begin{array}{l}\text { - Conocimiento en la } \\
\text { gestión, construcción de } \\
\text { planes e implementación } \\
\text { de programas para la } \\
\text { oferta educativa, que ge- } \\
\text { neren escenarios de pro- } \\
\text { moción de una cultura } \\
\text { de paz y de participación } \\
\text { ciudadana. } \\
\text { - Conocimiento de esce- } \\
\text { narios de participación, } \\
\text { interacción y experien- } \\
\text { cias, específicamente } \\
\text { dirigidos a los niños víc- } \\
\text { timas del conflicto para } \\
\text { restitución del derecho a } \\
\text { la educación. }\end{array}$ & $\begin{array}{l}\text { - Generar e implementar } \\
\text { iniciativas educativas que } \\
\text { respondan a las necesida- } \\
\text { des e intereses de los ni- } \\
\text { ños víctima del conflicto } \\
\text { y propendan por propiciar } \\
\text { una cultura de paz. } \\
\text { - Gestionar encuentros } \\
\text { institucionales para darles } \\
\text { la oportunidad de partici- } \\
\text { par a los niños en diálogos, } \\
\text { socialización de su expe- } \\
\text { riencia, memoria histórica } \\
\text { a partir de diferentes ex- } \\
\text { presiones artísticas. }\end{array}$ & $\begin{array}{l}\text { - Reconocer a la di- } \\
\text { versidad humana que } \\
\text { propicie el respeto a las } \\
\text { diferencias. }\end{array}$ \\
\hline
\end{tabular}




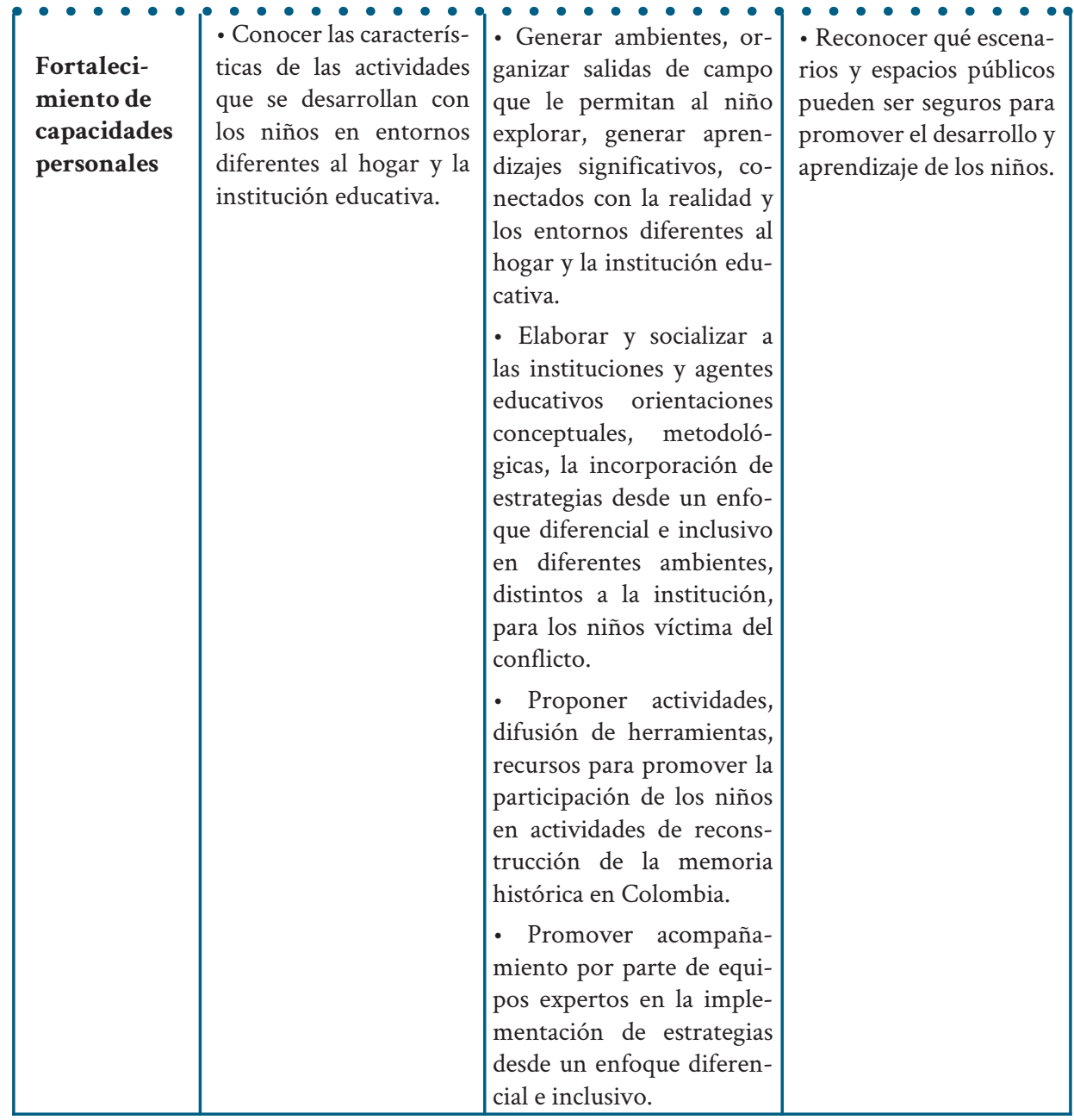

\section{Nivel de gobernanza}

Este nivel se refiere a instancias del gobierno que generan recursos, llegan a acuerdos, aprueban normas y permiten generar acciones para promover la formación de educadores que promuevan una educación para la paz.

Tabla 6.10. Competencias para la formación de educadores que promuevan la educación para la pazNivel de gobernanza.

\begin{tabular}{|c|c|c|c|}
\hline Categorías & Conocimientos & Prácticas & Valores \\
\hline $\begin{array}{l}\text { Análisis, } \\
\text { reflexión y } \\
\text { evaluación } \\
\text { continua del } \\
\text { contexto }\end{array}$ & $\begin{array}{l}\text { - Conocer las acciones } \\
\text { que aportan la gene- } \\
\text { ración de una cultura } \\
\text { de paz. } \\
\text { - Conocer estrategias }\end{array}$ & $\begin{array}{l}\text { - Promover acciones para } \\
\text { la generación de una cul- } \\
\text { tura de paz; actitudes, } \\
\text { tradiciones, comporta- } \\
\text { mientos y estilos de vida }\end{array}$ & $\begin{array}{l}\text { Propiciar espacios de } \\
\text { democracia y participa- } \\
\text { ción en los que se respe- } \\
\text { ten los derechos sociales y } \\
\text { culturales. }\end{array}$ \\
\hline
\end{tabular}




\begin{tabular}{|c|c|c|c|}
\hline & $\begin{array}{l}\text { educativas para la for- } \\
\text { mación de una cultura } \\
\text { de paz y ciudadanía }\end{array}$ & $\begin{array}{l}\text { basados en el respeto a } \\
\text { la vida, la práctica de la } \\
\text { no-violencia, la educación } \\
\text { y el diálogo, el respeto y } \\
\text { promoción de: los dere- } \\
\text { chos humanos, al desarro- } \\
\text { llo, a la igualdad, afianzar } \\
\text { los principios de libertad, } \\
\text { justicia, democracia, so- } \\
\text { lidaridad, pluralismo, di- } \\
\text { versidad cultural y respeto } \\
\text { a la soberanía e integridad } \\
\text { territorial (ONU, 1999). } \\
\text { - Socializar normas y per- } \\
\text { mitir participación comu- } \\
\text { nitaria, proponer, progra- } \\
\text { mas para la formación en } \\
\text { paz y ciudadanía. } \\
\text { - Reorientar recursos pre- } \\
\text { supuestales, propiciar la } \\
\text { capacidad institucional y } \\
\text { de talento humano exis- } \\
\text { tente en las diversas en- } \\
\text { tidades que fomentan la } \\
\text { formación para la paz. }\end{array}$ & $\begin{array}{l}\text { - Lograr una partici- } \\
\text { pación comunitaria. } \\
\text { - Garantizar procesos } \\
\text { de autogestión de gru- } \\
\text { pos y comunidades. }\end{array}$ \\
\hline $\begin{array}{l}\text { Fortaleci- } \\
\text { miento de } \\
\text { capacidades } \\
\text { personales }\end{array}$ & $\begin{array}{l}\text { - Conocer estrategias de } \\
\text { articulación de actores } \\
\text { para el logro de planes } \\
\text { de política pública de } \\
\text { garantía de derechos de } \\
\text { los niños, y del desarro- } \\
\text { llo pleno de los niños de } \\
\text { contextos afectados por } \\
\text { el conflicto armado. } \\
\text { - Conocimiento de las } \\
\text { políticas, planes, pro- } \\
\text { gramas con relación a } \\
\text { la educación para la pri- } \\
\text { mera infancia, la inter- } \\
\text { culturalidad, inclusión, } \\
\text { enfoque diferencial. }\end{array}$ & $\begin{array}{l}\text { - Coordinar acciones de } \\
\text { gobierno con institucio- } \\
\text { nes y actores para lograr la } \\
\text { participación, la solución } \\
\text { adecuada y el compromi- } \\
\text { so con la comunidad. } \\
\text { - Propiciar la coopera- } \\
\text { ción basada en confianza } \\
\text { y honestidad, con accio- } \\
\text { nes transparentes entre } \\
\text { los gestores políticos y la } \\
\text { administración de las ins- } \\
\text { tituciones (CDR, 2009). } \\
\text { - Promover acciones para } \\
\text { el cumplimiento de los } \\
\text { planes, programas en el } \\
\text { marco de transparencia y } \\
\text { control ciudadano. } \\
\text { - Desarrollar planes de } \\
\text { trabajo con productos e } \\
\text { indicadores de impacto en } \\
\text { la educación para la pri- } \\
\text { mera infancia, con énfasis } \\
\text { intercultural, de inclusión } \\
\text { y de atención diferencial a } \\
\text { diversas poblaciones. }\end{array}$ & $\begin{array}{l}\text { - Garantizar gobernan- } \\
\text { za en los programas y } \\
\text { planes para los niños } \\
\text { víctimas del conflicto } \\
\text { armado. } \\
\text { - Educación inclusiva } \\
\text { como proceso perma- } \\
\text { nente, de calidad para } \\
\text { todos, respetando la di- } \\
\text { versidad y las distintas } \\
\text { necesidades, caracterís- } \\
\text { ticas y expectativas de } \\
\text { aprendizaje de los edu- } \\
\text { candos y de las comuni- } \\
\text { dades (MEN). }\end{array}$ \\
\hline
\end{tabular}




\section{Condiciones para garantizar el derecho a la educación de calidad}

El trabajo mencionado en las secciones anteriores debe desarrollarse como un derecho de todos los niños. Este trabajo comprende la generación de ambientes y espacios que valoren y reconozcan a los niños y niñas como sujetos de derechos y potenciales transformadores de su realidad (Rodríguez-Huesa et al., 2016; Singer et al., 2008), en procesos determinados mediante las interacciones en el ámbito educativo, familiar y comunitario (Fernández-Barrera, 2009).

Por este motivo, se explican dichas condiciones desde la perspectiva de garantía del derecho a la educación de Katarina Tomasevski (Tomasevski, 2004). Para que las acciones educativas se garanticen como derecho, deben cumplirse cuatro condiciones:

- Disponer: significa que las acciones educativas se den y tengan un escenario institucional.

- Dar acceso: significa que las acciones educativas lleguen a quienes están dirigidas, es decir, a los niños, sus familias y sus comunidades.

- Que sean apropiadas: significa que las acciones educativas sean de buena calidad y sean apropiadas para el logro de los aprendizajes buscados.

- Que sean flexibles e inclusivas: significa que las acciones educativas sean adaptables, adaptadas, y que incluyan a los niños y a todos sus beneficiarios en sus diferencias y singularidades.

Esta es la base desde la cual este trabajo se analiza a partir del marco de sistemas competentes de Mathias Urban (Urban et al., 2012). Este marco nos muestra las acciones de garantía del derecho a la educación inicial, en el entorno de la educación para afrontar el conflicto y construir la paz, desde diferentes esferas de la atención a primera infancia que se conectan.

\section{Competencias para propiciar condiciones para garantizar el de- recho a la educación de calidad}

\section{Nivel individual}

De este nivel se enfatizan las competencias relacionadas con la coordinación de acciones que se deben propiciar para la garantía de los derechos de la educación en la primera infancia con calidad.

Tabla 6.11. Competencias para propiciar condiciones para garantizar el derecho a la educación de calidadNivel individual.

\begin{tabular}{|c|c|c|c|}
\hline Categorías & Conocimientos & Prácticas & Valores \\
\hline $\begin{array}{l}\text { Trabajo } \\
\text { articulado } \\
\text { entre insti- } \\
\text { tuciones con } \\
\text { garantía de } \\
\text { calidad. }\end{array}$ & $\begin{array}{l}\text { Conocimiento del } \\
\text { trabajo en aula en edu- } \\
\text { cación para la paz y de } \\
\text { las formas de ofrecerlo, } \\
\text { hacerlo idóneo y ha- } \\
\text { cerlo inclusivo con la } \\
\text { diversidad. }\end{array}$ & $\begin{array}{l}\text { - Ofrecer trabajo en aula } \\
\text { en educación para la paz. } \\
\text { - Dar acceso a beneficia- } \\
\text { rios al trabajo en aula en } \\
\text { educación para la paz. } \\
\text { - Diseñar trabajo en aula } \\
\text { en educación para la paz, }\end{array}$ & $\begin{array}{l}\text { - Ofertas de calidad en } \\
\text { educación inicial } \\
\text { - Acceso e inclusión en } \\
\text { educación inicial }\end{array}$ \\
\hline
\end{tabular}




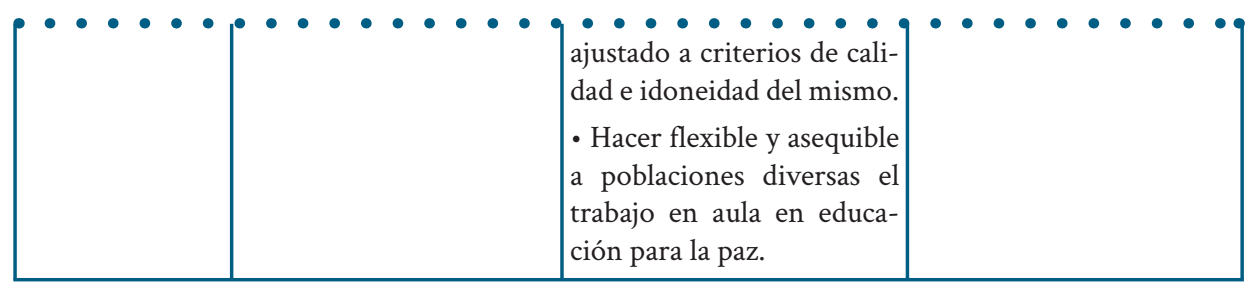

\section{Nivel institucional}

En este nivel se requiere de conocimientos, prácticas y valores orientados a la capacidad de proponer, permitir o dar acceso a condiciones que requiere la institución, de manera que garanticen el derecho a una educación de calidad, así como lograr un trabajo articulado con los diferentes agentes educativos que se encuentran en una institución y que están para garantizar y velar por el derecho a una educación de calidad para los niños. Algunos de los aportes de los participantes de la investigación son:

Articulación del trabajo en equipo: psicosocial, nutricionista, coordinador, docentes: "Sí se cuenta con un trabajo articulado; con la comisaría de familia en Santa Librada, la Unidad de mediación y resolución de conflicto que queda en Usme Pueblo. Con los jueces de paz que quedan en la iglesia, instituciones que nos apoyan". "Por ejemplo, la Cámara de comercio vino directamente y les dio una capacitación”. "También sería importante que vinieran las autoridades, que les cuenten a los usuarios qué les puede pasar si se presenta un incumplimiento de la norma, que esas entidades puedan concientizar las consecuencias de esos actos".

Programas, proyectos para la atención integral a la primera infancia:"La asociación tiene CDI y cada CDI tiene unas necesidades de la población, y en el caso de nosotros cada institución hace un proyecto pedagógico en el cual está enfocado, entonces el de nosotros este año como tal está enfocado hacia los valores, a través del juego y las dinámicas que se realizan, siempre van a ir a rescatar los valores que se fomentan en la persona y en la familia”.

Tabla 6.12. Competencias para propiciar condiciones para garantizar el derecho a la educación de calidadnivel institucional.

\begin{tabular}{|c|c|c|c|}
\hline Categorias & Conocimientos & Prácticas & Valores \\
\hline $\begin{array}{l}\text { Trabajo } \\
\text { articulado } \\
\text { entre insti- } \\
\text { tuciones con } \\
\text { garantía de } \\
\text { calidad. }\end{array}$ & $\begin{array}{l}\text { - Conocimiento del tra- } \\
\text { bajo en aula en educación } \\
\text { para la paz y de las formas } \\
\text { de ofrecerlo, hacerlo idó- } \\
\text { neo y hacerlo inclusivo } \\
\text { con la diversidad. }\end{array}$ & $\begin{array}{l}\text { - Ofrecer educación para la } \\
\text { paz desde el conjunto de la } \\
\text { institución } \\
\text { - Dar acceso a beneficiarios } \\
\text { a educación para la paz desde } \\
\text { el conjunto de la institución. } \\
\text { - Diseñar trabajo desde el } \\
\text { conjunto de la institución en } \\
\text { educación para la paz ajus- } \\
\text { tado a criterios de calidad e } \\
\text { idoneidad del mismo. } \\
\text { - Hacer flexible y asequible } \\
\text { a poblaciones diversas el } \\
\text { trabajo en educación para la } \\
\text { paz desde el conjunto de la } \\
\text { institución. }\end{array}$ & $\begin{array}{l}\text { - Ofertas de calidad en } \\
\text { educación inicial. } \\
\text { - Acceso e inclusión en } \\
\text { educación inicial. }\end{array}$ \\
\hline
\end{tabular}




\section{Nivel interinstitucional}

En este nivel se requiere de acciones conjuntas y de estrategias de gestión, monitoreo y acompañamiento a las instituciones que propician la educación para la paz. Los aportes de los agentes educativos relacionados con el este nivel de competencias son:

Trabajo articulado con otras instituciones: "Con la comisaría de familia en Santa Librada, la Unidad de mediación y resolución de conflicto que queda en Usme Pueblo". "Con los jueces de paz que quedan en la iglesia, instituciones que nos apoyan”.

“También un acompañamiento directo a las mamás, por ejemplo, las comisarías deberían hacer campañas, aquí les damos las rutas, pero sería importante que ellos vinieran y las guiaran, les dieran capacitaciones para que eviten el maltrato en los niños y en las mamás, gestionar para que las mismas comisarías trabajaran con los usuarios, no solo con nosotros”.

Tabla 6.13. Competencias para propiciar condiciones para garantizar el derecho a la educación de calidadNivel interinstitucional.

\begin{tabular}{|c|c|c|c|}
\hline Categorías & Conocimientos & Prácticas & Valores \\
\hline $\begin{array}{l}\text { Trabajo } \\
\text { articulado } \\
\text { entre insti- } \\
\text { tuciones con } \\
\text { garantía de } \\
\text { calidad. }\end{array}$ & $\begin{array}{l}\text { - Conocimiento del tra- } \\
\text { bajo de articulación y } \\
\text { gestión con diferentes } \\
\text { instancias e institucio- } \\
\text { nes que apoye el trabajo } \\
\text { en educación para la paz } \\
\text { y de las formas de ofre- } \\
\text { cerlo, hacerlo idóneo y } \\
\text { hacerlo inclusivo con la } \\
\text { diversidad. }\end{array}$ & $\begin{array}{l}\text { - Ofrecer educación para } \\
\text { la paz con articulación } \\
\text { y gestión con diferentes } \\
\text { instancias e instituciones. } \\
\text { - Dar acceso a benefi- } \\
\text { ciarios a educación para } \\
\text { la paz con articulación } \\
\text { y gestión con diferentes } \\
\text { instancias e instituciones. } \\
\text { - Diseñar trabajo con ar- } \\
\text { ticulación y gestión con } \\
\text { diferentes instancias e } \\
\text { instituciones, ajustado a } \\
\text { criterios de calidad e ido- } \\
\text { neidad del mismo. } \\
\text { - Hacer flexible y asequi- } \\
\text { ble a poblaciones diversas } \\
\text { el trabajo en educación } \\
\text { para la paz con articula- } \\
\text { ción y gestión con dife- } \\
\text { rentes instancias e insti- } \\
\text { tuciones. }\end{array}$ & $\begin{array}{l}\text { - Ofertas de calidad en } \\
\text { educación inicial. } \\
\text { - Acceso e inclusión en } \\
\text { educación inicial. }\end{array}$ \\
\hline
\end{tabular}

\section{Nivel de gobernanza}

Este nivel se refiere a instancias del gobierno que generan recursos, llegan a acuerdos, aprueban normas, y definen algunas líneas de política y acción. Algunos de los testimonios de los participantes se refieren a:

Generación de lineamientos del sistema educativo a las instituciones y a sus actores:

“Orientación a la formación específica en competencias ciudadanía, cátedra para la paz y nor- 
mas de convivencia". "Existen los lineamientos de cero a siempre". "La guerra no se termina, porque mientras que no haya una política estable de gobierno, donde realmente a la gente se eduque, no va a hacer posible".

Tabla 6.14. Competencias para propiciar condiciones para garantizar el derecho a la educación de calidadNivel de gobernanza.

\begin{tabular}{|c|c|c|c|}
\hline Categorías & Conocimientos & Prácticas & Valores \\
\hline $\begin{array}{l}\text { Trabajo } \\
\text { articulado } \\
\text { entre insti- } \\
\text { tuciones con } \\
\text { garantía de } \\
\text { calidad. }\end{array}$ & $\begin{array}{l}\text { - Gestionar con las } \\
\text { entidades territoria- } \\
\text { les correspondientes el } \\
\text { cumplimiento del de- } \\
\text { recho a la educación de } \\
\text { los niños víctimas del } \\
\text { conflicto armado como } \\
\text { parte de la garantía uni- } \\
\text { versal de los derechos de } \\
\text { los niños. } \\
\text { - Establecer planes, } \\
\text { programas, estrategias } \\
\text { educativas y directrices } \\
\text { de política pública que } \\
\text { brinden oportunidades } \\
\text { de acceso, calidad y per- } \\
\text { manencia de la pobla- } \\
\text { ción afectada por el con- } \\
\text { flicto colombiano como } \\
\text { parte de la garantía uni- } \\
\text { versal de los derechos de } \\
\text { los niños. }\end{array}$ & $\begin{array}{l}\text { Gestionar con las en- } \\
\text { tidades territoriales co- } \\
\text { rrespondientes el cum- } \\
\text { plimiento del derecho a } \\
\text { la educación de los niños } \\
\text { víctimas del conflicto ar- } \\
\text { mado como parte de la } \\
\text { garantía universal de los } \\
\text { derechos de los niños. } \\
\text { - Establecer planes, pro- } \\
\text { gramas, estrategias edu- } \\
\text { cativas y directrices de po- } \\
\text { lítica pública que brinden } \\
\text { oportunidades de acceso, } \\
\text { calidad y permanencia de } \\
\text { la población afectada por } \\
\text { el conflicto colombiano } \\
\text { como parte de la garantía } \\
\text { universal de los derechos } \\
\text { de los niños. }\end{array}$ & $\begin{array}{l}\text { - Garantizar el derecho } \\
\text { a la educación en la pri- } \\
\text { mera infancia. } \\
\text { - Generar un marco } \\
\text { general de seguimien- } \\
\text { to, acompañamiento } \\
\text { y cumplimiento en las } \\
\text { ofertas de calidad y ac- } \\
\text { ceso e inclusión en edu- } \\
\text { cación inicial. }\end{array}$ \\
\hline
\end{tabular}

\section{Conclusiones}

La educación inicial es un interesante campo en el cual los niños tienen altas oportunidades de aprendizaje, por estar en momentos críticos de su desarrollo (Mustard, 2007), y por el importante avance en su comprensión de la naturaleza intelectual y emotiva tras las acciones de las personas (Flórez-Romero, Arias-Velandia y Torrado Pacheco, 2011). Esta es una importante base para el trabajo en acciones educativas para la paz y el afrontamiento del conflicto y sus consecuencias desde los escenarios de esta educación (Posada-Gilède y Parales-Quenza, 2012). Como se ha planteado ya repetidamente, estos espacios son óptimos para dar puntos de encuentro entre el acervo previo y el acervo por adquirirse, con respecto al conocimiento e interés de los niños por el mundo social (Arias-Velandia y Flórez-Romero, 2011).

Estas oportunidades de formación y crecimiento para los niños y para otras personas relacionadas con ellos dependen de la labor educadora de los adultos a su alrededor, bien se trate de profesores o de adultos en otros roles. Para esto, es importante que quienes laboren en la educación integral a la primera infancia observen con de- 
tenimiento y reflexionen sobre el desarrollo de su labor en este marco, en los efectos que ella genera, y en cómo puede ser parte de articulaciones productivas entre sus niveles individual, institucional, interinstitucional y de gobernanza (Urban et al., 2012). Esto, a su vez, implica asumir la labor de los educadores iniciales y de los educadores comunitarios y de familias, como una carrera reglamentada, con admisión, escalafonamiento y remuneración propia (Dimaté-Rodríguez, 2017; Dweck, 2015; Russ et al., 2016).

En el escenario de la educación para la paz, para afrontar el conflicto y para superar el conflicto armado colombiano, estas acciones educativas se apuntalan en la gran capacidad en proceso de desarrollo en los niños de reconocerse a sí mismos, con su propia acción y capacidad (Chaux, 2012), articulada con la comprensión de emociones, afectos, motivos y acciones de los otros, en un marco de normas, principios y reconocimiento a cada uno (Rodríguez-Huesa et al., 2016; Singer et al., 2008). Esto requiere del trabajo en las siguientes líneas de labores en las acciones educativas:

- Visión profesional del trabajo en primera infancia y círculos de influencia en los niños, con observación y reflexión sobre el mismo y con perspectiva de articulación con la labor de otros en este mismo ámbito.

- Articulación de quienes trabajan en la institución para que esta actúe como un todo que garantiza disponibilidad, acceso, idoneidad, calidad e inclusión en la diversidad en la educación para la paz con los niños en primera infancia, sus familias, sus hogares y sus comunidades.

- Logro del cometido del punto anterior con ayuda del fortalecimiento de la acción conjunta orientada de la institución, en alianza de trabajo con otras instituciones y otros actores que trabajan en diferentes campos de atención y educación integral a la primera infancia. Esto a través de nuevas alianzas y del fortalecimiento de alianzas y dinámicas ya existentes.

- Soporte al trabajo institucional e interinstitucional del punto anterior, mediante el facilitar la creación de escenarios para dichas labores, fortalecer algunos ya existentes, gestionar garantía de derechos de los niños con criterio de equidad, y destinar y gestionar recursos a estas labores.

\section{Referencias}

Arias-Velandia, N. y Flórez-Romero, R. (2011). Aporte de la obra de Piaget a la comprensión de problemas educativos: su posible explicación del aprendizaje. Revista Colombiana de Educación, 60, 93-105.

Bandura, A. (1986). The explanatory and predictive scope of self-efficacy theory. Journal of Social and Clinical Psychology, 4(3), 359-373.

Bronfenbrenner, U. (1994). Ecological models of human development. Readings on the Development of Children, 2(1), 37-43.

Bruer, J. (1997). Escuelas para pensar. La nueva ciencia del aprendizaje en el aula. Madrid: Paidós Ibérica / Ministerio de Educación y Ciencia, Reino de España.

Castañeda-Bernal, E. (2016). Lineamiento técnico de la Estrategia de Cero a Siempre relacionado con las violencias asociadas al conflicto armado a las que están expuestos los niños y niñas en primera infancia y su abordaje en el marco de la atención integral.

Chaux, E. (2012). Educación, convivencia y agresión escolar. Documento de orientaciones técnicas, administrativas y pedagógicas para la atención educativa a estudiantes con discapacidad en el marco de la educación inclusiva. Bogotá: Colombia, Ministerio de Educación Nacional.

Dimaté-Rodriguez, C. (2017). Desarrollo profesional docente: aporte a la construcción de políticas docentes. En C. Dimaté-Rodríguez et. al. (eds.), Hacia la construcción de una política pública so- 
bre la formación de maestros (141-165). Bogotá: Pontificia Universidad Javeriana / Asociación Colombiana de Facultades de Educación.

Dweck, C. (2015). Carol Dweck revisits the growth mindset. Education Week, 35(5), 20-24.

Flavell, J. (1999). Cognitive development: Children's knowledge about the mind. Annual Review of Psychology, 50(1), 21-45.

Flórez-Romero, R., Arias-Velandia, N., Guzmán-Rodríguez, R.J. y Restrepo, M. (2014). Promoción del aprendizaje de la lectura inicial y prevención de las dificultades en su comprensión. Investigación y experiencia en Bogotá y Chía. En R. Guzmán-Rodríguez (comp.), Lectura y Escritura. Cómo Se enseña y se aprende en el aula (14 - 44). Chía: Universidad de La Sabana.

Flórez-Romero, R., Arias-Velandia, N. y Torrado Pacheco, M. (2011). Teoría de la Mente en Tareas de Falsa Creencia y Producción Narrativa en Preescolares: Investigaciones Contemporáneas. Revista Colombiana de Psicología, 20(2), 249-264.

Gifre-Monreal, M. y Guitart, M. (2013). Consideraciones educativas de la perspectiva ecológica de Urie Bronferbrenner. Contextos Educativos. Revista de Educación, (15), 79-92.

Gutiérrez, P. y Ruiz, E. (2012). Orígenes y Evolución de la Atención Temprana. Una Perspectiva Histórica de la Génesis de la Atención Temprana en Nuestro País. Agentes Contextos y Procesos. Psicología Educativa, 18 (2), 107-122. Guzmán, R., Ghitis, T. y Ruiz, L. (2018). Lectura y escritura en los primeros años. Transiciones en el desarrollo y en el aprendizaje. Chía: Universidad de La Sabana.

Karmiloff-Smith, A. (1994). Más allá de la modularidad. La ciencia cognitiva en la perspectiva de desarrollo. Madrid: Alianza.

Köhler, W. (1959). Gestalt psychology. New York: Liveright.

Koivula, M., Gregoriadis, A., Rautamies, E., \& Grammatikopoulos, V. (2017). Finnish and Greek early childhood teachers' perspectives and practices in supporting children's autonomy. Early Child Development and Care, 189(6), 990-1003 DOI: 10.1080/03004430.2017.1359583

Leontiev, A. (1981). Actividad. Conciencia. Personalidad. La Habana: Pueblo y Educación.

Mateos, M. (2009). Metacognición y educación. Buenos Aires: Aique.

Montealegre, R. (2005). La actividad humana en la psicología histórico-cultural. Avances en Psicología Latinoamericana, 23(1), 33-42.

Mustard, J. (2007). Experience-based brain development: scientific underpinnings of the importance of early child development in a global world (43-86). Early child development: from measurement to action. Washington DC: The World Bank.

Piaget, J. (1969). Biología y conocimiento: ensayo sobre las relaciones entre las regulaciones orgánicas y los procesos cognitivos. Madrid: Siglo XXI.

Posada-Gilède, R. y Parales-Quenza, C. J. (2012). Violencia y desarrollo social: más allá de una perspectiva de trauma. Universitas Psychologica, 11(1), 255-267.

Quintana-Cabanas, J. (1995). Teoría de la educación. Concepción antinómica de la educación. Madrid: Dykinson.

República de Colombia (2006), Colombia por la primera infancia; Política pública por los niños y niñas, desde la gestación hasta los 6 años - Bogotá.

Rodríguez-Huesa, A., Flórez-Romero, R. y Gómez-Muñoz, D. (2016). La formación de ciudadanía en escenarios de educación inicial: una experiencia con madres comunitarias. Panorama, 10(18), 102-119.

Ruiz, C. y Orcasita, L. (2018). Factores resilientes y rendimiento escolar en lectura en adolescentes de la Comuna 13 en Cali. Trabajo de grado (tesis), Maestría en Educación, Facultad de Humanidades y Ciencias Sociales, Pontificia Universidad Javeriana, Santiago de Cali.

Ruiz-Cardozo, L., Ñañez-Rodríguez, J. y Capera-Figueroa, J. (2019). Experiencias locales de la formación ciudadana en la infancia en instituciones educativas públicas de Ibagué - Tolima, Colombia. Panorama, 13(25), 71-86.

Runge-Peña, A. y Muñoz-Gaviria, D. (2012). Pedagogía y praxis (práctica) educativa o educación. De nuevo: una diferencia necesaria. Revista Latinoamericana de Estudios Educativos, 8(2), 75-96.

Russ, R., Sherin, B., \& Sherin, M. (2016). What constitutes teacher learning? En D. Gitomer y C. Bell (eds.), Handbook of Research on Teaching (391-438). Washington DC: American Education 
Research Association, AERA.

Sen, A. (2000). El desarrollo como libertad. Gaceta Ecológica, 55, 14-20.

Singer, E., De Haan, D., Van Keulen, A. y Bekkema, N. (2008). Los procesos de socialización en la primera infancia. Juegos, conflictos y reconciliación en los centros infantiles. Ámsterdam: B.V. Utgeverij SWP.

Stenhouse, L. (1998). Investigación y desarrollo del curriculum. Madrid: Morata.

Tomasevski, K. (2004). Indicadores del derecho a la educación. Revista iidh, 40, 341-388.

Urban, M., Vandenbroeck, M., Van Laere, K., Lazzari, A., \& Peeters, J. (2012). Towards Competent Systems in Early Childhood Education and Care. Implications for Policy and Practice. European Journal of Education, 47(4), 508-526.

Wellman, H. M., Cross, D., \& Watson, J. (2001). Meta-analysis of theory-of-mind development: The truth about false belief. Child Development, 72(3), 655-684. 


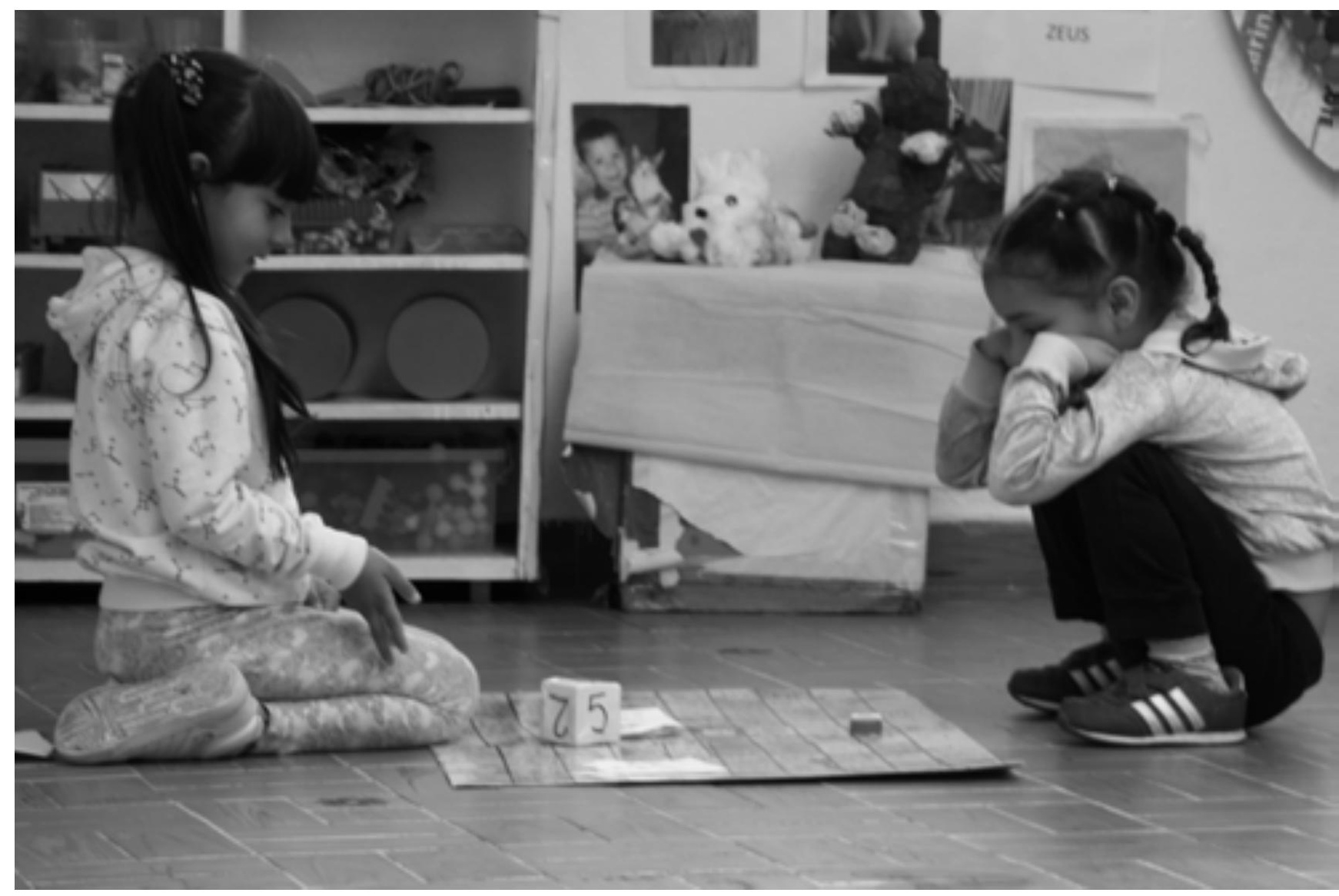




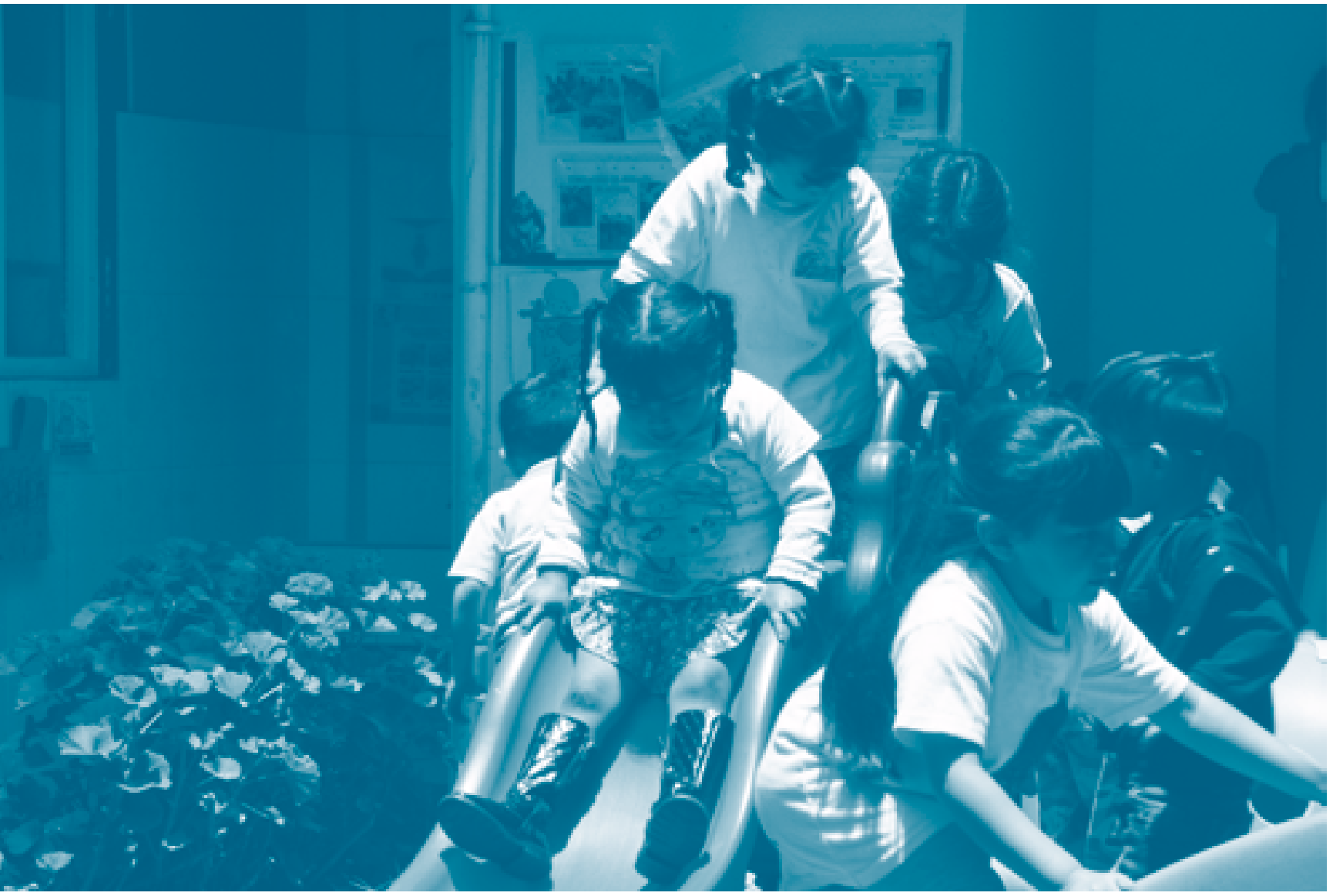

Capítulo 7.

Participación de los niños en la investigación 
$\mathrm{E}$ n este capítulo se presentan las perspectivas de niños y niñas en torno a aspectos sobre el conflicto colombiano que se consideran esenciales conocer con miras a ser tenidos en cuenta en propuestas de cualificación del talento humano, con el que día a día la primera infancia comparte en los distintos escenarios de educación inicial del país. El capítulo empieza con una reflexión sobre la inclusión de los más pequeños en la investigación, y luego desarrolla teóricamente estos aspectos clave que fueron indagados con ellos: calidad de vida, trayectorias de vida, relaciones interpersonales y la escuela como lugar seguro ocupan este espacio del capítulo; para después adentrarse en cómo se llevó a cabo la inclusión de estos inusuales participantes en el estudio, los hallazgos más destacados, lo que los docentes de estos niños y niñas también aportaron al respecto y su transformación en una propuesta de competencias para el talento humano que trabaja en educación inicial, que surge de aquello que expresan, viven y sienten los niños y niñas.

\section{In vestigación cualitativa con niños}

La investigación cualitativa es un tipo de investigación que considera las interpretaciones de los sujetos sobre sus acciones, la construcción intersubjetiva de significados que son productos sociales y las prácticas sociales en el marco de las que se producen los sucesos sociales (Macri, 2010). Flick (como se citó en Macri, 2010), indica que este tipo de aproximación investigativa está orientada hacia el sentido, el contexto, la interpretación, el entendimiento y la reflexión. Es decir, es una perspectiva microsocial que atiende prioritariamente a las relaciones sociales y a los comportamientos de las personas.

En la investigación cualitativa, el contexto conceptual tiene como función iluminar teóricamente los hallazgos. Los conceptos y sus relaciones proporcionan el primer marco de interpretación que se enriquece con los datos durante el transcurso de la investigación. No obstante, es poco usual en las investigaciones tomar las perspectivas de los niños y, más aún, resistirse a la interpretación que de ellas hace el adulto, ya que como afirman Mieles y Tonon (2015):

Por largos periodos de la historia, niños y niñas fueron poco visibles en el espacio de lo público (Alzate, 2003; Ariés, 1986, 2001; Bajo y Beltrán, 1998; Delgado, 1998; DeMause, 1991; Rodríguez y Manarelli, 2007). Esta opacidad los mantenía anónimos frente a los adultos responsables de tomar las decisiones en el plano del bienestar colectivo, lo que significa una escasa preocupación por explorar o conocer las apreciaciones, valoraciones y sentimientos que los niños y niñas tenían sobre su propia vida. (p.27)

Esta situación obedece a que se ha considerado durante mucho tiempo que los niños no están todavía en condiciones de expresar sus sentimientos y necesidades, debido a que se asume que a causa de su inmadurez no pueden dar información confiable. Sin embargo, su participación es importante, porque son sus vivencias y las experiencias que han tenido las que requieren una orientación y atención adecuadas de parte del educador y de otros agentes que acompañan su proceso, en el caso de investigaciones sobre intervenciones educativas, pedagógicas o asistenciales. Así mis- 
mo, es necesario reconocer la importancia de atender el presente de los niños y no solo su proyección al futuro (Mieles y Tonon, 2015; Guzmán, 2010).

En esta investigación se decidió involucrar a los niños "dándoles voz" para conocer las experiencias que han vivido en el conflicto y/o como producto del desplazamiento de ellos mismos o de sus familiares, puesto que "el conocimiento de la situación real de la niñez desde su propia perspectiva permitirá comprender un poco más el tipo de sociedad que hemos construido y que ha producido esa determinada forma de vivir la infancia” (Mieles y Tonon, 2015, p.29).

\section{Conceptos para indagar las perspectivas de los niños y niñas en torno al conflicto colombiano}

De conformidad con las categorías y subcategorías planteadas en la investigación, que ya fueron abordadas en los capítulos previos, se definieron unos aspectos claves para ser explorados desde la perspectiva de los niños y niñas. Estos fueron:

- Calidad de vida.

- Trayectorias de vida (el hogar, la cultura, el desplazamiento, la identidad).

- Relaciones interpersonales.

- Resolución de conflictos.

- Escuela como lugar seguro.

De acuerdo con Verdugo, Arias, Gómez y Schalock (2012), la calidad de vida se define como:

Una categoría multidimensional, compuesta por las mismas dimensiones para todas las personas, que está influida tanto por factores ambientales como personales, así como por su interacción, y que se mejora a través de la autodeterminación, los recursos, la inclusión y las metas en la vida. (p.18)

Teniendo en cuenta lo establecido por estos autores, se aborda la calidad de vida desde la perspectiva de la información que dan los niños y lo que esto implica en términos de las competencias de los educadores.

Por otro lado, se entiende la trayectoria de vida como la expone Bourdieu (citado por Lera et al., 2007), como la "serie de posiciones sucesivamente ocupadas por un mismo agente (o un mismo grupo) en un espacio en sí mismo en movimiento y sometido a incesantes transformaciones" (p.37). La necesidad de conocer y comprender las trayectorias de cada niño radica, entonces, en ese movimiento propio de la vida, que para niños víctimas del conflicto o pertenecientes a familias víctimas del conflicto, cualquiera sea su tipo, es aún más drástico e impactante. Por esto, siguiendo a Lera et al. (2007):

Es importante comprender cómo "estos sujetos", "estos grupos sociales", han transitado de una situación a otra y cómo recuerdan o perciben situaciones de cambios y en qué aspectos de su vida: ¿qué tipo de cambios han tenido que enfrentar?, ¿cómo han ocurrido estos cambios, en qué dirección?, ¿de qué forma han sido afectados los sujetos y su entorno?, ¿pueden identificarse nuevos posicionamientos frente a los cambios? (p. 38) 
Estas son, a su vez, algunas preguntas que pueden surgir respecto a los niños que se encuentran en las instituciones educativas y sobre quienes, sin duda alguna, surgen más preguntas para conocer y entender de forma apropiada su trayectoria de vida. Esta no solo comprende situaciones de la dinámica propia en familia; en ella también se contemplan procesos culturales de los que han hecho parte, circunstancias únicas que pueden suceder en ese tránsito de un lugar a otro, debido, por ejemplo, al desplazamiento forzado.

Las trayectorias son aquellas situaciones de toda índole que constituyen la historia de vida de cada uno de los niños y niñas, que por su naturaleza implican un movimiento de emociones, respuestas y cambios profundos que marcan el desarrollo de cada uno de ellos y que afectan su situación actual, demandando de parte del educador una atención determinada.

Dentro de estas trayectorias se incluyen aspectos relacionados con su vida en el hogar y las modificaciones que pudo tener la dinámica de la familia a lo largo de la vida de los niños y niñas; también se indagaron las situaciones en que provienen de una cultura diferente a aquella en la que están participando actualmente y sus situaciones de desplazamiento, es decir, el hogar, la cultura, el desplazamiento, la identidad. Estos otros conceptos se presentan a continuación.

Se entiende el hogar, como el domicilio habitual de un niño o niña, en el que se lleva a cabo su vida privada; en este caso, no necesariamente es el lugar en el que se encuentra la familia o acudientes directos, quienes tienen la responsabilidad de atender sus necesidades y garantizarles una buena calidad de vida. Es el lugar en el que el niño o niña desarrolla la mayoría de actividades fuera de la institución educativa.

La cultura hace referencia al contexto en el que el niño o niña vive ciertas costumbres, ideas, tradiciones propias de su lugar de procedencia o que adquiere y observa de sus familiares o acudientes cercanos. Según Hevia y Kaluf (2005), la cultura es:

El conjunto de los rasgos distintivos espirituales, materiales, intelectuales y afectivos que caracterizan a una sociedad o a un grupo social y que abarca, además de las artes y las letras, los modos de vida, las maneras de vivir juntos, los sistemas de valores, las tradiciones y las creencias. (p.16)

Por su parte, Geertz (2003) expone el impacto del concepto de cultura en el concepto del hombre y de tal forma la relación inequívoca entre estos conceptos; "la cultura, la totalidad acumulada de esos esquemas o estructuras, no es solo un ornamento de la existencia humana, sino que es una condición esencial de ella.” (p.52). En el caso de los niños y niñas con quienes se trabajó, en su gran mayoría han tenido que moverse de una cultura a otra que les resulta ajena.

De otro lado, se habla de desplazamiento en la circunstancia en que el niño, niña o su familia tuvieron que abandonar su hogar por situaciones distintas a su voluntad o la de sus familiares o acudientes. Según el Banco Mundial (2015), el desplazamiento se entiende como "La situación de las personas que dejan sus hogares o huyen debido 
a los conflictos, la violencia, las persecuciones y las violaciones de los derechos humanos." (párr.1).

Dado que esta indagación se hizo en la institución educativa, se trabajaron además otros conceptos que tienen especial importancia en este ámbito: relaciones interpersonales, resolución de conflictos y lugar seguro. El concepto de relaciones interpersonales se considera importante, porque es un aspecto sobre el que los educadores requieren ciertas competencias para intervenir en el proceso de formación de los niños. Según Verdugo et al. (citados por el Ministerio de Educación Nacional [MEN], 2017): "Hace referencia a la posibilidad de vincularse con distintas personas, tener amigos, una familia o red de apoyo. (...) Se valora a través de indicadores que indagan por las relaciones afectivas, familiares, sociales, (...) entre otros” (p.56).

Por su parte, la identidad es una realidad subjetiva, distanciada, íntima, activa y propositiva, que da sentido a la autoimagen, moviéndose entre los subjetivo y lo objetivo, entre la naturaleza y la cultura (Villuendas, 1986).

Sobre el concepto de resolución de conflictos, en esta investigación se considera como el desarrollo de habilidades que les permiten a los niños negociar y proponer acciones que lleven a la solución de situaciones conflictivas.

Otro concepto indagado con los niños fue el de la escuela como lugar seguro, entendido esto como el ambiente en el cual los niños se sienten protegidos, valorados y entendidos; en el que pueden expresarse, desarrollarse y participar. Se asume la escuela como la institución educativa en la que el niño adquiere habilidades y conocimientos que aportan al desarrollo de sus habilidades para la vida. Así lo afirma Crespillo (2010), al referirse a la escuela como el espacio en el cual "se realiza educación, donde se cumple la educación, donde se ordena la educación” (p.1). Igualmente, este autor afirma que en la actualidad la escuela "es considerada como una forma de vida de la comunidad, es decir, la escuela transmite aquellos aprendizajes y valores que se consideran necesarios en la comunidad y llevan a los alumnos a utilizar y mejorar sus capacidades" (Crespillo, 2010, p.1).

Conviene aclarar que aunque no resulta clara la inclusión de la dimensión educativa al pensar en la función social del jardín maternal, porque el contrato fundacional original le asigna al jardín maternal una función de asistencia, más tarde este contrato se va recreando, adjudicándole paulatinamente el carácter educativo a estas instituciones (Soto y Violante, 2001), en esta investigación lo anterior se tuvo en cuenta porque se incluyeron niños, niñas y educadores del nivel de jardín, que hacen parte de instituciones educativas.

La significación social de la escuela tiene que ver con el lugar de los saberes y el conocimiento, y con las formas de la transmisión y de la apropiación (Cullen, como se citó en Soto y Violante, 2001). La especificidad de la institución escolar en relación con otras instituciones radica precisamente en un mandato social centrado en la transmisión de saberes (Frigerio y Poggi, como se citó en Soto y Violante, 2001). Sin 
contenido no hay enseñanza, cualquier proyecto educativo acaba concretándose en la aspiración de conseguir algunos efectos en los sujetos que se educan. Refiriendo estas afirmaciones al tratamiento científico de la enseñanza, se puede decir que sin formalizar los problemas relativos al contenido no existe discurso riguroso ni científico sobre la enseñanza, porque estaríamos hablando de una actividad vacía o con significado al margen del para qué sirve. Cuando hay enseñanza es porque se enseña algo o se ordena el ambiente para que alguien aprenda algo (Sacristán y Pérez, como se citó en Soto y Violante, 2001). Sin embargo, cabe destacar que el universo de lo que se enseña en el nivel inicial resulta mucho más amplio y prioriza conocimientos, saberes y aprendizajes de carácter no escolar.

En este sentido, las fuentes para decidir qué enseñar en el nivel inicial, para el que también se busca definir las competencias del talento humano, han de incluir "saberes culturales, pautas de crianza, aspectos evolutivos (además de los) saberes disciplinares" (Soto y Violante, 2001, p.6). El jardín maternal, en tanto institución educativa ha de contemplar la enseñanza de contenidos que contribuyan a enriquecer el desarrollo personal y social de los niños y niñas como así también la ampliación de su universo cultural (Zabalza, como se citó en Soto y Violante, 2001). Hay que recalcar que, dentro de las competencias de los educadores del nivel inicial, se requiere incluir en los procesos de enseñanza el fortalecimiento del desarrollo de habilidades que favorezcan en los niños y niñas la posibilidad de adecuarse de la mejor manera posible a las condiciones del contexto al que han llegado y a la comprensión de las situaciones que han tenido que vivir.

La escuela es un lugar privilegiado para favorecer este desarrollo, pues según afirma Rogoff (como se citó en Soto y Violante, 2001), los adultos y los niños mayores facilitan el desarrollo infantil de destrezas culturalmente valoradas, tanto de acuerdo con un plan previo, como en los intercambios que caracterizan a las relaciones humanas. En este proceso los adultos tienden puentes que permiten a los niños y niñas relacionar lo conocido con lo nuevo y comprender cómo actuar en situaciones nuevas. Los adultos facilitan por medio de -claves emocionales sobre la naturaleza de las situaciones -modelos no verbales de cómo comportarse -interpretaciones verbales y no verbales de eventos y conductas -palabras que clasifican objetos y eventos.

Resalta Rogoff (como se citó por Soto y Violante, 2001), que en los contextos de interacción, en los procesos de comunicación cotidiana, los sujetos comparten centros de atención conjunta y esfuerzos por compartir las interpretaciones, lo que permite una mutua comprensión. Esto supone la intersubjetividad, definida como la comprensión compartida sobre la base de un centro de atención común. "El proceso de comunicación, tanto verbal como no verbal, es una actividad social que puede ser considerada como puente entre dos interpretaciones de una misma situación. Por su naturaleza la comunicación supone intersubjetividad” (Rogoff, 1990, p.104).

Además de indagar acerca de las vivencias de los niños y niñas en la escuela, también se indagó sobre lo que hacían algunos de ellos en el espacio público. Se entiende por 
espacio público las instalaciones y espacios donde se encuentre el niño o la niña y a las que tienen acceso todos los ciudadanos, como parques, centros culturales, vías, andenes, etc. Según el Decreto 1504 de 1998, Artículo 2, emitido por el Ministerio de Vivienda de Colombia:

El espacio público es el conjunto de inmuebles públicos y los elementos arquitectónicos y naturales de los inmuebles privados destinados por naturaleza, usos o afectación a la satisfacción de necesidades urbanas colectivas que transcienden los límites de los intereses individuales de los habitantes. (p.1)

\section{Proceso de investigación con los niños}

Para conocer las perspectivas de los niños y niñas se diseñaron talleres con actividades que pudieran ser desarrolladas en el aula y que favorecieran su expresión libre. Sus expresiones se mantuvieron tal como ellos las dijeron, sin recurrir a interpretaciones de los adultos. A partir de estos hallazgos se construyó una propuesta de competencias, como han sido presentadas en el resto del libro.

\section{Participantes e instrumentos de recolección de información}

Participaron un total de 163 niños y niñas de grados prejardín y jardín, entre los 3 y 4 años y medio de edad. Su inclusión en el estudio se realizó luego de que cada uno otorgara asentimiento informado y con autorización de sus padres o acudientes.

Los talleres empleados como instrumentos de recolección de datos se diseñaron de acuerdo con la propuesta de filosofía para niños; en ellos se trataron temas como el buen trato y la solicitud de ayuda; cuidado de los niños y niñas en casa para identificar relaciones familiares; las situaciones conflictivas haciendo referencia a la percepción de los niños y niñas sobre un conflicto y la proposición de acuerdos para manejar dicha situación. En la Tabla 7.1. se presentan dichos instrumentos, el objetivo de cada uno y la metodología seguida en las sesiones.

Se tuvo cuidado de recoger la información de manera natural en el aula, organizando las sesiones con momentos de trabajo en grupo y de interacción individual de los niños y niñas con el educador.

Tabla 7.1. Instrumentos usados para la recolección de la información aportada por los niños y niñas que participaron en la investigación.

\begin{tabular}{|c|c|c|}
\hline $\begin{array}{l}\text { Nombre del } \\
\text { instrumento }\end{array}$ & Objetivo & $\begin{array}{l}\text { Desarrollo de } \\
\text { las sesiones }\end{array}$ \\
\hline A1: ¡Vamos a conocernos! & $\begin{array}{l}\text { Caracterizar y conocer a los niños y niñas } \\
\text { a través de un primer encuentro personal } \\
\text { e individual. }\end{array}$ & $\begin{array}{l}\text { El desarrollo de estos ta- } \\
\text { lleres se basó en la pro- } \\
\text { puesta de Filosofía para }\end{array}$ \\
\hline A2: ¡Cuento sin nombre! & $\begin{array}{l}\text { Relacionar el contenido de este cuento } \\
\text { con la identidad de cada uno por medio } \\
\text { de preguntas reflexivas sobre su identi- } \\
\text { dad y gustos. }\end{array}$ & $\begin{array}{l}\text { Niños, en la que hay tres } \\
\text { momentos principales. } \\
\text { i. Apertura con un sa- } \\
\text { ludo y la adecuación del } \\
\text { ambiente; consiste en la }\end{array}$ \\
\hline
\end{tabular}




\begin{tabular}{|c|c|c|}
\hline B1: ¿Qué es un conflicto? & $\begin{array}{l}\text { Conocer las percepciones que tienen los } \\
\text { niños sobre ¿qué es un conflicto?, ¿qué es } \\
\text { una agresión?, ¿qué es una pelea?, ¿qué es } \\
\text { un disgusto?, e invitarlos a que ellos mis- } \\
\text { mos propongan acuerdos para mejorar } \\
\text { las situaciones conflictivas, por medio de } \\
\text { la formulación de preguntas de reflexión } \\
\text { sobre los diferentes tipos de conflictos que } \\
\text { viven los niños en su entorno y la discu- } \\
\text { sión acerca de cómo ellos pueden proponer } \\
\text { soluciones o reflexiones sobre la situación. }\end{array}$ & $\begin{array}{l}\text { formación del círculo } \\
\text { que invita al diálogo y } \\
\text { que permita que todos } \\
\text { los estudiantes puedan } \\
\text { verse entre sí. } \\
\text { ii. Momento de discu- } \\
\text { sión y de ejecución del } \\
\text { plan de discusión (pre- } \\
\text { guntas guías que pro- } \\
\text { vocan el diálogo entre } \\
\text { los niños). }\end{array}$ \\
\hline B2: ¿Quién me cuida? & $\begin{array}{l}\text { Conocer las relaciones familiares y el de- } \\
\text { sarrollo de los niños y niñas en el tiempo } \\
\text { libre mediante la formulación de preguntas } \\
\text { de reflexión. } \\
\text { Identificar las relaciones familiares y su in- } \\
\text { fluencia en los niños. }\end{array}$ & $\begin{array}{l}\text { iii. Reflexión y expresión } \\
\text { artística sobre los temas } \\
\text { y preguntas tratados en } \\
\text { la sesión. }\end{array}$ \\
\hline $\begin{array}{l}\text { C1 y C2: El cuento de } \\
\text { Puchungo. }\end{array}$ & $\begin{array}{l}\text { Identificar qué es un buen trato y cómo pe- } \\
\text { dir ayuda a través de preguntas de reflexión. }\end{array}$ & \\
\hline
\end{tabular}

\section{Tratamiento de la información recolectada}

Como ya se mencionó, en esta investigación no se hizo interpretación de lo que dijeron los niños; para registrar lo que querían expresar, se adelantaron diferentes actividades que se recogieron en dibujos. Cuando los estaban terminando, pasaba un adulto a tener interacción directa con cada niño, para preguntarle qué había dibujado y el adulto transcribía textualmente lo que decía el niño, como aparece en la Imagen 1.

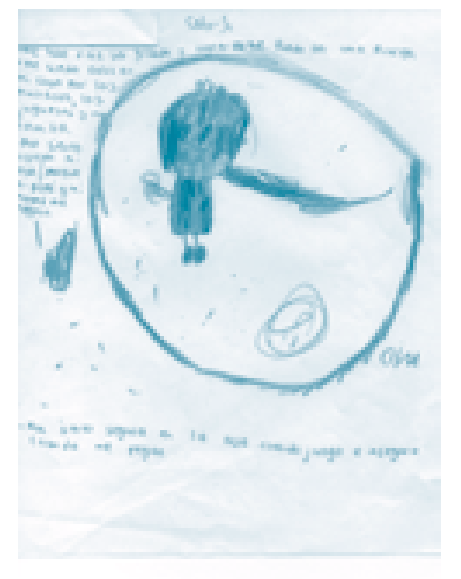




\section{La voz de los niños}

A partir de lo dicho por los niños y niñas durante los talleres, emergieron unas categorías nucleares que sirvieron para identificar los temas recurrentes en los discursos de los participantes. A continuación, se describe lo hallado en cada una de estas categorías y en relación con los aspectos clave señalados al inicio del capítulo: calidad de vida, trayectorias de vida, relaciones interpersonales, resolución de conflictos y escuela como lugar seguro.

\section{Recomposición familiar y convivencia con familia extendida.}

En cuanto a las trayectorias de vida en la subcategoría de hogar y familias, se evidencia una alta recomposición familiar, por circunstancias de diferente índole que hacen que el núcleo familiar se altere, sea cual fuere su tipología inicial, por ejemplo, una familia de padre, madre e hijos, que ahora se compone de padre, madrastra, madre e hijos.

Lo que llamamos recomposición familiar es evidente en la voz de los niños y niñas, al encontrar afirmaciones como:
"Me cuida Cristian, el novio de mi mamá. Mi papá vive lejos en un lago”. "Vivo con mi mamá, hermanito, el papá de mi hermanito, mi tío y me cuida la señora Gloria”. "Vivo con dos tíos, un padrastro, mi mamá, mis dos hermanos y mis primas. Una prima se murió". "Vivo con mi mamá, mi hermano, mi gato, el novio de mi mamá”. "Vivo con mi mamá y mi papá. Mi papá no está, él no es familiar de nosotros. Mi papá está con otra, pero me recoge”.

Como parte de esa recomposición familiar se puede evidenciar, además, una nueva dinámica familiar en la que en repetidas ocasiones se lleva a la convivencia dentro del hogar con la familia extendida. Esta convivencia con familiares o parientes más allá de la familia nuclear se hizo visible, en testimonios como los siguientes:

\footnotetext{
"Vivo con dos tíos, un padrastro, mi mamá, mis dos hermanos y mis primas. Una prima se murió". "Vivo con mi mamá, hermanito bebé, hermano grande, tío, abuelo y abuela. Me hace feliz mi gato". "Vivo con mi hermana, tíos, tías, mi papá y mi mamá”. "No vivo con mi papá, él está lejos. Vivo con mi abuelita y el tío Pablo”.
}

Es preciso entender en algunos casos que la recomposición familiar está relacionada con la convivencia con familia extendida.

\section{Abandono o ausencia de uno o ambos padres}

También se presentan evidencias de abandono o ausencia de uno de los padres o de ambos, que como se mencionó con anterioridad son parte de las situaciones de recomposición familiar y es uno de los cambios que se pueden encontrar en el núcleo familiar de los niños. El abandono se entiende como lo define el MEN (2011):

Según el ICBF, el abandono es "una forma de maltrato infantil que se configura cuando los progenitores o representantes legales de niños, niñas y adolescentes no suplen las necesidades que garantizan sus derechos, absteniéndose de proporcionar los alimentos, vivienda y educación o exponiéndolos a actos que atenten contra su dignidad e integridad física”. (p.1)

La ausencia de uno o ambos padres está vinculada a periodos de tiempo especí- 
ficos por diferentes circunstancias en las que uno o ambos padres no están presentes en el hogar o en el entorno inmediato del niño. Según Montoya, Castaño y Moreno (2015):

Cuando se habla de ausencia, se hace referencia al sentimiento de ausencia, es decir, no solamente si la ausencia ha sido por abandono o muerte de alguno de los padres, sino también por la negligencia, el rechazo o el maltrato, significados como ausencia de afecto, atención y cuidados necesarios para el niño. (p.183)

En las voces de los niños que se indagaron para esta investigación, se identificaron diferentes referencias a abandono o ausencia de uno o de ambos padres. Para el primer caso se encontraron ejemplos como:

"Mi casa es como una nevera. Mi mamá vive muy lejos". "A mi abuela le digo mamita, cuando yo crecí y era bebé mi mamá se fue de la casa”.

Por otra parte, en cuanto a situaciones de ausencia de uno de los padres, se evidenció lo siguiente:

\begin{abstract}
"Mi papá vive con niños. Me cuida mi mamá". "Me mudé a Colombia cuando tenía 3 años, de Venezuela, porque empezaron a destruir casas. Vivía con toda mi familia allá. Vivo con mi mamá y con el que va a ser mi papá. Mi papá vive en Venezuela”. "Mi mamá se fue a Zipaquirá, va y viene por mí y me vuelve a dejar. Mi tío me cuida cuando mi mamá no está. En las noches con mi papá me lleva a la cama". "No juego con mi mamá porque a ella no le gusta. Yo sí juego con mi papá". "Mi papá no trabaja, se acuesta y ya. (A) Mi mamá le toca trabajar mucho".
\end{abstract}

\title{
Cuidadores
}

A su vez, y como consecuencia de la recomposición familiar, la convivencia con familia extendida, el abandono o ausencia de uno o ambos padres, se presentan diferentes figuras de lo que es un cuidador para los niños; en algunos lo asumen diferentes miembros de la familia o de la comunidad de los niños como hermanos, primos, abuelos, tíos, vecinos, etc.

Según Exteberria (1998), hay casos en los que los niños, niñas o adolescentes pueden ser cuidadores,

es decir, niños, niñas y adolescentes que cuidan de sus padres o madres discapacitados, de sus abuelos...; que toman para sí la principal responsabilidad en la ejecución de las tareas domésticas por una peculiar situación familiar; que se responsabilizan de la educación y cuidado de sus hermanos menores ante la incapacidad, indiferencia o negligencia de sus padres. Niños, niñas y adolescentes, en fin, que cargan sobre sus espaldas con tareas de atención sanitaria, doméstica y psicológica impropias para su edad. (p.29)

En las voces de los niños en esta investigación se identificaron situaciones en las que ellos identifican como cuidadores a terceros diferentes a sus padres, como:

"Mi mamá está en el cielo. Me cuida mi papá y a veces mi hermano de 7 años". "Juego y trabajo en la dulcería de mi abuela y mi abuelo cuando salgo del colegio".

E incluso a veces terceros que no son familiares de los niños, como en el siguiente caso:

"Vivo con mi mamá, hermanito, el papá de mi hermanito, mi tío y me cuida la señora Gloria". 


\title{
Violencia interpersonal: intrafamiliar y comunitaria
}

Otro factor evidenciado en la voz de los niños es la violencia. Se encontraron diferentes tipos de violencia a la que los niños están expuestos. La violencia tiene diferentes tipos y circunstancias que hacen de este un concepto complejo. Para efectos de este análisis, nos referiremos a la violencia y sus tipos como la contempla la OMS (2002):

\begin{abstract}
El uso intencional de la fuerza o el poder físico, de hecho o como amenaza, contra uno mismo, otra persona o un grupo o comunidad, que cause o tenga muchas probabilidades de causar lesiones, muerte, daños psicológicos, trastornos del desarrollo o privaciones.

La clasificación utilizada en el Informe mundial sobre la violencia y la salud divide a la violencia en tres grandes categorías según el autor del acto violento: violencia dirigida contra uno mismo, violencia interpersonal y violencia colectiva. Esta categorización inicial distingue entre la violencia que una persona se inflige a sí misma, la infligida por otro individuo o grupo pequeño de individuos, y la infligida por grupos más grandes, como los Estados, grupos políticos organizados, milicias u organizaciones terroristas. (p.4)
\end{abstract}

De acuerdo con los siguientes apartes de expresiones de los niños y niñas, se puede catalogar la violencia encontrada como violencia interpersonal, pues abarca la violencia intrafamiliar o de pareja y la violencia comunitaria. La primera se da entre miembros de la familia o compañeros sentimentales, y la segunda entre individuos relacionados que pueden o no conocerse y se da fuera del hogar (OMS, 2002).

Los niños y niñas expresan, por ejemplo:

"A mí me pegan, porque me porto mal con mi mamá, me pegan en la casa”. "Cuando estaba en la barriga de mi mamá, el sábado, el vecino del lado le disparó a mi hermano y se salvó y revivió". "Me pegan, me pellizcan, me gritan". "Mi papá le pegó a mi mamá con un vidrio. Mi papá está peleando con mi mamá fuera de la casa". "Vivimos yo y mi mamá que me está pegando". "Mi papá en Villavo le pegaba a mi mamá".

Por otra parte, se identificaron algunas situaciones en las que si bien no se puede constituir un hecho o acto de violencia interpersonal, como lo califica la OMS (2002), se puede entender como desavenencia familiar dada la falta de detalles de ese punto por parte del niño:

"Mi papá bravo con mi mamá, pelean".

\section{Desplazamien to interno y externo}

También se identificó en la voz de los niños, en las frases y la descripción sobre sus dibujos, hechos o situaciones tanto de desplazamiento interno como externo. Como lo menciona Castel (citado por González, 2018) “Al desplazamiento interno lo determina: a) el carácter forzado; b) la permanencia dentro de las fronteras de la propia nación; y c) la responsabilidad de atención que reposa en el Estado” (p.104).

Estas características pueden ser identificadas en los siguientes casos:

\footnotetext{
"Soy caqueteño, nací en Lupita, a mi mamá le enterraron un cuchillo en Bogotá y murió".

"Toda mi familia está en el campo, (a) mi abuelito lo mataron y está en el cielo, por eso nos vinimos".
} 
También hay casos en los que se puede observar un desplazamiento regional dentro de Colombia, pero sin poder asegurar si se trata o no de un evento de desplazamiento forzado:

"Mi papá vivía en la costa y yo nací en Bogotá". "Mi papá nació en el Huila y nos mudamos".

En cuanto al desplazamiento externo, en el que se evidencia una movilización o desplazamiento forzado que implica el cruce de una frontera internacionalmente reconocida, como el caso de las fronteras entre Venezuela y Colombia, también se hicieron comentarios:

"Nací en Machique, Venezuela". "Nací en Nachica, Venezuela" "Me mudé a Colombia cuando tenía 3 años, de Venezuela, porque empezaron a destruir casas. Vivía con toda mi familia allá. Vivo con mi mamá y con el que va a ser mi papá. Mi papá vive en Venezuela”.

En un conflicto armado se provocan acciones de diferente índole que llevan a que ciertos derechos no puedan ser garantizados. Esto afecta a la población civil en general y dentro de ella a los niños, a quienes se les violan, entre otros, los derechos a la existencia, al desarrollo, a la ciudadanía y a la protección contemplados en la Ley 1098 de 2006, Código de la Infancia y la Adolescencia.

Según UNICEF (2014a):

Los niños se ven afectados de manera particular por las Minas Antipersonal (APL), las Municiones Sin Explotar (UXO) y los Artefactos Explosivos Improvisados (IED), el reclutamiento y utilización por parte de los grupos armados, la violencia sexual asociada al conflicto, el desplazamiento interno, y el confinamiento/carencia de asistencia humanitaria. (párr.5)

Esto, sin duda alguna, afecta todo el entorno en el que se encuentra o desarrolla el niño o niña, impidiéndole encontrar el bienestar necesario en su contexto, debido al desarraigo y afectaciones sobre la construcción de identidades, al desconocimiento de su ciudadanía social y su voz para la toma de decisiones, la inseguridad y temor para circular por los entornos sociales, la marginalidad, exclusión y estigmatización, la desprotección física y los riesgos para la vida, el maltrato, la violencia intrafamiliar y sexual, la desnutrición, el deterioro de las condiciones físicas y psicológicas y las dificultades cognitivas y emocionales.

El desplazamiento forzado es una de las acciones del conflicto que más ha aquejado a la primera infancia; implica para los niños, según la Organización de Estados Iberoamericanos [OEI] y Save the Children (2009), cuadros de ansiedad, culpa y sentimientos de desvalimiento, rabia y hostilidad, incapacidad para superar y expresar el dolor individual, interiorización de la desigualdad y la violencia y trastornos del sueño. Como consecuencia directa del desplazamiento forzado, el núcleo familiar del niño se ve alterado y le produce un continuo movimiento emocional que percibe de los adultos y que se traducen en algunos casos en episodios de violencia intrafamiliar (UNICEF, 2000). Estos episodios hacen que el niño o niña viva experiencias dolorosas dentro y fuera de su hogar, por lo que un lugar seguro en el que sus emociones y su ansiedad puedan tener una respuesta positiva es difícil de encontrar o de identificar. 
Como consecuencia directa de las situaciones descritas, el gobierno de Colombia -con el fin de garantizar la protección de los derechos fundamentales de la primera infancia-, se vio en la necesidad de establecer lineamientos técnicos en los que determina acciones para garantizar, entre otros, una educación continua e inclusiva a aquellos niños desplazados por la violencia. Uno de estos es el Lineamiento Técnico de la Estrategia de Cero a Siempre relacionado con las violencias asociadas al conflicto armado a las que están expuestos los niños en primera infancia y su abordaje en el marco de la atención integral (Congreso de la República de Colombia, 2016). Bajo estas directrices se establecen las situaciones de vulnerabilidad en las que se encuentran los niños y la forma en que se deben atender sus necesidades con la participación de múltiples agentes gubernamentales y privados, dentro de los cuales se encuentran las instituciones educativas.

Precisamente es en estas situaciones y efectos del desplazamiento forzado que se requiere un acompañamiento de profesionales de la psicología, el trabajo social y especialmente educativo. Este tipo de violencia obliga a la primera infancia a vivir situaciones de dolor, angustia, incertidumbre e inestabilidad que requieren de especial atención, que debe ser garantizada en aquellos lugares a los que lleguen buscando ese bienestar que se les negó en el lugar del que salieron.

En la búsqueda de ese bienestar en un lugar nuevo, y si se cuenta con esa posibilidad, los niños empiezan a asistir a una institución educativa, un espacio que puede ser seguro para ellos y que tiene la obligación de garantizar y velar por el desarrollo físico, social, afectivo y cognitivo. Por lo anterior, surge entonces la necesidad de que el talento humano que los recibe cuente con ciertas herramientas y estrategias educativas y pedagógicas que apoyen los procesos que deben desarrollar estos niños y niñas.

\section{Desplazamiento forzado externo: migración venezolana a Colombia}

Dentro de las problemáticas colombianas actuales también se encuentra la migración masiva de venezolanos a las diferentes regiones del país, en las que se da respuesta a la crisis social, económica, educativa y humanitaria de ese país. Las cifras oficiales de venezolanos en Colombia son 1.174.743, población que se concentra en Bogotá, ciudad en la que residen 221.766 ciudadanos venezolanos, representando así el 22,23\% del total en Colombia (El País, 2019).

En el reporte emitido por Migración Colombia, el 31 de diciembre de 2018, se estimó que hay 39.398 venezolanos indocumentados solo en la región central, específicamente en Bogotá. En dicho reporte se presentan cifras del departamento de Cundinamarca, en donde se encuentra un total de 58.541 venezolanos, de los cuales solo 28.579 , que representan menos del $50 \%$, tienen la documentación en orden (Ministerio de Relaciones Exteriores, 2019).

Para darle cumplimiento al propósito de garantizar el desarrollo de los niños sin distinción alguna y velar por su derecho a la educación, es necesario hablar de aspec- 
tos fundamentales como las problemáticas socioeducativas, desplazamiento interno y externo, violencia y conflicto armado. Se sabe que dentro de las problemáticas sociales y educativas se encuentran aquellas que no solo afectan ambos espacios, dado que dentro del ámbito educativo se encuentran además problemáticas sociales. Según Jurado (2002):

Las problemáticas socioeducativas presentadas han llevado a que se tome a la infancia como un actor social, que dentro de los procesos y de los ámbitos en los cuales se desenvuelve, presenta una demanda hacia nuevas reflexiones sobre su lugar desde la sociedad, la cultura y la educación. (p.3)

Del mismo modo, en 2017 el ICBF atendió a 26.349 niños y niñas de nacionalidad venezolana, de los cuales 3.346 eran menores de 5 años. En contraste con estas cifras, Rojas (2018) afirma que 13.549 niños y niñas de ese país se encuentran registrados dentro del sistema educativo colombiano. Estos estudiantes, presentan problemas relacionados con los bajos niveles de educación con los que vienen desde Venezuela y casos de matoneo que afectan su proceso de aprendizaje, ya que muchas veces salen de su país con muy bajos recursos, dejando atrás sus estudios en colegios públicos en donde la educación no era de calidad, o huyendo de su estado de desescolarización, lo que les representa dificultades añadidas cuando deben enfrentarse a la educación colombiana (Rivera, 2018).

De acuerdo con lo anterior, la población venezolana debe ser parte de las consideraciones de inclusión en Colombia, planteada como un aspecto integral de los derechos humanos, de equidad y justicia para todos los niños y niñas, en los que se contempla la diversidad como un valor educativo que puede ser formado y construido en el aula, desde la formación en valores (cooperación, solidaridad, comunidad, respeto, valoración de las diferencias), y el desarrollo de pensamiento crítico por parte de los estudiantes.

\section{Noción y acciones de buen convivir}

Por último, en las voces de los niños fue posible identificar nociones o acciones alusivas al buen convivir con los demás y con los animales de compañía. Con buen convivir se hace referencia a un conjunto de acciones encaminadas a mantener con los demás y el entorno que lo rodea una sana relación y convivencia. Si bien hay ciertas normas o valores que guían la sana convivencia dentro del contexto en el que los niños se desenvuelven, ellos pueden ser conscientes de algunas acciones o formas en las que pueden mantener esa sana o buena convivencia con quienes los rodean, ya sean pares, docentes o familiares. Algunas de estas acciones, por ejemplo, están encaminadas al uso de estrategias como el buen trato, el respeto por la diferencia y las diferentes formas de resolución de conflictos para mantener relaciones o vínculos sanos con los demás.

Como ejemplo de lo anterior, se expresó lo siguiente:

"Debemos disculparnos, dar abrazos y besos". "Ellos se están disculpando. Se están dando la mano porque se estaban peleando por un lápiz”. "Si un amigo está bravo, le preguntamos ¿por 
qué estás bravo, nos quedamos aquí?". "Ella a mí me había pegado y yo le dije a la profe y la profe le dijo que se disculpara y ella se disculpó: ¿Me perdonas?, y yo le dije que sí. Nos cogimos de la mano y nos pusimos a hablar y a jugar".

Se evidencian así diferentes mecanismos de resolución de conflictos, encaminados a fortalecer o manejar una buena convivencia entre quienes se encuentran en el entorno inmediato del niño, en la institución educativa especialmente.

\section{Los educadores en relación con los niños y niñas víctimas del conflicto}

Durante las sesiones de trabajo con los niños y niñas que hicieron parte de este estudio, sus docentes realizaron reflexiones alrededor de los testimonios hechos por ellos. Estas reflexiones constituyen un aporte adicional para la definición de competencias requeridas en los educadores para atender a la primera infancia en situación de conflicto presentada en todo el libro, y desde la perspectiva de los niños y niñas, como se muestra en este capítulo. Una síntesis de lo expresado por los educadores se presenta en toda esta sección, pero antes de ello se profundiza acerca de la educación inclusiva para víctimas del conflicto, el ambiente inclusivo de aprendizaje y el educador como garante de comunidad en el aula, que son aspectos en los cuales los educadores deben enmarcar su quehacer con la primera infancia afectada por el conflicto.

\section{Educación inclusiva y niños y niñas víctimas del conflicto}

Al hablar de la institución educativa como escenario de recepción de niños desplazados, bien sea interna o externamente, se hace necesario hablar del concepto de educación inclusiva, debido a las circunstancias en las que se encuentran al llegar a un nuevo contexto. Según el MEN (2009), la educación inclusiva se entiende como un proceso en el que se vela por el acceso, participación y el aprendizaje de todos los niños en un contexto educativo, sin hacer distinción alguna por su condición o características diversas, pero partiendo de ellas para realizar los ajustes y definir las estrategias necesarias para suplir las necesidades comunes y particulares dentro del aula. Así las cosas, el proceso de inclusión en el contexto educativo requiere de una participación activa de parte de toda la institución para generar los cambios necesarios que, por medio de estrategias pedagógicas, permitan a los niños, sea cual fuere su condición, gozar del derecho a la educación en equidad y de calidad.

El MEN (2009), plantea ciertas características de la educación inclusiva en las que expone para su ejecución la innovación y propuesta de nuevos caminos pedagógicos, la creación y diseño de prácticas de aula que vayan más allá de la integración o invitación a los niños, el fortalecimiento de espacios comunes e inclusivos que partan de los beneficios de la diversidad, dándole el valor que debería tener dentro del contexto educativo.

De conformidad con lo anterior, es preciso aclarar que la inclusión no hace referencia solamente a niños en condición de discapacidad; por el contrario, y como 
se mencionó con anterioridad, tiene un espectro más amplio del que las víctimas del conflicto armado hacen parte. Se habla de inclusión de niños y niñas víctimas del conflicto armado por las situaciones en las que se encuentran, y en el caso del desplazamiento forzado, por la necesidad de garantizar su derecho a la educación en igualdad de condiciones, teniendo en cuenta el contexto del que vienen y las condiciones psicológicas y físicas en las que llegan a la nueva institución educativa.

Cuando los niños afectados por el conflicto armado o por el desplazamiento interno o externo se enfrentan a una nueva institución, se pueden identificar diferentes dificultades tanto para los niños como para los miembros de la institución misma, que en muchas ocasiones desconocen el contexto violento del que provienen. Según la investigación realizada por Vera, Palacio y Patiño (2014):

\begin{abstract}
Algunas investigaciones han reportado las dificultades a las que se enfrentan las comunidades escolares al recibir a la población desplazada por violencia política. Por un lado, se encuentran los resultados de las investigaciones de Cortés y Castro (2005) y Castañeda et al., (2004) que señalan los problemas de adaptación que muestran los niños y las niñas en el escenario escolar. Cortés y Castro (2005) mencionan las dificultades de integración y malestar emocional y concluyen que los niños no solo están afectados por la falta de condiciones mínimas de su desarrollo, sino que además asumen el costo emocional de una violencia que la escuela desconoce. (p.14)
\end{abstract}

Por lo anterior, la educación inclusiva, en la que se propone dar respuesta a esas necesidades de los niños y niñas víctimas de conflicto armado, es la vía de acción y de definición de parámetros que determinan la intervención, apoyo y acercamiento de todos los agentes de la institución para ayudar a los niños a desarrollar el proceso de resiliencia y de comprensión que requieren para encontrar su bienestar emocional y cognitivo, en el que la educación es determinante. En este punto surge, entonces, la relación directa entre los niños afectados por el conflicto armado debido al desplazamiento forzado, la educación y las instituciones educativas. Los educadores, figuras claves en esa relación, tienen la gran responsabilidad de garantizar y hacer los ajustes para que ese proceso de inclusión cumpla con los fines y objetivos para procurar el bienestar de los niños y las niñas. Para lograr lo anterior es preciso, sin embargo, entender primero que la inclusión es un proceso que requiere de una planeación y participación activa de todos los agentes o talento humano que tratan con esta población.

Como lo menciona el MEN (2007), para lograr la inclusión y llevar a cabo este proceso,

ha sido necesario que gradualmente el sistema educativo defina y aplique concepciones éticas que permitan considerar la inclusión como un asunto de derechos y de valores, lo que está significando implementar estrategias de enseñanza flexibles e innovadoras que abren el camino a una educación que reconoce estilos de aprendizaje y capacidades diferentes entre los estudiantes y que, en consonancia, ofrece diferentes alternativas de acceso al conocimiento y evalúa diferentes niveles de competencia. (párr.12).

El talento humano que trabaja con esta población debe implementar entonces estrategias que respondan a las necesidades identificadas en esta población. 


\section{Ambiente inclusivo de aprendizaje}

Lo expuesto en el apartado anterior será posible y evidenciable por medio del trabajo dentro y fuera del aula que realizan los educadores con los niños, permitiendo que estas consideraciones y valores se encuentren presentes en la cotidianidad. Por esto, se toma en cuenta el concepto de aulas inclusivas, en las que los valores de inclusión, sus características y condiciones deben estar contempladas en el trabajo y la responsabilidad del docente en el entorno educativo.

Sin embargo, para abordar el tema de aulas inclusivas es necesario aclarar aquellos conceptos que están en constante relación con las mismas y que, a su vez, conforman una gran variedad de condiciones para su cumplimiento. Para comenzar, García (2008) afirma que la única manera de que existan aulas inclusivas es que el ambiente pueda adaptarse a la realidad sociocultural y socioeducativa de los niños. Bajo esta concepción se puede decir que normalmente los educadores deben hacer un diagnóstico que les permita conocer los espacios en los cuales se desenvuelven todos y cada uno de los niños y niñas, así como también sus condiciones personales, académicas, sociales y familiares; pero, según el autor, esta acción no es suficiente dentro de las aulas inclusivas, ya que además de hacer esto, es necesario adaptar el contexto, las normativas, los espacios y otros aspectos que están en constante relación con los niños y niñas y la realidad sociocultural y socioeducativa, como fue mencionado anteriormente.

García (2008), además, afirma que los cambios en las instituciones educativas que reciben inmigrantes, como es el caso de Colombia en este momento, "deben adaptarse a las nuevas necesidades de la sociedad (...) siendo la escuela la encargada de que las personas desarrollen las actitudes y las capacidades que son precisas para que los sujetos se puedan integrar sin dificultad" (p.90).

Booth y Ainscow (como se citó en García, 2008), explican que la inclusión implica procesos para incrementar participación de los estudiantes, por lo que la inclusión va internamente atada al tema de la participación, la seguridad, la construcción de espacios y de comunidades de aceptación y respeto, apoyando así a García (2008), quien afirma que "en las escuelas y clases inclusivas se insiste en la construcción de la comunidad, donde cada persona es un miembro importante y valioso” (p.92).

\section{Educador como garante de comunidad en el aula}

En las aulas inclusivas es de suma importancia que los estudiantes se sientan seguros, protegidos y felices. Se sabe que todos los niños, niñas y jóvenes tienen derecho a una educación, pero es importante decir que requieren de una institución en donde se provea esa educación, en donde se favorezcan procesos y prácticas que tengan como eje central la seguridad física y emocional de los estudiantes. UNICEF (2014b) afirma que es necesaria la construcción de ambientes protectores dentro de la escuela, vistos como un espacio seguro de participación, expresión y desarrollo 
en donde se empodere a los niños, las niñas y los jóvenes con herramientas para la construcción de su vida.

Como consecuencia de lo anterior, el papel del educador es determinante. Según Pérez, Roa, Vargas e Isaza (2014):

En contextos de condiciones precarias, como pobreza y vulnerabilidad, los docentes destacados muestran un alto grado de compromiso. Esto se concreta en la responsabilidad de asumir los resultados de su práctica, pues aunque reconocen las dificultades del contexto, no atribuyen a esto el éxito o el fracaso en los aprendizajes de sus estudiantes (Arancibia, 1992). Además, son docentes que reconocen el impacto de su trabajo en estos contextos, lo que se relaciona con la posición política frente a su quehacer y la consideración de este como un elemento clave en la construcción de mejores condiciones y relaciones en la sociedad, en lo cual es central la formación de sujetos con determinadas capacidades y conocimientos. Así, el compromiso de los docentes destacados es también con la escuela y con la comunidad. (p.174)

El MEN, en los Lineamientos de formación docente para la atención diferencial y pertinente de niños, niñas y adolescentes en condición de vulnerabilidad, situación de desplazamiento y en contextos de violencia, hace mención específica de la importancia del conocimiento del contexto en el cual la práctica docente toma sentido y tiene lugar. En este mismo documento se expone que dentro de la situación de violencia es imperativo que los docentes sean capaces de:

Entender su propia realidad desde las concepciones sociales, económicas y culturales, poder comprender las posturas ideológicas de los actores del conflicto desde diversas posturas conceptuales, los mecanismos para poder atenuar las acciones que se dan dentro del conflicto y que involucran a niños, niñas y adolescentes, la capacidad de entender el contexto para poder trabajar sobre el conflicto y las incertidumbres, tener en perspectiva aquellas potenciales acciones de los actores del conflicto para dar una respuesta que proteja a sus estudiantes en el momento de un reclutamiento, de un desplazamiento. (MEN, 2011, p.37)

En este sentido, se entiende la labor del educador no solo como mediador o acompañante del proceso de desarrollo, sino también como un agente asegurador y proveedor de ambientes seguros, de confianza, de interacciones acertadas, de procesos de participación, socialización y democracia en los que los niños se sientan parte de un espacio y que sean libres de compartir sus pensamientos, ideas y sentimientos en un lugar seguro, con el fin de promover la construcción de ambientes de aula inclusivos.

\section{La voz de los educadores}

Luego de la contextualización previa efectuada en los apartados previos, se presentan por categorías emergentes, al igual que se hizo con los aportes de los niños y niñas, lo expresado por los educadores.

\section{Violencia familiar}

Aunque las educadoras participantes en esta investigación en algunos casos tienen conocimiento de acontecimientos violentos vividos por los niños de forma indirecta, el desconocimiento de los educadores sobre el contexto actual o pasado del 
niño es evidente. Estos acontecimientos son relatados por los niños en ambientes de confianza y seguridad con el educador, tal como lo exponen:

\footnotetext{
"Vienen de violencia familiar, sus contextos ahora el nuevo concepto de familia que no tienen". "No se sabe qué niños de los que tiene la sede han sido agredidos". "Nunca se tiene en cuenta la situación de los niños". "Cuando estamos en el salón de clase y cuentan que el papá llegó "jincho" (alto estado de alicoramiento), y le pegó a la mamá. Yo escucho todo y trabajo con ellos sobre su vida". "Hay supuestos beneficios que llevan a los padres a que sean irresponsables, acoso, violencia intrafamiliar...".
}

Si bien no se evidencian aspectos de violencia proyectados y dirigidos a los niños y niñas, existe una violencia indirecta, al ser los testigos de acciones violentas entre sus padres o en su contexto familiar inmediato. Como resultado de ello, existen consecuencias palpables en los niños y niñas que se encuentran en estas situaciones, como lo dice Carracedo (2015), al afirmar que:

\footnotetext{
Se ha tomado conciencia sobre los riesgos que entraña esta situación y, es por eso, que estos menores han pasado a ser reconocidos como las "víctimas invisibles" y a ser tratadas como víctimas directas de la violencia entre los progenitores. (p.82)
}

Estas exposiciones a hechos de violencia que viven los niños generan consecuencias psicoemocionales, físicas, mentales y demás, que se evidencian al corto, mediano o largo plazo, dependiendo de los ambientes y las situaciones a los que se vean expuestos.

Además, los docentes hablan de un grado de deshumanización con la que ellos mismos viven al igual que los miembros de la institución educativa respecto a casos de violencia intrafamiliar, llegando al punto de llamarlos "actos comunes"; evidenciado en el testimonio de un docente al comentar que:

\footnotetext{
"Igual es que nos hemos acomodado tanto a las situaciones que hay grado de deshumanización y las situaciones se hacen comunes. Es común que el padre llegue borracho y les pegue y hay que humanizarse y ver cómo eso afecta a las niñas y a los niños, sin ser violentos."
}

Este aspecto muestra no solo que los docentes se han acostumbrado a este tipo de acontecimientos, sino que el camino hacia la violencia parte de estos sentimientos y actos de deshumanización. Como afirma Gelabert (2015), "la deshumanización permite, posibilita y legitima el ejercicio de la violencia” (p.57). Este autor asegura que "la violencia parte siempre de la deshumanización" (p.58), pues se considera el primer paso para cualquier acto violento frente a cualquier población. Esta afirmación les otorga mayor relevancia a las condiciones de los niños y, a su vez, a las condiciones de los educadores que se encuentran en constante relación con situaciones de violencia; al mismo tiempo le da aún más validez e importancia al educador, porque es quien tiene la responsabilidad de promover el desarrollo de valores y pautas que vayan encaminadas a la integralidad de la persona y a su humanización.

Sin embargo, se muestra la iniciativa de los docentes por indagar sobre los procesos de los niños y sobre las concepciones que tienen acerca de las situaciones de su vida diaria, lo cual lleva a la reflexión que, si bien se presentan grados de deshumaniza- 
ción en el cuerpo docente respecto a estas situaciones, también existe la iniciativa por parte de ellos para la indagación responsable sobre la realidad de los hechos. Esto se encuentra en el testimonio de una educadora cuando expresa:

"Como están en medio de un contexto violento, hay que indagar si son víctimas o victimarios. Considero que es importante conocer esas concepciones o representaciones de lo que se tiene por violento, víctima, victimarios".

\section{Recomposición familiar y convivencia con familia extendida}

Entre los testimonios de los docentes se encontraron alusiones a una recomposición familiar, partiendo a su vez de una descomposición nuclear de la familia y de afirmaciones sobre la convivencia con otros miembros familiares. Esta convivencia con otros miembros, ajenos a ese núcleo familiar puede generar comportamientos en los niños, ajenos a aquellos inculcados por los padres o miembros de la familia. Esto se evidencia en testimonios como este:

"Yo tengo un caso de un niño que tiene a mucha gente al lado, pero ni el papá ni la mamá lo atienden y vive atendido por diferentes personas".

También se puede identificar un elemento clave dentro de este testimonio, que no hace referencia a un cuidador ajeno, sino que no existe una persona específica a cargo del cuidado y atención del niño.

De igual forma se tienen en cuenta ciertos aspectos que mencionan los educadores, que hacen referencia a la ausencia de pautas de crianza y a una transformación profunda de valores, evidenciados en los comportamientos de los niños y en los pocos conocimientos que tienen sobre las situaciones familiares. Las pautas de crianza son fundamentales dentro de las dinámicas familiares y la construcción de personas que desarrollen su ciudadanía. Estas pautas de crianza son acogidas por los niños a través de procesos de modelamiento y ejemplo de aquellos adultos con los que convive y que muestran un cierto grado de autoridad, lo cual se puede evidenciar por medio del juego libre y del juego de roles de los niños y niñas. El evidenciar estos comportamientos en el aula lleva a reflexionar sobre los modelos y las situaciones a las que están expuestos. Esto se ve en afirmaciones como:

\footnotetext{
"En el familiar tenemos ausencia de pautas de crianza que son las que deben tener los niños, hay una descomposición familiar, hay un desconocimiento de las necesidades de sus propios hijos". "Hay una disposición emocional de las niñas y los niños, el niño no sabe si lo trae el tío, si es su segundo padre, o el cuarto y eso hace que haya un desequilibrio emocional y no hay valores sino una transformación de valores". "Estamos abarcando a las familias, porque a veces llegan tíos, abuelos, primos, vecinos y así, estamos llegando a la comunidad" "Yo tengo el caso de un niño colombo-venezolano y su mamá cambia de pareja cada rato y su papá tiene pareja y yo he visto cómo su proceso es lento, tiene un proceso de un niño de cinco años y no tiene procesos de atención”.
}

En estos testimonios se evidencian consecuencias en el área del desarrollo del niño, por condiciones inadecuadas e inestables en su contexto familiar. Sobre estas situaciones, Castillo y Merino (2017) mencionan que existen consecuencias emocionales y en su desarrollo cognitivo en los niños y niñas que viven desintegración familiar, 
al sustentar que: "El desarrollo del cerebro del niño depende de las experiencias que vive, del vínculo directo en la organización cerebral, además, existen períodos específicos, llamados períodos ventana, que requieren determinados estímulos para el óptimo desarrollo de algunas áreas cerebrales" (p.13).

\section{Desconocimiento de las necesidades de los niños y la victimización}

En la palabra de los educadores se identificaron elementos que responden a una falta de cuidado de los niños y niñas en su contexto familiar, partiendo de un desconocimiento de las necesidades de ellos y de procesos de victimización, tomando como punto de partida los sentimientos de los niños. Si bien las educadoras mencionan la evidencia de estos procesos dentro del ámbito familiar, es también pertinente extenderla al aula de clase, ya que son espacios de democracia y participación.

Las situaciones violentas vividas por los niños en sus hogares tienen consecuencias no solo de desarrollo, sino de autoestima y de somatización de ciertos actos que luego terminan ejemplificándolos con sus pares. Además, los niños expuestos a situaciones de conflicto en el hogar pueden presentar problemas de socialización y rechazo por parte de otros (Romo, Anguiano, Pulido y Camacho, 2008). Estas manifestaciones deben ser atendidas dentro del contexto escolar, fungiendo este como un contexto seguro y de socialización amable.

Respecto a esto, Fierro (2007) establece que la falta de cuidado o visibilidad de los niños "consistente en un eclipsamiento del alumno en función de otras prioridades, hace quedar marginada tanto la atención de sus necesidades, como la garantía de recibir un trato respetuoso y equitativo en la escuela" (p.2). Si bien esta autora hace explícita referencia al contexto educativo, esto mismo se puede trasladar al contexto familiar, en donde las necesidades físicas, sociales, emocionales, cognitivas, recreativas y demás están siendo pasadas por alto, con lo que se deja de lado el bienestar propio de los niños.

Estos fenómenos se evidencian en los testimonios de los educadores, cuando expresan:

\footnotetext{
"Hay muchos niños que son minimizados desde su propia casa". "La victimización hay que verla porque la mayoría se sienten víctimas". "Los niños son invisibles, no son participantes, se destierran de sus viviendas y llegan a otro contexto y de ahí no salen. El niño es totalmente invisible". "La pregunta es cómo plantearse ese encuentro del niño que fue invisibilizado ante la historia de un país para incluirlo en otro espacio en el que también va hacer invisibilizado”.
}

\section{Falta de reconocimiento de la trayectoria de los niños}

En los relatos de los educadores participantes en esta investigación, se identificaron referencias al desconocimiento sobre el origen de los niños, entendido este como "el lugar de procedencia de una persona o cosa; el medio económico y social en el que nace una persona" (Real Academia Española, 2001). No solo se habla del lugar como aspecto físico, sino que se toma en consideración la historia del niño, su trayectoria de vida, en cuanto a sus entornos sociales, culturales, económicos, familiares y los demás entornos y ambientes que puedan dar cuenta de una historia del niño. 
El tema del origen de los niños se ve íntimamente atado al tema de sus derechos, ya que al desconocer la identificación de una procedencia clara del niño se le está negando no solo su reconocimiento social, sino también la aceptación, integración y la inclusión dentro de una sociedad. Conforme a esto, existen dos derechos que están altamente ligados al reconocimiento del origen del niño: el derecho a ser registrado, ya que "el no registrar a un niño, niña o adolescente es impedir o negarle la posibilidad de saber quién es y cuál es su origen, lo que limitará su derecho a tener una vida digna" (Pérez, 2013, p.1157). Relacionado con esto se encuentra el derecho a una identidad, aspecto que no solo es fundamental dentro del desarrollo de la persona en aspectos emocionales y psicológicos, sino que también forma parte del sentido de pertenencia a un país o región y que define las formas de actuar, sentir e interpretar el mundo.

Estos aspectos se pueden evidenciar en los siguientes testimonios:

\footnotetext{
"Me doy cuenta de que los padres no son reales con la información y nunca llevan soportes". "Reconocer los orígenes nos hacen más sensibles para reconocer las problemáticas de las niñas y los niños". "Se habla de programas de inclusión, de programas culturales, pero no les permitimos a los niños decirme 'seño', si viene de la Costa. Hay niños que dicen 'profe', 'veci', y no les permitimos expresarse de acuerdo con su contexto". "Para mí es necesario conocer la historia de cada niño desde su mundo y no desde lo que su familia quiere aparentar para poder comprender y ayudar a transformar". "Pienso que es una tarea del docente desde el reconocimiento de la historia y abordar las problemáticas en las aulas de clase y resolver las situaciones desde el aula y sensibilizar a los niños sobre las problemáticas de los otros". "En mi colegio se habla de diversidad e inclusión, pero hay un fenómeno es que "bienvenidos, hermanos venezolanos', pero eso se hace es para tener más alumnos, pero no reconociendo su diferencia y esto solo queda en el discurso. A nivel cultural la institución educativa no tiene la capacidad para reconocer la diferencia de cada uno, llegan al aula estigmatizados". "El tema es que hay una estigmatización, antes eran los costeños, pero ahora son los venezolanos".
}

Este desconocimiento expresado por los educadores trae como consecuencia la falta de reconocimiento del origen por parte (según los educadores) de la institución educativa y la mayoría de su cuerpo de trabajo, la cual genera a su vez estigmas sociales frente al país o región de proveniencia del niño, así como también la falta de visibilidad del niño sobre su cultura y costumbres, ignorando que la institución educativa juega un papel muy importante en los procesos de socialización de los niños.

Esta afirmación resalta la importancia que tienen las instituciones educativas de llevar a cabo procesos de socialización en los que se respete la identidad y se reconozca al otro como una persona con derechos y deberes, pertenecientes a una comunidad y a una cultura. A su vez, es necesario que estos procesos partan del ejemplo de los educadores y demás miembros de una institución en los cuales no solo se exprese, sino que se actúe con base en este principio, ya que pueden servir de modelos para el reconocimiento de los niños como parte de un grupo social. Esta pertenencia va muy ligada a las comunidades que se forman dentro de las instituciones entre pares, pero también hace referencia a ese sentido de identidad respecto a unas costumbres que forman parte de una cultura y una historia. En la siguiente imagen se recoge el testimonio de una niña que expresa sus sentimientos acerca de su lugar de origen. 


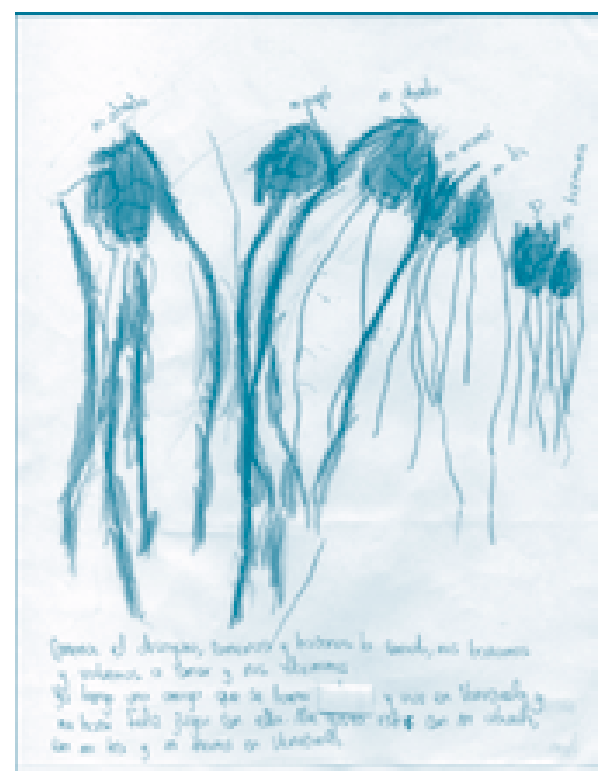

Imagen 7.2. Dibujo de una niña y transcripción literal de su relato acerca del mismo.

\section{Acciones para la resolución de conflictos}

Los educadores mencionan aspectos relacionados con el manejo de emociones y acciones concretas enfocadas a la resolución de conflictos presentados dentro del aula y fuera de ella, teniendo en cuenta que estas acciones concretas están enfocadas en el alumno y en los docentes. Al momento de la intervención para la resolución de un conflicto, no tienen un orden específico, sino que depende de la situación, de los actores principales e inclusive los secundarios y lo que en ese momento se pueda llevar a cabo para que haya un entendimiento de la situación y de la importancia de la reflexión y la resolución de estos.

Sin embargo, existen aspectos claves como la participación, la comunicación, el entendimiento del otro, el reconocimiento propio y enfocarse en la posible solución cuando se aborda un conflicto. En coherencia con esto, propuestas como la del Ministerio de Justicia de Colombia presentan una serie de pasos a seguir por parte de los actores principales del conflicto para darle una solución pacífica; estos se muestran en la siguiente figura.

Figura 7.1. Pasos para la resolución de conflictos. Fuente: Ministerio de Justicia (sf).

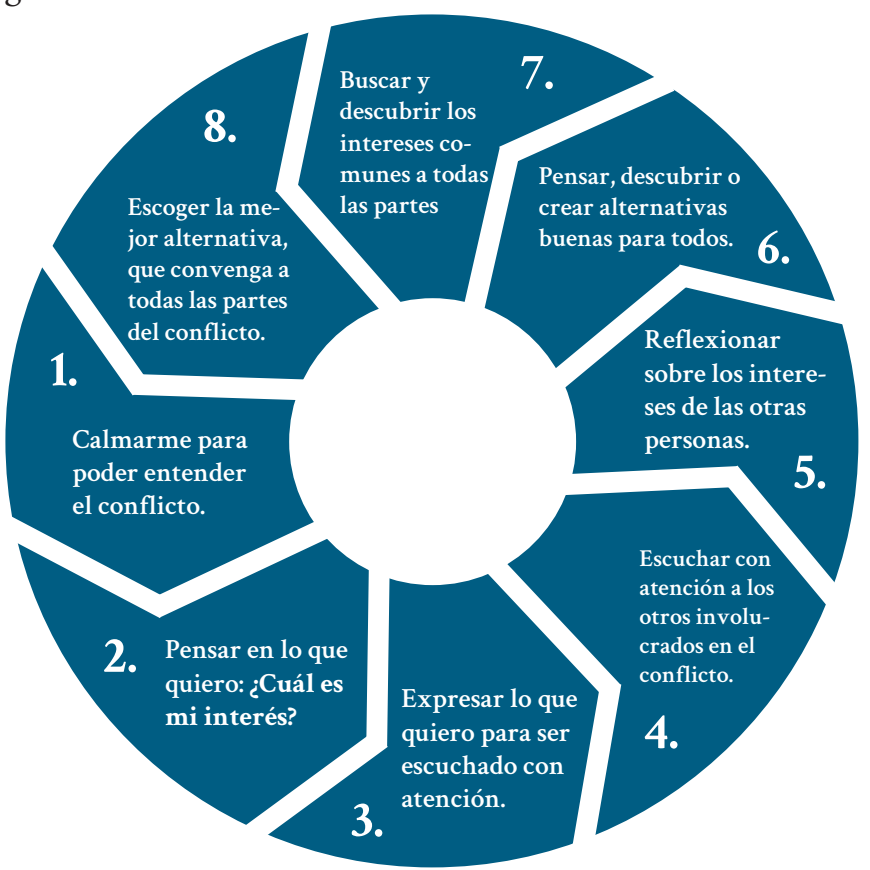


Estos aspectos se evidenciaron en algunos testimonios de los educadores al explicar que:

"Tenemos que ser neutrales en los conflictos, hay niños juiciosos y el culpable es el otro niño, por eso se deben conocer las dos historias". "En la medida que reconozcamos los orígenes del conflicto, así mismo se puede abordar el conflicto en el aula y dilucidar las historias de vida de los niños y afrontar conflictos del aula". "Lo primero es indagar el por qué se presentó el conflicto". "Indagar y escuchar las versiones de cada una de las partes. Mediar". "Me convierto en mediador para reconocer la situación". "Llegar a acuerdos, construcción pedagógica, que socialicen y negocien". "No hay conflicto del estudiante que sea mínimo".

Un aspecto importante por resaltar en los testimonios de los educadores es que muestran que están atentos a los conflictos presentados y a intervenir en el momento oportuno, si bien no a dar solución a la situación, sí para prestar un servicio de orientación y acompañamiento durante este proceso. A su vez, el hecho de que no consideren ningún conflicto del estudiante como mínimo, lleva a suponer que se presentan en la cotidianidad de las jornadas educativas de los niños y que, aunque en algunos casos se pueda considerar como de poca importancia, los educadores procuran que todo conflicto se resuelva.

Todos estos aspectos se ven reflejados en un ambiente institucional en el que se debe tener como meta "una escuela que enseñe a vivir, a desarrollarse de forma integral (...) con énfasis en el trabajo de las emociones, para lograr una calidad emocional del niño" (Aresté, s.f., p.26), basada en la seguridad emocional y en la construcción de una autoestima saludable del estudiante. El aspecto emocional en el desarrollo integral de los niños y de las niñas es fundamental, ya que en los testimonios de las docentes se pudieron identificar sentimientos y emociones consecuencia de la exposición constante a violencia, abuso y otros tipos de conflictos dañinos para el niño. Se hicieron alusiones a esto en las siguientes afirmaciones:

"La prevención de abuso y emociones de cómo nos reconocemos a partir de la tristeza, la alegría, acciones que me pongan triste que me afecten, que me produzcan alegría, que me produzcan rabia. La rabia es una de las emociones que no tenemos en cuenta y es una de las emociones más fuertes en ellos, nosotros pensamos que los niños pequeños manejan la alegría, el amor, pero no, hay mucha rabia detrás". "Otros niños sienten rabia de creer que si yo expresaba lo que sentía, el adulto no me va a creer. Por qué tengo que contar si no me van a creer". "En los estudiantes se pueden encontrar hilos de resentimiento (...)".

Respecto al tema de las emociones, es fundamental educar a los niños en una construcción de autoestima y autoimagen; la autoestima es "tener la certeza interior de la propia valía, la conciencia de ser un individuo único, de ser alguien que no solamente tiene capacidades, sino también limitaciones" (Laporte, 2006, p.9) y la autoimagen es "la imagen que tienen de sí mismos" (Laporte, 2006, p.9), y se forja a medida que los niños observan y escuchan a sus padres y a sus educadores. La construcción de la autoimagen es un aspecto que, si bien se basa en la relación consigo mismo, también surge de una construcción social, en la cual influyen los comentarios y pensamientos del entorno social. Este aspecto se evidencia cuando las docentes mencionan que:

"Llegaron al autorretrato. Los racistas son ellos mismos, eso es conflicto, eso es violencia". "Lo importante es que el niño se identifique como un sujeto proponente de sentimientos y emociones". 


\section{Procesos educativos violentados}

Dentro del contexto educativo en el que están los educadores que relataron sus vivencias y opiniones sobre las realidades del aula y de los niños, se destacaron aspectos que responden a una violación de procesos educativos de los niños:

\footnotetext{
“Así no controle esfínteres se lo llevan a la profesora, el niño no habla bien, no importa, así llévenselo a la profesora. Se está pasando por encima de las situaciones”. "En qué momento tengo 35 niños y no puedo pasar porque no cabemos. Eso también me parece violento". "Yo tuve que hacer una maestría para entender por qué le pido a un niño de primero que aprenda con violencia”. "Cuando se hacen las comisiones de evaluación, yo paso este niño porque tienen este recorrido, pero profe, no lo puede pasar porque eso no funciona así en el siguiente año, llega el otro año y los padres dicen 'el año pasado no aprendieron nada'. Eso es una violencia. En ambientes educativos se vive una violencia institucional". "Ellos reciben niños por llenar aulas, pero no prestan interés en lo que debe atender y dar las pautas para trabajar con esas niñas y niños". "Cuando se reciben los niños no se piensa en su bienestar".
}

En estos testimonios se identifican aspectos claves en el desarrollo integral del niño, que parten de una mirada global y errónea de la escolarización de los niños. Si bien es necesario que los niños vayan al colegio, este proceso se debe dar adecuadamente, teniendo siempre como prioridad el bienestar de los niños, aspecto que, según lo expresan las educadoras, está siendo ignorado y por lo tanto se están violando los derechos de los niños. A su vez, se tiene en cuenta el aspecto de la falta de un diagnóstico al entrar a la institución y, por lo tanto, la ubicación del grado visto como una asignación que depende de la edad y no de sus capacidades y desarrollo. En consecuencia, se asume que existen niños en niveles inadecuados, siendo forzados a vivir procesos que no corresponden a su nivel de desarrollo y que además están siendo pasados de nivel en nivel sin tener en cuenta los procesos adquiridos y los aprendizajes esperados.

Las educadoras mencionan otro aspecto esencial, que es la capacitación sobre las pautas para trabajar con diferentes poblaciones y estudiantes que cada vez son más diversos. Este tema tiene fundamento en el entender que la capacitación docente "permite evitar la obsolescencia de los conocimientos del personal (...) y también permite adaptarse a los cambios en la sociedad, los productos, los servicios y las diversas demandas del mercado" (Vásquez, 2017, párr.2); más específicamente, permite "mantenerse al día en cuanto a los enfoques educativos, metodológicos y didácticos, los avances científicos y las tecnologías pedagógicas” (Vásquez, 2017, párr.3).

Finalmente, existe otro aspecto que llama la atención sobre los procesos educativos, que se desliga un poco del tema de desarrollo y se enfoca más hacia las condiciones físicas de las aulas de clases, que representan una limitación tanto para los docentes como para los estudiantes. Estas limitaciones se basan en temas de movilidad, de espacio para libre expresión y libre andar, aspectos que se vuelven esenciales en la práctica docente. 


\section{Socialización}

Abordar los procesos de socialización de la primera infancia dentro del núcleo familiar, social y cultural desde una perspectiva multicultural, implica el reconocimiento de que la constitución paulatina como seres humanos y la construcción de la propia identidad, se definen en contraste con los otros, con los diferentes (Mieles y García, 2010). La fase de socialización primaria, que ocurre generalmente en el seno de la familia, cualquiera sea su condición, "se efectúa en circunstancias de enorme carga emocional; sin esa adhesión emocional a los otros significantes, el proceso de aprendizaje sería difícil, cuando no imposible” (Berger y Luckman, como se citó en Mieles y García, 2010).

Todo individuo nace dentro de una estructura social objetiva en la cual encuentra a los otros significantes que están encargados de su socialización y que le son impuestos, estos mediatizan el mundo para él, seleccionan aspectos del mundo según la situación que ocupan dentro de la estructura social y en virtud de las idiosincrasias individuales, biográficamente arraigadas (Mieles y García, 2010). Por ello se afirma que la socialización en las sociedades que conservan más genuinamente sus tradiciones puede crear unas identidades socialmente más definidas de antemano; es el caso de las comunidades indígenas, afrocolombianas o campesinas, poco influidas por culturas foráneas; por el contrario, en las sociedades complejas, los procesos de socialización convierten en un laberinto las trayectorias individuales mediante las que se pretende aprehender la realidad social y donde la ecuación "un grupo social igual a cultura” no funciona (Pujadas, como se citó en Mieles y García, 2010).

Cabe señalar que en una sociedad como la nuestra, altamente fragmentada, con presencia de conflictos y violencia que rayan en la deshumanización, los fundamentos sociales sobre los cuales se produce la incorporación de las nuevas generaciones generan una dificultad mayor a los padres y madres, cuidadores y cuidadoras o encargados de la crianza y la educación, considerando que día a día los referentes vividos o destacados por los medios de comunicación son, en muchos casos, extremadamente negativos y atentan contra la idea de grupo social consciente de sus responsabilidades y comprometido con el bienestar y la felicidad de cada uno de sus integrantes (Mieles y García, 2010).

\section{Propuesta de competencias}

\section{Nivel individual}

Estas competencias se construyeron como resultado del análisis de las voces de los niños. Se plantean solamente para el nivel individual, dado que las implicaciones que ellas tienen para los otros niveles (institucional, interinstitucional y de gobernanza), están recogidas en las competencias ya presentadas en los otros capítulos y que derivaron de los conceptos eje de toda la investigación. 
Tabla 7.2. Competencias relacionadas con la participación de los niños en la investigación - Nivel individual.

\begin{tabular}{|c|c|c|}
\hline Conocimientos & Prácticas & Valores \\
\hline 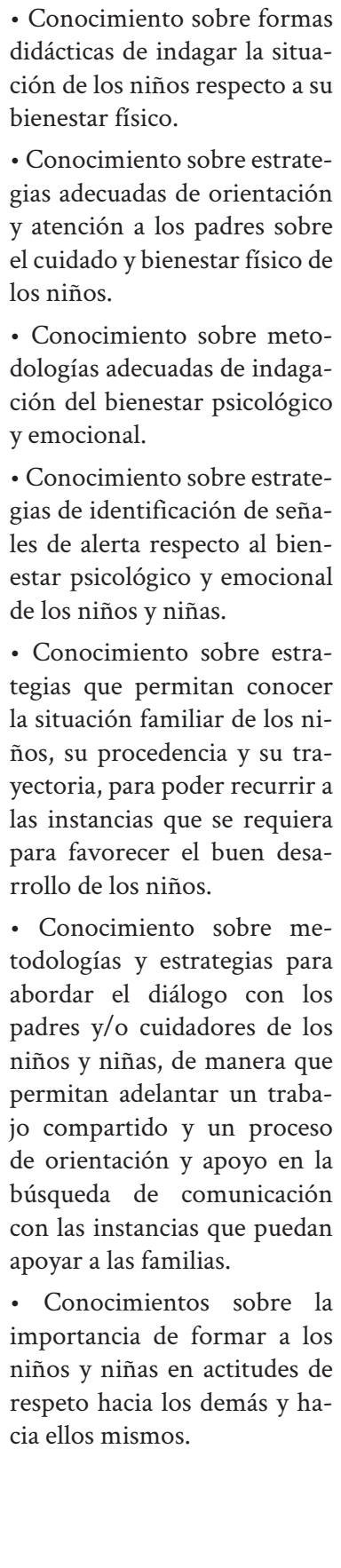 & 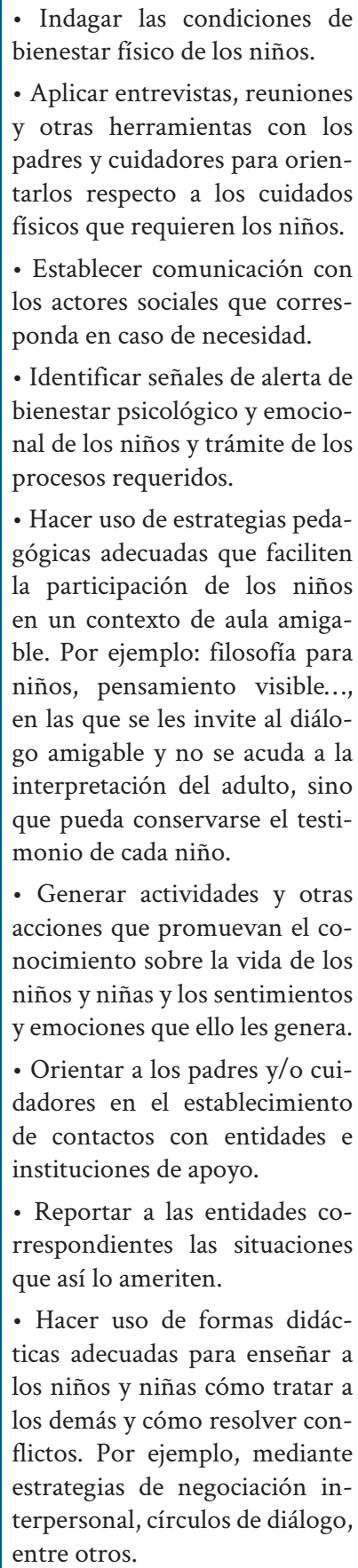 & $\begin{array}{l}\text { - Reconocer la importancia } \\
\text { del bienestar físico de los ni- } \\
\text { ños y niñas. } \\
\text { - Reconocer la importancia } \\
\text { de preservar el bienestar psi- } \\
\text { cológico y emocional de los } \\
\text { niños y niñas. } \\
\text { - Reconocer y valorar el lugar } \\
\text { de origen de cada niño o niña. } \\
\text { - Analizar las implicaciones } \\
\text { de sus trayectorias } \\
\text { - Evaluar las condiciones ac- } \\
\text { tuales de bienestar de cada } \\
\text { niño. } \\
\text { - Valorar la importancia de la } \\
\text { adaptación del niño al nuevo } \\
\text { medio. } \\
\text { - Reconocer la necesidad de } \\
\text { acoger al niño o niña en el } \\
\text { aula como sitio seguro. } \\
\text { - Reconocer la importancia } \\
\text { de generar espacios y condi- } \\
\text { ciones en los que los niños } \\
\text { aprendan a respetarse, aun } \\
\text { cuando vengan de situaciones } \\
\text { en las que prime el atropello. }\end{array}$ \\
\hline
\end{tabular}


Como puede notarse en las competencias que se plantean en el nivel individual, se derivan de allí otras que podrían corresponden a los otros niveles del sistema. Por ejemplo, en lo que respecta al conocimiento de las trayectorias de los niños y sus familias, la institución educativa debe implementar mecanismos de recolección de información acerca de la procedencia e historia de los niños para proporcionarla a quien corresponda y especialmente a los educadores, que son quienes están en contacto directo con los niños, así como diseñar estrategias de capacitación continua a los diferentes actores que interactúan con los niños y niñas para poder atender estas situaciones.

Por otra parte, en el nivel interinstitucional se necesitan mecanismos de diálogo ágil, oportuno y pertinente tendiente a atender las necesidades de los niños, y en el nivel de gobernanza se requiere del diseño y puesta en marcha de políticas que promuevan y faciliten la atención adecuada a estos niños, así como la inclusión de educadores en la formulación de política pública, teniendo en cuenta que, además, es muy importante proveer a los educadores las condiciones adecuadas para que puedan adelantar su trabajo con calidad.

Se reitera que no se presentan aquí las competencias de otros niveles, porque ya han sido trabajadas en los otros conceptos abordados en esta investigación.

\section{Conclusiones}

Existen ciertas perspectivas de los niños y niñas que son pertinentes a la hora de pensar en programas de cualificación para el talento humano que trabaja en educación inicial con población afectada por el conflicto. Entre los niños y niñas participantes fueron recurrentes testimonios que dan cuenta de dinámicas familiares diversas como recomposición familiar, convivencia con familia extendida, abandono y violencia intrafamiliar. Estas perspectivas son importantes ya que son potenciales generadoras de conflictos que pueden impactar negativamente a los niños y niñas y por tanto demandan de los equipos de talento humano una comprensión y actuación específica que incorpores la perspectiva del sentir de los niños y niñas.

\section{Referencias}

Aresté, J. (s.f.). Las emociones en educación infantil: sentir, reconocer y expresar

(Tesis de pregrado). Universidad Internacional de La Rioja, Logroño, España. Recuperado de: https:// cutt.ly/frqO4Wg

Banco Mundial. (2015). Preguntas frecuentes: desplazamiento forzado, una crisis mundial cada vez mayor. Recuperado de: https://cutt.ly/Xe69HhM

Carracedo, S. (2015). Menores testigos de violencia entre sus progenitores: repercusiones a nivel psicoemocional (Tesis de doctorado). Universidad de Vigo, Vigo, España.

Castillo, S., y Merino, Z. (2018). La desintegración familiar: impacto en el desarrollo emocional de los niños. Journal of Science and Research, 3(9), 10-18. https://doi.org/10.26910/issn.2528-8083vol3iss9.2018pp10-18p

Congreso de la República de Colombia. (2016). Ley 1804 de 2016. Por la cual se establece la política 
de estado para el desarrollo integral de la primera infancia de cero a siempre y se dictan otras disposiciones. Bogotá, Colombia: Congreso de la República de Colombia.

Crespillo, E. (2010). La escuela como institución educativa. Pedagogía Magna, 5, 257-261. Recuperado de: https://dialnet.unirioja.es/servlet/articulo?codigo $=3391527$

El País. (2019). Aumenta a 1.174.000 la cifra de venezolanos residiendo en Colombia. Recuperado de: https://www.elpais.com.co/colombia/aumenta-a-1-174-000-la-cifra-de-venezolanos-residiendo-en.html

Exteberria, I. (1998) Cuidadores informales menores de edad. Zerbitzuan: Gizarte zerbitzuetarako aldizkaria $=$ Revista de servicios sociales, 34, 29-37.

Fierro, M. (2007). La invisibilización del alumno: un fenómeno inadvertido del sistema escolar mexicano. REICE. Revista Iberoamericana sobre Calidad, Eficacia y Cambio en Educación, 5(4), 83102.

García, J. (2008). Aulas inclusivas. Bordón. Revista de pedagogía, 60(4), 89-105. Recuperado de: https://dialnet.unirioja.es/servlet/articulo?codigo $=2912295$

Geertz, C. (2003). La interpretación de las culturas. Barcelona, España: Gedisa.

Gelabert, T. (2015). Lo humano, la deshumanización y la inhumanidad. Apuntes filosófico-políticos para entender la violencia y la barbarie desde J. Butler. Análisis. Revista de Investigación Filosófica, 2(1), 49-61. Recuperado de: https://papiro.unizar.es/ojs/index.php/analisis/article/ view/922

González, S. (2018). El desplazamiento forzado interno. Una comparación entre Colombia y Perú. Estudios Políticos, 53, 100-125. http://doi.org/10.17533/udea.espo.n53a05

Guzmán, R. J. (2010). Escuela y concepciones de infancia. Bogotá, Colombia: Magisterio.

Hevia, R., y Kaluf, C. (2005). Diversidad cultural: materiales para la formación docente y el trabajo en el aula. Volumen 3. Santiago de Chile, Chile: Oficina Regional de Educación de la UNESCO para América Latina y el Caribe. Recuperado de: https://unesdoc.unesco.org/ark:/48223/ pf0000151226

Jurado, J. (2002). Problemáticas socioeducativas de la infancia y la juventud contemporánea. Estudios Pedagógicos, 28, 205-216. https://dx.doi.org/10.4067/S0718-07052002000100013

Laporte, D. (2006). Autoimagen, autoestima y socialización: guía práctica con niños de 0 a 6 años (Vol. 58). Madrid, España: Narcea Ediciones.

Lera, C., Genolet, A., Rocha, V., Shoenfeld, Z., Guerriera, L., y Bolcatto, S. (2007). Trayectorias: un concepto que posibilita pensar y trazar otros caminos en las intervenciones profesionales de trabajo social. Revista Cátedra Paralela, 4,33-39.

Macri, M. (2010). Estudiar y trabajar: perspectivas y estrategias de los adolescentes. Buenos Aires, Argentina: La Crujía.

Mieles, M., y García, M. (2010). Apuntes sobre socialización infantil y construcción de identidad en ambientes multiculturales. Revista Latinoamericana de Ciencias Sociales, Niñez y Juventud, 8(2), 809-819. Recuperado de: http://www.umanizales.edu.co/revistacinde/index.html.

Mieles, M., y Tonon, G. (2015). Calidad de vida y niñez. Santa Marta, Colombia: Universidad del Magdalena.

Ministerio de Educación Nacional. (2011). Abandono: un delito que se castiga con cárcel. Centro virtual de Noticias de Educación. Recuperado de: https://www.mineducacion.gov.co/cvn/1665/ w3-article-290374.html

Ministerio de Educación Nacional. (2009). Educación inclusiva con calidad "Construyendo capacidad institucional para la atención a la diversidad. Guía. Bogotá, Colombia. Recuperado de: http:// docs.wixstatic.com/ugd/adb7b9_bac1dfbf7f9e45ebbf044e3b4f934eb2.pdf

Ministerio de Educación Nacional. (2007). Educación para todos. Recuperado de: https://www.mineducacion.gov.co/1621/article-141881.html

Ministerio de Educación Nacional. (2011). Lineamientos de formación docente para la atención diferencial y pertinente de niños, niñas y adolescentes en condición de vulnerabilidad, situación de desplazamiento y en contextos de violencia. Bogotá, Colombia. Recuperado de: http://colombiaaprende.edu.co/html/micrositios/1752/articles-320687_documento.pdf 
Ministerio de Justicia. (s.f.). Pasos para resolución de conflictos [Infografía]. Recuperado de https:// www.minjusticia.gov.co/ninos/PasosParaSolucionarConflictos

Ministerio de Relaciones Exteriores. (2019). Venezolanos en Colombia. Recuperado de: http://migracioncolombia.gov.co/index.php/es/prensa/infografias/infografias-2019/9984-venezolanos-en-colombia.

Ministerio de Vivienda. (1998). Decreto 1504 de 1998. Por el cual se reglamenta el manejo del espacio público en los planes de ordenamiento territorial. Bogotá, Colombia: Ministerio de Vivienda.

Montoya, D., Castaño, N. y Moreno, N. (2016). Enfrentando la ausencia de los padres: recursos psicosociales y construcción de bienestar. Revista Colombiana de Ciencias Sociales, 7(1), 181-200.

OMS. (2002). Informe mundial sobre la violencia y la salud. Washington DC. Estados Unidos. Recuperado de: https://cutt.ly/FrqexDb

Organización de Estados Iberoamericanos y Save the Children. (2009). Colombia: huellas del conflicto en la primera infancia. Bogotá, Colombia. Recuperado de: https://cutt.ly/pe8Vkkz

Pérez, A., Roa, C., Vargas, A., e Isaza, L. (2014). ¿Qué caracteriza a un docente destacado? Rasgos de la práctica en los primeros grados de escolaridad. Revista Colombiana de Educación, 67, 171-200.

Pérez, M. (2013). El entorno familiar y los derechos de las niñas, los niños y los adolescentes: una aproximación. Boletín Mexicano de Derecho Comparado, 46(138), 1151-1168. Recuperado de: https://cutt.ly/wrqOaBV

Real Academia Española. (2001). Diccionario de la lengua española (22 edición). Recuperado de: http://www.rae.es/rae.html

Rivera, M. (2018). La travesía de los niños venezolanos con la educación pública. El Espectador. Recuperado de https://www.elespectador.com/noticias/bogota/la-travesia-de-los-ninos-venezolanos-con-la-educacion-publica-articulo- 812525

Rojas, T. (2018). Colegio: el refugio de los niños venezolanos en Colombia. Semana. Recuperado de: https://www.semana.com/educacion/articulo/los-ninos-venezolanos-que-entran-al-sistema-educativo-colombiano/568138

Romo, N., Anguiano, B., Pulido, R., y Camacho, G. (2008). Rasgos de personalidad en niños con padres violentos. Revista de Investigación en Psicología, 11(1), 117-127.

Soto, C., y Violante, R. (2001). Los contenidos de la enseñanza en el jardín maternal. Informe final no publicado. Recuperado de: https://cutt.ly/Je63fK8

UNICEF. (2000). Esta guerra no es nuestra. Niños y desplazamiento forzado en Colombia. Bogotá, Colombia. Recuperado de: https://cutt.ly/GrqrenU

UNICEF. (2014b). SITAN. Situación y Análisis de la Infancia y Adolescencia en Colombia. Bogotá, Colombia: Recuperado de: https://www.unicef.org.co/sitan/1-derecho-a-la-existencia

UNICEF. (2014a). Situación de la Infancia. Bogotá, Colombia. Recuperado de: https://www.unicef. org.co/situacion-de-infancia

Vásquez, R. (2017). La importancia de la capacitación docente. Río Piedras, Puerto Rico: Centro para la Excelencia Académica. Universidad de Puerto Rico. Recuperado de: http://cea.uprrp.edu/ la-capacitacion-docente-y-su-importancia/

Vera, A., Palacio, J., y Patiño. L. (2014). Población infantil víctima del conflicto armado en Colombia. Perfiles Educativos, 36(145), 12-31.

Verdugo, M., Arias, B., Gómez, L., y Schalock, R. (2009). Escala GENCAT de calidad de vida. Manual de aplicación. Barcelona: Institut Ctalá d’Asstència i Serveis Socials y Departamento de Acción Social y Ciudadanía de la Generalitat de Catalunya.

Villuendas, M. (1986). La identidad cognitiva. Estructura mental del niño entre 4 y 7 años. Madrid, España: Narcea Ediciones 


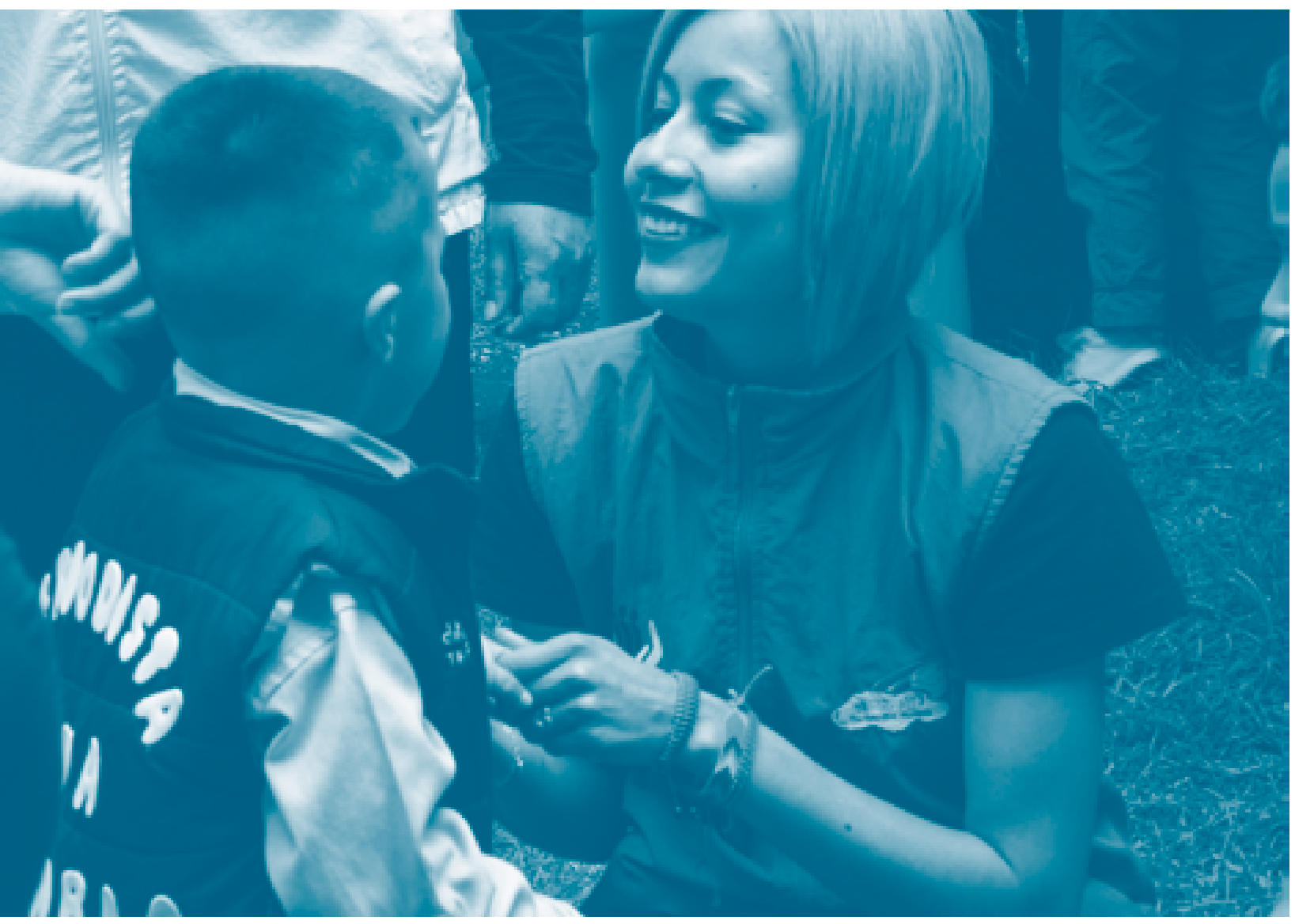

Capítulo 8.

Recomendaciones para la política pública de primera infancia desde cada uno de los conceptos establecidos en la investigación 
$\mathrm{A}$ continuación se presentan las recomendaciones para la política pública de primera infancia desde cada uno de los conceptos establecidos en la investigación: Identidades profesionales en la educación para la primera infancia, Comprensión y síntesis interpretativa del conflicto colombiano, Políticas públicas para la atención de la primera infancia víctima del conflicto colombiano, Acciones educativas de educación para la paz en la primera infancia y El conflicto en Colombia y su impacto en la calidad de vida de la primera infancia: entornos para la promoción del bienestar y el desarrollo infantil, así como aquellas que surgieron del trabajo particular con niños que se llevó a cabo en el estudio. Estas surgen del análisis de la información obtenida en el trabajo de campo y el aporte de los espacios de socialización con actores del nivel institucional, interinstitucional y de gobernanza.

Identidades profesionales en la educación para la primera infancia

Establecimiento de una identidad profesional colectiva en el que se posicione el concepto de profesionalización en el campo de la educación de la primera infancia

Es importante reconocer la diversidad de los perfiles del talento humano que trabaja con primera infancia, no obstante, se debe superar la mirada de la cualificación técnica y las transiciones y establecer una identidad profesional colectiva. Para ello es importante que se introduzca el concepto de profesionalización en el campo de la educación de la primera infancia, concepto que no debe ser entendido exclusivamente como la formación que conlleva la obtención de un título profesional, sino además como la preparación profesional y de formación continua que debe recibir el talento humano para fortalecer sus competencias en el trabajo que desarrollan con los niños, las familias y las comunidades. La política debe, por tanto, implementar planes que contribuyan al establecimiento de una identidad profesional colectiva, mediante procesos de formación sistemática de los equipos de trabajo.

Implementación de lineamientos para los programas de profesionalización y cualificación del talen to humano que trabaja con población afectada por el conflicto

La política debe asegurar que los programas de profesionalización y cualificación para los equipos que trabajan con primera infancia, familias y comunidades, sean consistentes con las necesidades y expectativas del talento humano, los niños, las familias y las comunidades con quienes trabajan. Es así como los programas de profesionalización y cualificación del talento humano que trabaja con población afectada por el conflicto deben estar acompañados por lineamientos de política que establezcan las competencias requeridas para el trabajo con esta población. Tales lineamientos deben contemplar formación especializada y diferencial para el talento humano que realiza procesos de acompañamiento y formación a las familias (CDI modalidad familiar), lo anterior teniendo en cuenta que los programas ofrecidos en las instituciones de educación superior se orientan de manera más general a fortalecer las competencias para el trabajo con niños. 
Es relevante establecer, además, los mecanismos para que dichas competencias sean conocidas y acogidas por las instituciones que profesionalizan y cualifican al talento que trabaja con población afectada por el conflicto colombiano o por conflictos $\mathrm{y}$ violencias diversas.

Establecimiento de espacios formales de reflexión crítica con la participación de representantes de los diversos niveles del sistema competente

La política debe garantizar que se generen espacios de reflexión crítica para la discusión de temáticas transversales a la atención de la primera infancia, teniendo en cuenta aspectos macro como los fundamentos que orientan las prácticas de cuidado y educación, así como los aspectos micro de la implementación. Se deben tener en cuenta en tales discusiones la voz de diferentes actores que provengan de disciplinas y prácticas profesionales diversas. Deben, por lo tanto, ser partícipes en dichos espacios los actores que administran y regulan la educación de la primera infancia, las instituciones que profesionalizan y cualifican al talento humano, representantes de las instituciones educativas y CDI en sus diversas modalidades, las universidades, los centros de investigación, representantes del talento humano que tiene contacto directo con los niños, las familias y las comunidades, y de manera fundamental, representantes de las familias y las comunidades de diversos contextos que han sido afectados por el conflicto colombiano o por otros tipos de conflictos o violencias.

La política debe garantizar, además, que se generen procesos de monitoreo y evaluación que incluyan la perspectiva de actores institucionales, pero también la del talento humano, las familias y las comunidades. Dichos procesos deben diseñarse de manera que no solo califiquen la calidad de los servicios prestados, sino que tengan como uno de los propósitos principales incorporar la reflexión crítica de las prácticas desarrolladas por los actores involucrados, para contribuir a fortalecer las competencias de todo el sistema competente responsable de proporcionar mejores condiciones de desarrollo a la primera infancia, las familias y las comunidades afectadas por el conflicto.

\section{Conformación de comunidades de aprendizaje en los Centros de Desarrollo Infantil (CDI), tanto en modalidades familiares como institucionales}

La política debe considerar implementar en los CDI, tanto en las modalidades familiares como institucionales, las comunidades de aprendizaje de manera que se puedan enriquecer las competencias del talento humano que trabaja con población afectada por el conflicto, por medio del aporte de los conocimientos y experiencias de las personas que conforman los equipos de trabajo, de la reflexión crítica de sus prácticas, y de los conocimientos que se pueden adquirir mediante los estudios de caso y demás experiencias desarrolladas con estas comunidades.

Implementación de evaluaciones sistemáticas de las condiciones de bienestar del talento humano que atiende población afectada por el conflicto, como parte de las condiciones sistémicas de apoyo 
Partiendo de que las historias de vida hacen parte de las identidades de quienes trabajan con primera infancia, y reconociendo que estas historias de vida evidencian que estos actores también atraviesan por diversas situaciones de conflicto experimentadas de forma directa o vicaria, dada su labor con población afectada por el conflicto colombiano o diversos tipos de conflictos o violencias, es fundamental que se establezca una evaluación rigurosa y continua de las condiciones de bienestar de todo el talento humano, de manera que se generen acciones para la atención y cuidado que garanticen el bienestar del talento humano, lo que repercutirá a su vez en mejor atención, cuidado y formación para los niños, las niñas y sus familias.

Estas evaluaciones deben tener en cuentas no solo las condiciones de bienestar psicológico y emocional, sino además las condiciones de bienestar físico y material (incluyendo aspectos como remuneración salarial) de los equipos de trabajo.

Comprensión y síntesis interpretativa del conflicto colombiano

Desde la categoría de los orígenes, las múltiples causas y factores de permanencia de los distintos tipos de conflicto a los que están expuestos los niños y sus familias, incluido el conflicto armado, se recomienda:

Promover una mirada múltiple acerca de las causas y factores que han incidido en el conflicto colombiano, por medio de encuentros de memoria histórica, conversatorios y coloquios con actores territoriales relevantes.

Promover un espíritu crítico y una mirada amplia que se resista a los juicios o explicaciones monocausales y vaya más allá de la perspectiva de "buenos y malos", mediante el ejercicio de lectura y discusión de diferentes fuentes teóricas recomendadas en un corpus bibliográfico base.

Implementar mecanismos para que todo el talento humano que trabaja con primera infancia, familias y comunidades, desarrollen prácticas sistemáticas que contribuyan a la desnaturalización de conductas violentas y al desarrollo de conductas prosociales que repercutan en el establecimiento de una cultura de paz.

\section{Desde la categoría de los efectos de los distintos tipos de conflicto, incluido el conflicto armado, sobre los niños y sus familias, se recomienda:}

Dar a conocer al talento humano, en todos los niveles, el enfoque territorial de la implementación de los acuerdos de paz, por medio de procesos de divulgación de los planes territoriales, el sentido de dichos planes y las posibilidades de interacción con ellos desde los centros de atención e instituciones educativas en las regiones.

Conocer el enfoque de derechos y el concepto amplio de víctima del conflicto y de diferentes violencias, mediante la socialización de la ley de víctimas, su historia y beneficios.

Promover un relacionamiento empático con la población afectada por los conflictos 
desde una mirada amplia que reconozca a las víctimas no solo del conflicto colombiano y sus derivaciones, sino de diferentes violencias y conflictos.

Es importante que desde la política se establezcan mecanismos para que el talento humano conozca la historia de vida de los niños, las familias y las comunidades, de manera que pueda brindar una atención diferencial y especializada cuando la población atendida ha sido afectada por distintos tipos de conflictos o violencias.

En resumen, se recomiendan acciones concretas en tres direcciones, el encuentro con el otro para promover la multiplicidad de las miradas, la sugerencia de un mínimo corpus teórico que promueva una mirada crítica de las causas factores y efectos, así como el conocimiento de la política pública, sobre todo en lo que tiene que ver con víctimas y enfoques territoriales y por último generar acciones desde la comunicación y divulgación que promuevan la empatía y la mirada amplia sobre qué significa ser víctima en Colombia.

\section{Políticas públicas para la atención de la primera infancia vícti- ma del conflicto colombiano}

\section{Conocimientos sobre política pública y legislación actores de política pública}

Conocimientos básicos sobre política pública, legislación, arquitectura institucional, administración pública e incidencia política para generar propuestas consistentes y viables para la población víctima del conflicto colombiano.

Es indispensable que el talento humano que trabaja de forma directa con los niños, y aquellos que brindan soporte desde otros niveles del sistema, conozca la legislación y políticas establecidas para el manejo de casos de conflicto y puedan diseñar e implementar propuestas que respondan a las necesidades locales.

\section{Roles y responsabilidades en el marco de la política pública}

Especificar roles y responsabilidades institucionales para promover acciones integrales y viables de implementación para la garantía de los derechos de la primera infancia y la población víctima de conflictos. Sin duda parte de esto se encontró en los documentos de política, sin embargo, al indagar los conocimientos y prácticas de diversos actores del sistema, se evidenciaba que sus roles y responsabilidades se comprendían tan solo en el marco de implementación de programas o proyectos específicos y resultaba complejo para los actores poderse visualizar como actores de política pública.

\section{Rutas de atención}

A pesar de identificar casos de conflicto (no solo armado), en los centros de atención, no fue tan evidente que existen rutas particulares o específicas para el abordaje de estos casos, lo que pone en debate la implementación de acciones de política en las que se explicita su priorización.

Sin desconocer que existen unas rutas de atención para población en condición de vulnerabilidad, es prioritario generar acciones particulares que favorezcan la activación de rutas que ha dispuesto la legislación para población víctima del conflicto colombiano y poner en debate, en las instancias correspondientes, cuando estas rutas no funcionan por fallas en los niveles de gobernanza o alianzas interinstitucionales. 


\section{Recursos}

Es indispensable que cada uno de los actores, especialmente los del nivel de gobernanza, puedan priorizar, y blindar, recursos de orden nacional, departamental y local para población en condición de vulnerabilidad y víctimas de conflictos para la implementación de directrices referentes al conflicto y primera infancia.

De igual forma, explicitar las formas en que se deben y pueden gestionar los recursos públicos, privados, internacionales, comunitarios (entre otros), para garantizar la implementación de acciones de política pública priorizadas para la primera infancia y el conflicto colombiano (rutas, instituciones, procesos, formatos).

Garantizar/Verificar la inclusión de los temas de infancia y población víctima del conflicto en los diferentes instrumentos de política (según nivel territorial), así como partidas presupuestales y esquemas de monitoreo y seguimiento explícitos.

\section{Monitoreo y seguimiento}

Realizar acompañamiento permanente en el nivel departamental, local e institucional no descentralizado para verificar la implementación de acciones estipuladas por la ley y las políticas. Este tipo de acompañamiento implica, además de generar conocimiento y comprensión de las acciones a realizar, un proceso en el que se pueda apoyar a los equipos locales para proponer cómo se pueden generar acciones en los diferentes niveles del sistema, especialmente aquel en el que se presta atención directa a niños, niñas, familias y comunidades que respondan a los criterios establecidos por las directrices de política, sin que ello afecte las dinámicas, estilos y necesidades locales.

Por último, se sugiere optimizar los recursos de seguimiento y evaluación para minimizar la sobrecarga administrativa para los agentes educativos y equipos de trabajo.

\section{Acciones educativas de educación para la paz en la primera infancia}

Estas recomendaciones se presentan en los tres ejes puestos bajo subtítulos a continuación: Ejes del desarrollo de la educación para la paz desde la primera infancia, Necesidades de fortalecimiento y formación de educadores para la paz en primera infancia y Estrategias de gobernanza.

\section{Ejes del desarrollo de la educación para la paz desde la primera infancia}

En el desarrollo de la educación para la paz desde la primera infancia, se recomienda la incorporación de este tema y el de resolución pacífica de conflictos en currículos, actividades y trabajos de formación en instituciones de educación y de atención y educación de la primera infancia. En el mismo sentido, se recomienda garantizar, en lineamientos de políticas de primera infancia, que se promuevan rutas institucionales y criterios para la atención que promuevan cultura de paz, convivencia pacífica, participación y valoración de las diferencias en cada una de las modalidades de atención. Esto necesariamente se da generando apoyo a equipos de educadores en esta labor, para fortalecer la solución creativa de conflictos en las instituciones que son colegios; para fortalecer la participación, valoración de las diferencias y seguimiento de normas en las instituciones de atención y educación de primera infancia y sus familias; y en todas las instituciones, para el fortalecimiento de autoconcepto y elaboración de planes propios en los niños. 
Con respecto al trabajo específico con niños y familias de poblaciones víctima de los conflictos colombianos, se recomienda desarrollar acciones para dar herramientas y conocimiento a educadores sobre rutas de atención específicas para trabajar con estas personas. Esto incluye generar claridad frente a los criterios que deben tener los agentes educativos, y equipos de trabajo en general, sobre resolución de conflictos y prevención de conflictos en los escenarios de atención a la primera infancia y a familias en general, y no solamente en escenarios educativos.

Se plantea entonces que los ejes para el desarrollo de estos fines sean los programas de formación inicial y de cualificación o formación continua que tienen los educadores de primera infancia, que contengan lo enunciado (sentido de educación en la primera infancia desde una perspectiva de construcción de paz), y que se desarrollen mediante estrategias de formación de educadores iniciales para promover la educación para la paz, con condiciones para garantizar el derecho a la educación de calidad para todos.

Todas estas recomendaciones se logran mediante el fortalecimiento de la formación de educadores iniciales, que se expone en la siguiente sección.

\section{Necesidades de fortalecimiento y formación de educadores para la paz en primera infancia}

Las recomendaciones que se venían exponiendo en el punto anterior convergen en una recomendación de profesionalización de la labor de educadoras y educadores de primera infancia. Dicha profesionalización se entiende como avanzar hacia el conocimiento y práctica diestra de conocimiento de las comunidades con las cuales se trabaja, y de los sistemas de apoyo para atender sus necesidades de educación inicial.

En este sentido, se recomienda en la formación de educadores para la paz en primera infancia y en el fortalecimiento de su labor, lo siguiente:

- Fortalecer en los educadores de primera infancia capacidades de planeación, toma de decisiones en la actividad de aula, creatividad y pensamiento crítico, junto con otras competencias que no son de enseñanza, pero sí de establecimiento de relaciones con niños, equipos de instituciones y padres y sus comunidades.

- Sensibilizar ante los puntos de vista y opiniones de los niños como valiosa fuente de información sobre los procesos que se desarrollan.

- Crear estrategias de formación que partan de la dimensión humana del educador, incluyendo en ellas sus inquietudes personales y su propia historia, y desarrollarla con respecto a las necesidades de estos docentes y a las necesidades locales.

- Formular el desarrollo profesional de educadores de primera infancia para la paz como un curso de carrera, o como plan o proyecto de desarrollo profesional personal que articule objetivos personales, disponer recursos para realizarlos y las situaciones presentes en el contexto.

Todas estas recomendaciones de formación y fortalecimiento del trabajo de educadores iniciales para la paz, necesitan de apoyos en las coordinaciones y direcciones institucionales, interinstitucionales y de entes decisores. Por eso, se expresan recomendaciones sobre dicho apoyo en la siguiente sección. 


\section{Estrategias de gobernanza}

Las políticas en educación se concretan y “aterrizan” en la acción de los educadores. Sin embargo, para que esto suceda se necesita de acciones coordinadas y de apoyo de varias instancias, entre ellas las de coordinación de políticas. En el caso de las acciones de educación para la paz, el asunto central es el abordaje de los conflictos, el desarrollo de competencias didácticas y relacionales en los educadores de primera infancia, así como las acciones de apoyo a estos educadores para lograr que esta educación tenga garantías de calidad: educación inicial para la paz disponible, accesible, aceptable y flexiblemente adaptable a la diversidad de las personas.

Los niveles e instancias de gobierno no son los únicos responsables por el desarrollo de las acciones, pero son altamente responsables de crear condiciones para el desarrollo de las acciones que se realizan en la educación para la primera infancia. El abordaje desde el apoyo institucional macro, interinstitucional o de gobernanza, da un liderazgo importante para sostener, facilitar y promover el desarrollo de la profesionalidad en quienes realizan la atención y educación en primera infancia. Por lo tanto, estas recomendaciones buscan facilitar la formación, las condiciones de trabajo y desarrollar intervenciones en educadores de primera infancia para la paz y afrontamiento de los conflictos.

La primera recomendación de este nivel es fortalecer las acciones de educadoras y educadores para actuar como equipos. Esta forma de actuar en este ámbito promueve trabajos más coordinados y positivos. Por tanto, se recomienda asegurar el fortalecimiento permanente de la capacidad de dichos equipos mediante:

- La disposición de momentos de trabajo con los niños en red, con oportunidades de aprendizaje en red in situ y de aprendizaje y desarrollo en momentos de trabajo sin niños, para fortalecer competencias, juicio y relación de los educadores con sus comunidades atendidas.

- La garantía permanente de construir capacidades y participación en proyectos integradores, para fortalecer capacidad de educadoras y educadores de anticipación y decisión en el momento.

- La garantía de acompañamiento, guía y liderazgo desde las direcciones a nivel centro e instituciones, para fortalecer procesos y condiciones de trabajo desde lo que muestran y desde lo que se propone al talento humano de cada uno de los centros.

La segunda recomendación es fortalecer permanentemente la capacidad de equipos de educadoras, educadores y sus apoyos, por medio de las siguientes acciones:

- Realizar tutoría personal en cada centro con ayuda de equipos más avanzados de otros centros en los mismos procesos, para fortalecer su capacidad de juicio y relación con comunidades.

- Garantizar espacios de participación y encuentro personal entre personal de centros, niños y familias, para fortalecer el sentido de comunidad con acuerdos sobre valores de trabajo con niños.

- Hacer públicas rutas de atención y seguimiento a niños y familias con diferentes condiciones apoyando el liderazgo de directivos y coordinadores sobre el talento humano de centros en esta labor, para fortalecer rutas de atención, derechos, inclusión y roles de actores clave en estos procesos.

La tercera recomendación es fortalecer la misma labor de coordinación, dirección y coordinación de políticas, por medio de estas acciones: 
- Desarrollar evaluación formativa colectiva hacia dónde y en qué puntos podemos fortalecer procesos, para monitorear y fortalecer las acciones desarrolladas.

- Gestionar con entidades territoriales condiciones, locaciones y recursos para educación de niños y familias, especialmente proveniente de condiciones vulnerables y con historia de víctimas de conflicto armado, y con esto fortalecer educación para la paz realmente inclusiva.

- Desarrollar planes, programas y directrices de educación para la paz que estén disponibles, sean accesibles, sean apropiadas e idóneas y sean flexibles hacia la diversidad, para fortalecer también una educación para la paz realmente inclusiva.

\section{El conflicto en Colombia y su impacto en la calidad de vida de la primera infancia: entornos para la promoción del bienestar y el desarrollo infantil}

\section{Entornos que promueven el bienestar físico y material}

- Garantizar sistemas de monitoreo y seguimiento que permitan identificar el estado de salud y nutrición de la población víctima del conflicto.

- Garantizar el establecimiento de políticas institucionales, locales o regionales para la promoción de la salud y prevención de la enfermedad infantil.

- Garantizar, en las instituciones, los recursos y la disposición de espacios necesarios para la recreación, la motricidad y la expresión corporal.

- Fomentar el desarrollo de la libertad del niño o niña, a partir de una revisión de las condiciones del espacio vital o hábitat infantil.

- Garantizar la promoción de ambientes seguros y adecuados con condiciones de calidad.

- Proponer escenarios para el trabajo con las familias víctimas del conflicto que permita garantizar condiciones adecuadas para el cuidado de calidad, la atención infantil y el desarrollo integral.

- Garantizar la existencia y funcionamiento de las redes de atención en salud y redes de apoyo para las familias.

\section{Entornos que promueven el bienestar psicológico y emocional}

- Garantizar las habilidades necesarias para reconocer y actuar sobre posibles condiciones de vulneración de derechos de niños y niñas.

- Garantizar las condiciones de calidad para la observación y seguimiento del estado infantil, y para la remisión a centros de atención especializada.

- Generar estrategias para la promoción de condiciones de bienestar y satisfacción afectiva infantil.

- Fomentar la comunicación afectiva, la expresión de sentimientos y emociones y el apoyo emocional, especialmente en población afectada por el conflicto.

- Garantizar políticas para la promoción de la salud mental, la autoestima y la resiliencia.

- Garantizar el establecimiento, conocimiento, uso y participación en las Rutas Integrales de Atención para la Primera Infancia (RIA), y del Programa de Atención Psicosocial y Salud Integral a Víctimas (PAPSIVI), especialmente en los territorios.

\section{Entornos que promueven el bienestar familiar y comunitario}

- Garantizar y promover prácticas de participación familiar y comunitaria para la protección infantil.

- Proponer estrategias para la atención de las necesidades familiares y comunitarias por medio de redes de colaboración o cooperación local o regional. 
- Garantizar las acciones y mecanismos para mejorar las pautas de crianza familiar y el cuidado comunitario.

- Contar con mecanismos que permitan el monitoreo, seguimiento y evaluación de la atención familiar.

- Garantizar la articulación de los servicios de atención y cuidado infantil en las comunidades, con especial énfasis en comunidades afectadas por el conflicto.

\section{Entornos que promueven el desarrollo personal e interpersonal}

- Generar capacidades para la observación del desarrollo infantil y de las formas para potencializarlo.

- Plantear estrategias eficientes para la sistematización de los cambios en el desarrollo infantil.

- Generar estrategias para el desarrollo de la conciencia de sí y del otro, que permitan la construcción de una cultura de paz.

- Generar espacios de desarrollo que sean sensibles a las características contextuales y territoriales.

\section{Entornos que promueven el desarrollo social y cultural}

- Garantizar las condiciones para la conservación de los conocimientos y herencias culturales y de los conocimientos ancestrales de los sitios de origen.

- Proponer y desarrollar estrategias para la inclusión, la atención a la diversidad y la equidad de los servicios de atención educativa.

- Generar las condiciones para la promoción del desarrollo cultural del niño o niña.

- Fomentar los diálogos interculturales a partir de la participación familiar.

- Generar estrategias para la participación infantil en la producción cultural.

\section{Participación de los niños en la in vestigación}

Es muy importante tomar en cuenta a los niños en la definición de cualquier acción que se quiera emprender y que los involucre. A continuación se presentan las recomendaciones que se derivan de lo expresado por ellos mediante el desarrollo de diferentes estrategias pedagógicas adecuadas a su edad. Es necesario anotar que los niños participantes corresponden a la modalidad institucional, debido a que fue la población a la que se tuvo acceso.

\section{Conocimiento de la biografía de los niños y acceso de los educadores a dicha información}

Para llevar a cabo un buen proceso de atención y educación de los niños es muy importante que se conozcan sus historias, en especial por quienes tienen un contacto más directo con ellos como son sus educadores: saber de dónde vienen, cuáles han sido sus trayectorias, cuál es el estado actual de su familia, con quién viven, quién se encarga de su cuidado y atención en el hogar. Esto es necesario para garantizar el respeto a los derechos de los niños, en lo que respecta a recibir atención, cuidados y educación acordes con sus particularidades.

Más allá de cumplir con los requisitos administrativos de diligenciar una ficha de datos personales, es necesario recoger información que resulte útil para el diseño y 
puesta en práctica de estrategias que contribuyan a promover el desarrollo infantil. Igualmente, es importante que la información se mantenga actualizada gracias a la interacción cotidiana que tiene el educador con los niños, lo que demanda una gran apertura e interés de parte del educador y las condiciones para tener una comunicación fluida con los niños y con sus cuidadores. En este sentido, la interacción cotidiana entre el educador y los niños, se constituye en una gran oportunidad de escuchar sus voces y de favorecer su interacción con el entorno.

Ahora bien, en algunos lugares visitados durante la investigación se encontró que la institución recogía información sobre los niños, pero los educadores no tenían acceso a ella, lo que los deja sin el suficiente conocimiento para afrontar la atención, el cuidado y la educación de los niños teniendo en cuenta las necesidades específicas de ellos y sus particulares situaciones. Si bien se entiende la buena intención de no revictimizar a los niños, también es necesario señalar la importancia que tiene para una buena atención y educación de los niños su conocimiento por parte del educador. Solamente así podrá diseñar y poner en práctica estrategias que respondan a las particularidades de cada uno y no limitarse a cumplir protocolos.

En este orden de ideas, cabe resaltar la importancia de formar a los educadores en el buen manejo de la información y en la articulación de ella con el diseño de las estrategias que pondrá en práctica cotidianamente.

\section{Organización de procesos institucionales}

Se recomienda formar a los directivos de las instituciones como líderes que puedan orientar los procesos de soporte organizacional para la buena atención y educación de los niños, mediante un trabajo en equipo que involucre talento humano de distintas profesiones y oficios que atienda directa e indirectamente a los niños. El trabajo articulado de distintos actores facilitará la promoción del desarrollo infantil y el cumplimiento de los derechos de los niños.

Así mismo, evitará la duplicidad de trabajo, tanto como la ausencia de él por desconocimiento de lo que hacen los otros miembros de la institución. Es el director el llamado a organizar, poner en marcha, monitorear y reorientar procesos de atención y educación a los niños, en cooperación con todos los actores de la institución.

\section{Puesta en práctica de la política pública}

Diseñar la política pública siempre es más sencillo que ponerla en práctica. Por eso es necesario acompañar su desarrollo en las instituciones y estar atentos a las vicisitudes que se presentan en el día a día. Hay que tener en cuenta que la calidad de la atención y educación de los niños se promueve por medio de la definición de las políticas públicas; sin embargo, ellas no se garantizan hasta tanto sea puestas en práctica.

Es importante analizar las dificultades que puedan presentarse en la puesta en práctica de la política por razones personales, profesionales o laborales de los educadores, 
condiciones particulares de las instituciones, formas de relación entre instituciones o por varias de las razones anteriores, para proponer correctivos oportunamente.

\section{Participación de los educadores}

Muy relacionado con el punto anterior, se destaca la importancia de contar con la participación activa de los educadores en el diseño de la política pública, en su puesta en práctica y especialmente en su evaluación y planteamiento de propuestas de mejoramiento de la atención y la educación de los niños.

Ignorar el valor de esta participación activa implica desconocer que la garantía de la calidad en la atención y la educación de los niños está en la vida cotidiana. Quienes pueden dar cuenta de ella son quienes están en contacto directo con los niños. La participación de los educadores tiene un gran potencial de cualificación de la oferta que se hace a la infancia

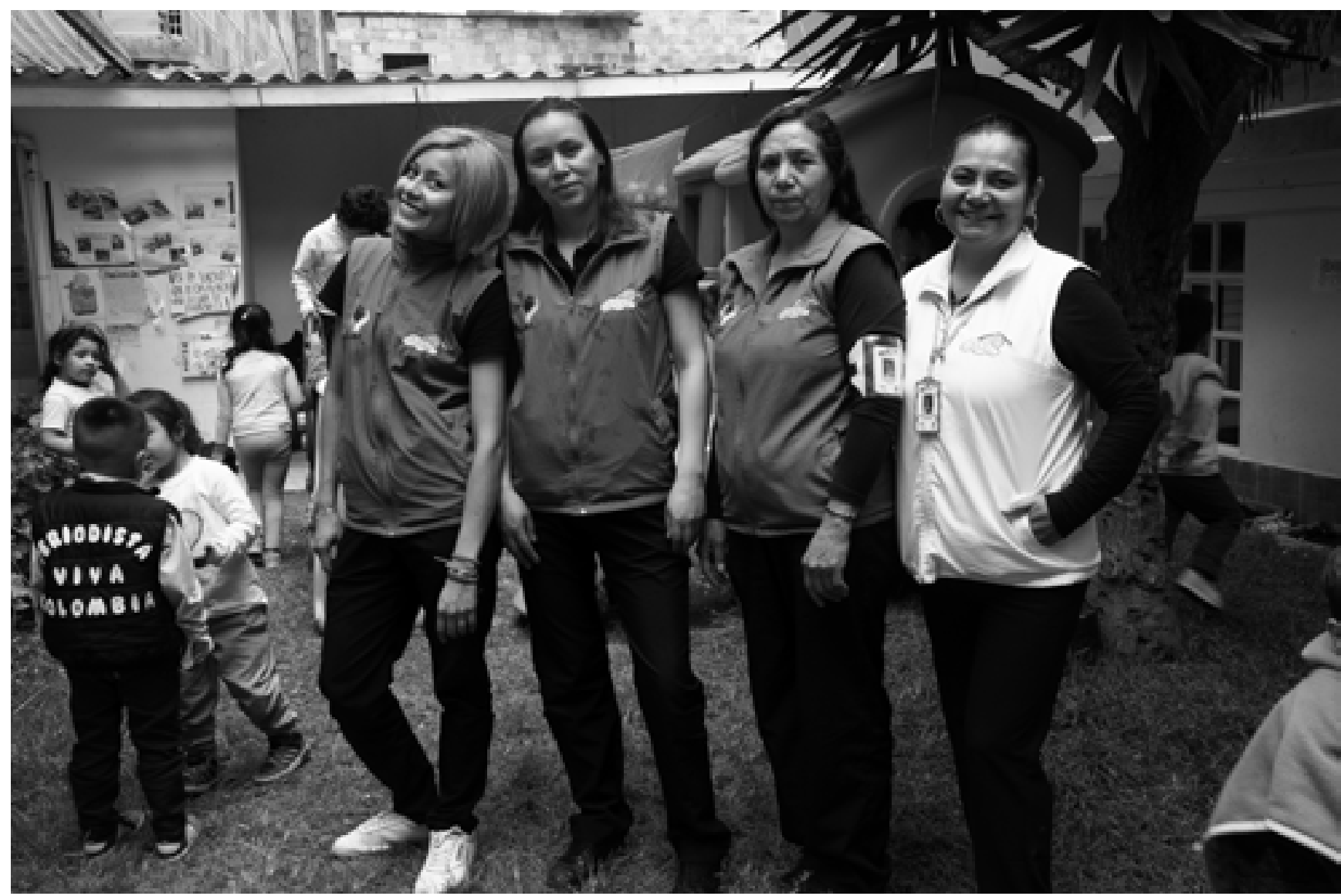


